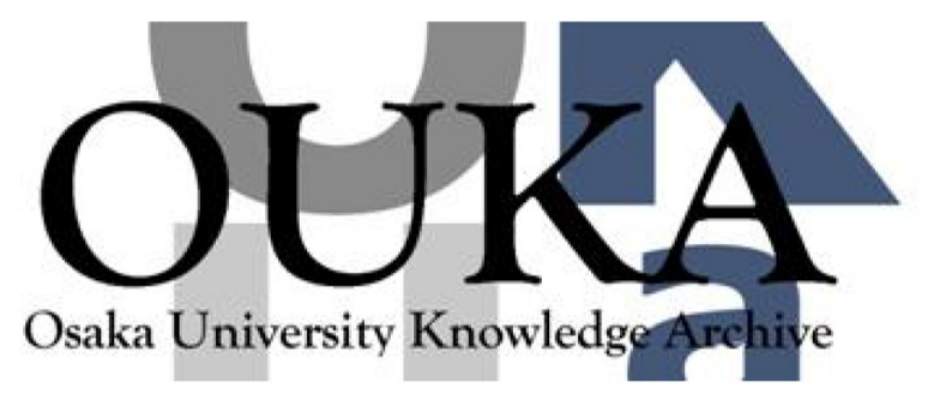

\begin{tabular}{|c|l|}
\hline Title & $\begin{array}{l}\text { Generation of Novel Polycyclic Aromatic } \\
\text { Compounds by Tandem Cyclization of Macrocyclic } \\
\text { Aryleneethyny lenes }\end{array}$ \\
\hline Author(s) & Nobusue, Shunpe i \\
\hline Citation & \\
\hline Issue Date & \\
\hline oaire:version & VoR \\
\hline URL & https://hdl. handle. net/11094/54388 \\
\hline rights & \\
\hline Note & \\
\hline
\end{tabular}

Osaka University Knowledge Archive : OUKA

https://ir. Library. osaka-u. ac. jp/

Osaka University 
Generation of Novel Polycyclic Aromatic Compounds by Tandem Cyclization of Macrocyclic Aryleneethynylemes

\author{
A dissertation submitted to \\ THE GRADUATE SCHOOL OF ENGINEERING SCIENCE \\ OSAKA UNIVERSITY \\ in partial fulfillment of the requirements for the degree of \\ DOCTOR OF PHILOSOPHY IN ENGINEERING
}

Shumpei Nobusue

MARCH 2013 


\section{Chapter 1: General Introduction}

1.1. Conjugated Cyclic System: Annulenes, Dehydroannulenes, and Dehydrobenzoannulenes (DBAs) 2

1.2. DBAs as Constituent Units of Three-Dimensional Architectures 3

1.3. DBAs as Precursors of Carbon-Rich Materials 6

1.4. Purpose of this Thesis 9

1.5. References and Notes 12

Chapter 2: Synthesis and Dynamic Behavior of Propeller-Shaped Tris(dehydrobenzo[14]annulene)s

2.1. Introduction 18

2.2. Synthesis of Tris([14]DBA)s 21

2.3. Calculated Relative Stabilities of Conformers of Tris([14]DBA)s 24

2.4. Crystal and Theoretical Structures 26

2.5. Conformations and Dynamic Behaviors of Tris[14]DBAs in Solution 32

2.6. Conclusion 39

2.7. Experimental Section 40

2.8. References and Notes 49 
Chapter 3: Oxidative Cyclodimerization that Folllows Tandem Cyclization of Dehydrobenzo[14]anmulenes Induced by Alkyllithium

3.1. Introduction 54

3.2. Reaction of [14]DBA with $n$-Butyllithium and Structural Elucidations

3.2.1. Reaction of [14]DBA derivatives 56

3.2.2. Crystal structures of dimeric products 58

3.2.3. Structure Elucidation of $15 \mathrm{~b}$ by ${ }^{1} \mathrm{H}$ NMR, ${ }^{13} \mathrm{C}$ NMR, HMQC, and HMBC spectra 59

3.2.4. Structure Elucidation of $\mathbf{1 6} b$ by ${ }^{1} \mathrm{H}$ NMR, ${ }^{13} \mathrm{C}$ NMR, HMQC, and HMBC spectra 64

3.3. Theoretical Investigation of Dimer Formations 70

3.4. Investigation of the Generality of Dimer Formation 74

3.5. Optical and Electrochemical Properties of Dimeric Products 76

3.6. Conclusion 77

3.7. Experimental Section 79

3.8. References and Notes 91

Chapter 4: Symthesis and Properties of Indeno[2,1-a]fluorene Dimer Having Twisted Cyclooctatetraene Core

4.1. Introduction 96

4.2. Synthesis, Crystal Structure, and Properties of Indeno[2,1-a]fluorene Dimer 99

4.3. Skeletal Rearrangement of Indeno[2,1-a]fluorene Dimer 103

4.4. Optical and Electrochemical Properties 106

4.5. Conclusion 108

4.6. Experimental Section 109

4.7. References and Notes 111 
Chapter 5: Tetracyclopentatetraphenylene: Synthesis and Properties of Conjugated Macrocyclic System Consisting of as-Indacene Substructure

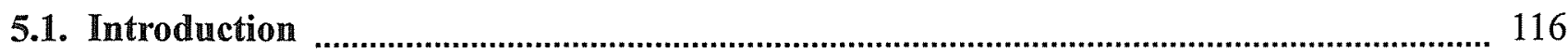

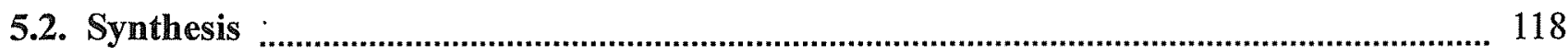

5.3. Theoretical Calculation ......................................................................................................... 119

5.4. Crystal Structure and Optical Properties ......................................................................... 121

5.5. Variable-Temperature ${ }^{1} \mathrm{H}$ NMR Measurements ................................................................ 124

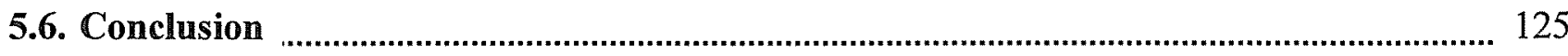

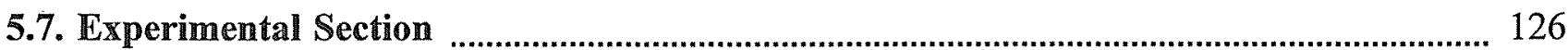

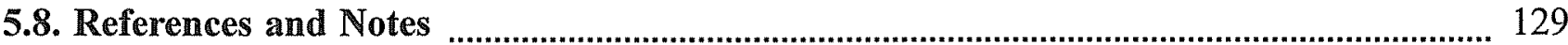

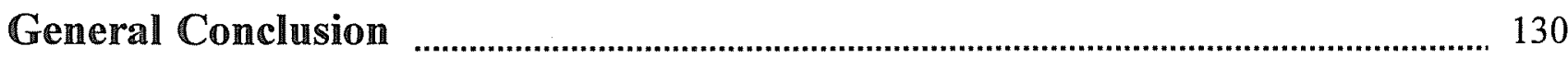

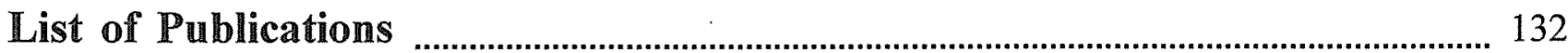

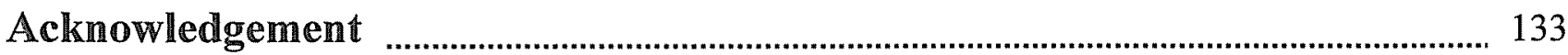


Dehydrobenzoannulenes (DBAs) belong to a class of conjugated cyclic aryleneethynylenes. Recently, much attention has been focused on DBAs as shaped-persistent macrocycles and as precursors to novel polycyclic aromatic hydrocarbons. In this respect, the author investigated the dynamic behaviors of propeller-shaped molecules consisting of DBAs as shape-persistent components and the transformation of DBAs into structurally novel polycyclic aromatic hydrocarbons taking advantage of the high reactivity of the acetylene units. Additionally, the author investigated the synthesis and properties of novel polycyclic aromatic hydrocarbons inspired by the results obtained from the skeletal transformation of DBAs.

In Chapter 1, the author describes the history of the research in DBAs including the current interests as the background of this thesis. The motivation and purpose of this thesis are described subsequently.

In chapter 2, the synthesis and dynamic behavior of propeller-shaped tris[14]DBA 1 and its extended homolog 2 , which consist of core benzene ring that is fused by three [14]DBA blades, are described. Although the overlap between the adjacent blades seemed extremely large, it was shown that the ring inversion took place readily, indicating the acetylene units bent with low activation energies. Through this work, it was revealed that the acetylene linkages can be deformed much more than that are generally recognized in the transition state of the ring flip.
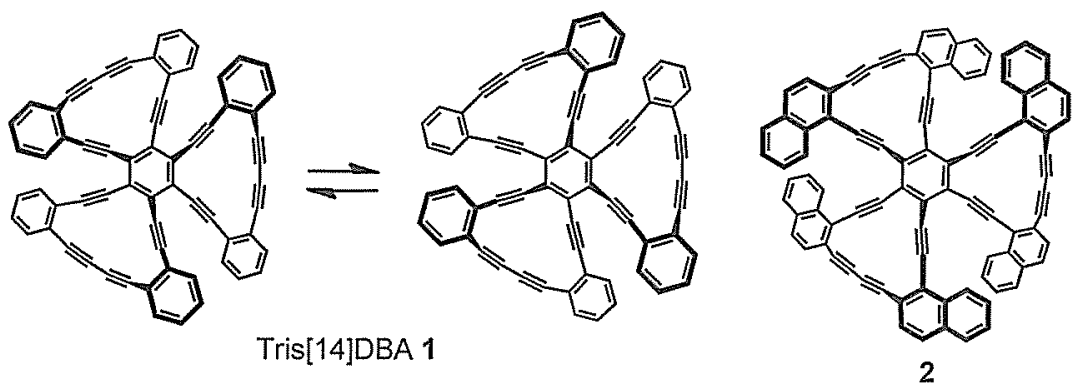

Chapter 3 describes the generation of novel polycyclic hydrocarbons by cyclodimerization following tandem transannular bond formations between sp carbon atoms of [14]DBA 3. Namely, reaction of [14]DBA 3 with $n$-BuLi led to an unprecedented cyclodimerization to form eight-membered ring product 5 in which two indeno[2,1-a]fluorene components are connected by a single and a double bonds, following three-fold transannular bond formations. Though the 
cyclodimerization mechanism is not fully understood, it is assumed that the biradical character of a plausible intermediate 4 may play a major role. These results demonstrate that novel carbon frameworks which are otherwise difficult to obtain can be prepared by intramolecular bond formations of dehydrobenzoannulenes.

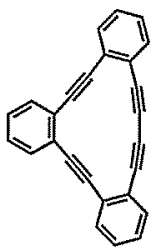

[14]DBA 3
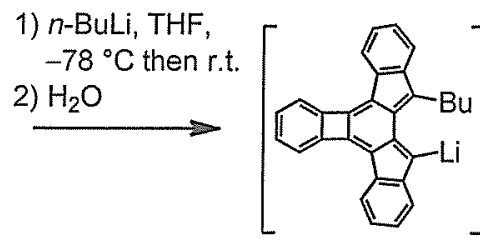

4

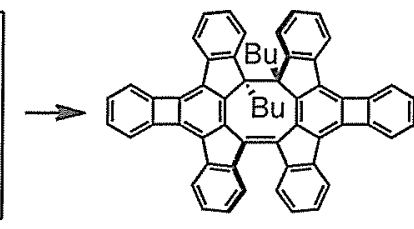

5

In Chapter 4, inspired by the formal [4+4] cyclodimerization of an indenofluorene intermediate proposed in Chapter 3, 11,11':12,12'-biindeno[2,1-a]fluorenediylidene (9), which consists of two indeno[2,1-a]fluorene units connected by two double bonds, was synthesized by [4+4] cycloaddition of indeno $[2,1-a]$ fluorene derivative 7 in-situ generated from dibromide 6 and subsequent elimination of $\mathrm{HBr}$ from dimer 8. Compound $\mathbf{9}$ adopts a twisted conformation to avoid steric repulsion, therefore contains twisted cyclooctatetraene (COT) ring in the center. Structure and physical properties of 9 in connection with anti-aromatic character, were investigated by X-ray analysis, cyclic voltammetry, UV-vis and NMR spectroscopies, quantum and simulations.

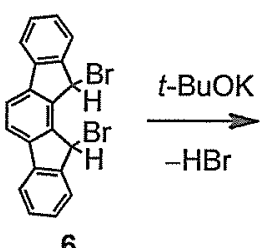

6

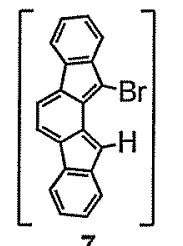

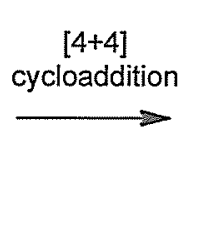

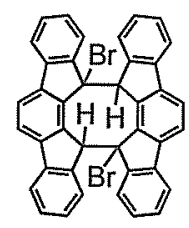

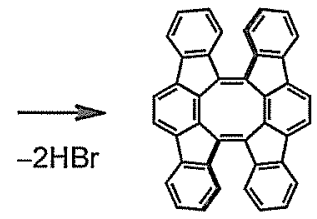

9

Chapter 5 described the synthesis and properties of tetramesityl-substituted tetracyclopenta[def,jkl,pqr,vwx]tetraphenylene derivative $10 \mathrm{~b}$ consisting of alternating five- and six-membered rings around the central COT core. The ${ }^{1} \mathrm{H}$ NMR measurement of $\mathbf{1 0 b}$ exhibited anti-aromatic character due to the inner $8 \pi(\mathrm{COT})$ and outer $20 \pi$ conjugated cyclic systems. Although the quantum chemical calculations indicated that the spin density distributions of parent compound 10a is delocalized over the molecule favoring the $D_{4 h}$ structure, X-ray analysis of $\mathbf{1 0 b}$ as well as calculations for the model compound $10 \mathrm{c}$ favored the less symmetric $D_{2 h}$ structure.

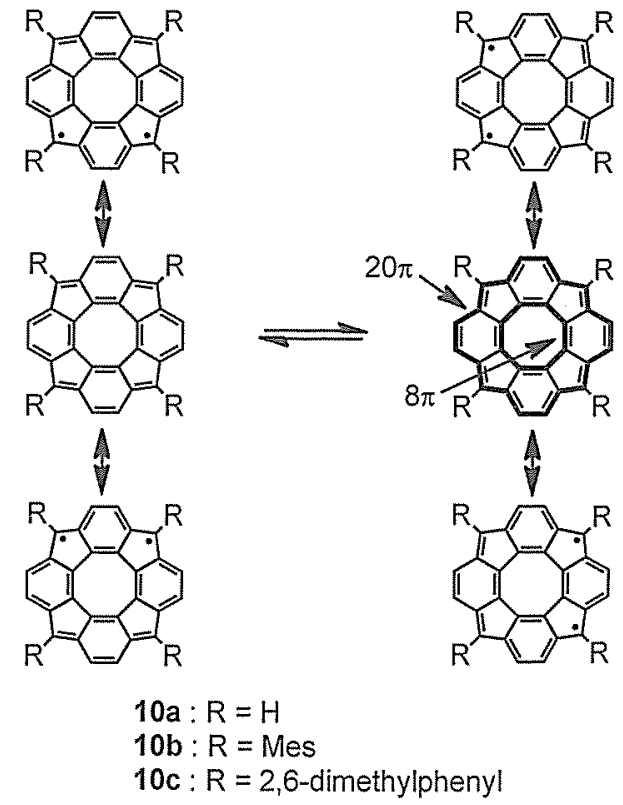


Chapter 1

General Introduction 


\subsection{Conjugated Cyclic System: Annulenes, Dehydroannulemes, and Dehydrobenzoannulenes}

(DBAs)

Since Sondheimer defined in the early $1960 \mathrm{~s},{ }^{1}$ a great deal of researches about $[\mathrm{n}]$ annulenes have been investigated. [ $\mathrm{n}$ ]Annulene is the monocyclic hydrocarbon consisting of alternating single and double bonds where the number in brackets denotes the number of $\mathrm{sp}^{2}$ carbon atoms. The annulene chemistry was developed throughout the 1960s and 1970s, and a numerous number of annulenes consisting of various ring sizes and geometries were synthesized mainly in order to provide experimental insights for the Hückel rule, ${ }^{2}$ which predicts that relatively large monocyclic hydrocarbons with $(4 n+2) \pi$ electrons will have properties similar to those of benzene, whereas those with $4 \mathrm{n} \pi$ electrons will not. [18], [24], and [30]annulenes 1-3 are the first series of annulenes, which were synthesized by Sondheimer et al. ${ }^{1,3}[12]$ Annulene $(4),{ }^{4}[14]$ annulene $(5),{ }^{5}$ and [16]annulene (6) ${ }^{6}$ were reported independently by Sondheimer and Schröder. Following the Hückel rule, the annulenes $\mathbf{1}, \mathbf{3}$, and $\mathbf{5}$ are divided into $(4 n+2) \pi$ electron system, whereas the annulenes 2,4 , and $\mathbf{6}$ are classified as $4 \mathrm{n} \pi$ systems.

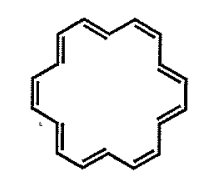

[18]annulene (1)<smiles>C1=C\C=C/C=C\C=C/C=C\C=C/1</smiles>

[12]annulene (4)

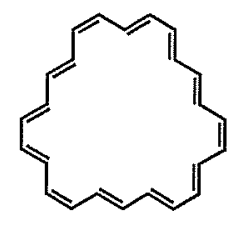

[24]annulene (2)

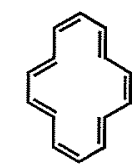

[14]annulene (5)

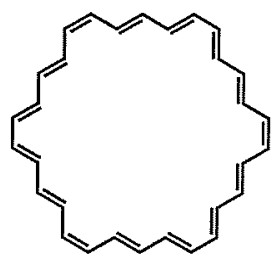

[30]annulene (3)

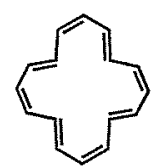

[16]annulene (6)

Figure 1. Representative annulenes 1-6.

A replacement of one or more double bonds of annulenes with acetylene units affords dehydroannulenes. On the other hand, introducing one or more benzene rings to annulenes or dehydroannulenes furnishes benzoannulenes or dehydrobenzoannulenes (DBAs), respectively. The installing benzene rings to annulenes provides stability of the macrocycles system in general. 
For instance, representative dehydroannulenes, benzoannulenes, and dehydrobenzoannulenes are shown in Scheme 2. Hexadehydro[12]annulene (7), which has three triple bonds within the macrocyclic ring, was reported by Untch and Wysocki. ${ }^{7}$ Dodecadehydro[18]annulene (8) was synthesized by Sondheimer. ${ }^{8}$ Octadehydro[22]annulene (9) possessing a diyne and a cumulene units was reported by Nakagawa. ${ }^{9}$ Benzoannulenes include, for instance, tribenzo[12]annulene (10), ${ }^{10}$ benzo[14]annulene (11), ${ }^{11}$ and benzo[18]annulene (12). ${ }^{12}$ Examples of dehydrobenzoannulenes (DBAs) are tetradehydrotribenzo[12] annulene (13), ${ }^{13}$ hexadehydrotribenzo[12]annulene (14), ${ }^{14}$ and dodecadehydrotribenzo[18]annulene (15). ${ }^{15}$

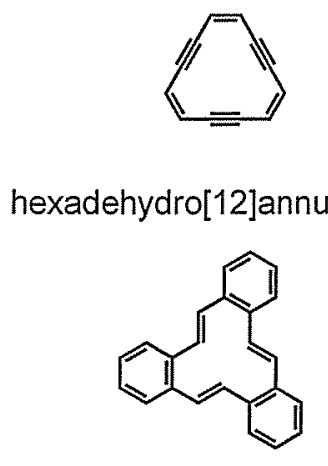

tribenzo[12]annulene (10)

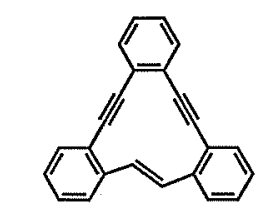

tetradehydrotribenzo-

[12]annulene (13)

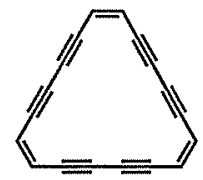

dodecadehydro[18]annulene (8)

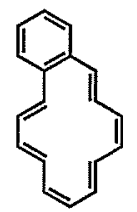

monobenzo[14]annulene (11)

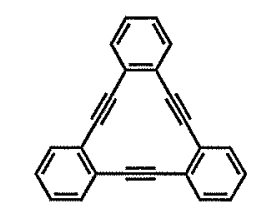

hexadehydrotribenzo-

[12]annulene (14)

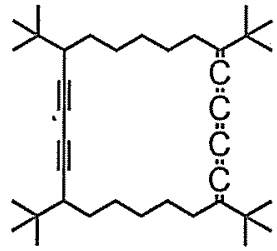

octahydro[22]annulene (9)

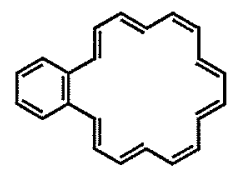

monobenzo[18]annulene (12)

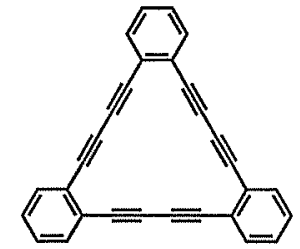

dedecadehydrotribenzo-

[18]annulene (15)

Figure 2. Examples of dehydroannulenes 7-9, benzoannulenes 10-12, and dehydrobenzoannulenes (DBAs) 13-15.

As described above, the main purpose to synthesize these annulenes is to investigate the aromatic character in connection with the Hückel rule. However, throughout the studies, it was revealed that the aromatic character in these systems becomes weaker as the ring size increases and/or the number of triple bond increases. In the event, as the researches on annulenes based on the Hückel rule progressed, additional motivations for annulene research were required. As a consequence, the 
interests for annulene had progressively declined in the 1980s.

\subsection{DBAs as Constituent Units of Three-Dimensional Architectures}

During the last decade, a great deal of renewed interest has been freshly focused on the annulene chemistry regarding the relationship between structural and electronic properties, ${ }^{16}$ because a number of synthetic methods were developed including the Pd-catalyzed cross-coupling reactions between $\mathrm{sp}$ and $\mathrm{sp}^{2}$ carbon atoms, ${ }^{17}$ allowing the construction of a diversity of complex structures which were otherwise difficult to reach. In particular, dehydroannulene and dehydrobenzoannulenes (DBAs) have been studied as shape-persistent aryleneethynylene macrocycles. Compared to conjugated aromatic molecules, it is easier to construct expanded three-dimensional architectures because of the linear triple bonds which are devoid of steric hindrance. In this respect, a variety of macrocycles consisting of DBA units have been synthesized.

Orthocyclophynes containing more than four benzene rings adopt non-planar twisted conformations and have been investigated with regard to their unique structure and properties relationships caused by the twisted structures. For instance, cyclophyne $\mathbf{1 6}$ having four phenylene-ethynylene units was revealed from X-ray crystallographic analysis that it adopted a twisted, tub-shaped conformation of the macrocycle. ${ }^{18}$ On the other hand, cyclic hexamer 17 adopts a

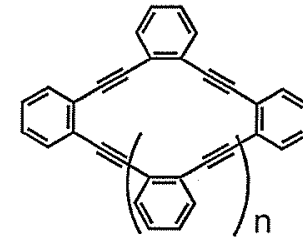

$16: n=1$

$17: n=2$

$18: n=7$

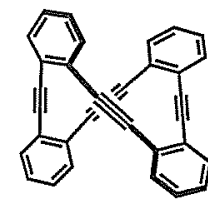

16

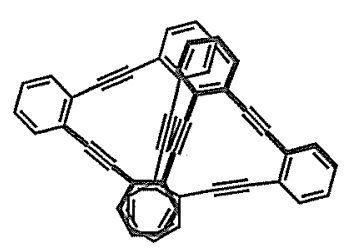

17

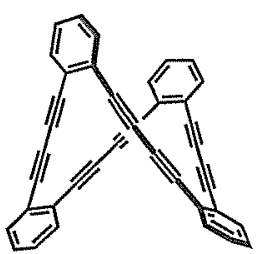

19

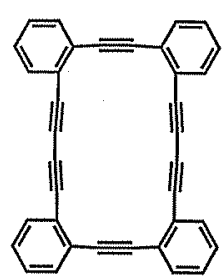

20a $: R=H$ $20 \mathrm{~b}: \mathrm{R}=t-\mathrm{Bu}$

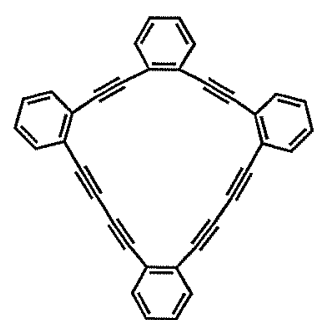

21

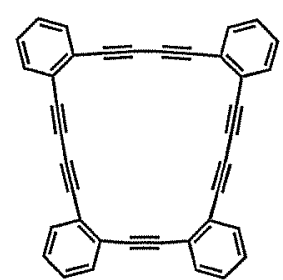

22

Figure 3. Examples of DBAs possessing twisted or helical conformations. 
helical conformation. ${ }^{18}$ However, the larger homolog, decamer 18, adopts no longer helical but complex three-dimensional conformation because of the large macrocyclic ring size. ${ }^{19}$ Butadiyne-bridged macrocycle 19 was revealed to adopt a twisted conformation too. ${ }^{20}$ On the other hand, the ethynylene-butadiynylene macrocycles 20,21 , and 22 were reported to adopt non-planar saddle-like conformations. ${ }^{21}$ An interesting aspect of these macrocycles is the interconversions between the twisted forms via ring inversions. For example, variable-temperature NMR studies of $20 \mathrm{a}$ revealed that the ring inversion takes place with an energy barrier of $9.3 \mathrm{kcal} / \mathrm{mol}$.

Similar studies regarding conformations and ring inversions were performed for even larger cyclophynes. Twisted conformations were observed for tetrayne-bridged cyclophynes such as $23^{22}$ and $24^{23}$ Partly meta-bridged cyclophynes 25 and $\mathbf{2 6}$, on the other hand, were shown to adopt twisted and helical conformations by theoretical calculations, and interconversions between conformational isomers of $\mathbf{2 5}$ and $\mathbf{2 6}$ did not take place because of the steric constraints. ${ }^{24}$

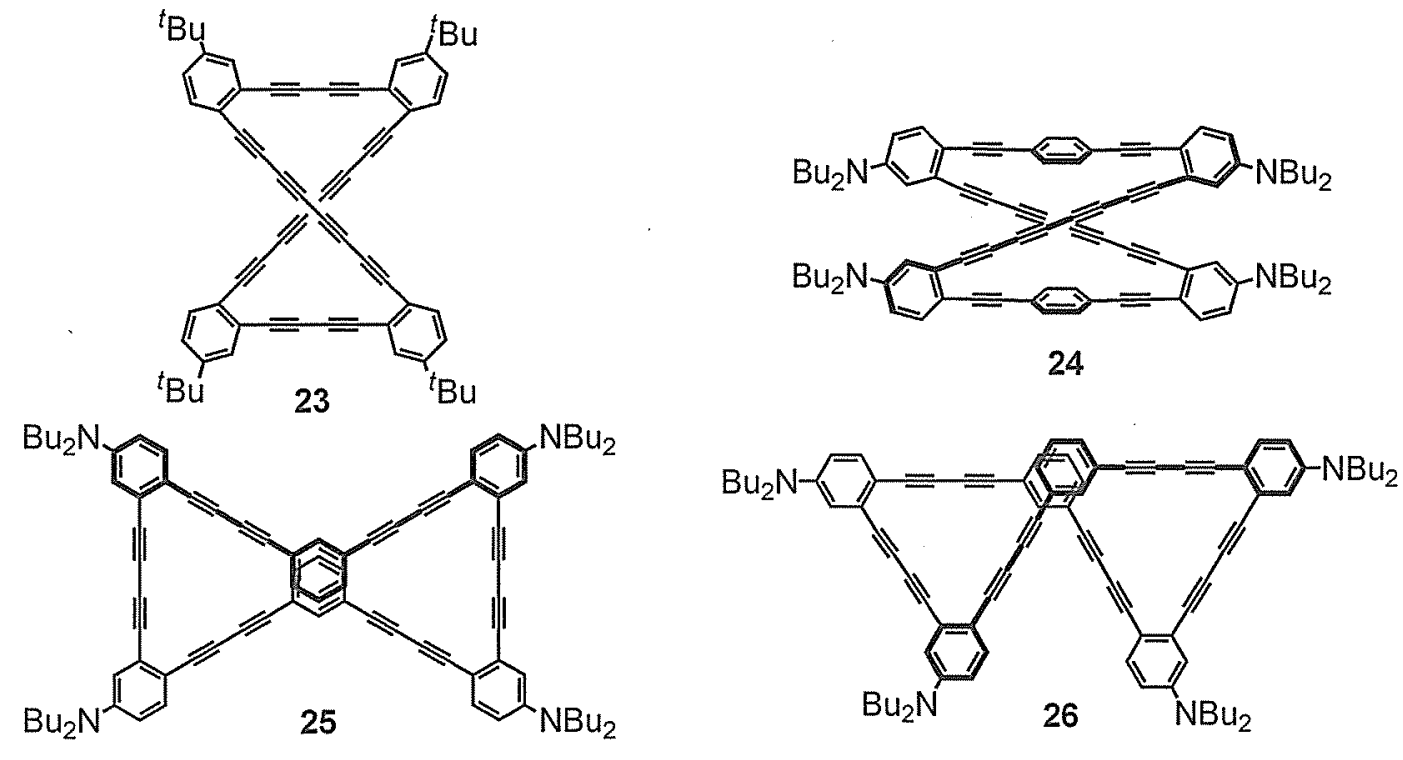

Figure 4. Examples of DBAs having twisted and helical conformations.

Cage-like three-dimensional macrocycles were synthesized by relatively simple synthetic method. As the first member of this class, cyclophane $27\left(\mathrm{C}_{60} \mathrm{H}_{18}\right)$ was synthesized by Rubin et al. ${ }^{25}$ Interestingly, dehydrogenation down to $\mathrm{C}_{60} \mathrm{H}_{14}{ }^{-}$by the loss of four hydrogen atoms was observed in the negative mode ion cyclotron resonance mass spectrum of 27 , suggesting possible polyyne 
cyclization pathway leading to [60]fullerene. ${ }^{26}$ Extremely large, three-dimensional phenylene-ethynylene macrocycles 28 and 29 were synthesized by Moore et al. ${ }^{27}$ The linearity of acetylene unit and rigid frameworks of DBAs play a principle role for the assembly of geometrically well-defined nanoarchitectures.
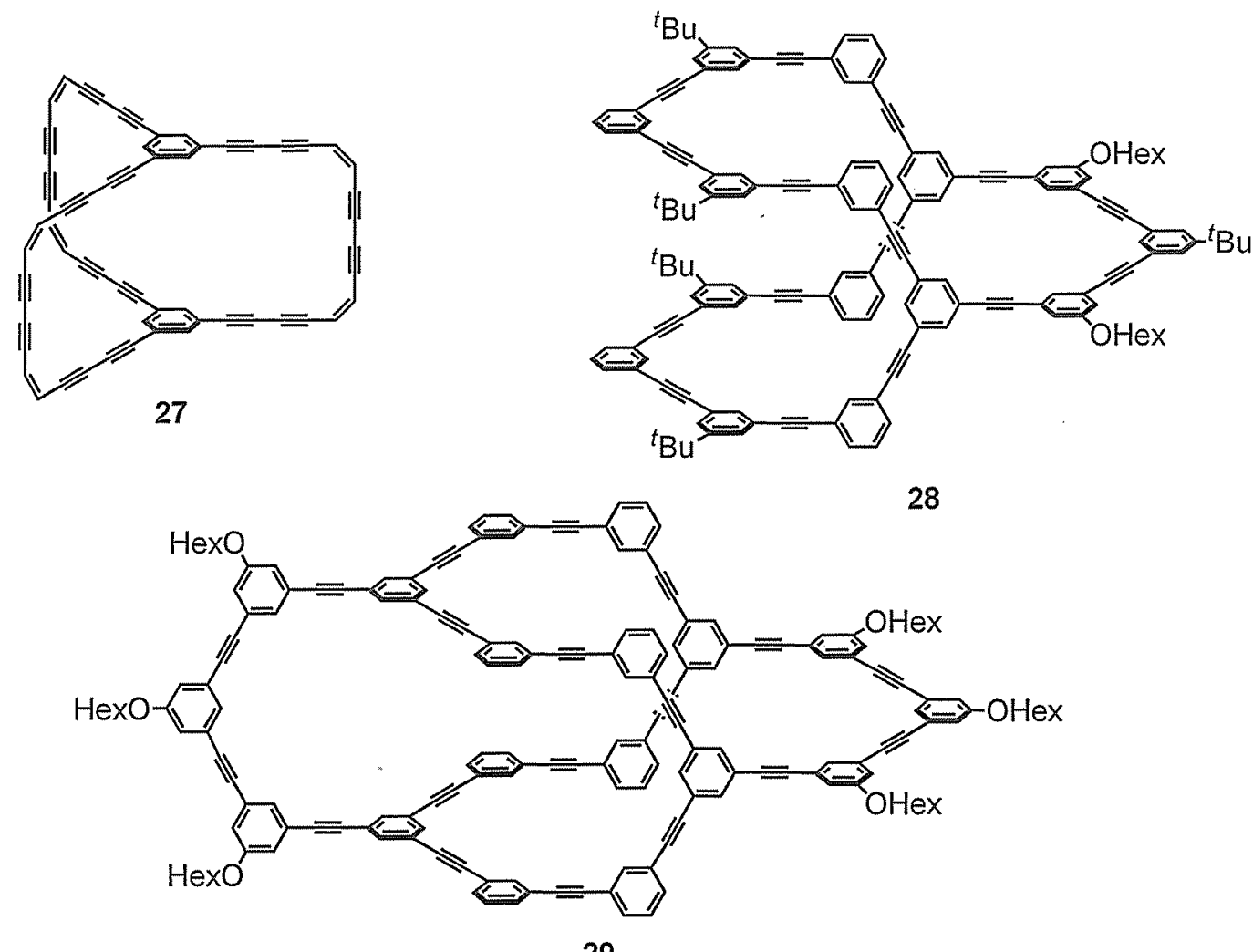

29

Figure 5. Examples of large macrocycles.

\subsection{DBAs as Precursors of Carbon-Rich Materials}

Another aspect in recent studies on DBAs is their use as precursors of carbon-rich compounds and materials. DBAs have rich potential to serve as precursors to transform into carbon rich materials because of the high reactivity of the acetylene units. For instance, Vollhardt reported that dodecadehydrotetrabenzo[20]annulene ([20]DBA) (20a) exploded violently with an orange light to yield ordered carbon materials which was shown by TEM to possess onion- and tube-like structures. $^{28}$ Youngs and Vollhardt reported that strained octadehydrotribenzo[14]annulene ([14]DBA) (30) having a butadiye unit underwent topochemical polymerization induced by photoirradiation or by applying pressure, even though the structure of the polymer was not 
reasonably characterized. ${ }^{29}$ From the packing structure of the crystal, trans-trans geometry of the polymer chain was suggested (Scheme 1).
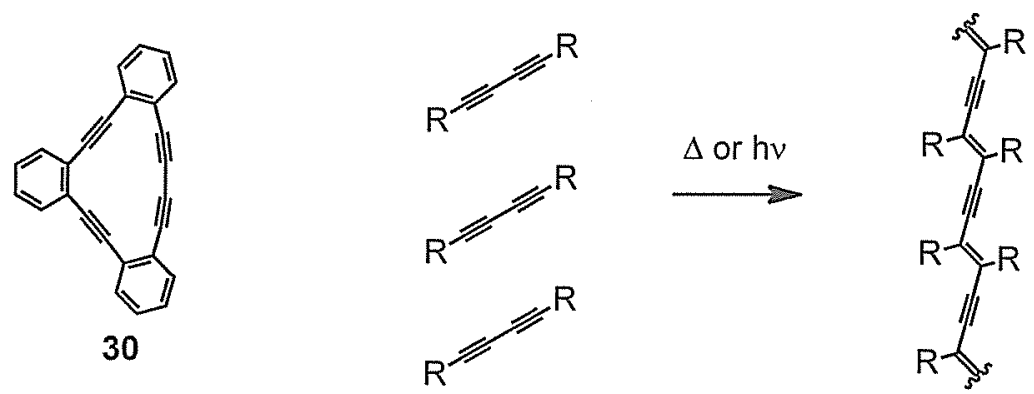

Scheme 1. [14]DBA 30 and schematic representation of polymerization.

On the other hand, scattering examples of the synthesis of polycyclic aromatic compounds by transformation of DBAs induced by chemical stimuli were reported recently. Highly ethynylated compounds have rich potential to transform into polycyclic aromatic hydrocarbons by intramolecular bond formations between the sp carbon atoms because of high reactivity of carbon-carbon triple bonds. ${ }^{30} \mathrm{~A}$ pioneering work regarding cyclizations of DBA was reported by Youngs where lithium-induced transannular tandem cyclization of [12]DBA 14 afforded benzo $[a]$ indeno[2,1-c]fluorene derivative 32 (Scheme 2 ). ${ }^{31}$ The same lithium-induced tandem cyclization was also observed for the larger homolog [16]DBA 16, producing more extended polycyclic compound $33 .^{31 \mathrm{c}}$

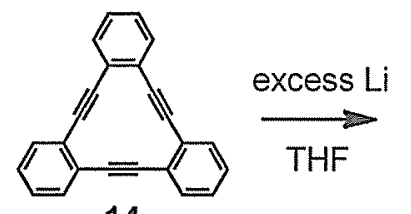

14

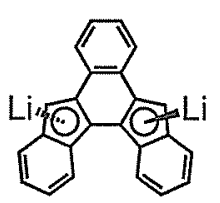

$\underset{\mathrm{THF}}{\stackrel{\mathrm{MeOH}}{\longrightarrow}}$

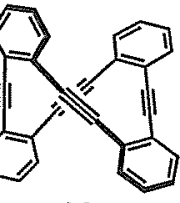

16

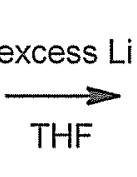

$\overrightarrow{T H F}$

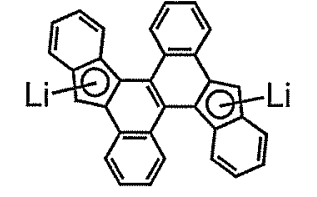

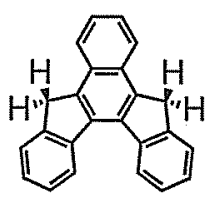

32

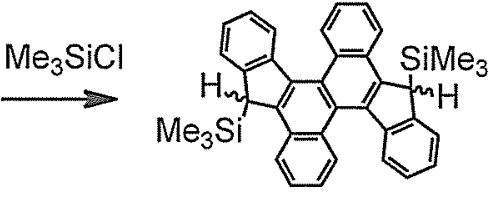

33

Scheme 2. Lithium-induced cyclizations of [12]DBA 14 and [16]DBA 16. 
The transformation of [12]DBA 14 into benzo[a]indeno[2,1-c]fluorene 32 was also achieved by the $\mathrm{Bu}_{3} \mathrm{SnH}$-promoted radical cascade reactions by Alabugin (Scheme 3 ). ${ }^{32}$ This cyclization method has been extensively studied for multiple alkyne-containing compounds, mostly acyclic compounds. ${ }^{30 b, c, 33}$

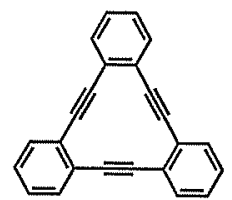

14

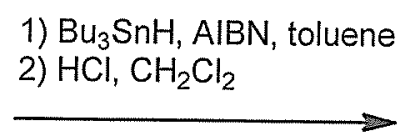

2) $\mathrm{HCl}, \mathrm{CH}_{2} \mathrm{Cl}_{2}$

Scheme 3. $\mathrm{Bu}_{3} \mathrm{SnH}$-promoted cascade cyclization of [12]DBA 14.

Another method to induce transannular cyclization to afford polycyclic frameworks is the use of electrophiles. For example, iodine- or iodine monobromide-induced cyclization of [8]DBA 34 furnished dibenzopentalenes $35,{ }^{34}$ which were subjected to transition metal-catalyzed cross-coupling reactions to afford various derivatives of dibenzopentalenes, which are of interest as optoelectronic materials (Scheme 4). Iodine-induced cyclizations were observed in butadiyne-bridged [12]DBA 36 to give highly reactive indeno[1,2-b]fluorene derivative $37 .{ }^{35}$ However, this reaction turned out to be difficult to reproduce as claimed by Haley ${ }^{36}$ and by Tobe, ${ }^{37}$ most probably because of the lability of

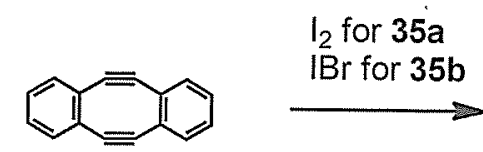

34

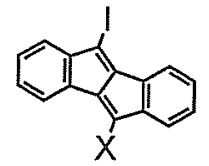

$$
X=I(35 a), B r(35 b)
$$

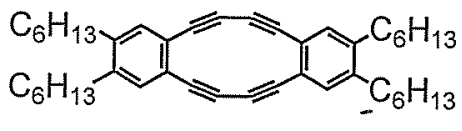

36
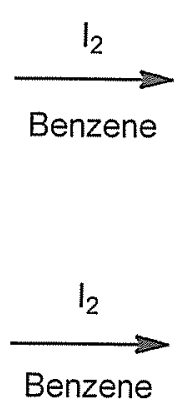

38

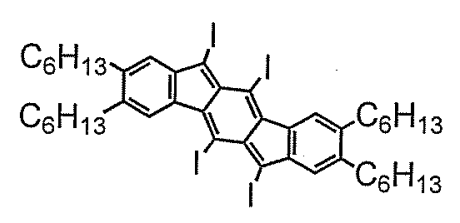

37

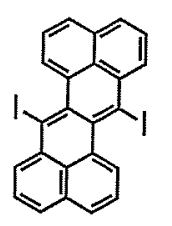

39

Scheme 4. Electrophile-induced cyclization of [8]DBA 34, [12]DBA 36, and [10]DBA 38. 
37 toward oxygen. More recently, iodine-induced cyclization was applied for [10]DBA 38 to synthesize stable derivatives of zethrene via diiodide $39 .^{38}$

The last method used for transannular cyclization of DBA is the use of nucleophiles, although this method may be limited to strained DBAs because simple DBAs are inert to nucleophiles. There exist to my knowledge one example: alkyllithium-induced cyclization of [8]DBA 34 was reported by Otera and Orita to give dibenzopentalene derivatives 40 (Scheme 5). ${ }^{39}$

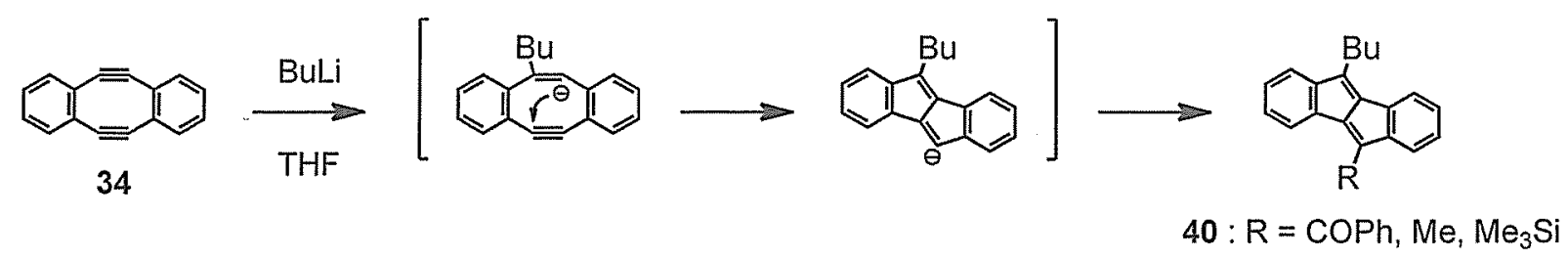

Scheme 5. Nucleophile-induced cyclizations of [8]DBA 34.

As described above, although there are scattering examples of transannular cyclizations of DBAs leading to novel polycyclic aromatic compounds, systematic researches of tandem cyclization have not been done.

\subsection{Purpose of this Thesis}

On the basis of the background mentioned above, the author carried out the following studies relevant to DBAs as (i) a shape-persistent building block of large molecules and (ii) reactive precursors to transform into novel polycyclic aromatic compounds in first half of this thesis. In the second half, the author investigated the synthesis and properties of novel polycyclic aromatic compounds related to indenofluorenes inspired by the results of the first half of the thesis.

In Chapter 2, the author described the synthesis and dynamic bahaviors of propeller-shaped tris(dehydrobenzo[14]annulene)s (tris[14]DBAs), which consist of core benzene ring that is fused by three [14]DBA 30 blades. Although it has already reported that a $\mathrm{C}-\mathrm{C} \equiv \mathrm{C}-\mathrm{C}$ unit can be considerably deformed from linearity and behave more flexible than one may imagine in overcrowded transition states of conformational isomerization, ${ }^{40}$ the ring inversion of tris[14]DBAs seems to be difficult because the overlap of neighboring blades is so large that a heavily distorted transition state of the 
acetylene units is necessary. In this respect, the author investigated the structures and conformational interconversions due to flopping of the [14]DBA units in the propeller-shaped tris[14]DBAs by using computational methods, X-ray crystallographic analysis, and variable-temperature NMR measurements.

While the [14]DBA framework was used as the shape-persistent building blocks of three-dimensional architectures in Chapter 2, Chapter 3 deals the [14]DBA derivatives as precursors to transform into novel polycyclic aromatic compounds by intramolecular $\mathrm{C}-\mathrm{C}$ bond formations between the sp carbon atoms taking advantage of the high reactivity of deformed acetylene units. [14]DBA is regarded as an intriguing framework for the multiple bond formation because of the presence of four closely located triple bonds. In the event, the author discovered an unprecedented cyclodimerization induced by addition of $n$-butyllithium to form eight-membered ring products in which two indeno[2,1-a]fluorene components are connected by a single and a double bonds, following three-fold transannular bond formations. The author conjectured that the biradical character of a plausible intermediate possessing an indeno[2,1-a]fluorene ${ }^{41}$ substructure may play a major role for this unexpected dimerization. This assumption inspired the author to hold an idea of novel aromatic framework related to indenofluorene isomers as described below.

In Chapter 4, the author described the formation and characterization of $11,11^{\prime}: 12,12$ '-biindeno[2,1-a]fluorenediylidene, which consists of two indeno[2,1-a]fluorene structures connected by two double bonds. The formation mechanism based on a concerted [4+4] cycloaddition, which is a symmetry forbidden thermal process, ${ }^{42}$ is discussed. Additionally, the X-ray analysis of the product revealed a highly twisted cyclooctatetraene unit which has not been reported yet. $^{43}$ The electronic properties and anti-aromatic character due to the twisted cyclooctatetraene structure are also discussed.

Chapter 5 described the synthesis and properties of tetracyclopenta[def,jkl,pqr,vwx]tetraphenylene consisting of alternating five- and six-membered rings around the central cyclooctatetraene core. Although indeno[1,2-b]fluorene ${ }^{44}$ and indeno[2,1-a]fluorene ${ }^{41}$ derivatives were reported previously, their structural isomer indeno[2,1-c]fluorene was not thus far reported. Since the title compound consists of alternating indeno[2,1-c]fluorene structures, it exhibits biradical character. It also has 
prominent anti-aromatic character due to the presence of an inner $8 \pi$ (cyclooctatetraene) and an outer $20 \pi$ conjugated cyclic systems. These properties are discussed on the basis of theoretical and experimental (i.e. X-ray analysis and NMR spectrum) methods. 


\subsection{References and Notes}

(1) Sondheimer, F.; Wolovsky, R. J. Am. Chem. Soc. 1962, 84, 260-269.

(2) Yates, K. Hückel Molecular Orbital Theory; Academic Press: New York, 1978.

(3) (a) Sondheimer, F.; Wolovsky, R. Tetrahedron 1959, 3-6. (b) Sondheimer, F.; Wolovsky, R. J. Am. Chem. Soc. 1959, 81, 1771-1772. (c) Sondheimer, F.; Amiel, Y.; Gaoni, Y. J. Am. Chem. Soc. 1962, 84, 270-274. (d) Sondheimer, F.; Ameil, Y.; Gaoni, Y. J. Am. Chem. Soc. 1962, 84, 274-284.

(4) Oth, J. F. M.; Röttle, H.; Schröder, G. Tetrahedron Lett. 1970, 61-66.

(5) Sondheimer, F.; Gaoni, Y. J. Am. Chem. Soc. 1960, 84, 5765-5766.

(6) (a) Schröder, G.; Oth, J. F. M. Tetrahedron Lett. 1966, 4083-4088. (b) Schröder, G.; Martin, W.; Oth, J. F. M. Angew. Chem. Int. Ed. Engl. 1967, 8, 870-871.

(7) (a) Untch, K. G.; Wysocki, D. C. J. Am. Chem. Soc. 1966, 88, 2608-2610. (b) Sondheimer, F.; Wolovsky, R.; Garratt, P. J.; Calder, I. C. J. Am. Chem. Soc. 1966, 88, 2610.

(8) Okamura, W. H.; Sondheimer, F. J. J. Am. Chem. Soc. 1967, 89, 5991-5992.

(9) (a) Iyoda, M.; Miyazaki, H.; Nakagawa, M. J. Chem. Soc., Chem. Commun. 1972, 431-432. (b) Iyoda, M.; Miyazaki, H.; Nakagawa, M. Bull. Chem. Soc. Jpn. 1976, 49, 2306-2309.

(10) Staab, H. A.; Graf, F.; Junge, B. Tetrahedron Lett. 1966, 743-749.

(11) (a) Meissner, U. E.; Gensler, A.; Staab, H. A. Angew. Chem. Int. Ed. Engl. 1976, 15, 365-366.

(b) Staab, H. A.; Meissner, U. E.; Weinachy, W.; Gensler, A. Chem. Ber. 1979, 112, 3895-3906.

(12) (a) Meisser, U.; Gensler, A.; Staab, H. A. Tetrahedron Lett. 1977, 3-6. (b) Meissner, U.; Gensler, A.; Staab, H. A. Chem. Ber: 1979, 112, 3907-3913.

(13) (a) Campbell, J. D.; Eglinton, G.; Henderson, W.; Raphael, R. A. Chem. Commun. 1966, 87-89.

(b) Staab, H. A.; Graf, F. Tetrahedron Lett. 1966, 751-757. (c) Brunner, H.; Hausser, K. H.; Rawitscher, M.; Staab, H. A.; Graf, F. Tetrahedron Lett. 1966, 2775-2779. (d) Staab, H. A.; Graf, F. Chem. Ber. 1970, 105, 1107-1118.

(14) Darby, N.; Cresp, T. M.; Sondheimer, F. J. Org. Chem. 1977, 42, 1960-1967.

(15) Haley, M. M.; Brand, S. C.; Pak, J. J. Angew. Chem. Int. Ed. Engl. 1997, 36, 836-838.

(16) Recent reviews on various aspects of annulene, see: (a) Youngs, W. J.; Tessier, C. A.; Bradshaw, J. D. Chem. Rev. 1999, 99, 3153-3180. (b) Hopf, H. Classics in Hydrocarbon Chemistry; 
Wiley-VCH: Weinheim, 2000; p 197. (c) Kennedy, R. D.; Lloyd, D.; McNab, H. J. Chem. Soc., Perkin Trans. 1 2002, 1601-1621. (d) Marsella, M. J. Acc. Chem. Res. 2002, 35, 944-951. (e) Meier, H. Synthesis 2002, 1213-1228. (f) Marsden, J. A.; Palmer, G. J.; Haley, M. M. Eur. J. Org. Chem. 2003, 2355-2369. (g) Spitler, E. L.; Johnson II, C. A.; Haley, M. M. Chem. Rev. 2006, 106, $5344-5386$.

(17) Marsden, J. A.; Haley, M. M. in Metal-Catalyzed Cross-Coupling Reactions, 2nd ed.; de Meijere, A., Diederich, F., Eds.; Wiley-VCH: Weinheim, 2004; p 317.

(18) Solooki, D.; Bradshaw, J. D.; Tessier, C. A.; Youngs, W. J.; See, R. F.; Churchill, M.; Ferrara, J. D. J. Organomet. Chem. 1994, 470, 231-236.

(19) Baldwin, K. P.; Simons, R. S.; Rose, J.; Zimmerman, P.; Hercules, D. M.; Tessier, C. A.; Youngs, W. J. J. Chem. Soc., Chem. Commun. 1994, 1257-1258,

(20) Guo, L.; Bradshaw, J. D.; Tessier, C. A.; Youngs, W. J. J. Chem. Soc., Chem. Commun. 1994, 243-244.

(21) Dosa, P. I.; Erben, C.; Iyer, V. S.; Vollhardt, K. P. C.; Wasser, I. M. J. Am. Chem. Soc. 1999, 121, 10430-11431.

(22) Heuft, M. A.; Collins, S. K.; Yap, G. P. A.; Fallis, A. G. Org. Lett. 2001, 3, 2883-2886.

(23) Haley, M. M.; Bell, M. L.; Brand, S. C.; Kimball, D. B.; Pak, J. J.; Wan, W. B. Tetrahedron Lett. $1997,38,7483-7486$.

(24) Heuft, M. A.; Collins, S. K.; Fallis, A. G. Org. Lett. 2003, 5, 1911-1914.

(25) (a) Rubin, Y.; Parker, T. C.; Kahn, S. I.; Holliman, C. L.; McElvany, S. W. J. Am. Chem. Soc. 1996, 118, 5308-5309. (b) Rubin, Y. Chem. Eur. J. 1997, 3, 1009-1016.

(26) (a) Rubin, Y.; Parker, T. C.; Pastor, S. J.; Jalisatgi, S.; Boulle, C.; Wilkins, C. L. Angew. Chem. Int. Ed. 1998, 37, 1226-1229. (b) Tobe, Y.; Nakagawa, N.; Naemura K.; Wakabayashi, T.; Shida, T.; Achiba, Y. J. Am. Chem. Soc. 1998, 120, 4544-4545.

(27) (a) Wu, Z.; Lee, S.; Moore, J. S. J. Am. Chem. Soc. 1992, 114, 8730-8732. (b) Wu, Z.; Moore, J.

S. Angew. Chem. Int. Ed. Engl. 1996, 35, 297-299.

(28) Boese, R.; Matzger, A. J.; Vollhardt, K. P. C. J. Am. Chem. Soc. 1997, 119, 2052-2053.

(29) (a) Baldwin, K. P.; Bradshaw, J. D.; Tessier, C. A.; Youngs, W. J. Synlett 1993, 853-855. (b) 
Baldwin, K. P.; Matzger, A. J.; Scheiman, D. A.; Tessier, C. A.; Vollhardt, K. P. C.; Youngs, W. J. Synlett 1995, 1215-1218.

(30) For recent general discussion about alkyne cyclizations, see: (a) Wang, K. K. Chem. Rev. 1996, 96, 207-222. (b) Gilmore, K.; Alabugin I. V. Chem. Rev. 2011, 111, 6513-6556. (c) Alabugin, I. V.; Gilmore, K.; Monoharan, M. J. Am. Chem. Soc. 2011, 133, 12608-12623.

(31) (a) Youngs, W. J.; Djebli, A.; Tessier, C. A. Organometallics 1991, 10, 2089-2090. (b) Malaba, D.; Djebli, A.; Chen, L.; Zarate, E. A.; Tessier, C. A.; Youngs, W. J. Organometallics 1993, 12, 1266-1276. (c) Bradshaw, J. D.; Solooki, D.; Tessier, C. A.; Youngs, W. J. J. Am. Chem. Soc. 1994, $116,3177-3179$.

(32) Alabugin, I. V.; Gilmore, K.; Patil, S.; Monoharan, M.; Kovalenko, S. V.; Clark, R. J.; Ghiviriga, I. J. Am. Chem. Soc. 2008, 130, 11535-11545.

(33) (a) Alabugin, I. V.; Manoharan, M.; Breiner, B.; Lewis, F. D. J. Am. Chem. Soc. 2003, 125, 9326-9342. (b) Alabugin, I. V.; Manoharan, M. J. Am. Chem. Soc. 2005, 127, 9534-9545. (c) Alabugin, I. V.; Manoharan, M. J. Am. Chem. Soc. 2005, 127, 12583-12594. (d) Alabugin, I. V.; Timokhin, V. I.; Abrams, J. N.; Manoharan, M.; Abrams, R.; Ghiviriga, I. J. Am. Chem. Soc. 2008, 130, 10984-10995. (e) Byers, P. M.; Alabugin, I. V. J. Am. Chem. Soc. 2012, 134, 9609-9614.

(34) Xu, F.; Peng, L.; Orita, A.; Otera, J. Org. Lett. 2012, 14, 3970-3973.

(35) Zhou, Q.; Carroll, P. J.; Swager, T. M. J. Org. Chem. 1994, 59, 1294-1301.

(36) Chase, D. T.; Rose, B. D.; McClintock, S. P.; Zakharov, L. N.; Haley, M. M. Angew. Chem. Int. Ed. 2011, 50, 1127-1130.

(37) Takeda, T.; Inukai, K.; Tahara, K.; Tobe, Y. J. Org. Chem. 2011, 76, 9116-9121.

(38) Umeda, R.; Hibi, D.; Miki, K.; Tobe, Y. Org. Lett. 2009, 11, 4104-4106. (b) Umeda, R.; Hibi, D.; Miki, K.; Tobe, Y. Pure Appl. Chem. 2010, 82, 871-878.

(39) Babu, G.; Orita, A.; Otera, J. Chem. Lett. 2008, 37, 1296-1297.

(40) (a) Toyota, S.; Yamamoto, T.; Makino, T. Tetrahedron 2001, 57, 3521-3628. (b) Makino, T.; Toyota, S. Bull. Chem. Soc. Jpn. 2005, 78, 917-928. (c) Toyota, S. Chem. Rev. 2010, 110, $5398-5424$.

(41) (a) Étienne, A.; Le Berre, A. C. R. Hebd. Seances Acad. Sci. 1956, 242, 1493-1496. (b) A. 
Étienne, A.; Le Berre, A. C. R. Hebd. Seances Acad. Sci. 1956, 242, 1899-1901. (c) Le Berre, A. C. R. Hebd. Seances Acad. Sci. 1956, 242, 2365-2367. (d) Le Berre, A. Ann. Chim. 1957, 13, 371-379. (e) Shimizu, A.; Tobe, Y. Angew. Chem. 2011, 123, 7038-7042; Angew. Chem. Int. Ed. 2011, 50, 6906-6910.

(42) Woodward, R. B.; Hoffmann, R. J. Am. Chem. Soc. 1965, 87, 395-397.

(43) For recent reviews on tub-shaped and planar cyclooctatetraene, see: (a) Klärner, F. G. Angew. Chem. Int. Ed. 2001, 40, 3977-3981. (b) Nishinaga, T.; Ohmae, T.; Iyoda, M. Symmetry 2010, 2, $76-97$.

(44) (a) Chase, D. T.; Rose, B. D.; McClintock, S. P.; Zakharov, L. N.; Haley, M. M. Angew. Chem. Int. Ed. 2011, 50, 1127-1130. (b) Chase, D. T.; Fix, A. G.; Rose, B. D.; Weber, C. D.; Nobusue, S.; Stockwell, C. E.; Zakharov, L. N.; Lonergan, M. C.; Haley, M. M. Angew. Chem. Int. Ed. 2011, 50, 11103-11106. (c) Chase, D. T.; Fix, A. G.; Kang, S. J.; Rose, B. D.; Weber, C. D.; Zhong, Y.; Zakharov, L. N.; Lonergan, M. C.; Nuckolls, C.; Haley, M. M. J. Am. Chem. Soc. 2012, 134, 10349-10352. 
-16 - 
Choupter 2

Synthesis and Dymamic Behavior of Propeller-Shaped Tris(dehydrobenzo[14]annulleme)s 


\subsection{Introduction}

Propeller-shaped polycyclic aromatic compounds, which consist of a core benzene ring fused by three aromatic blades have been attracting considerable interest in view of their unique conformations and the relevant dynamic behaviors. ${ }^{1}$ These include suitably substituted derivatives of triphenylene, ${ }^{2}$ extended homologues of triphenylene including hexabenzotriphenylene, ${ }^{3-7}$ and decacyclenes $^{8}$ which in principle can adopt $C_{2}$ and/or $D_{3}$ conformations. For a prototypical propeller-shaped compound, hexabenzotriphenylene (1), Pascal reported that it adopted a strongly twisted $D_{3}$-symmetric conformation when it was synthesized by a high temperature vacuum pyrolysis of phenanthrene-9,10-dicarboxylic anhydride. ${ }^{3}$ Through an extensive computational study, he concluded that the $D_{3}$ isomer of 1 is thermodynamically more stable than the $C_{2}$ isomer. He also proposed a rule of thumb for the $C_{2} / D_{3}$ dichotomy of sterically overcrowded triphenylene and decacyclene derivatives: the $D_{3}$ conformation is preferred if the central benzene ring is expected to be aromatic (i.e. delocalized benzene-like bonds with small bond alternation), whereas the $C_{2}$ conformation will be observed if the central ring is nonaromatic (i.e. bonds with high degree of bond alternation). In other words, this rule may be understood as follows: if the core benzene ring is less flexible (i.e. more resistant to deform) than the blades, as in the case of $\mathbf{1}$, the blades will be twisted into a chair-like form of $D_{3}$ symmetry, because such twist will not disturb the overlap between $\mathrm{p}$ orbitals in the peripheral aromatic rings. Conversely, if the blades are more resistant toward deformation than the core benzene ring, as in the case of substituted triphenylenes, the core benzene ring will be distorted into a twist boat-like form of $C_{2}$ symmetry, because the local overlap between $\mathrm{p}$ orbitals of the peripheral benzene rings will be kept in this form. The Pascal's rule was supported by several experimental observations. For example, Pérez and Guitián reported the isolation of the $C_{2}$ conformer of 1 as a kinetic product of the palladium-catalyzed cyclotrimerization of in-situ generated 9,10-didehydrophananthrene and the conversion of the $C_{2}$ to the $D_{3}$ isomer by heating. ${ }^{4}$ The barriers $\left(\Delta \mathrm{G}^{\neq}\right)$of the interconversion between the enantiomeric $C_{2}$ isomers and that of $C_{2}-D_{3}$ isomerization were determined to be 11.7 and $26.2 \mathrm{kcal} / \mathrm{mol}$, respectively. Kinetically favored formation of the $C_{2}$ isomer was also observed in nickel-catalyzed cyclotrimerization of 9,10-didehydrophenanthrene. ${ }^{5}$ Very recently, the synthesis of hexa-tert-butyl derivative of 1 by regioselective $\mathrm{FeCl}_{3}$-mediated Scholl cyclization was reported. ${ }^{9}$ Though the dynamic behavior was not described, it was shown to 
adopt a $D_{3}$ symmetric structure in crystalline state by X-ray crystallography. Additionally, Mount and Galow revealed that hexamethyltriphenylene (2), one of ideal candidates to examine the Pascal's $C_{2} / D_{3}$ dichotomy, underwent a rapid interconversion of two enantiomeric $C_{2}$ conformers and a slower $C_{2}-D_{3}$ interconversion, thus providing a strong support to the rule. ${ }^{2 \mathrm{c}}$
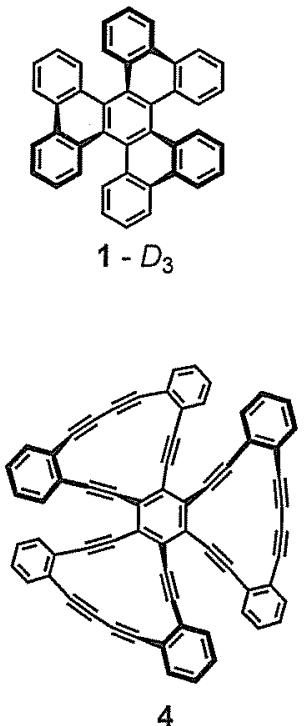
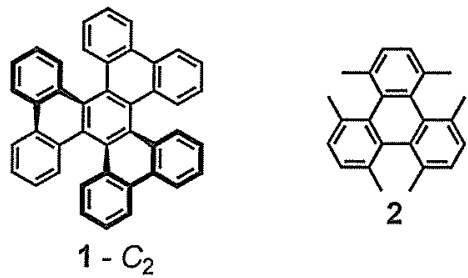

2

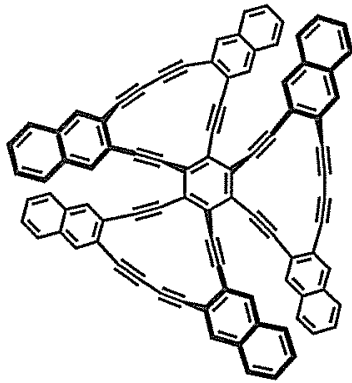

5

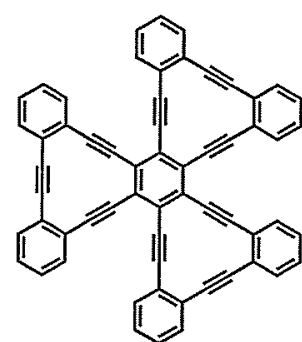

3

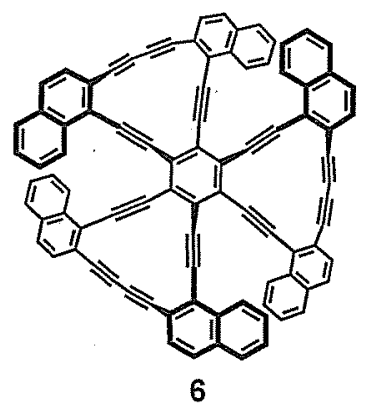

As a nominally $D_{3 \mathrm{~h}}$-symmetric molecule consisting of dehydroannulene rings, the synthesis of triply fused dehydrobenzo[12]annulene 3 consisting of 12-membered dehydroannulene rings was reported previously. ${ }^{10}$ DFT calculations predict that it adopts a nearly planar conformation with a small twist angle of $7.5^{\circ}$, indicating that the steric crowding between the blades of 3 is small. ${ }^{11}$ In the case of higher homologue 4 , having dehydrobenzo[14]annulene rings, ${ }^{12}$ and its naphthalene homologues 5 and 6, however, considerable overcrowding in the ground state is expected, because it is not possible to draw a nominal $D_{3 \mathrm{~h}}$ structure without partial overlap of the blades. This is more obvious in the naphthalene homologues 5 and 6 than in 4 (Figure 1, for the structures of 4-6 in the $D_{3}$ and $C_{2}$ conformations optimized by DFT calculations). Intuitively, therefore, the barriers for their conformational interconversion seem substantially large with those of $\mathbf{5}$ and $\mathbf{6}$ being larger than that of 4. If the Pascal's rule is applicable to $4-6$, they are supposed to adopt the $D_{3}$-symmetic conformation, because the central ring must exhibit aromatic character (i.e. small bond length alternation) due to relatively weak aromaticity of the dehydrobenzo[14]annulene system. Because 
Pascal only argued about the choice of the $C_{2}$ and $D_{3}$ conformations for the triphenylene- and decacyclene-based propeller-shaped compounds, the structures of molecular propellers bearing blades with greater flexibility, due to large ring size as well as weak aromaticity, will provide information regarding how steric overcrowding affects the conformational selectivity.

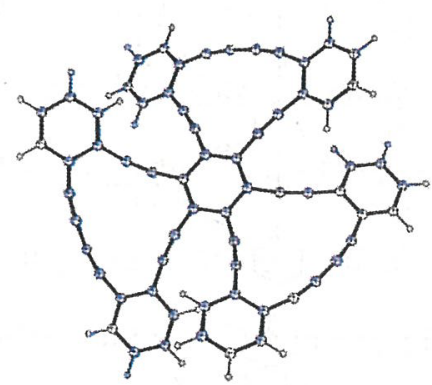

4- $D_{3}$

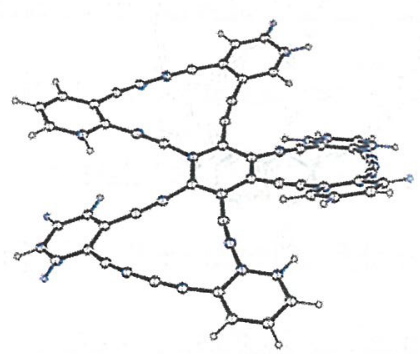

4- $C_{2}$

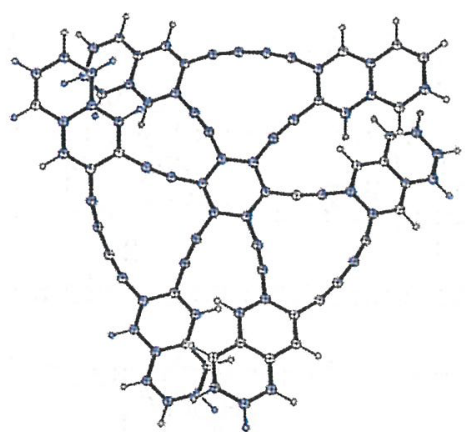

5- $D_{3}$

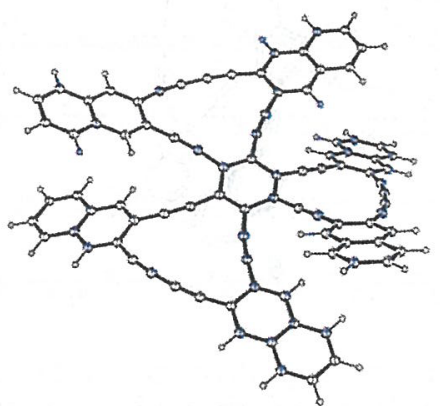

5- $C_{2}$

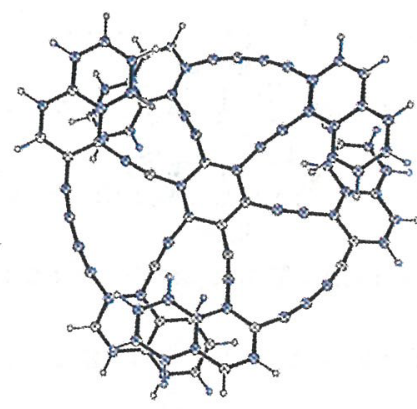

6- $D_{3}$

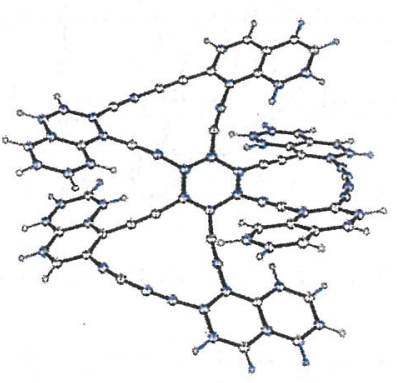

6- $C_{2}$

Figure 1. Calculated geometries of $D_{3}$ and $C_{2}$ conformers of 4-6 optimized by DFT calculations at the B3LYP/6-31G* levels of theory.

As to the conformational mobility of alkynes, it has been reported by Toyota that a $\mathrm{C}-\mathrm{C} \equiv \mathrm{C}-\mathrm{C}$ unit can be substantially deformed from linearity and behaves more flexible than one may imagine in extremely overcrowded transition states of conformational isomerization in which this unit causes major steric hindrance. ${ }^{13}$ From the calculated geometries of $D_{3}$-optimized structures (Figure 1), however, the racemization of 4-6 via ring inversions of the [14]DBA blades seems to be difficult, because overlap of neighboring blades are so large that heavily distorted transition state of acetylene units is necessary for the slippage of the blades, although the conformational exchanges of $\mathbf{1}$ and 2 took place with activation barriers that were smaller than one might imagine. ${ }^{14}$ In this respect, it is interesting to see how flexible the [14]DBA blades are in the conformational interconversion of 4-6. 
From the above points of view, the author synthesized compounds 4-6 and investigated their conformational properties by computational methods, X-ray crystallographic analyses, and variable-temperature NMR (VT-NMR) studies, of which results are the topics of this article.

\subsection{Synthesis of Tris([14]DBA)s}

Compounds 4-6 were synthesized by attaching six diethynylarene units to the central benzene ring followed by intramolecular oxidative coupling as shown in Scheme 1. For the preparation of 4, direct substitution of hexabromobenzene (11) with TMS-protected $o$-diethynylbenzene $\mathbf{1 0}^{15}$ was carried out to give a six-fold substitution product 12 in $37 \%$ yield. Removal of the TMS protecting group gave 13 which was subjected without isolation to subsequent oxidative coupling using $\mathrm{Cu}(\mathrm{OAc})_{2} \cdot \mathrm{H}_{2} \mathrm{O}$ in pyridine at room temperature, yielding 4 as a pale yellow solid which turned dark quickly when the solvent was evaporated to dryness. The dark brown solid was definitely insoluble to any solvent. Because of its sensitivity, exact yield of 4 in the final step was not determined. ${ }^{16}$ Even in solution, it becomes gradually darkened at room temperature. Only crystals containing acetone (vide infra), which were used for the X-ray crystallographic analysis (Figure 3), can be stored without appreciable decomposition.

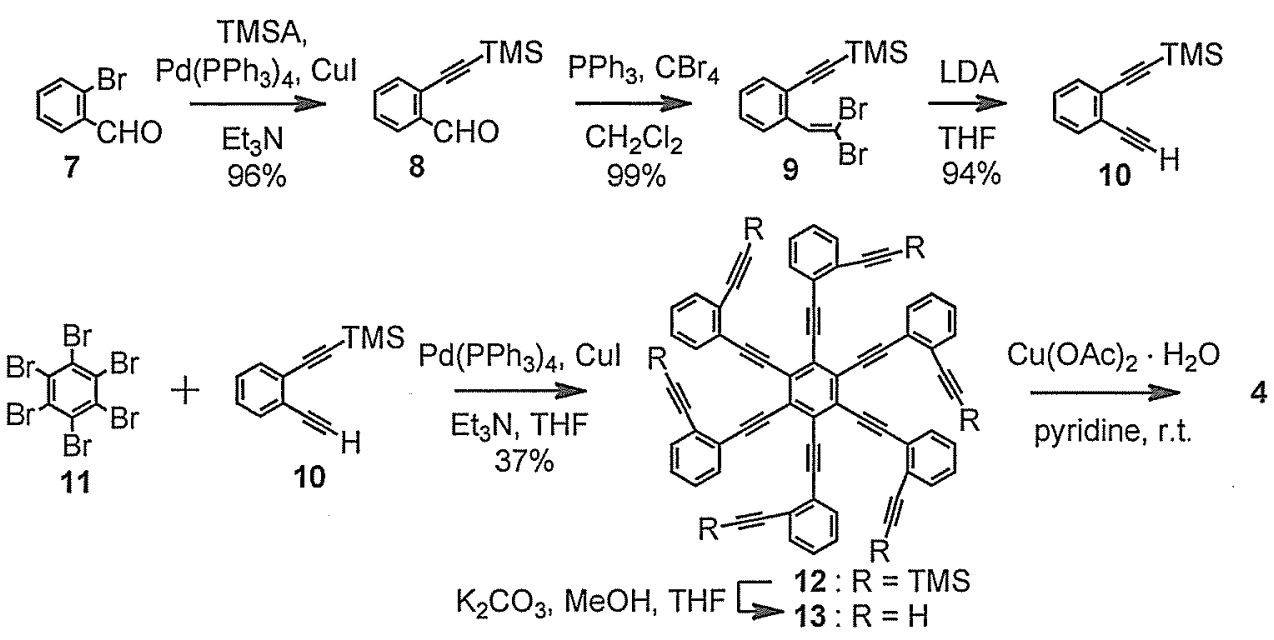

Scheme 1. Synthesis of compound 4.

For the preparation of 5 , the key precursor 19 was prepared by cross-coupling of iodide 16 with 
hexaethynylbenzene (18), ${ }^{17}$ because larger steric crowding may hinder the coupling reaction in direct substitution route (Scheme 2). The Hagihara-Sonogashira coupling reaction of $\mathbf{1 8}$ derived from its TMS derivative $17^{18}$ with 16 gave a six-fold substitution product 19 in $11 \%$ yield. After removal of the TMS group of $\mathbf{1 9}$, oxidative coupling of $\mathbf{2 0}$ was conducted at room temperature in a similar manner to that of $\mathbf{1 3}$ to give naphthalene homologue $\mathbf{5}$ as a pale yellow solid. Since compound $\mathbf{5}$ was even less stable than 4 , the yield was not determined exactly.

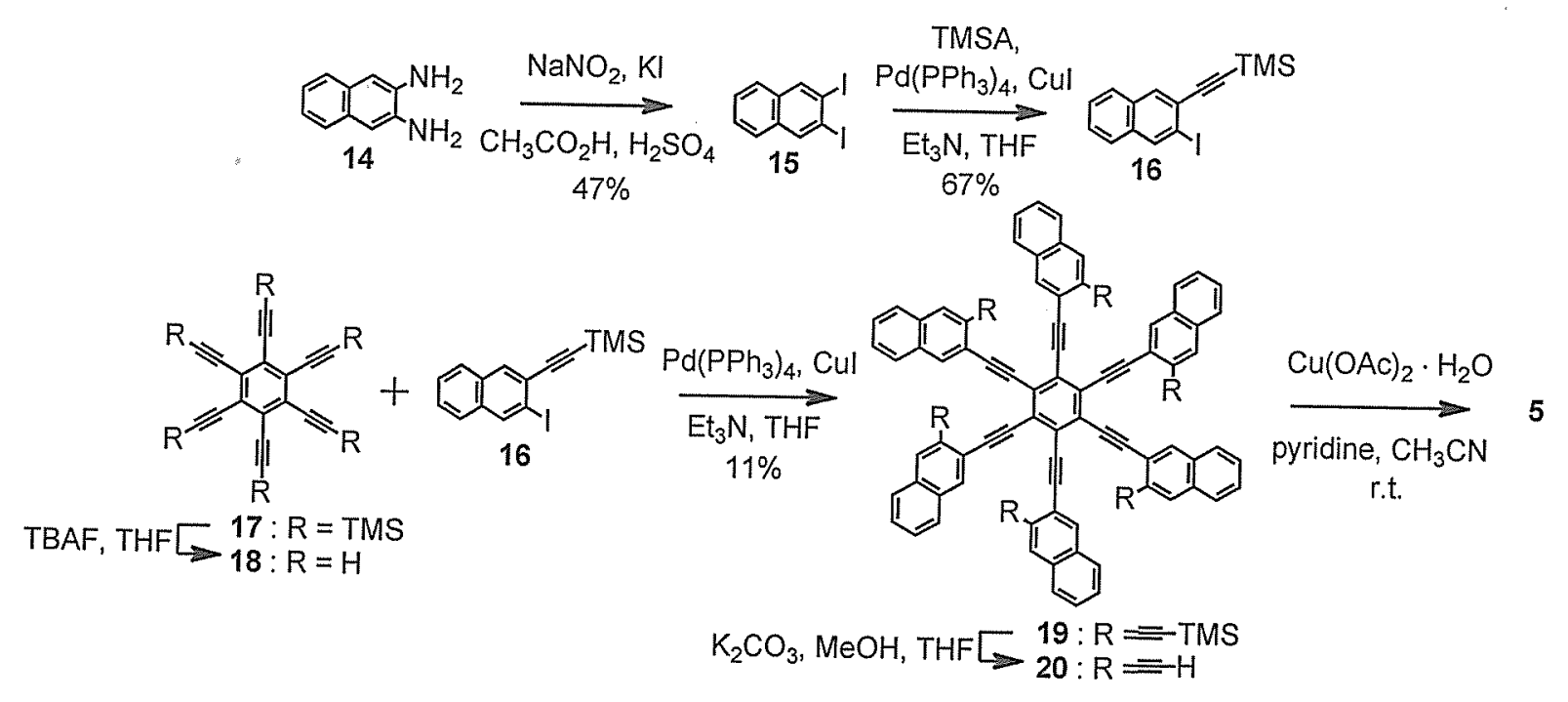

Scheme 2. Synthesis of compound 5 .

For the synthesis of 6 , the preparation of the key precursor 31 was carried out in two pathways, "Route A" and "Route B" (Scheme 3). As a result, while the cross-coupling of iodide 30 with hexaethynylbenzene (18) gave $\mathbf{3 1}$ in only 13\% yield (Route B), direct substitution of hexabromobenzene (11) with TMS-protected $o$-diethynylnaphthalene 25 gave 31 in as much as $51 \%$ yield (Route A). The intramolecular oxidative coupling of 32 derived from removal of the TMS protecting group of 31 was carried out at $70^{\circ} \mathrm{C}$, yielding the naphthalene homologue 6 in $7 \%$ yield. Compound 6 was not obtained when the reaction was conducted at room temperature. Similar to 4 , compound 6 was only stable in crystals containing solvent molecules. Absorption spectra of 4-6 and their key precursors 12, 19, and 31 are shown in Figure 2. While 12, 19, and 31 show broad absorption bands, compounds 4-6 exhibit absorptions with vibrational structures at longer wavelengths than the corresponding precursors. 
21

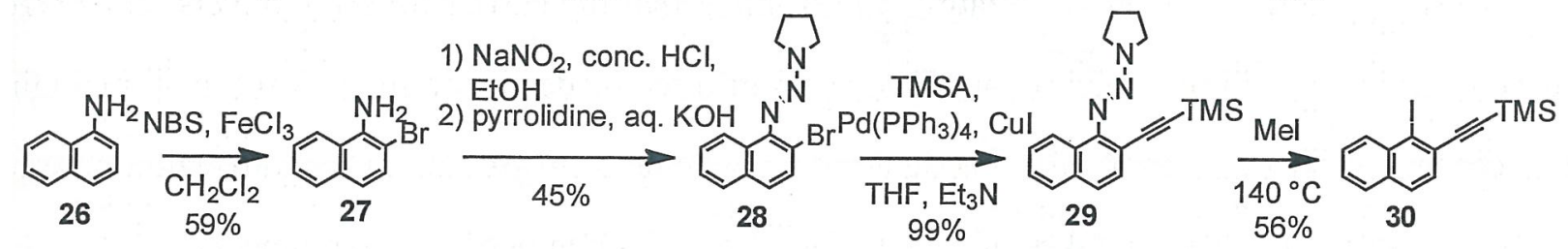

"Route A"

"Route B"

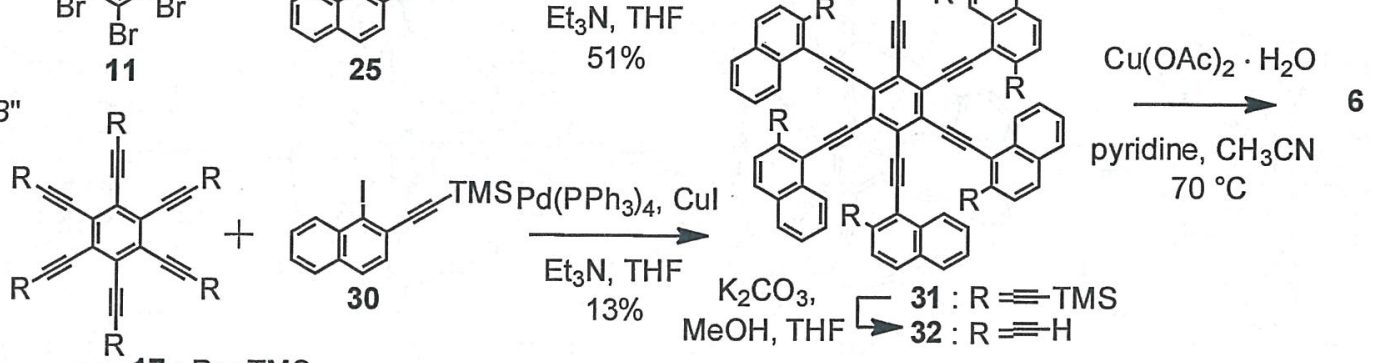

TBAF, THF $[17: \mathrm{R}=$ TMS

Scheme 3. Synthesis of compound 6.

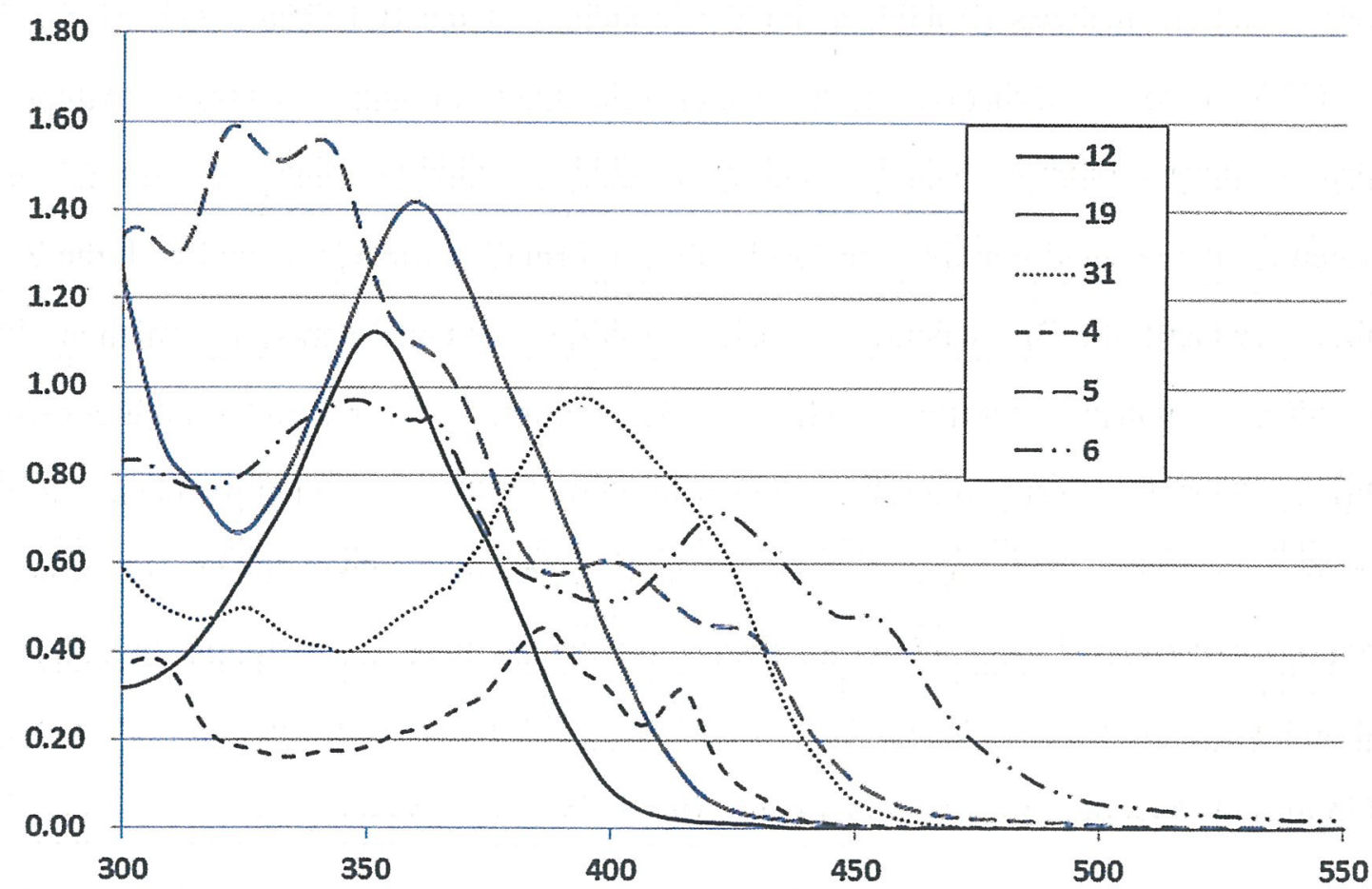

Figure 2. UV/vis absorption spectra of $4-6$ and the Precursor 12, 19, and $\mathbf{3 1}$. 


\subsection{Calculated Relative Stabilities of Conformers of Tris([14]DBA $) \mathrm{s}$}

The interconversion between the $C_{2}$ - and $D_{3}$-symmetric conformations of 4 is shown in Scheme 4 , which represents one of the shortest pathways assuming that the barrier for interconversion between two $D_{3}$ enantiomers via the synchronous inversions of three blades is too high. A full map including all of conformational exchanges for $\mathbf{6}$ is depicted in Scheme 5. Apparently, interconversion between the $D_{3}$-symmetric enantiomers takes place via at least two $C_{2}$-symmetric diastereomers.

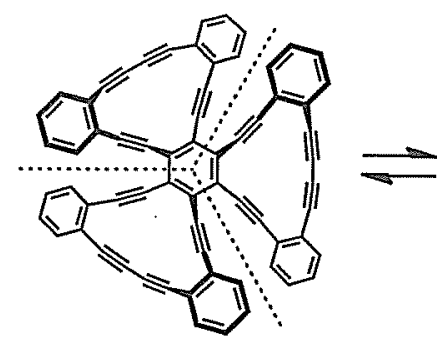

$(P)-D_{3}$

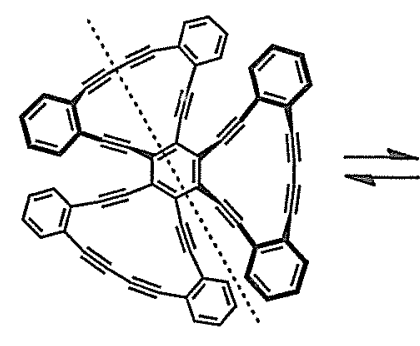

$\mathrm{C}_{2}$

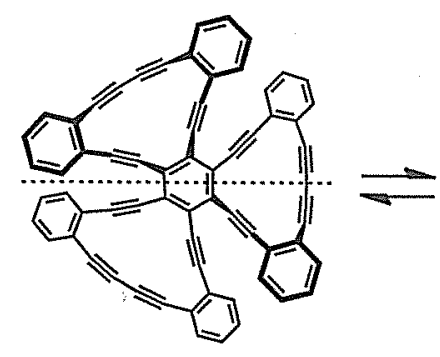

$\mathrm{C}_{2}$

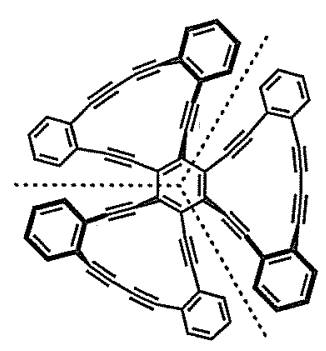

(M) $-D_{3}$

Scheme 4. One of the shortest pathways for interconversion between $D_{3}$-isomers.

To estimate the relative stabilities of the $C_{2}$ and $D_{3}$ conformers of 4-6, the author performed semiempirical MO calculations (PM3) and DFT calculations at the B3LYP/6-31G*, M05/6-31G*, and M05-2X/6-31G* levels of theory. The relative energies are summarized in Table 1. Although the energy differences between $C_{2}$ and $D_{3}$ conformations are smaller compared to $1,^{3}$ all the computational results showed a preference for the $D_{3}$ conformation for 4 in accord with the Pascal's rule. On the other hand, the DFT calculations using the M05 series of functionals, which are known to predict well noncovalent interactions such as $\pi-\pi$ interaction, ${ }^{19}$ tend to show a preference for the $C_{2}$ conformers; more specifically, the calculations using the M05-2X functional predicted that the $C_{2}$ conformer of 1,2-naphtho homologue 6 is significantly more stable than the $D_{3}$ conformer. The results from the M05/6-31G* calculations are always in-between these two extremes, favoring the $D_{3}$ form for $\mathbf{4}$ and $\mathbf{5}$ and the $C_{2}$ form for $\mathbf{6}$. The reason for the difference depending on the functional is discussed in the subsequent section in comparison with their X-ray structures. 


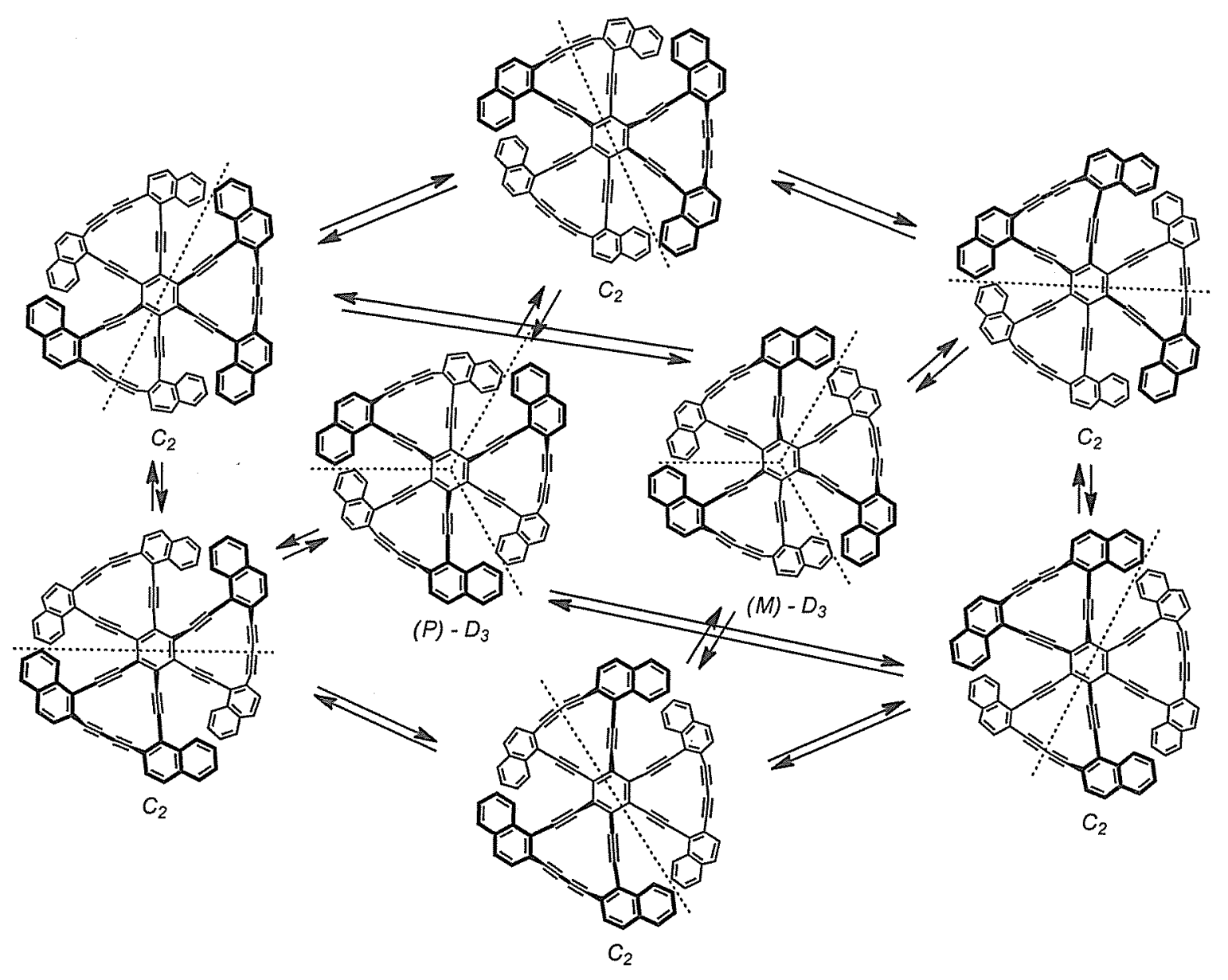

Scheme 5. Full Map of Conformational Exchanges of 6

Table 1. Calculated Energies for the $D_{3}$ and $C_{2}$ Conformers of 4-6

\begin{tabular}{ccccc}
\hline & PM3 & DFT: & DFT: & DFT: \\
\hline $4-D_{3}{ }^{a}$ & 1.31679260 & -2828.83846744 & -2526.90883007 & -2528.63811333 \\
$4-C_{2}{ }^{a}$ & 1.31804673 & -2528.83532543 & -2526.90609908 & -2528.63562897 \\
difference $^{b}$ & 0.79 & 1.97 & 1.71 & 1.56 \\
$\mathbf{5}-D_{3}{ }^{a}$ & 1.48209747 & -3450.70124240 & -3448.06103312 & -3450.44805176 \\
$\mathbf{5}-C_{2}{ }^{a}$ & 1.48343864 & -3450.69805184 & -3448.06017074 & -3450.44847102 \\
difference $^{b}$ & 0.84 & 2.00 & 0.54 & -0.26 \\
$\mathbf{6}-D_{3}{ }^{a}$ & 1.49547974 & -3450.69238780 & -3448.05688818 & -3450.45130881 \\
$\mathbf{6}-C_{2}{ }^{a}$ & 1.49936546 & -3450.68530680 & -3448.05860465 & -3450.45646389 \\
difference $^{b}$ & 2.44 & 4.44 & -1.08 & -3.24 \\
\hline
\end{tabular}

${ }^{a}$ Calculated energies are given in hartree (au) $(1 \mathrm{au}=627.51 \mathrm{kcal} / \mathrm{mol})$.

${ }^{b}$ The calculated energy differences, $\Delta H_{\mathrm{f}}^{\circ}\left(C_{2}\right)-\Delta H_{\mathrm{f}}^{\mathrm{o}}\left(D_{3}\right)(\mathrm{PM} 3)$ and $E\left(C_{2}\right)-E\left(D_{3}\right)(\mathrm{DFT})$ are given in $\mathrm{kcal} / \mathrm{mol}$. Positive values indicate the preference for the $D_{3}$ conformation. 


\subsection{Crystal and Theoretical Structures}

The X-ray crystallographic analysis of 4 was carried out for crystals containing a disordered acetone molecule, because it is stabilized in the acetone-containing crystals. The parent [14]DBA was also reported to be unstable and polymerize even in crystals. ${ }^{20}$ However, some arylbutadiyne derivatives, which are unstable in concentrated solutions and as amorphous solids, are known to become substantially stable in crystals. ${ }^{21}$

The crystal contains a pair of $P$ - and $M$-enantiomers adopting an approximate $D_{3}$-symmetric conformation of a propeller-shape, indicating the preference of this conformation in the crystalline state. The twisting of the three [14]DBA blades are not equal most probably due to the presence of a disordered acetone molecule located atop of ring A (Figure 3). The nonbonded distances between the closest carbons of the terminal benzene rings of adjacent blades, $C(18) \ldots C(27), C(40) \ldots C(49)$, and $\mathrm{C}(62) \ldots \mathrm{C}(5)$ are $3.414,3.276$, and $3.495 \AA$, respectively, indicating that the blade near the solvent molecule (ring A) is more distorted than the other two because of the steric conflicts (carbon numbers are depicted in Figure 3). The averaged nonbonded distance is $3.395 \AA$, almost equal to the sum of the van der Waals radius of carbon atom. The dihedral angles between the central benzene

Table 2. Comparison of experimental and calculated geometries of the $D_{3}$ isomer of 4 .

\begin{tabular}{ccccc}
\hline & X-ray & B3LYP & M05 & M05-2X \\
\hline endocyclic bond length $[\AA]^{a}$ & 1.405 & 1.416 & 1.412 & 1.405 \\
exocyclic bond length $[\AA]^{b}$ & 1.428 & 1.438 & 1.432 & 1.425 \\
closest nonbonded distance $[\AA]^{c}$ & 3.395 & 3.558 & 3.464 & 3.323 \\
${\text { core-blade dihedral angle }\left[{ }^{\circ}\right]^{d}}^{c}$ & 25.55 & 19.52 & 18.70 & 17.61 \\
${\text { distorted triple bond angle }\left[{ }^{\circ}\right]^{e}}^{e}$ & 167.33 & 168.20 & 167.91 & 168.02 \\
\hline
\end{tabular}

${ }^{a}$ Bond length of the central benzene ring endocyclic to the [14]DBA ring.

${ }^{b}$ Bond length of the central benzene ring exocyclic to the [14]DBA ring.

${ }^{c}$ Closest nonbonded distances between the closest carbons of the terminal benzene rings of adjacent blades (i.e. $\mathrm{C}(18) \ldots \mathrm{C}(27)$ in Figure 3).

${ }^{d}$ Dihedral angles between the mean plane of the central benzene ring and that of the diphenylbutadiyne unit (16 carbon atoms in total; i.e., $\mathrm{C}(4)-\mathrm{C}(19)$ in Figure 3).

${ }^{e}$ Bond angles around the "spoke" acetylene unit (e.g. $\mathrm{C}(1)-\mathrm{C}(2)-\mathrm{C}(3)$ in Figure 3).

${ }^{f}$ For the experimental structure, the averaged values for the three or six relevant distances or angles are given. 
ring and the three peripheral mean planes, $C(4)-C(19), C(26)-C(41)$, and $C(48)-C(63)$ are relatively small $\left(24.5^{\circ}, 23.0^{\circ}\right.$, and $29.3^{\circ}$, respectively) compared to those of $1\left(28.2^{\circ}-30.0^{\circ}\right)$, indicating that the distortion is shared by the triple bonds. The average bond length of the central ring of 4 involved in the [14]DBA ring (endocyclic) is $1.405 \AA$ whereas that of exocyclic bond is $1.428 \AA$. The bond length alternation is less pronounced than that of $\mathbf{1}$ (1.397 vs. $1.434 \AA$ ). In addition, the central ring of 4 adopts a much shallower chair conformation with the dihedral angles of $4.14^{\circ}-7.20^{\circ}$ than those of 1 (dihedral angles: $14.8^{\circ}-17.6^{\circ}$ ). All these results indicate that 4 are less distorted than $\mathbf{1}$. The most deformed triple bonds are found at the "spoke" bonds such as $\mathrm{C}(1)-\mathrm{C}(2)-\mathrm{C}(3)$ with an average angle of $167.3^{\circ}$, though such deformation is typically observed for other [14]DBA derivatives. ${ }^{20}$
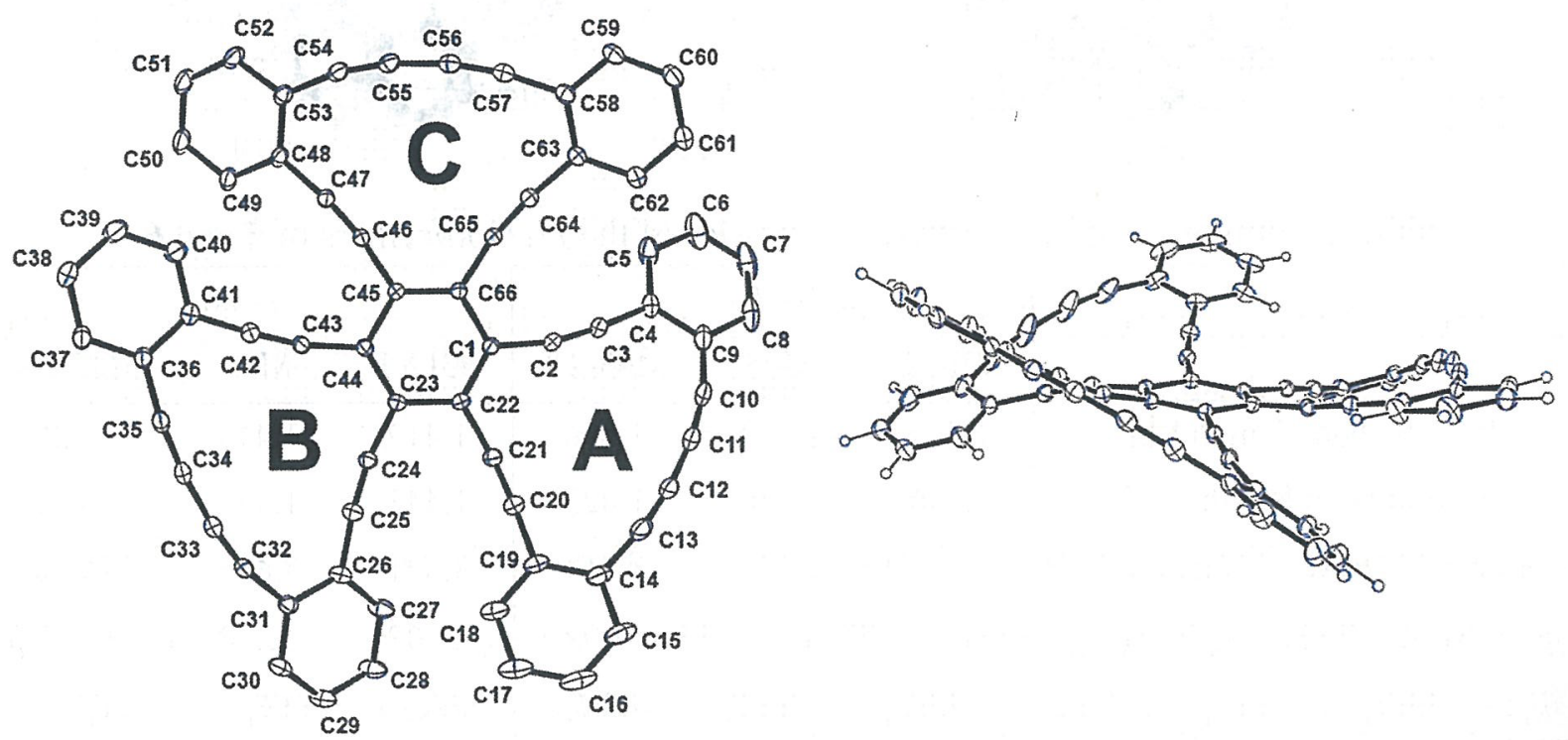

Figure 3. Molecular structure of 4 with numbering (Top view: hydrogens omitted for clarity) and a side view with thermal ellipsoids at $30 \%$ probability (solvent molecule omitted).

Table 2 lists representative structural parameters for the $D_{3}$ conformer of 4 obtained from the X-ray analysis and those from the DFT calculations using different functionals. The corresponding parameters for the $D_{3}$ conformers of 5 and $\mathbf{6}$ are listed in Table 3. As shown in Table 2, the theoretical results using the M05-2X/6-31G* functional agreed reasonably well with the X-ray structure of 4 with regard to the bond lengths and angles and reproduced the experimental data slightly better than the B3LYP/6-31G* method. On the other hand, the former results underestimate the twisting of the 
blades relative to the core benzene ring and therefore overestimate the close contact between the adjacent blades than the experimental data. This trend is in accord with the fact that the M05 series of functionals reproduce the molecular structures which include noncovalent interactions better than the most frequently used B3LYP method, although they tend to overestimate the attractive interactions. ${ }^{19}$
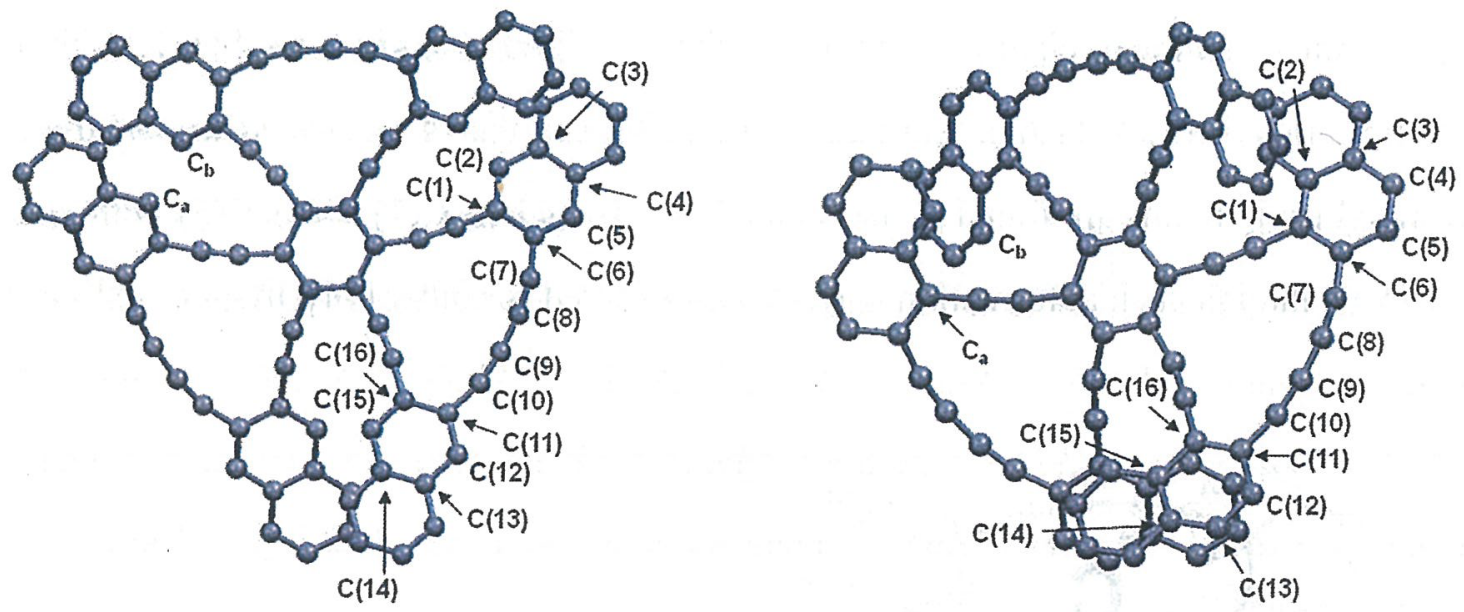

Table 3. Comparison of Calculated Geometries of the $D_{3}$ Conformers of 5 and $\mathbf{6}$.

\begin{tabular}{c|ccc|ccc}
\hline & \multicolumn{3}{|c|}{5 - $D_{3}$} & \multicolumn{3}{c}{ 6- $D_{3}$} \\
& B3LYP & M05 & M05-2X & B3LYP & M05 & M05-2X \\
\hline endocyclic bond length $[\AA]^{a}$ & 1.417 & 1.413 & 1.406 & 1.417 & 1.413 & 1.406 \\
exocyclic bond length $[\AA]^{b}$ & 1.436 & 1.430 & 1.423 & 1.443 & 1.437 & 1.430 \\
closest nonbonded distance $[\AA]^{c}$ & 3.583 & 3.313 & 3.109 & 3.841 & 3.634 & 3.294 \\
core-blade dihedral angle $\left[{ }^{\circ}\right]^{d}$ & 19.78 & 16.83 & 13.92 & 25.08 & 22.50 & 17.02 \\
distorted triple bond angle $\left[{ }^{\circ}\right]^{e}$ & 167.81 & 168.19 & 168.66 & 166.19 & 166.27 & 167.28 \\
\hline
\end{tabular}

${ }^{a}$ Bond length of the central benzene ring endocyclic to the [14]DBA ring.

${ }^{b}$ Bond length of the central benzene ring exocyclic to the [14]DBA ring.

${ }^{c}$ Closest nonbonded distances between $\mathrm{C}_{\mathrm{a}} \ldots \mathrm{C}_{\mathrm{b}}$ indicated in the above Figures.

${ }^{d}$ Dihedral angles between the mean plane of the central benzene ring and that of the diphenylbutadiyne part of the dinaphthylbutadiyne unit (i.e., $\mathrm{C}(1)-\mathrm{C}(16)$ in the above Figures).

${ }^{e}$ Bond angles around the "spoke" acetylene unit, corresponding to e.g. $C(1)-C(2)-C(3)$ in Figure 3.

Crystals of 6 suitable for X-ray analysis was obtained by recrystallization from a mixture of $o$-dichlorobenzene and acetonitrile (Figure 4), though they contained two dichlorobenzene solvent molecules which were disordered atop and below one of the distorted [14]DBA units (ring D). 
Similar to the case of 4 , compound 6 was stabilized in the crystals containing solvent molecules. Strikingly, in accord with the DFT calculations using the M05-2X functional, compound 6 was revealed to adopt an approximate $C_{2}$-symmetric conformation in crystalline state.
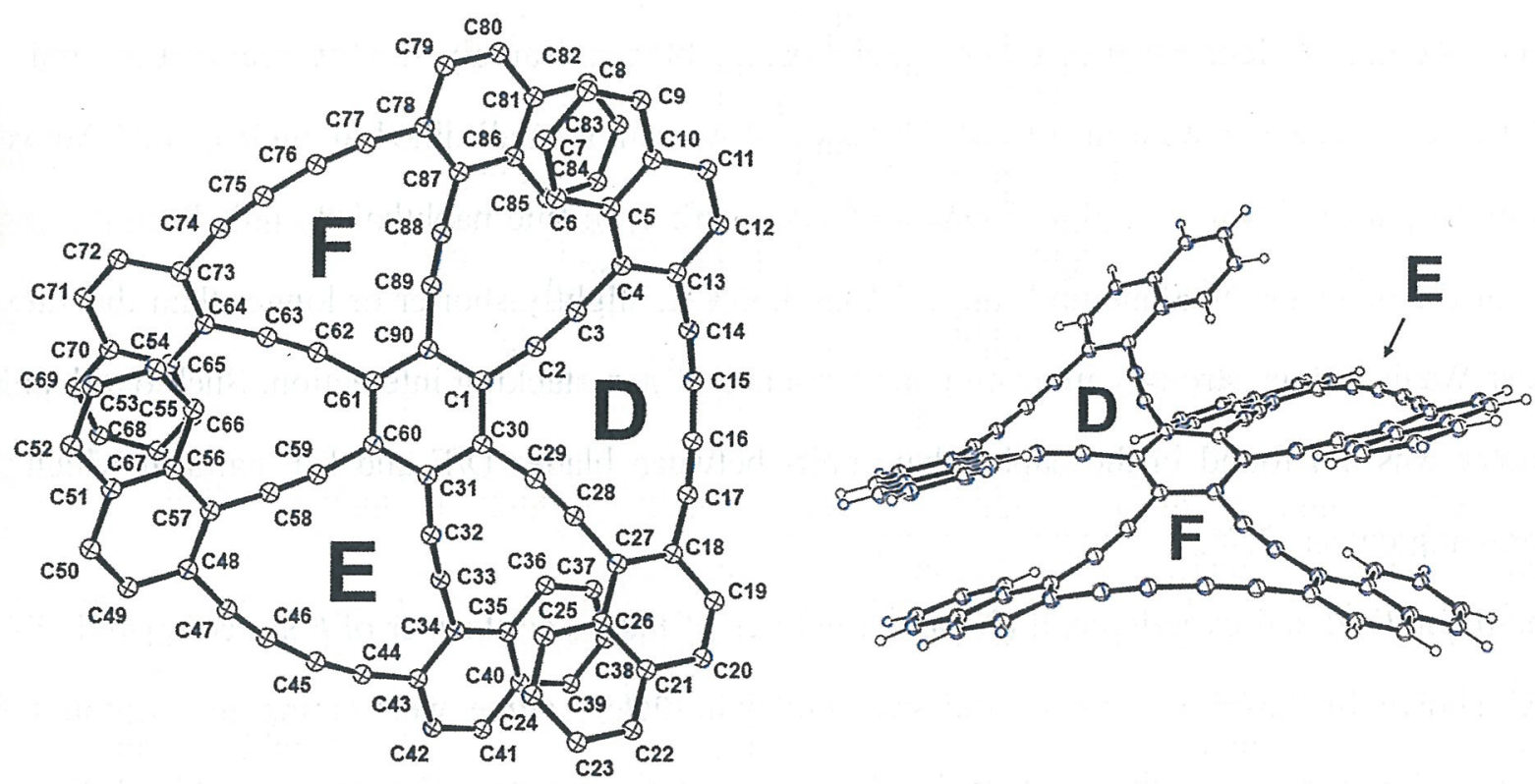

Figure 4. Molecular structure of 6 with numbering (Top view: hydrogens omitted for clarity) and a side view with thermal ellipsoids at $30 \%$ probability (solvent molecule omitted).

As to the bond length alternations of central ring, while the endocyclic bond lengths are 1.424 and $1.415 \AA$, the exocyclic bond lengths are 1.411 and $1.427 \AA$. Namely, the bond lengths do not depend on whether it is endo- or exocyclic; two bonds $(\mathrm{C}(1)-\mathrm{C}(90)$ and $\mathrm{C}(31)-\mathrm{C}(60)$ in Figure 4) are relatively short, whereas the other four bonds are relatively long. Therefore, the bond lengths of the central ring reflect the $C_{2}$ symmetry and do not exhibit alternating changes. Similar to the case of 4 , the bond length difference is smaller than that of $1{ }^{3}$ Since 6 adopts a $C_{2}$-symmertic structure in spite of the aromatic character of the central ring, it may no longer be obliged to follow the Pascal's rule.

The most notable feature of the crystal structure of $\mathbf{6}$ is the unique structure of the two [14]DBA units which are deformed into a "warped" shape. The third [14]DBA unit (ring E) adopts almost planar dinaphthylbutadiyne substructure. The bond angles of the "spoke" acetylene units $\left(166.6^{\circ}\right.$ $\left.176.6^{\circ}\right)$ are similar to those of 4 . The bond angles of the butadiyne units $\left(165.0^{\circ}-168.7^{\circ}\right)$, however, are slightly smaller than those of $4\left(166.0^{\circ}-171.8^{\circ}\right)$, although the similar degree of distorsions has 
been frequently observed. ${ }^{22}$ The dihedral angle between the naphthalene rings of the "warped" [14]DBA unit (i.e., $\mathrm{C}(34)-\mathrm{C}(43)$ vs. $\mathrm{C}(48)-\mathrm{C}(57)$ in Figure 4 ) is $39.8^{\circ} .{ }^{23}$ To our knowledge, [14]DBAs deformed in such structure as that of 6 have not been reported previously.

Another remarkable structural feature in the crystal structure of 6 is the small dihedral angles between the naphthalene rings in a pair of neighboring blades. Namely, the two naphthalene units in blades $\mathrm{D}$ and $\mathrm{F}$ are located nearly parallel to each other with a small dihedral angle of $6.1^{\circ}$ between their mean planes. Moreover, the distances of each carbon of one naphthalene unit from the mean plane of the other naphthalene unit range 3.185-3.553 $\AA$, slightly shorter or longer than the sum of van der Waals radius, strongly indicating the presence of $\pi-\pi$ stacking interaction. Such overlapping geometry was not found in the naphthâlene units between blades $\mathrm{D} / \mathrm{E}$ and $\mathrm{E} / \mathrm{F}$ pairs in which the dihedral angle was $37.4^{\circ}$.

The theoretical and experimental (X-ray) structures of the $C_{2}$ conformer of $\mathbf{6}$ are compared (Table 4). As shown in Table 4, most of the structural parameters agree well taking into account the presence of two $o$-dichlorobenzene molecules per 6 in the crystal. The most notable difference, however, was found between the theoretical structures, particularly in the relative geometry of the two closely located naphthalene rings. As described above, in the crystal structure, the naphthalene units in rings $\mathrm{D}$ and $\mathrm{F}$ locate nearly parallel to each other with a small dihedral angle of $6.1^{\circ}$ between the mean planes. This geometry was best reproduced in the calculations with M05-2X functional which showed a dihedral angle of $13.2^{\circ}$; the dihedral angles in the B3LYP and M05 structures are $29.9^{\circ}$ and $17.3^{\circ}$, respectively. On the other hand, since the M05-2X functional tends to overestimate the noncovalent interactions, the dihedral angles between the naphthalene units in rings $\mathrm{D} / \mathrm{F}$ and $\mathrm{E} / \mathrm{F}$ are underestimated $\left(15.4^{\circ}\right)$ compared to the experimental result $\left(37.4^{\circ}\right)$. The overlapping geometry between the naphthalene rings of 6 , however, suggests that the $\pi-\pi$ interaction may contribute to the stability of the $C_{2}$ conformer. To estimate the stabilization energy, single point calculations for two naphthalene molecules located at the geometry same as that of the crystal structure were undertaken and its energy was compared with the twice of single naphthalene molecule having the same geometry. As a result, the calculations using the M05-2X functional showed a preference for the dimeric naphthalene with a stabilization energy of $2.96 \mathrm{kcal} / \mathrm{mol}$, whereas the B3LYP and M05 methods exhibited repulsive interactions with destabilization energies of $4.72 \mathrm{kcal} / \mathrm{mol}$ and 0.12 


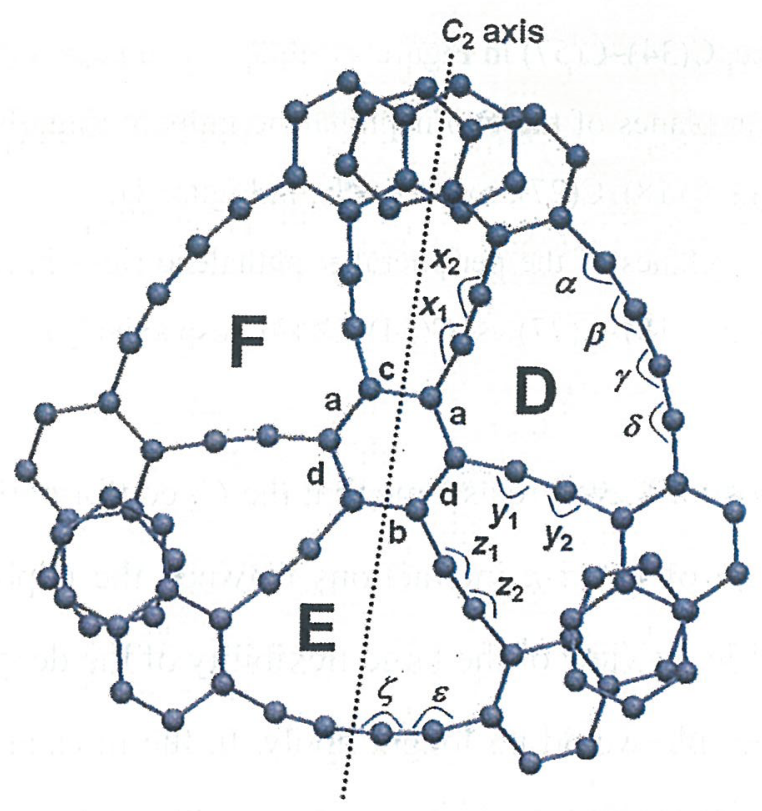

Table 4. Comparison of experimental and calculated geometries of the $C_{2}$ isomers of 6 .

\begin{tabular}{|c|c|c|c|c|}
\hline & X-ray & DFT/B3LYP & DFT/M05 & DFT/M05-2X \\
\hline \multirow[t]{2}{*}{ endo bond length $[\AA]$} & $\mathrm{a}=1.424$ & $a=1.417$ & $\mathrm{a}=1.413$ & $\mathrm{a}=1.406$ \\
\hline & $\mathrm{b}=1.415$ & $\mathrm{~b}=1.419$ & $\mathrm{~b}=1.415$ & $\mathrm{~b}=1.408$ \\
\hline \multirow[t]{2}{*}{ exo bond length $[\AA]$} & $\mathrm{c}=1.411$ & $c=1.446$ & $\mathrm{c}=1.438$ & $\mathrm{c}=1.430$ \\
\hline & $\mathrm{d}=1.427$ & $\mathrm{~d}=1.442$ & $\mathrm{~d}=1.435$ & $d=1.428$ \\
\hline core-blade dihedral angle $\left[{ }^{\circ}\right]^{a}$ & 30.73 & 36.52 & 31.19 & 28.94 \\
\hline \multirow[t]{6}{*}{ "spoke" triple bond angle $\left[{ }^{\circ}\right]$} & $x_{1}=171.4$ & $x_{1}=169.61$ & $x_{1}=170.85$ & $x_{1}=171.00$ \\
\hline & $x_{2}=172.7$ & $x_{2}=175.94$ & $x_{2}=174.68$ & $x_{2}=174.39$ \\
\hline & $y_{1}=169.4$ & $y_{1}=170.52$ & $y_{1}=171.23$ & $y_{1}=169.97$ \\
\hline & $y_{2}=175.0$ & $y_{2}=176.05$ & $y_{2}=173.86$ & $y_{2}=172.70$ \\
\hline & $z_{1}=166.6$ & $z_{1}=166.34$ & $z_{1}=166.84$ & $z_{1}=167.17$ \\
\hline & $z_{2}=176.6$ & $z_{2}=176.85$ & $z_{2}=175.84$ & $z_{2}=175.02$ \\
\hline \multirow[t]{6}{*}{ triple bond angle in diyne unit $\left[{ }^{\circ}\right]$} & $\alpha=168.7$ & $\alpha=166.94$ & $\alpha=168.26$ & $\alpha=168.72$ \\
\hline & $\beta=167.8$ & $\beta=169.14$ & $\beta=168.47$ & $\beta=168.88$ \\
\hline & $\gamma=168.7$ & $\gamma=168.45$ & $\gamma=168.48$ & $\gamma=169.47$ \\
\hline & $\delta=165.0$ & $\delta=167.86$ & $\delta=168.43$ & $\delta=167.76$ \\
\hline & $\varepsilon=170.6$ & $\varepsilon=169.13$ & $\varepsilon=169.67$ & $\varepsilon=169.33$ \\
\hline & $\zeta=170.6$ & $\zeta=171.37$ & $\zeta=171.13$ & $\zeta=171.50$ \\
\hline $\begin{array}{l}\text { dihedral angle between naphthalene } \\
\text { rings of }[14] \mathrm{DBA} \text { units }\left[^{\circ}\right]^{b}\end{array}$ & $1.78,39.83$ & $7.71,34.86$ & $6.85,26.03$ & $9.11,22.46$ \\
\hline $\begin{array}{c}\text { dihedral angle between peripheral } \\
\text { naphthalene rings in adjacent [14]DBA } \\
\text { units }\left[^{\circ}\right]^{c}\end{array}$ & $6.07,37.44$ & $29.91,37.78$ & $17.31,19.87$ & $13.18,15.41$ \\
\hline
\end{tabular}

${ }^{a}$ Dihedral angles between the mean plane of the central benzene ring and that of the dinaphthylbutadiyne unit 
of ring $\mathrm{E}$ (24 carbons in total, i.e. C(34)-C(57) in Figure 4).

${ }^{b}$ Dihedral angles between mean planes of the two naphthalene units in rings $\mathrm{E}$ and $\mathrm{D}$ (i.e. $\mathrm{C}(34)-\mathrm{C}(43) \mathrm{vs}$, $\mathrm{C}(48)-\mathrm{C}(57)$, and $\mathrm{C}(4)-\mathrm{C}(13)$ vs. $\mathrm{C}(18)-\mathrm{C}(27)$, respectively, in Figure 4).

${ }^{c}$ Dihedral angles between mean planes of the peripheral naphthalene rings in adjacent [14]DBA blades (i.e. $C(4)-C(13)$ vs. $C(78)-C(87)$, and $C(18)-C(27)$ vs. $C(34)-C(43)$, respectively)

$\mathrm{kcal} / \mathrm{mol}$, respectively. The author therefore assume that the $C_{2}$ conformation of 6 is more stable than the $D_{3}$ isomer mainly because of the $\pi-\pi$ interactions between the naphthalene rings. Though the results conflict the Pascal's rule, in view of the large flexibility of the dehydro[14]annulene ring, it is reasonable to assume that the rule would no longer apply. In the molecular propellers consisting of [14]DBA units, because the [14]annulene ring can be readily deformed from planarity without affecting the overlap of $\mathrm{p}$ orbitals in either central of peripheral aromatic rings. Either $C_{2}$ or $D_{3}$ form will become favored depending on the subtle change of the steric/electronic interactions.

\subsection{Conformations and Dynamic Behaviors of Tris[14]DBAs in Solution}

$\mathrm{X}$-ray crystallographic analysis showed that 4 and 6 adopt the $D_{3}$ - and $C_{2}$-symmetric structures, respectively, in crystalline state. The author next investigated the conformations and the relevant dynamic behaviors of 4-6 in solution.

The ${ }^{1} \mathrm{H}$ NMR spectra of 4 and 5 at $30^{\circ} \mathrm{C}$ are shown at the top of Figure 6 (a) and (b), respectively, which exhibited four and six signals for the aromatic protons. The assignments of the signals were carried out on the basis of the coupling patterns and the calculated chemical shifts in gas phase derived from the GIAO-HF/6-31G* method for the $D_{3}$-conformers optimized by the DFT calculations with B3LYP/6-31G* level of theory (Table 5). ${ }^{24}$ The author also performed the implicit solvent model of the ${ }^{1} \mathrm{H}$ NMR chemical shifts calculations. ${ }^{25}$ The chemical shifts of 6 were also calculated for the $C_{2}$-conformer optimized by the M05-2X/6-31G* level of theory. The calculated chemical shifts using the solvent model agree better the experimental results than those calculated for gas phase. For 4, though the observed and calculated chemical shifts of solvent model are in reasonable agreement $(<0.1 \mathrm{ppm})$, relatively large discrepancies $(0.2-0.3 \mathrm{ppm})$ are observed for the protons $\mathrm{H}_{\mathrm{a}}$ and $\mathrm{H}_{\mathrm{b}}\left(\mathrm{H}_{\mathrm{c}}\right.$ as well for 5) which suffer from anisotropic effects of the aromatic ring of the 
adjacent [14]DBA unit. In the case of [14]DBA itself, the calculated chemical shifts agree better with those of the experimental shifts, though all the calculated chemical shifts are uniformly downfield shifted $(0.15-0.29$ ppm by HF/6-31G* in gas phase, $0.05-0.14$ ppm by B3LYP/6-31G* in solvent model calculation, Figure 5).

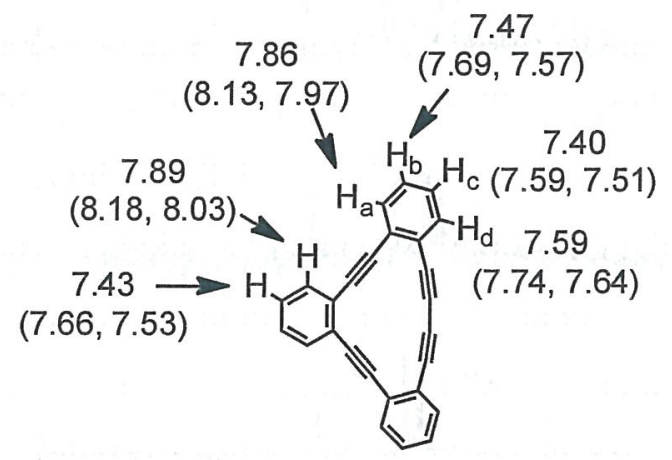

Figure 5. Experimental ${ }^{26}$ and calculated (in blacket, GIAO-HF/6-31G*//B3LYP/6-31G* in gas phase, and GIAO-B3LYP/6-31G*//B3LYP/6-31G* in implicit solvent model $\left(\mathrm{CHCl}_{3}\right)$, respectively) chemical shifts of [14]DBA.
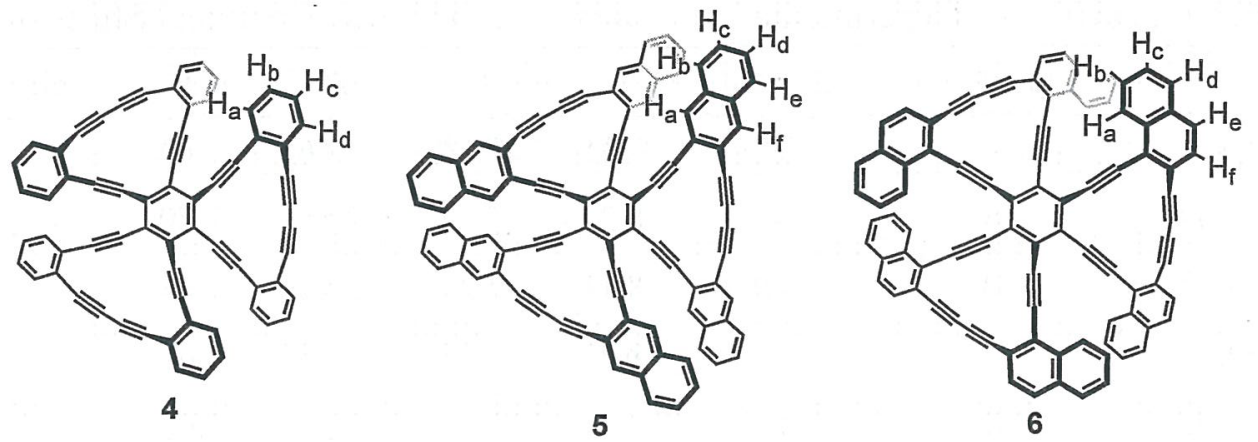

(a)
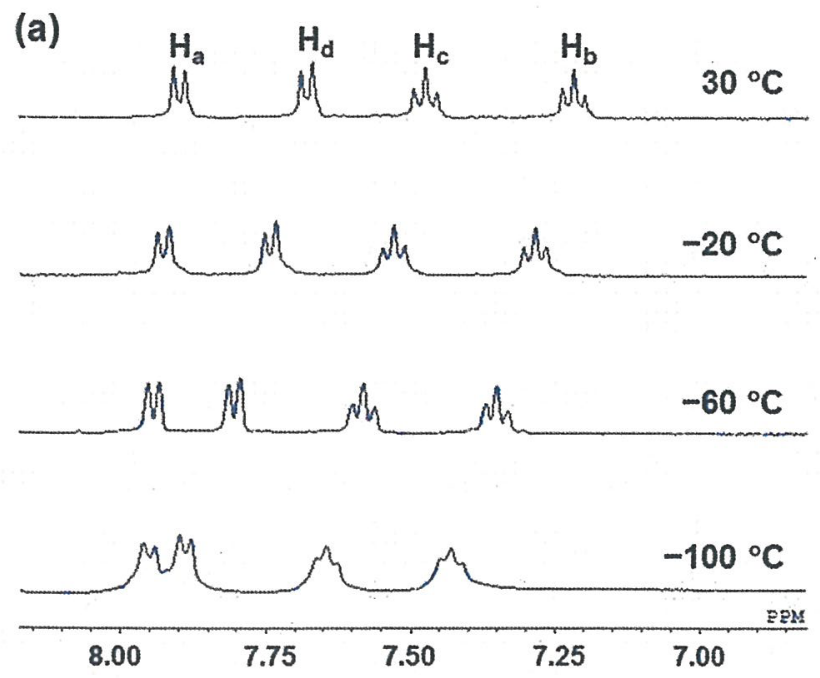

(b)
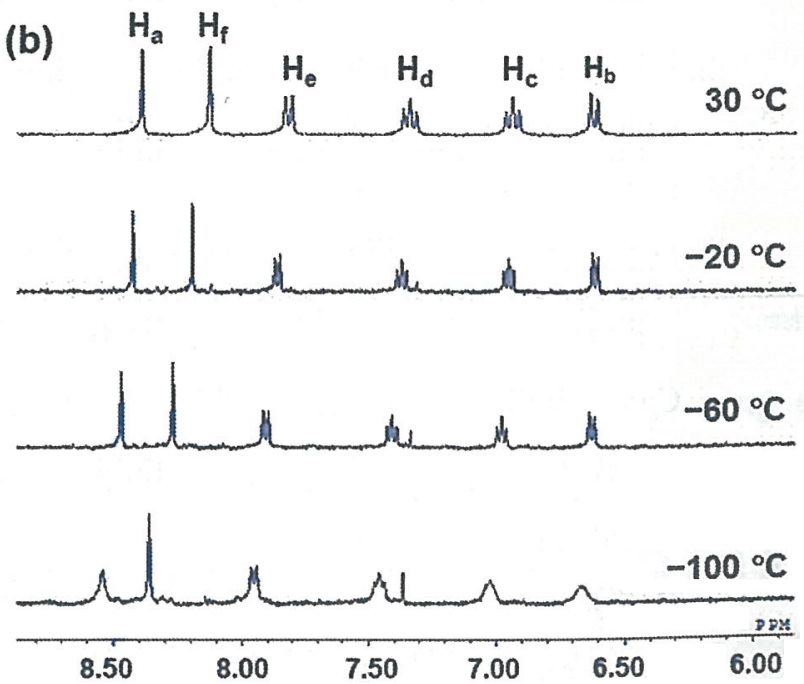

Figure 6. Partial VT- ${ }^{-1}$ HMR spectra of a) 4 and b) 5 in THF- $d_{8}$ with assignments $(300 \mathrm{MHz},-100$ 
to $\left.30^{\circ} \mathrm{C}\right)$.
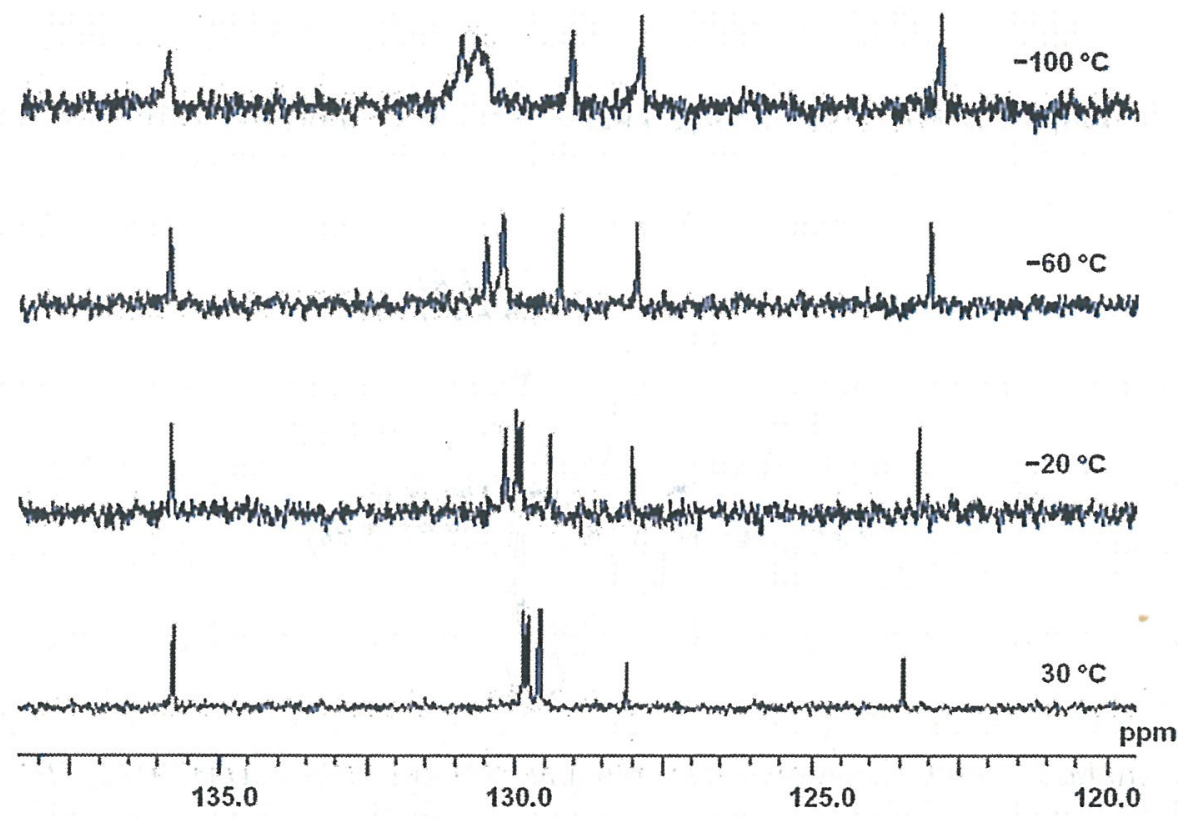

Figure 7. VT- ${ }^{13} \mathrm{C}$ NMR spectra of $4\left(100 \mathrm{MHz}, \mathrm{THF}-d_{8}, 30\right.$ to $\left.-100{ }^{\circ} \mathrm{C}\right)$

Table 5. Comparison of Experimental and Calculated ${ }^{1} \mathrm{H}$ NMR Chemical Shifts of 4-6. ${ }^{a}$

\begin{tabular}{|c|c|c|c|c|c|c|c|c|c|}
\hline & & Calculation & solvent & $\mathrm{H}_{\mathrm{a}}$ & $\mathrm{H}_{\mathrm{b}}$ & $\mathrm{H}_{\mathrm{c}}$ & $\mathrm{H}_{\mathrm{d}}$ & $\mathrm{H}_{\mathrm{e}}$ & $\mathrm{H}_{\mathrm{f}}$ \\
\hline \multirow{5}{*}{4} & Exp. $^{c}$ & - & THF & 7.88 & 7.20 & 7.46 & 7.66 & & \\
\hline & Calcd. $D_{3}$ & A & - & 8.34 & 7.34 & 7.55 & 7.70 & & \\
\hline & Calcd. $D_{3}$ & B & THF & 8.11 & 7.23 & 7.48 & 7.63 & & \\
\hline & Calcd. $C_{2}$ & $\mathrm{~A}$ & - & 8.28 & 7.29 & 7.56 & 7.63 & & \\
\hline & Calcd. $C_{2}$ & $\mathrm{~B}$ & THF & 8.11 & 7.20 & 7.50 & 7.63 & & \\
\hline \multirow{5}{*}{5} & Exp..$^{c}$ & - & THF & 8.39 & 6.63 & 6.94 & 7.34 & 7.82 & 8.13 \\
\hline & Calcd. $D_{3}$ & $\mathrm{~A}$ & - & 8.96 & 7.33 & 7.33 & 7.60 & 7.99 & 8.17 \\
\hline & Calcd. $D_{3}$ & B & THF & 8.47 & 6.97 & 7.19 & 7.41 & 7.68 & 7.87 \\
\hline & Calcd. $C_{2}$ & A & - & 8.89 & 7.14 & 7.24 & 7.58 & 7.98 & 8.16 \\
\hline & Calcd. $C_{2}$ & B & THF & 8.54 & 6.89 & 7.18 & 7.46 & 7.75 & 7.93 \\
\hline \multirow{7}{*}{6} & Exp. $^{d}$ & - & $p$-DCB & 8.74 & 6.84 & 6.79 & 7.12 & 7.35 & 7.29 \\
\hline & Calcd. $D_{3}$ & $\mathrm{~A}$ & - & 9.80 & 7.59 & 7.48 & 7.72 & 7.90 & 7.75 \\
\hline & Calcd. $D_{3}$ & B & $o-\mathrm{DCB}$ & 9.33 & 7.14 & 7.26 & 7.54 & 7.71 & 7.69 \\
\hline & Calcd. $C_{2}$ & A & - & 9.45 & 7.51 & 7.40 & 7.61 & 7.77 & 7.64 \\
\hline & Calcd. $C_{2}$ & $\mathrm{C}$ & - & 8.89 & 6.64 & 6.78 & 6.97 & 7.18 & 7.28 \\
\hline & Calcd. $C_{2}$ & B & $o$-DCB & 9.06 & 7.25 & 7.31 & 7.54 & 7.71 & 7.69 \\
\hline & Calcd. $C_{2}$ & $\mathrm{D}$ & $o$-DCB & 8.83 & 6.74 & 6.98 & 7.22 & 7.48 & 7.47 \\
\hline
\end{tabular}


${ }^{a}$ Averaged chemical shifts for the six relevant protons.

${ }^{b}$ For the calculation in gas phase, GIAO-HF/6-31G*//B3LYP/6-31G* method was used. In the implicit solvent model calculation ${ }^{27}$ by using GIAO-B3LYP/6-31G*//B3LYP/6-31G* method, the CPCM polarizable conductor calculation model was used to the PCM calculation. ${ }^{28}$ For 6 , the chemical shifts calculation for the $C_{2}$-conformer optimized by $\mathrm{M} 05-2 \mathrm{X} / 6-31 \mathrm{G}^{*}$ basis-set was also performed. A: GIAO-HF/6-31G*//B3LYP/6-31G*, B: GIAO-B3LYP/6-31G*//B3LYP/6-31G*, $\quad$ C: GLAO-HF/6-31G*//M05-2X/6-31G*, D: GIAO-B3LYP/6-31G*//M05-2X/6-31G*.

${ }^{c}$ Experimental chemical shifts for 4 and 5 in THF- $d_{8}$ at $30^{\circ} \mathrm{C}$.

${ }^{d}$ Experimental chemical shifts for 6 in $p$-dichlorobenzene- $d_{4}$ at $150^{\circ} \mathrm{C}$. All experimental chemical shifts are upfield shifted compared with those of the calculated values because measurements were conducted in an aromatic solvent, in which the proton chemical shifts of aromatic compounds generally exhibits upfield shifts compared with nonaromatic solvents. ${ }^{29}$

The ${ }^{13} \mathrm{C}$ NMR spectrum of 4 at $30^{\circ} \mathrm{C}$, shown in the top of Figure 7, exhibits seven signals and that of 5 eleven signals (see Experimental Section) for the aromatic carbons, which is consistent with the $D_{3}$-symmetric conformation. However, the observation of highly-symmetric ${ }^{1} \mathrm{H}$ and ${ }^{13} \mathrm{C}$ NMR signals indicates two possibilities regarding the conformational behavior in solution: (i) both $\mathbf{4}$ and 5 adopt the $D_{3}$-symmetric structure and the ring inversion to the $C_{2}$ form is too slow on the NMR time-scale, or (ii) the racemization takes place rapidly on the NMR time-scale to exhibit time-averaged signals of the $C_{2^{-}}$and $D_{3}$-symmetric conformations. In the former case, since the racemization of the $D_{3}$-conformers via the $C_{2}$-isomer should be slow, $P$ and $M$ enantiomers of $D_{3}$-symmetric 4 and 5 may be separated by chiral chromatography. ${ }^{30}$ To this end, optical resolution using a variety of chiral columns was attempted. ${ }^{31}$ Despite intensive studies, however, enantiomeric peak separation of neither $\mathbf{4}$ nor 5 was observed, suggesting that the second possibility is more likely.

To gain insights for the conformational equilibrium, the author performed VT-NMR experiments. If the rate of ring inversion becomes slow enough on the NMR time-scale, line broadening or appearance of additional peaks due to lower-symmetric $C_{2}$ conformation is expected. In the event, however, separation of the ${ }^{1} \mathrm{H}$ NMR signals was not observed even at $-100{ }^{\circ} \mathrm{C}$ for both 4 and 5 as shown in Figure 6, though apparent down field shifts of some of the signals were observed. ${ }^{32}$ By increasing the temperature the ${ }^{1} \mathrm{H}$ NMR spectrum of 4 did not change (Figure 8). Since ${ }^{13} \mathrm{C}$ NMR measurements of $\mathbf{5}$ at low temperature were hampered due to low solubility, only low temperature 
${ }^{13} \mathrm{C}$ NMR measurements of 4 were performed. Whereas the spectrum at $30{ }^{\circ} \mathrm{C}$ showed distinctly sharp signals, the signals of 4 at $-100{ }^{\circ} \mathrm{C}$ in THF- $d_{8}$ exhibited considerable broadening, indicating the slowdown of the exchange rate at this temperature. However, the coalescence was not observed (Figure 6).

Compound 4 crystallizes in the $D_{3}$ form in agreement with the theoretical calculations which predict that the $D_{3}$ conformer is more stable than the $C_{2}$ form. However, the VT-NMR did not provide any information regarding the solution conformation and its dynamic behavior. Consequently, on the basis of the theoretical calculations and the results of the chiral chromatography, the author assume that 4 adopts the $D_{3}$ form which racemizes rapidly through the $C_{2}$ isomers. Since compound 5 behaves like 4 in solution with regard to the VT-NMR and chiral chromatography, the author assume that it also adopts the $D_{3}$ form with low kinetic barrier for the $C_{2}-D_{3}$ or both $C_{2}-D_{3}$ and $C_{2}-C_{2}$ interconversions.

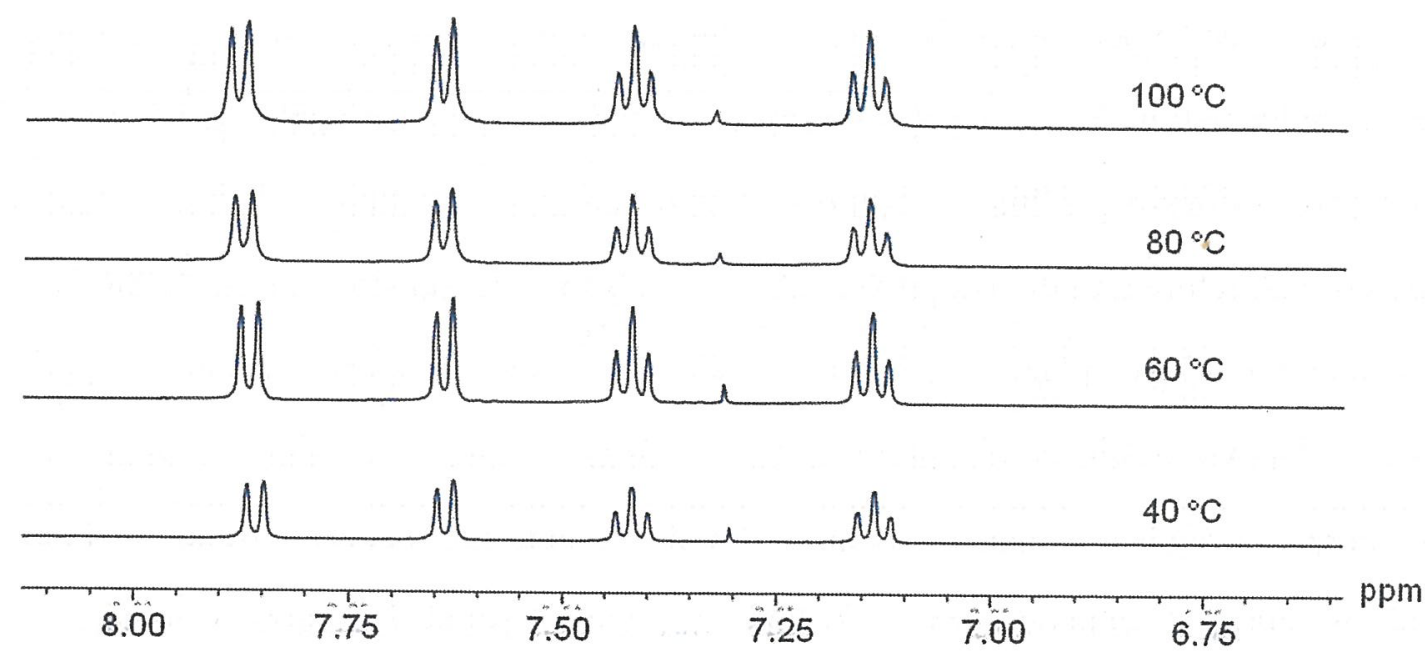

Figure 8. VT- ${ }^{1} \mathrm{H}$ NMR spectra of $4\left(400 \mathrm{MHz}, 1,1,2,2\right.$-tetrachloroethane- $d_{2}, 40$ to $\left.100{ }^{\circ} \mathrm{C}\right)$

In contrast to the VT-NMR spectra of $\mathbf{4}$ and $\mathbf{5}$, which did not give definitive information regarding their solution conformations, the ${ }^{1} \mathrm{H}$ NMR measurements of 6 provided insight on the conformational behavior. First, ${ }^{1} \mathrm{H}$ NMR spectrum at $150{ }^{\circ} \mathrm{C}$ in $p$-dichlorobenzene- $d_{4}$ exhibited a sharp double signal for the naphthalene proton $\mathrm{H}_{\mathrm{a}}$ at $\delta 8.75 \mathrm{ppm}$ which was isolated from other aromatic proton signals (Figure 9). As the temperature was lowered to $60^{\circ} \mathrm{C}$, the signal became significantly broadened. In toluene- $d_{8}$ too, a broad signal was observed at $60{ }^{\circ} \mathrm{C}$ indicating slow down of the conformational 
exchanges (Figure 10). Below $20^{\circ} \mathrm{C}$, the signal was resolved into three doublets, which showed the presence of the $C_{2}$-symmetric conformation in solution and, at the same time, the absence of the $D_{3}$ conformer as seen in crystalline state. It should be pointed out that the decoalescence into the signals due to the $C_{2}$-symmetric conformation is observed only when all the interconversion rates become slow enough on the NMR time-scale (See Scheme 5), because a time-averaged highly-symmetric signal corresponding to a mixture of interchanging conformations should be observed if only a part of interconversion takes place rapidly. This behavior also suggests that the $C_{2}-C_{2}$ conversion rate becomes slow enough below $20^{\circ} \mathrm{C}$ on the NMR time scale and, more importantly, the absence of the $D_{3}$ conformer of 6 as indicated from the equal intensities of the three doublets. These results are consistent with those based on the theoretical and crystallographic studies (vide supra) in a sense that the $C_{2}$ conformer is more stable. The barrier for the $C_{2}-C_{2}$ interconversion was estimated to be 16.2 $\mathrm{kcal} / \mathrm{mol}$ at the coalescence temperature $\left(50^{\circ} \mathrm{C}\right)$ of the two signals observed at lower fields $(\Delta v=$ $33.2 \mathrm{~Hz}$ ). Upon further cooling down to $-80^{\circ} \mathrm{C}$, the two signals at lower fields started to recombine and the doublet at a higher field became broadened again. This recombination of the signals can be attributed to an accidental isochrony of two different types of protons in the process of downficld shifts on decreasing the temperature.

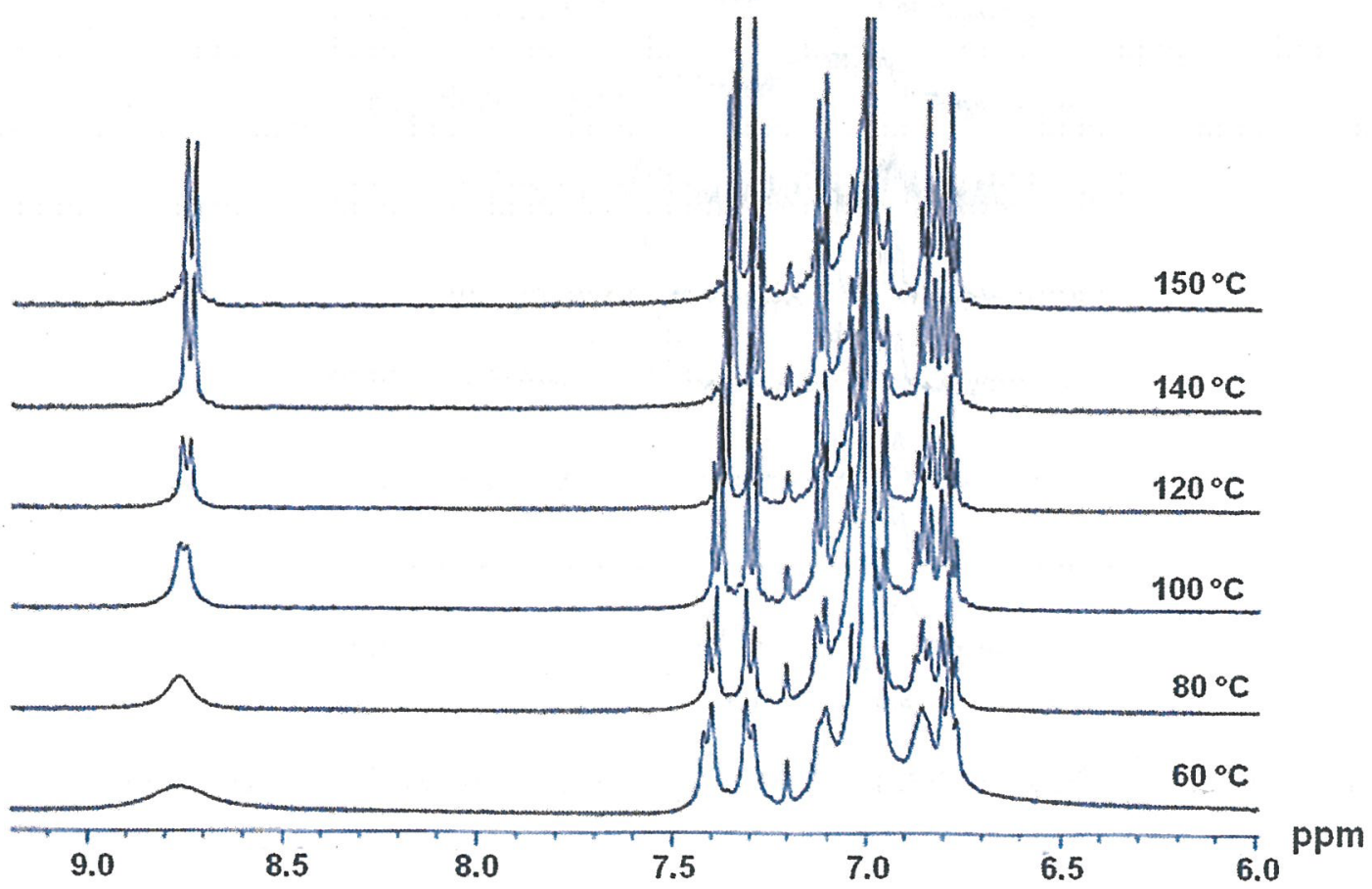

Figure 9. VT- ${ }^{1} \mathrm{H}$ NMR spectra of $6\left(400 \mathrm{MHz}, p\right.$-dichlorobenzene- $d_{4}, 60$ to $\left.150{ }^{\circ} \mathrm{C}\right)$ 
Thus compound 6 turned out to exhibit a conformational behavior which is different from that of hexabenzotriphenylene (1) but similar to that of hexamethyltriphenylene (2). In the former case, the $D_{3}$ isomer was estimated by theoretical study to be more stable by ca. $8 \mathrm{kcal} / \mathrm{mol}{ }^{3}$ The barrier for the interconversion between the less stable $C_{2}$ isomers was determined by VT-NMR to be $11.7 \mathrm{kcal} / \mathrm{mol}$ at $247 \mathrm{~K}$, whereas that for the $C_{2}-D_{3}$ isomerization was determined by kinetic study of the $C_{2}$ to $D_{3}$ conversion to be $26.2 \mathrm{kcal} / \mathrm{mol}{ }^{[4 \mathrm{~b}]}$ In the case of triphenylene derivative 2 , on the contrary, the barrier for the more stable $C_{2}-C_{2}$ interconversion was determined by VT-NMR to be $10.2 \mathrm{kcal} / \mathrm{mol}$ at $220 \mathrm{~K}$, whereas that for the $C_{2}$ to $D_{3}$ isomerization was estimated by computational study to be about $25 \mathrm{kcal} / \mathrm{mol}^{2 \mathrm{c}}$ The barrier for the more stable $C_{2}-C_{2}$ interconversion of 6 at $50{ }^{\circ} \mathrm{C}$ is estimated to be $16.2 \mathrm{kcal} / \mathrm{mol}$. However, the barrier for the $C_{2}-D_{3}$ isomerization is not determined experimentally. The relatively low barrier despite of the large overlapping of the dehydroannulene blades is ascribed to the flexibility of the acetylene linkages which can be deformed substantially in the transition state of the ring flip.

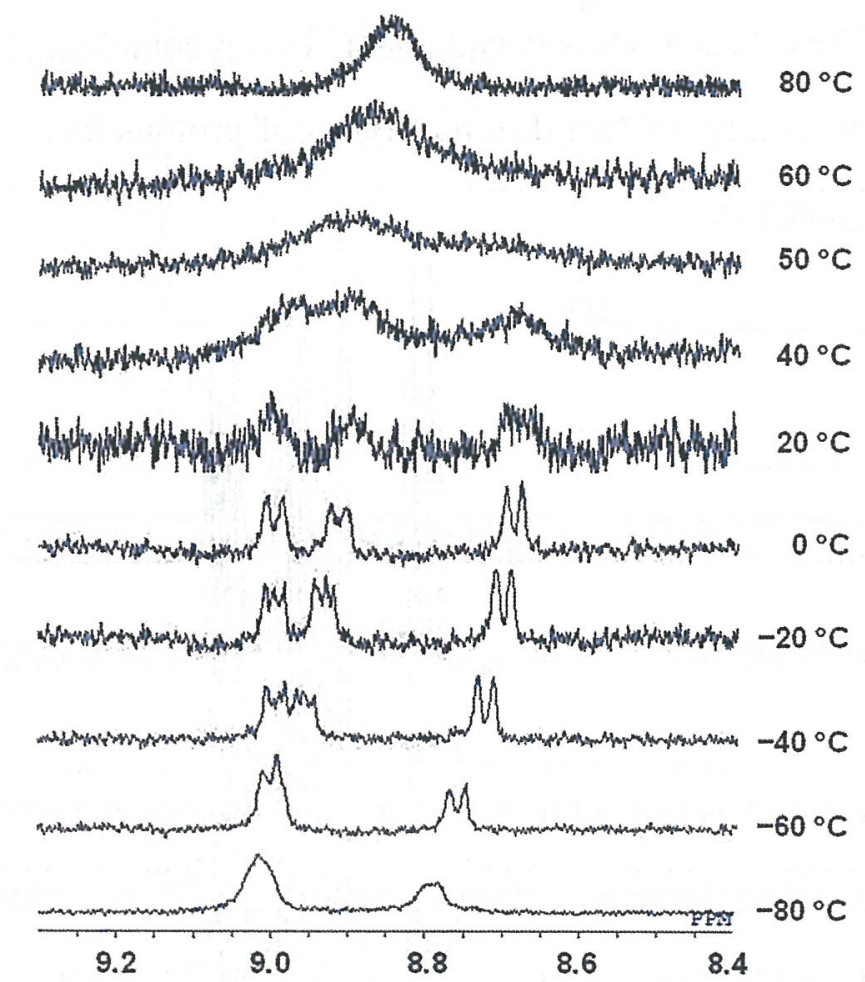

Figure 10. Partial VT- ${ }^{1} \mathrm{H}$ NMR spectra of 6 for $\mathrm{H}_{\mathrm{a}}$ proton in toluene- $d_{8}\left(400 \mathrm{MHz},-80\right.$ to $\left.80{ }^{\circ} \mathrm{C}\right)$ 


\subsection{Conclusion}

In solid state molecular propeller 4 consisting of [14]DBA blades adopts an approximate $D_{3}$-symmetric structure in which the individual [14]DBA ring twists substantially to avoid steric repulsion between the peripheral benzene rings. By contrast, naphthalene homologue 6 crystallizes in a $C_{2}$-symmetric structure, in which the acetylene units are strongly distorted to make two of the blades in an "arched" shape. The crystal structures are compared with those derived from the DFT calculations using different functionals. On the basis of the crystal structure and the relative energies estimated from the calculations using the M05-2X functional for the $C_{2}$ and $D_{3}$ conformers, together with the stabilization energy estimated for the naphthalene dimer model, the author conclude that the $C_{2}$ conformer of 6 is stabilized by the $\pi-\pi$ interactions between the naphthalene units of a pair of adjacent blades. As to the dynamics in solution, VT-NMR experiments of 4 and 5 suggest that the conformational interconversions take place rapidly upon the NMR time-scale, though no quantitative information was obtained. On the other hand, from the VT-NMR measurements of 6, the barrier for the $C_{2}-C_{2}$ exchange was estimated to be $16.2 \mathrm{kcal} / \mathrm{mol}$. Though these results are at first counterintuitive in view of the overcrowded molecular structures, it is in accord with the remarkable flexibility of acetylene linkages in the rotational isomerism of sterically crowded acetylene

derivatives. ${ }^{13}$ The present results are useful for molecular design of shape-persistent as well as shape-shifting ${ }^{33}$ molecules based on [14]DBA and related dehydrobenzoannulene units, particularly when the molecular flexibility and dynamic properties concern. 


\subsection{Experimental Section}

General Experimental Methods. ${ }^{1} \mathrm{H}$ and ${ }^{13} \mathrm{C}$ NMR spectra were recorded in $\mathrm{CDCl}_{3}$ at $30{ }^{\circ} \mathrm{C}$ unless otherwise stated. When $\mathrm{CDCl}_{3}$ or THF- $d_{8}$ or DMSO- $d_{6}$ was used as a solvent, the chemical shifts were referenced to the residual solvent protons in the ${ }^{1} \mathrm{H}$ NMR $(7.26,3.58,2.49 \mathrm{ppm}$, respectively) and to solvent carbons in the ${ }^{13} \mathrm{C} \operatorname{NMR}(77.0,67.4,39.7 \mathrm{ppm}$, respectively). When $p$-dichlorobenzene- $d_{4}$ or toluene- $d_{8}$ was used as a solvent, the chemical shifts were referenced to TMS as an internal standard in ${ }^{1} \mathrm{H}$ NMR spectra. Mass spectral analyses were performed with EI, $\mathrm{FAB}$, or laser desorption ionization (LDI) mode. IR spectra were recorded as a $\mathrm{KBr}$ disk or a neat film. Melting points were measured with a hot-stage apparatus equipped with a thermometer. Column chromatography and TLC were performed with silica gel (70-230 mesh) and precoated silica gel plates, respectively. Preparative recycling GPC separation was undertaken using two $600 \mathrm{~mm} \times$ $20 \mathrm{~mm} \mathrm{GPC}$ columns with $\mathrm{CHCl}_{3}$ as the eluent.

All reagents were obtained from commercial suppliers and used as received. Solvents were dried (drying agent in parentheses) and distilled prior to use: THF $\left(\mathrm{CaH}_{2}\right.$ followed by sodium benzophenone ketyl), $\mathrm{Et}_{3} \mathrm{~N}(\mathrm{KOH}), i \mathrm{Pr}_{2} \mathrm{NH}(\mathrm{KOH})$, pyridine $(\mathrm{KOH})$.

2-(2,2-Dibromoethenyl)-1-[(Trimethylsilyl)ethynyl]benzene (9). To a solution of $\mathrm{PPh}_{3}(52.0 \mathrm{~g}, 198$ $\mathrm{mmol})$ in $\mathrm{CH}_{2} \mathrm{Cl}_{2}(200 \mathrm{~mL})$ was added a solution of $\mathrm{CBr}_{4}(23.0 \mathrm{~g}, 99.3 \mathrm{mmol})$ in $\mathrm{CH}_{2} \mathrm{Cl}_{2}(100 \mathrm{~mL})$ at $0{ }^{\circ} \mathrm{C}$. After stirring for $30 \mathrm{~min}$ at $0^{\circ} \mathrm{C}$, a solution of $8^{34}(10.0 \mathrm{~g}, 49.4 \mathrm{mmol})$ in $\mathrm{CH}_{2} \mathrm{Cl}_{2}(100 \mathrm{~mL})$ was added at the same temperature. After stirring at room temperature for $30 \mathrm{~min}$, a saturated aqueous solution of $\mathrm{NaHCO}_{3}$ was added, and the reaction mixture was extracted with $\mathrm{CHCl}_{3}$. The extract was washed with brine and dried over anhydrous $\mathrm{MgSO}_{4}$. After removal of the solvent, the residue was purified by chromatography (silica gel, hexanes/AcOEt $=1 / 9)$ to afford $9(17.5 \mathrm{~g}, 99 \%)$ as a yellow oil. 9: ${ }^{1} \mathrm{H}$ NMR (300 MHz): $\delta=7.77(\mathrm{~s}, 1 \mathrm{H}), 7.74(\mathrm{dd}, J=7.5,1.5 \mathrm{~Hz}, 1 \mathrm{H}), 7.46(\mathrm{dd}, J=7.5,1.5 \mathrm{~Hz}$, 1H), 7.32 (ddd, $J=7.5,7.5,1.6 \mathrm{~Hz}, 1 \mathrm{H}), 7.26$ (ddd, $J=7.5,7.5,1.6 \mathrm{~Hz}, 1 \mathrm{H}), 0.28(\mathrm{~s}, 9 \mathrm{H}) ;{ }^{13} \mathrm{C} \mathrm{NMR}$ (100 MHz): $\delta=133.7,135.7,132.0,128.1,128.0,127.7,122.6,102.7,100.7,91.1,0.05$; IR (neat): vbar $=3062,3020,2959,2898,2157,1928,1602,1094,1041,950,855,758,731,700 \mathrm{~cm}^{-1}$; MS (EI): $m / z 360,358,356$ (rel. intensity ca. 1:2:1, $\left(M^{+}\right)$); elemental analysis calcd (\%) for $\mathrm{C}_{13} \mathrm{H}_{14} \mathrm{Br}_{2} \mathrm{Si}$ : C 43.60, H 3.94; found: C 43.50, H 3.86. 
2-Ethynyl-1-[(trimethysilyl)ethynyl]benzene (10). To a solution of $i \operatorname{Pr}_{2} \mathrm{NH}(7.0 \mathrm{~mL})$ in $\mathrm{THF}(50$ $\mathrm{mL})$ was added a solution of $n \mathrm{BuLi}$ in hexane $(1.56 \mathrm{M}, 29.0 \mathrm{~mL})$ at $0^{\circ} \mathrm{C}$ under an argon atmosphere. This solution was added dropwise via a syringe to a solution of 9 (4.02 $\mathrm{g}, 11.2 \mathrm{mmol})$ in THF (20 $\mathrm{mL}$ ) cooled to $-78^{\circ} \mathrm{C}$. After stirring for $10 \mathrm{~min}$ at $-78{ }^{\circ} \mathrm{C}$, a saturated aqueous solution of $\mathrm{NaHCO}_{3}$ was added. The mixture was extracted with ether, and the extract was washed with brine and dried over anhydrous $\mathrm{MgSO}_{4}$. After removal of the solvent, the residue was purified by chromatography (silica gel, hexanes/CHCl $\left.\mathrm{CHC}_{3}=19 / 1\right)$ to afford $10(2.09 \mathrm{~g}, 94 \%)$ as a pale yellow oil. 10: ${ }^{1} \mathrm{H}$ NMR (300 $\mathrm{MHz}) \delta 7.50-7.45(\mathrm{~m}, 2 \mathrm{H}), 7.28-7.25(\mathrm{~m}, 2 \mathrm{H}), 3.29(\mathrm{~s}, 1 \mathrm{H}), 0.27(\mathrm{~s}, 9 \mathrm{H})$. The spectral data agreed with those reported in the literature. ${ }^{35}$

Hexakis(\{2-[(trimethylsilyl)ethynyl]phynyl\}ethynyl)benzene (12). $\mathrm{Pd}\left(\mathrm{PPh}_{3}\right)_{4} \quad(358 \mathrm{mg}, 0.309$ $\mathrm{mmol})$ and $\mathrm{CuI}(54.0 \mathrm{mg}, 0.280 \mathrm{mmol})$ were added to a solution hexabromobenzene (11) (138 $\mathrm{mg}$, $0.268 \mathrm{mmol}$ ) and 10 (599 $\mathrm{mg}, 3.02 \mathrm{mmol}$ ) in degassed (by argon bubbling for $10 \mathrm{~min}) \mathrm{THF}(5 \mathrm{~mL})$ and $\mathrm{Et}_{3} \mathrm{~N}(5 \mathrm{~mL})$. The reaction mixture was stirred at $80^{\circ} \mathrm{C}$ under an argon atmosphere. The reaction was monitored by TLC and LDI-TOF mass spectrometry. After $25 \mathrm{~h}$, a saturated aqueous solution of $\mathrm{NH}_{4} \mathrm{Cl}$ was added, and the reaction mixture was extracted with $\mathrm{CHCl}_{3}$. The extract was washed with brine and dried over anhydrous $\mathrm{MgSO}_{4}$. After removal of the solvent, the residue was purified by chromatography (silica gel, hexanes/AcOEt $=97 / 3$ ). The product was washed with hexanes to afford $12(117 \mathrm{mg}, 37 \%)$ as a yellow solid. 12: $\mathrm{mp} 174.2-174.4{ }^{\circ} \mathrm{C} ;{ }^{1} \mathrm{H}$ NMR $(300 \mathrm{MHz}) \delta 7.60(\mathrm{dd}, J=7.5$, $1.5 \mathrm{~Hz}, 6 \mathrm{H}), 7.42(\mathrm{dd}, J=7.5,1.5 \mathrm{~Hz}, 6 \mathrm{H}), 7.20(\mathrm{dd}, J=7.5,1.5 \mathrm{~Hz}, 6 \mathrm{H}), 7.13$ (ddd, $J=9.0,9.0,1.5$ $\mathrm{Hz}, 6 \mathrm{H}), 0.04(\mathrm{~s}, 54 \mathrm{H}) ;{ }^{13} \mathrm{C}$ NMR $(75 \mathrm{MHz}) \delta 133.05,132.21,127.96,127.94,127.67,125.97$, 125.56, 103.23, 99.15, 98.27, 90.82, -0.18; IR (KBr) 3060, 2957, 2898, 2205, 2159, 1483, 1444, $1408,1250,864,843,757,699,644 \mathrm{~cm}^{-1}$; MS (LDI) $\mathrm{m} / \mathrm{z} 1256.2$ (M); Anal. Calcd for $\mathrm{C}_{84} \mathrm{H}_{78} \mathrm{Si}_{6}$ : C, 80.32; H, 6.26. Found: C, 80.30; H, 6.33.

Compound 4. To a suspension of $\mathrm{K}_{2} \mathrm{CO}_{3}(132 \mathrm{mg}, 0.955 \mathrm{mmol})$ in $\mathrm{MeOH}(20 \mathrm{~mL})$ was added a solution of $12(50.1 \mathrm{mg}, 39.9 \mu \mathrm{mol})$ in THF $(10 \mathrm{~mL})$ under an argon atmosphere. After stirring for 10 $\mathrm{h}$, the mixture was diluted with water and extracted with ether. The extract was dried over anhydrous $\mathrm{MgSO}_{4}$. Most of the solvent was removed under reduced pressure, and the residue was dissolved in 
$50 \mathrm{~mL}$ of ether. This solution containing 13 was added dropwise to a solution of $\mathrm{Cu}(\mathrm{OAc})_{2} \cdot \mathrm{H}_{2} \mathrm{O}(398$ $\mathrm{mg}, 1.99 \mathrm{mmol})$ in pyridine $(100 \mathrm{~mL})$ over a period of $9 \mathrm{~h}$, and the mixture was stirred for another 3 h. The reaction was monitored by TLC and LDI mass spectrometry. The reaction mixture was passed through a short silica gel column $\left(\mathrm{CHCl}_{3}\right)$. After removal of the solvents, the products were separated by recycling GPC and recrystallized from $\mathrm{CHCl}_{3} /$ acetone to afford 4 (6.3 $\mathrm{mg}, 19 \%$ isolated yield ${ }^{[16]}$ ) as a pale yellow solid, which decomposed gradually at room temperature. ${ }^{36} 4:{ }^{1} \mathrm{H}$ NMR $(300 \mathrm{MHz}$, $\left.\mathrm{THF}-d_{8}\right) \delta 7.84(\mathrm{dd}, J=7.5,0.3 \mathrm{~Hz}, 6 \mathrm{H}), 7.61(\mathrm{dd}, J=7.5,1.5 \mathrm{~Hz}, 6 \mathrm{H}), 7.38(\mathrm{ddd}, J=7.5,7.5,1.5$ $\mathrm{Hz}, 6 \mathrm{H}), 7.10$ (ddd, $J=7.5,7.5,0.3 \mathrm{~Hz}, 6 \mathrm{H}) ;{ }^{13} \mathrm{C}$ NMR $\left(75 \mathrm{MHz}, \mathrm{THF}-d_{8}\right) \delta 134.9,128.8,128.6$, 128.3, 127.3, 122.7, 101.1, 93.7, 86.7, 80.8; IR (KBr) 3058, 2924, 2851, 2214, 2168, 1507, 1470, $1448,1385,754,667,580 \mathrm{~cm}^{-1} ; \mathrm{MS}(\mathrm{FAB}) \mathrm{m} / \mathrm{z} 816\left(M^{\dagger}\right)$.

2,3-Diiodonaphthalene (15). To a solution of $\mathrm{NaNO}_{2}(105 \mathrm{mg}, 1.52 \mathrm{mmol})$ in concentrated sulfuric acid $(5 \mathrm{~mL})$ was added a solution of 2,3-diaminonaphthalene (14) (106 $\mathrm{mg}, 0.670 \mathrm{mmol})$ in acetic acid $(7 \mathrm{~mL})$ at $0^{\circ} \mathrm{C}$. After stirring for $10 \mathrm{~min}$ at $0{ }^{\circ} \mathrm{C}$, the purple suspension was added to a solution of potassium iodide $(1.14 \mathrm{~g}, 6.87 \mathrm{mmol})$ in water $(10 \mathrm{~mL})$ warmed to $60^{\circ} \mathrm{C}$. After stirring for $1 \mathrm{~h}$ at $60{ }^{\circ} \mathrm{C}$, a saturated aqueous solution of $\mathrm{NaHCO}_{3}$ was added, and the reaction mixture was extracted with ether. The extract was washed with a saturated aqueous solution of sodium thiosulfate and brine, and dried over anhydrous $\mathrm{MgSO}_{4}$. After removal of the solvent, the residue was purified by chromatography (silica gel, hexanes $\left./ \mathrm{CHCl}_{3}=19 / 1\right)$ to afford $15(120 \mathrm{mg}, 47 \%)$ as a white solid. $\mathbf{1 5}$ : ${ }^{1} \mathrm{H}$ NMR $(300 \mathrm{MHz}) \delta 8.42(\mathrm{~s}, 2 \mathrm{H}), 7.70-7.67(\mathrm{~m}, 2 \mathrm{H}), 7.51-7.48(\mathrm{~m}, 2 \mathrm{H})$. The spectral data agreed with those reported in the literature. ${ }^{37}$

2-Iodo-3-[(trimethylsilyl)ethynyl]naphthalene (16). $\mathrm{Pd}\left(\mathrm{PPh}_{3}\right)_{4}(151 \mathrm{mg}, 0.131 \mathrm{mmol})$ and CuI (70.1 $\mathrm{mg}, 0.368 \mathrm{mmol})$ were added to a solution of $15(4.20 \mathrm{~g}, 11.1 \mathrm{mmol})$ and (trimethylsilyl)acetylene $(1.60 \mathrm{~mL}, 11.3 \mathrm{mmol})$ in THF $(25 \mathrm{~mL})$ and $\mathrm{Et}_{3} \mathrm{~N}(15 \mathrm{~mL})$ under an argon atmosphere. After stirring at $60^{\circ} \mathrm{C}$ for $2 \mathrm{~h}$, the reaction mixture was passed through a short silica gel column $\left(\mathrm{CHCl}_{3}\right)$. After removal of the solvent, the residue was purified by chromatography (silica gel, hexanes/AcOEt $=19 / 1)$ to afford $16(2.63 \mathrm{~g}, 67 \%)$ as a pale yellow oil. 16: ${ }^{1} \mathrm{H} \mathrm{NMR}(300 \mathrm{MHz})$ $\delta 8.36(\mathrm{~s}, 1 \mathrm{H}), 8.00(\mathrm{~s}, 1 \mathrm{H}), 7.75-7.71(\mathrm{~m}, 1 \mathrm{H}), 7.69-7.66(\mathrm{~m}, 1 \mathrm{H}), 7.50-7.47(\mathrm{~m}, 2 \mathrm{H}), 0.35(\mathrm{~s}, 9 \mathrm{H})$; 
${ }^{13} \mathrm{C} \mathrm{NMR}(75 \mathrm{MHz}) \delta 140.0,134.0,132.4,132.2,127.6,127.4,126.6,126.1,106.7,98.6,97.1,-0.1$; IR (neat) 3054, 2958, 2897, 2160, 1577, 1487, 1421, 1314, 1249, 1176, 1130, 907, 841, 744, 699, $636 \mathrm{~cm}^{-1}$; MS (FAB) $m / z 350.2\left(M^{\dagger}\right)$; Anal. Calcd for $\mathrm{C}_{15} \mathrm{H}_{15} \mathrm{ISi}$ : C, 51.43; $\mathrm{H}, 4.32$. Found: $\mathrm{C}, 51.81$; $\mathrm{H}, 4.41$.

Hexakis(2-\{3-[(trimethysilyl)ethynyl]naphthyl\}ethynyl)benzene (19). To a solution of hexakis[(trimethylsilyl)ethynyl]benzene $(\mathbf{1 7})^{38}(140 \mathrm{mg}, 0.214 \mathrm{mmol})$ in THF $(10 \mathrm{~mL})$ was added a solution of tetra- $n$-butylammonium fluoride in THF $(1.0 \mathrm{M}, 220 \mu \mathrm{L}, 0.220 \mathrm{mmol})$ under an argon atmosphere. The reaction mixture was stirred at ambient temperature for $15 \mathrm{~min}$. The mixture was diluted with water and extracted with ether. The extract was dried over anhydrous $\mathrm{MgSO}_{4}$. Most of the solvent was removed under reduced pressure and the resultant wet solid, before it became completely dry, was dissolved in a mixture of THF $(15 \mathrm{~mL})$ and $\mathrm{Et}_{3} \mathrm{~N}(10 \mathrm{~mL})$ which had been degassed by argon bubbling for $15 \mathrm{~min} .16$ (450 mg, $1.28 \mathrm{mmol}), \operatorname{Pd}\left(\mathrm{PPh}_{3}\right)_{4}(51 \mathrm{mg}, 55 \mu \mathrm{mol})$, and $\mathrm{CuI}(15 \mathrm{mg}, 79 \mu \mathrm{mol})$ were added under an argon atmosphere, and the progress of the reaction was monitored by TLC and LDI-TOF mass spectrometry. After the reaction mixture was heated at $45^{\circ} \mathrm{C}$ for $17 \mathrm{~h}$, additional $\mathrm{Pd}\left(\mathrm{PPh}_{3}\right)_{4}(51 \mathrm{mg}, 55 \mu \mathrm{mol})$ and $\mathrm{CuI}(15 \mathrm{mg}, 79 \mu \mathrm{mol})$ were added to promote the reaction, and then the reaction mixture was heated at $80^{\circ} \mathrm{C}$ for another $48 \mathrm{~h}$. The reaction mixture was cooled to ambient temperature and passed through a short silica gel column $\left(\mathrm{CHCl}_{3}\right)$. The product was purified by chromatography (silica gel, hexanes $/ \mathrm{CHCl}_{3}=7 / 3$ ), and then recrystallized from $\mathrm{CH}_{2} \mathrm{Cl}_{2} / \mathrm{CH}_{3} \mathrm{CN}$ to afford $19(36.2 \mathrm{mg}, 11 \%)$ as a yellow solid. 19: m.p. It started to decompose at $240{ }^{\circ} \mathrm{C}$ and turned dark completely at $250{ }^{\circ} \mathrm{C}$ without showing melting point. ${ }^{1} \mathrm{H}$ NMR $(300 \mathrm{MHz}) \delta 8.19(\mathrm{~s}, 6 \mathrm{H}), 7.93(\mathrm{~s}, 6 \mathrm{H}), 7.67(\mathrm{~d}, J=8.7 \mathrm{~Hz}, 6 \mathrm{H}), 7.40(\mathrm{dd}, J=8.7,8.7 \mathrm{~Hz}, 6 \mathrm{H})$, 7.40 (ddd, $J=8.7,8.7,4.0 \mathrm{~Hz}, 6 \mathrm{H}), 7.31(\mathrm{dd}, J=8.7,1.2 \mathrm{~Hz}, 6 \mathrm{H}), 0.06(\mathrm{~s}, 54 \mathrm{H}) ;{ }^{13} \mathrm{C}$ NMR $(75$ $\mathrm{MHz}) \delta 133.61,133.55,132.4,132.3,128.3,127.7,127.4,127.1,126.9,122.7,122.2,103.6,98.91$, 98.86, 90.8, -0.2; IR (KBr) 3054, 2956, 2896, 2204, 2153, 1947, 1784, 1586, 1487, 1465, 1407 , 1249, 1159, 952, 893, 855, 745, 701, $646 \mathrm{~cm}^{-1}$; MS (LDI): $\mathrm{m} / \mathrm{z} 1556.4$ (M); Anal. Calcd for $\mathrm{C}_{108} \mathrm{H}_{90} \mathrm{Si}_{6}: \mathrm{C}, 83.34 ; \mathrm{H}$ 5.83. Found: C, 83.14; H, 5.47.

Compound 5. To a suspension of $\mathrm{K}_{2} \mathrm{CO}_{3}(110 \mathrm{mg}, 0.796 \mathrm{mmol})$ in $\mathrm{MeOH}(40 \mathrm{~mL})$ was added a 
solution of $19(82.9 \mathrm{mg}, 53.3 \mu \mathrm{mol})$ in THF $(15 \mathrm{~mL})$ under an argon atmosphere. After stirring for 3 $\mathrm{h}$, the mixture was diluted with water and extracted with $\mathrm{CH}_{2} \mathrm{Cl}_{2}(20 \mathrm{~mL})$. The extract was diluted with THF $(80 \mathrm{~mL})$. This solution containing 20 was added dropwise to a solution of $\mathrm{Cu}(\mathrm{OAc})_{2} \cdot \mathrm{H}_{2} \mathrm{O}$ (570 $\mathrm{mg}, 2.85 \mathrm{mmol}$ ) in degassed (by argon bubbling for $15 \mathrm{~min}$ ) pyridine $(80 \mathrm{~mL})$ and $\mathrm{CH}_{3} \mathrm{CN}(20$ $\mathrm{mL}$ ) over a period of $12 \mathrm{~h}$. The mixture was stirred for $12 \mathrm{~h}$ at room temperature before it was passed through a short silica gel column $\left(\mathrm{CHCl}_{3}\right)$. After removal of the solvent, the residue was washed with $\mathrm{CH}_{3} \mathrm{CN}$. The residual solid was purified by recycling GPC and HPLC (an ODS column, $\mathrm{CH}_{2} \mathrm{Cl}_{2}: \mathrm{CH}_{3} \mathrm{CN}=7: 13$ ) to afford 5 as a pale yellow solid, which decomposed rapidly at room temperature. ${ }^{33} 5:{ }^{1} \mathrm{H}$ NMR $\left(300 \mathrm{MHz}, \mathrm{THF}-d_{8}\right) \delta 8.39(\mathrm{~s}, 6 \mathrm{H}), 8.12(\mathrm{~s}, 6 \mathrm{H}), 7.83(\mathrm{~d}, J=8.1 \mathrm{~Hz}, 6 \mathrm{H})$, $7.34(\mathrm{dd}, J=8.1,7.8 \mathrm{~Hz}, 6 \mathrm{H}), 6.94(\mathrm{dd}, J=8.1,7.8 \mathrm{~Hz}, 6 \mathrm{H}), 6.63(\mathrm{~d}, J=8.1 \mathrm{~Hz}, 6 \mathrm{H}) ;{ }^{13} \mathrm{C} \mathrm{NMR}(75$ $\left.\mathrm{MHz}, \mathrm{THF}-d_{8}\right) \delta 136.6,133.31,133.25,130.0,129.2,128.7,128.4,128.3,128.2,124.9,120.1,102.0$, 93.4, 87.8, 81.3; MS (LDI, negative mode) $m / z 1116.9$ (M).

2-(Trimethylsilyl)ethynyl-1-naphthaldehyde (23). $\mathrm{Pd}\left(\mathrm{PPh}_{3}\right)_{4}(350 \mathrm{mg}, 0.303 \mathrm{mmol})$ and $\mathrm{CuI}(113$ $\mathrm{mg}, 0.593 \mathrm{mmol})$ was added to a solution of $22^{39}(4.55 \mathrm{~g}, 15.0 \mathrm{mmol})$ and (trimethylsilyl)acetylene $(2.60 \mathrm{~mL}, 18.4 \mathrm{mmol})$ in THF $(10 \mathrm{~mL})$ and $\mathrm{Et}_{3} \mathrm{~N}(10 \mathrm{~mL})$ under an argon atmosphere. After stirring at $70^{\circ} \mathrm{C}$ for $11 \mathrm{~h}$, an aqueous solution of $\mathrm{NH}_{4} \mathrm{Cl}$ was added. The reaction mixture was extracted with $\mathrm{CHCl}_{3}$. The extract was washed with brine and dried over anhydrous $\mathrm{MgSO}_{4}$. After removal of the solvent, the residue was purified by chromatography (silica gel, hexanes $/ \mathrm{CHCl}_{3}=7 / 3$ ) to afford 23 (3.34 g, 89\%) as a pale yellow oil. 23: ${ }^{1} \mathrm{H} \operatorname{NMR}(400 \mathrm{MHz}) \delta 11.04(\mathrm{~s}, 1 \mathrm{H}), 9.30(\mathrm{~d}, J=8.8,1.2 \mathrm{~Hz}$, $1 \mathrm{H}), 7.98$ (d, $J=8.4 \mathrm{~Hz}, 1 \mathrm{H}), 7.83$ (dd, $J=8.0,1.2 \mathrm{~Hz}, 1 \mathrm{H}), 7.67$ (ddd, $J=8.6,7.2,1.6 \mathrm{~Hz}, 1 \mathrm{H}$ ), $7.59(\mathrm{~d}, J=8.4 \mathrm{~Hz}, 1 \mathrm{H}), 7.56(\mathrm{ddd}, J=8.0,6.8,1.2 \mathrm{~Hz}, 1 \mathrm{H}), 0.32(\mathrm{~s}, 9 \mathrm{H}) ;{ }^{13} \mathrm{C} \mathrm{NMR}(100 \mathrm{MHz}) \delta$ $193.6,133.8,132.8,131.6,129.6,129.4,129.2,129.1,127.8,127.1,125.3,104.5,101.2,-0.43$; IR (neat) $3058,2960,2148,1688,1430,1250,1208,847,751,651 \mathrm{~cm}^{-1}$; MS (FAB) $m / z 253.4\left(M^{+}\right)$; Anal. Calcd for $\mathrm{C}_{16} \mathrm{H}_{16} \mathrm{OSi}$ : C, 76.14; $\mathrm{H}, 6.39$. Found: $\mathrm{C}, 75.92 ; \mathrm{H}, 6.07$.

1-(2,2-Dibromoethenyl)-2-[(trimethylsilyl)ethynyl]naphthalene (24). To a solution of $\mathrm{PPh}_{3}$ (12.6 $\mathrm{g}, 48.0 \mathrm{mmol})$ in $\mathrm{CH}_{2} \mathrm{Cl}_{2}(30 \mathrm{~mL})$ was added a solution of $\mathrm{CBr}_{4}(8.00 \mathrm{~g}, 24.1 \mathrm{mmol})$ in $\mathrm{CH}_{2} \mathrm{Cl}_{2}(20$ $\mathrm{mL}$ ) at $0{ }^{\circ} \mathrm{C}$ via a syringe under an argon atmosphere. After stirring at $0{ }^{\circ} \mathrm{C}$ for $10 \mathrm{~min}$, a solution of 
$23(3.04 \mathrm{~g}, 12.0 \mathrm{mmol})$ in $\mathrm{CH}_{2} \mathrm{Cl}_{2}(20 \mathrm{~mL})$ was added via a syringe at $0{ }^{\circ} \mathrm{C}$. After stirring at $0{ }^{\circ} \mathrm{C}$ for $10 \mathrm{~min}$, an aqueous solution of $\mathrm{NaHCO}_{3}$ was added, and the reaction mixture was extracted with $\mathrm{CHCl}_{3}$. The extract was washed with brine, and dried over anhydrous $\mathrm{MgSO}_{4}$. After removal of the solvent, the residue was purified by chromatography (silica gel, hexanes $/ \mathrm{CHCl}_{3}=7 / 3$ ) to afford 24 $(4.30 \mathrm{~g}, 87 \%)$ as a pale yellow oil. $24:{ }^{1} \mathrm{H}$ NMR $(400 \mathrm{MHz}) \delta 7.89(\mathrm{~d}, J=9.2 \mathrm{~Hz}, 1 \mathrm{H}), 7.83(\mathrm{dd}, J=$ 7.6, 1.6 Hz, 1H), $7.79(\mathrm{~s}, 1 \mathrm{H}), 7.78$ (d, $J=8.8 \mathrm{~Hz}, 1 \mathrm{H}), 7.56(\mathrm{ddd}, J=8.0,6.8,1.6 \mathrm{~Hz}, 1 \mathrm{H}), 7.54$ (d, $J=8.4 \mathrm{~Hz}, 1 \mathrm{H}), 7.52$ (ddd, $J=7.6,6.8,1.6 \mathrm{~Hz}, 1 \mathrm{H}), 0.34(\mathrm{~s}, 9 \mathrm{H}) ;{ }^{13} \mathrm{C} \mathrm{NMR}(100 \mathrm{MHz}) \delta 137.2$, $135.2,132.7,129.9,128.2,128.1,128.0,126.9,126.7,125.1,119.8,103.9,99.9,94.9,0.17$; IR (neat) 3057, 2958, 2147, 1593, 1500, 1247, 949, 835, 709, $633 \mathrm{~cm}^{-1}$; MS (FAB) $\mathrm{m} / z 408.3\left(\mathrm{M}^{\dagger}\right)$; Anal. Calcd for $\mathrm{C}_{17} \mathrm{H}_{16} \mathrm{Br}_{2} \mathrm{Si}: \mathrm{C}, 50.02 ; \mathrm{H}, 3.95$. Found: $\mathrm{C}, 49.98 ; \mathrm{H}, 3.61$.

1-Ethynyl-2-[(trimethylsilyl)ethynyl]naphthalene (25). To a solution of $i \operatorname{Pr}_{2} \mathrm{NH}(4.80 \mathrm{~mL}, 34.0$ $\mathrm{mmol})$ in THF $(40 \mathrm{~mL})$ was added a solution of $n \mathrm{BuLi}$ in hexane $(1.65 \mathrm{M}, 19.0 \mathrm{~mL}, 31.4 \mathrm{mmol})$ at 0 ${ }^{\circ} \mathrm{C}$. After stirring at $0{ }^{\circ} \mathrm{C}$ for $15 \mathrm{~min}$, the above solution was transferred via a syringe to a solution of $24(4.20 \mathrm{~g}, 10.3 \mathrm{mmol})$ in THF $(20 \mathrm{~mL})$ at $-78^{\circ} \mathrm{C}$. After stirring at $-78{ }^{\circ} \mathrm{C}$ for $20 \mathrm{~min}$, an aqueous solution of $\mathrm{NH}_{4} \mathrm{Cl}$ was added, and the reaction mixture was extracted with $\mathrm{CHCl}_{3}$. The extract was washed with brine, and dried over anhydrous $\mathrm{MgSO}_{4}$. After removal of the solvent, the residue was purified by chromatography (silica gel, hexanes $\left./ \mathrm{CHCl}_{3}=4 / 1\right)$ to afford $25(2.43 \mathrm{~g}, 95 \%$ ) as a pale yellow oil. 25: ${ }^{1} \mathrm{H}$ NMR (400 MHz) $\delta 8.37(\mathrm{~d}, J=8.4 \mathrm{~Hz}, 1 \mathrm{H}), 7.80(\mathrm{~d}, J=8.0 \mathrm{~Hz}, 1 \mathrm{H}), 7.76(\mathrm{~d}, J=$ $8.8 \mathrm{~Hz}, 1 \mathrm{H}), 7.59$ (ddd, $J=8.4,6.8,1.6 \mathrm{~Hz}, 1 \mathrm{H}), 7.52$ (d, $J=8.4 \mathrm{~Hz}, 1 \mathrm{H}), 7.51$ (ddd, $J=8.0,6.8,1.2$ $\mathrm{Hz}, 1 \mathrm{H}), 3.76(\mathrm{~s}, 1 \mathrm{H}), 0.34(\mathrm{~s}, 9 \mathrm{H}) ;{ }^{13} \mathrm{C}$ NMR $(100 \mathrm{MHz}) \delta 133.2,132.3,128.5,128.0,127.4,127.0$, $126.3,124.9,123.2,104.3,99.8,86.6,80.3,-0.01$; IR (neat) 3294, 2959, 2146, 1250, 946, 847, 749, $634 \mathrm{~cm}^{-1}$; MS (EI): $m / z 248.1\left(\mathrm{M}^{+}\right)$; HRMS (EI) calcd. for $\mathrm{C}_{17} \mathrm{H}_{16} \mathrm{Si} 248.1021$, found: 248.1006 .

Hexakis(1-\{2-[(trimethysilyl)ethynyl]naphthyl\}ethynyl)benzene (31). $\mathrm{Pd}\left(\mathrm{PPh}_{3}\right)_{4}(260 \mathrm{mg}, 0.225$ $\mathrm{mmol})$ and $\mathrm{CuI}(70.1 \mathrm{mg}, 0.368 \mathrm{mmol})$ were added to a solution of hexabromobenzene (11) (605 $\mathrm{mg}$, $1.10 \mathrm{mmol})$ and $25(2.43 \mathrm{~g}, 9.78 \mathrm{mmol})$ in a mixture of THF $(40 \mathrm{~mL})$ and $\mathrm{Et}_{3} \mathrm{~N}(10 \mathrm{~mL})$ which had been degassed by argon bubbling for $10 \mathrm{~min}$. After the reaction mixture was heated at $80^{\circ} \mathrm{C}$ for $20 \mathrm{~h}$ under an argon atmosphere, additional $\mathrm{Pd}\left(\mathrm{PPh}_{3}\right)_{4}(128 \mathrm{mg}, 0.111 \mathrm{~mol})$ and $\mathrm{CuI}(40 \mathrm{mg}, 0.21 \mathrm{mmol})$ 
were added to promote the reaction, and then the reaction mixture was heated at $80{ }^{\circ} \mathrm{C}$ for another 30 $\mathrm{h}$. The reaction mixture was cooled to room temperature and passed through a short silica gel column $\left(\mathrm{CHCl}_{3}\right)$. After removal of the solvent, the residue was washed with $\mathrm{CHCl}_{3}$ to afford 31 (649 $\mathrm{mg}$, $51 \%$ ) as a pale yellow solid. 31: m.p. $>340{ }^{\circ} \mathrm{C} ;{ }^{1} \mathrm{H}$ NMR $(400 \mathrm{MHz}) \delta 8.63(\mathrm{~d}, J=8.8 \mathrm{~Hz}, 6 \mathrm{H}), 7.64$ $(\mathrm{d}, J=8.4 \mathrm{~Hz}, 12 \mathrm{H}), 7.33(\mathrm{~d}, J=8.8 \mathrm{~Hz}, 6 \mathrm{H}), 7.18(\mathrm{dd}, J=8.0,7.6 \mathrm{~Hz}, 6 \mathrm{H}), 6.64(\mathrm{dd}, J=7.6,7.6$ $\mathrm{Hz}, 6 \mathrm{H}),-0.14(\mathrm{~s}, 54 \mathrm{H}) ;{ }^{13} \mathrm{C} \mathrm{NMR}(100 \mathrm{MHz}) \delta 133.3,132.1,128.48,128.46,128.3,127.5,127.3$, $126.9,126.6,124.9,123.7,104.1,100.4,97.2,96.4,-0.41$; IR (neat) 2956, 2196, 2148, 1248, 842, $818,750 \mathrm{~cm}^{-1}$; MS (LDI, negative mode) $\mathrm{m} / z \mathrm{z} 1556.2(\mathrm{M})$; Anal. Calcd for $\mathrm{C}_{108} \mathrm{H}_{90} \mathrm{Si}_{6}: \mathrm{C}, 83.34 ; \mathrm{H}$, 5.83. Found: $\mathrm{C}, 83.11 ; \mathrm{H}, 5.43$.

2-Bromo-1-[(1-pyrrolidinyl)diazenyl]naphthalene (28). $27^{40}(1.00 \mathrm{~g}, 4.50 \mathrm{mmol}$ was dissolved in EtOH $(15 \mathrm{~mL})$, and $12 \mathrm{M}$ aq. $\mathrm{HCl}(1.0 \mathrm{~mL})$ and water $(30 \mathrm{~mL})$ was added at $0{ }^{\circ} \mathrm{C}$, and then a solution of $\mathrm{NaNO}_{2}(265 \mathrm{mg}, 4.73 \mathrm{mmol})$ in water $(10 \mathrm{~mL})$ was added dropwise at $0{ }^{\circ} \mathrm{C}$. After stirring at $0^{\circ} \mathrm{C}$ for $15 \mathrm{~min}$, resulting suspension was added all at once to a solution of pyrrolidine $(3.0 \mathrm{~mL})$ in $1 \mathrm{M}$ aqueous solution of $\mathrm{KOH}(50 \mathrm{~mL})$ at $0^{\circ} \mathrm{C}$. After stirring at $0^{\circ} \mathrm{C}$ for $1 \mathrm{~h}$, the reaction mixture was diluted with water, and extracted with $\mathrm{CHCl}_{3}$. The extract was washed with brine, and dried over anhydrous $\mathrm{MgSO}_{4}$. After removal of the solvent, the residue was purified by chromatography (silica gel, hexanes/AcOEt $=4 / 1)$ to afford $28(621 \mathrm{mg}, 45 \%)$ as a red oil. 28: ${ }^{1} \mathrm{H}$ NMR (400 MHz, DMSO- $\left.d_{6}, 120^{\circ} \mathrm{C}\right) \delta 8.00(\mathrm{~d}, J=8.0 \mathrm{~Hz}, 1 \mathrm{H}), 7.88(\mathrm{~d}, J=8.0 \mathrm{~Hz}, 1 \mathrm{H}), 7.64(\mathrm{~d}, J=8.4 \mathrm{~Hz}, 1 \mathrm{H})$, $7.59(\mathrm{~d}, J=8.4 \mathrm{~Hz}, 1 \mathrm{H}), 7.54-7.46(\mathrm{~m}, 2 \mathrm{H}), 3.86-3.83(\mathrm{~m}, 4 \mathrm{H}), 2.09-2.06(\mathrm{~m}, 4 \mathrm{H}) ;{ }^{13} \mathrm{C}$ NMR $(100$ MHz, DMSO- $\left.d_{6}, 120^{\circ} \mathrm{C}\right) \delta 145.1,132.7,129.6,128.4,127.2,125.8,125.6,125.1,123.3,111.4,48.1$, 22.8; IR (neat) 2973, 2871, 1414, 1316, 804, 659, $614 \mathrm{~cm}^{-1}$; MS (FAB): $m / z 303.09\left(\mathrm{M}^{+}\right)$; Anal. Calcd for $\mathrm{C}_{14} \mathrm{H}_{14} \mathrm{BrN}_{3}$ : C, 55.28; H, 4.64. Found: C, 54.89; $\mathrm{H}, 5.01$.

\section{2-[(trimethylsilyl)ethynyl]-1-(1-Pyrrolidinyl)diazenylnaphthalene (29). $\mathrm{Pd}\left(\mathrm{PPh}_{3}\right)_{4}(118 \mathrm{mg}, 0.102$} $\mathrm{mmol})$ and $\mathrm{CuI}(50 \mathrm{mg}, 0.26 \mathrm{mmol})$ were added to a solution of $28(621 \mathrm{mg}, 2.04 \mathrm{mmol})$ and (trimethylsilyl)acetylene $\left(0.380 \mathrm{~mL}, 2.65 \mathrm{mmol}\right.$ ) in degassed (by argon bubbling for $10 \mathrm{~min}$ ) $\mathrm{Et}_{3} \mathrm{~N}$ $(10 \mathrm{~mL})$. After stirring at $80^{\circ} \mathrm{C}$ for $1.5 \mathrm{~h}$, the reaction mixture was cooled to room temperature and passed through a short silica gel column $\left(\mathrm{CHCl}_{3}\right)$. The product was purified by chromatography 
(silica gel, hexanes:AcOEt $=4: 1)$ to afford $29(650 \mathrm{mg}, 99 \%)$ as a yellow solid. 29: $\mathrm{mp}$ 85.0$87.0^{\circ} \mathrm{C} ;{ }^{1} \mathrm{H}$ NMR $\left(400 \mathrm{MHz}, \mathrm{DMSO}-d_{6}, 120^{\circ} \mathrm{C}\right) \delta 8.19(\mathrm{~d}, \mathrm{~J}=8.4 \mathrm{~Hz}, 1 \mathrm{H}), 7.84(\mathrm{~d}, \mathrm{~J}=8.8 \mathrm{~Hz}, 1 \mathrm{H})$, $7.60(\mathrm{~d}, \mathrm{~J}=8.8 \mathrm{~Hz}, 4 \mathrm{H}), 7.53-7.46(\mathrm{~m}, 2 \mathrm{H}), 7.41(\mathrm{~d}, \mathrm{~J}=8.8 \mathrm{~Hz}, 1 \mathrm{H}) 3.87-3.84(\mathrm{~m}, 4 \mathrm{H}), 2.08-2.05$ $(\mathrm{m}, 4 \mathrm{H}), 0.22(\mathrm{~s}, 9 \mathrm{H}) ;{ }^{13} \mathrm{C}$ NMR $\left(100 \mathrm{MHz}, \mathrm{DMSO}-d_{6}, 120^{\circ} \mathrm{C}\right) \delta 149.5,133.1,129.1,127.6,127.0$, $126.2,125.5,123.5,108.8,105.0,95.7,48.0,22.8,-0.5$; IR (neat) 2976, 2871, 2135, 1407, 1316, 952, 845, $747 \mathrm{~cm}^{-1}$; MS (EI) $\mathrm{m} / z$ 321.1 (M $\mathrm{M}^{+}$; Anal. Calcd for $\mathrm{C}_{19} \mathrm{H}_{23} \mathrm{~N}_{3} \mathrm{Si}$ : C, 70.98; H, 7.21. Found: C, $70.90 ; \mathrm{H}, 7.12$.

1-Iodo-2-[(trimethylsilyl)ethynyl]naphthalene (30). 29 (3.80 g, $1.18 \mathrm{mmol})$ and iodomethane (30 $\mathrm{mL}$ ) were added to an autoclave, and the autoclave was heated at $140{ }^{\circ} \mathrm{C}$ for $25 \mathrm{~h}$. After cooling to room temperature, the reaction mixture was dissolved in $\mathrm{CHCl}_{3}$. The solution was washed with water and brine. After removal of the solvent, the residue was purified by chromatography (silica gel, hexanes/AcOEt $=97 / 3)$ to afford $30(4.14 \mathrm{~g}, 56 \%)$ as a colorless oil. $30:{ }^{1} \mathrm{H}$ NMR $(400 \mathrm{MHz}) \delta 8.20$ $(\mathrm{d}, J=8.4 \mathrm{~Hz}, 1 \mathrm{H}), 7.73(\mathrm{~d}, J=8.4 \mathrm{~Hz}, 1 \mathrm{H}), 7.72(\mathrm{~d}, J=8.0 \mathrm{~Hz}, 1 \mathrm{H}), 7.57(\mathrm{ddd}, J=8.4,6.8,1.2 \mathrm{~Hz}$, $1 \mathrm{H}), 7.50(\mathrm{~d}, J=8.4 \mathrm{~Hz}, 1 \mathrm{H}), 7.49$ (ddd, $J=8.4,6.8,1.2 \mathrm{~Hz}, 1 \mathrm{H}), 0.34(\mathrm{~s}, 9 \mathrm{H}) ;{ }^{13} \mathrm{C} \mathrm{NMR}(100 \mathrm{MHz})$ $\delta 134.8,133.4,132.9,128.9,128.6,128.3,128.2,128.1,127.1,108.2,107.4,99.7,-0.04$; IR (neat) 3055, 2958, 2896, 2155, 1493, 1249, 917, 841, 759, $647 \mathrm{~cm}^{-1}$; MS (EI) m/z $349.9\left(\mathrm{M}^{+}\right)$; Anal. Calcd for $\mathrm{C}_{15} \mathrm{H}_{15} \mathrm{ISi}: \mathrm{C}, 51.43 ; \mathrm{H}, 4.32$. Found: $\mathrm{C}, 51.71 ; \mathrm{H}, 4.31$.

Hexakis(1-\{2-[(trimethysilyl)ethynyl]naphthyl\}ethynyl)benzene (31). 17 (328 $\mathrm{mg}, 0.500 \mathrm{mmol})$ in THF $(10 \mathrm{~mL})$ was added via a syringe to a suspension of $\mathrm{K}_{2} \mathrm{CO}_{3}(414 \mathrm{mg}, 3.00 \mathrm{mmol})$ in $\mathrm{MeOH}$ $(10 \mathrm{~mL})$. After stirring at room temperature under an argon atmosphere for $20 \mathrm{~min}$, an aqueous solution of $\mathrm{NH}_{4} \mathrm{Cl}$ was added, and the reaction mixture was extracted with ether. The extract was dried over anhydrous $\mathrm{MgSO}_{4}$. Most of the solvent was removed under reduced pressure and the resultant wet solid, before it became completely dry, was dissolved in a mixture of THF (20 mL) and $\mathrm{Et}_{3} \mathrm{~N}(20 \mathrm{~mL})$ which had been degassed by argon bubbling for $15 \mathrm{~min} .30$ (2.10 g, $\left.6.00 \mathrm{mmol}\right)$, $\mathrm{Pd}\left(\mathrm{PPh}_{3}\right)_{4}(116 \mathrm{mg}, 0.100 \mathrm{mmol})$ and $\mathrm{CuI}(29 \mathrm{mg}, 0.150 \mathrm{mmol})$ were added under an argon atmosphere. After the reaction mixture was heated at $45^{\circ} \mathrm{C}$ for $26 \mathrm{~h}$, additional $\mathrm{Pd}\left(\mathrm{PPh}_{3}\right)_{4}(116 \mathrm{mg}$, $0.100 \mathrm{mmol})$ and $\mathrm{CuI}(29 \mathrm{mg}, 0.150 \mathrm{mmol}$ ) were added to promote the reaction, and then the reaction mixture was heated at $85^{\circ} \mathrm{C}$ for another $94 \mathrm{~h}$. The reaction mixture was cooled to room 
temperature and passed through a short silica gel column $\left(\mathrm{CHCl}_{3}\right)$. The product was purified by chromatography (silica gel, hexanes/ $\mathrm{CHCl}_{3}=1 / 1$ ), and then recrystallized from $\mathrm{CH}_{2} \mathrm{Cl}_{2} / \mathrm{EtOH}$ to afford $\mathbf{3 1}(92.3 \mathrm{mg}, 13 \%)$ as a yellow solid. The spectral data are described above.

Compound 6. To a suspension of $\mathrm{K}_{2} \mathrm{CO}_{3}(134 \mathrm{mg}, 0.970 \mathrm{mmol})$ in $\mathrm{MeOH}(30 \mathrm{~mL})$ was added a solution of $31(99.7 \mathrm{mg}, 64.1 \mu \mathrm{mol})$ in THF $(50 \mathrm{~mL})$. After stirring at room temperature for $3.5 \mathrm{~h}$ under an argon atmosphere, an aqueous solution of $\mathrm{NH}_{4} \mathrm{Cl}$ was added, and the reaction mixture was extracted with ether. The extract was washed with brine and diluted with ether $(80 \mathrm{~mL})$. This solution containing 32 was added dropwise to a solution of $\mathrm{Cu}(\mathrm{OAc})_{2} \cdot \mathrm{H}_{2} \mathrm{O}(1.28 \mathrm{~g}, 6.41 \mathrm{mmol})$ in a mixture of pyridine $(100 \mathrm{~mL})$ and $\mathrm{CH}_{3} \mathrm{CN}(20 \mathrm{~mL})$, which had been degassed by argon bubbling for $15 \mathrm{~min}$, over a period of $18 \mathrm{~h}$ at $70{ }^{\circ} \mathrm{C}$. The mixture was stirred for another $2 \mathrm{~h}$ at $70^{\circ} \mathrm{C}$ before it was passed through a short silica gel column $\left(\mathrm{CHCl}_{3}\right)$. After removal of the solvent, the residue was purified by recycling GPC and to afford $6(5.1 \mathrm{mg}, 7 \%)$ as an orange solid, which decomposed gradually at room temperature. ${ }^{36,41}$ 6: $^{1} \mathrm{H}$ NMR $\left(400 \mathrm{MHz}, p\right.$-dichlorobenzene- $\left.d_{4}, 150^{\circ} \mathrm{C}\right) \delta 8.74(\mathrm{~d}, J=8.0 \mathrm{~Hz}, 6 \mathrm{H})$, $7.35(\mathrm{~d}, J=8.4 \mathrm{~Hz}, 6 \mathrm{H}), 7.29$ (d, $J=8.4 \mathrm{~Hz}, 6 \mathrm{H}), 7.12(\mathrm{~d}, J=8.0 \mathrm{~Hz}, 6 \mathrm{H}), 6.84(\mathrm{dd}, J=7.6,6.8 \mathrm{~Hz}$, $6 \mathrm{H}), 6.79$ (dd, $J=7.6,6.8 \mathrm{~Hz}, 6 \mathrm{H})$; MS (LDI, negative mode) $\mathrm{m} / \mathrm{z} 1116.7(M)$. 


\subsection{References and Notes}

(1) For a review on overcrowded polycyclic aromatic compounds, see: Pascal, Jr. R. A. Chem. Rev. 2006, 106, 4809-4819.

(2) (a) Hursthouse, M. B.; Smith, V. B. J. Fluorine Chem. 1977, 10, 145-155. (b) Frampton, C. S.; MacNicol, D. D.; Rowan, S. J. J. Mol. Struct. 1997, 405, 169-178. (c) Wang, Y.; Stretton, A. D.; McConnell, M. C.; Wood, P. A.; Parsons, S.; Henry, J. B.; Mount, A. R.; Galow, T. H. J. Am. Chem. Soc. 2007, 129, 13193-13200.

(3) Barnett, L.; Ho, D. M.; Baldridge, K. K.; Pascal Jr., R. A. J. Am. Chem. Soc. 1999, 121, 727-733.

(4) (a) Peña, D.; Pérez, D.; Guitián, E.; Castero, L. Org. Lett. 1999, 1, 1555-1557. (b) Peña, D.; Cobas, A.; Pérez, D.; Guitián, E.; Castero, L. Org. Lett. 2000, 2, 1629-1632.

(5) Bennett, M. A.; Kopp, M. R.; Wenger, E.; Willis, A. C. J. Organomet. Chem. 2003, 667, 8-15.

(6) Romero, C.; Peña, D.; Pérez, D.; Guitián, E. Chem. Eur. J. 2006, 12, 5677-5684.

(7) Alonso, J. M.; Díaz-Álvarez, A. E.; Criado, A.; Pérez, D.; Peña, D.; Guitián, E. Angew. Chem. 2012, 124, 177-181; Angew. Chem. Int. Ed. 2012, 51, 173-177.

(8) (a) Zimmermann, K.; Goddard, R.; Krüger, C.; Haenal, M. W. Tetrahedron Lett. 1996, 37, 83718374. (b) Gimzewski, J. K.; Joachim, C.; Schlittler, P. R.; Langlais, V.; Tang, H.; Johannsen, I. Science 1998, 281, 531-533. (c) Iglesias, B.; Peña, D.; Pérez, D.; Guitián, E.; Castedo, L. Synlett $2002,486-488$.

(9) A. Pradhan, P. Dechambenoit, H. Bock, F. Durola, Angew. Chem. 2011, 123, 12790-12793; Angew. Chem. Int. Ed. 2011, 50, 12582-12585.

(10) Yoshimura, T.; Inaba, A.; Sonoda, M.; Tahara, K.; Tobe, Y.; Williams, R. V. Org. Lett. 2006, 8, 2933-2936.

(11) Tahara, K.; Yoshimura, T.; Sonoda, M.; Tobe, Y.; Williams, R. V. J. Org. Chem. 2007, 72, 14371442.

(12) For previous syntheses of [14]DBA and its derivatives, see: (a) Baldwin, K. P.; Matzger, A. J.; Scheiman, D. A.; Tessier, C. A.; Vollhardt, K. P. C.; Youngs, W. J. Synlett 1995, 1216-1218. (b) Marsden, J. A.; Miller, J. J.; Haley, M. M. Angew. Chem. 2004, 116, 1726-1729; Angew. Chem. Int. Ed. 2004, 43, 1694-1697.

(13) (a) Toyota, S.; Yamamori, T.; Makino, T. Tetrahedron 2001, 57, 3521-3528. (b) Makino, T.; 
Toyota, S. Bull. Chem. Soc. Jpn. 2005, 78, 917-928. (c) Toyota, S. Chem. Rev. 2010, 110, 53985424.

(14) Recently, Haley reported the synthesis and optical properties of trefoil-shaped molecules in which three [14]DBA rings fused to the central triphenylene, dehydrobenzo[12]annulene, or dehydrobenzo[18]annulene core. However, because of the large core size, these would not exhibit hindered rotation around the [14]DBA blades: Takeda, T.; Fix, A. G.; Haley, M. M. Org. Lett. 2010, $12,3824-3827$.

(15) (a) Huynh, C.; Linstrumelle, G. Tetrahedron 1988, 44, 6337-6344. (b) John, J. A.; Tour, J. M. J. Am. Chem. Soc. 1994, 116, 5011-5012.

(16) About one sixth volume of an eluent of GPC containing purified 4 was evaporated to dryness, the residue was weighed, and its purity was checked by NMR. From this experiment the yield of 4 was estimated approximately $24 \%$ by using $\mathrm{CHBr}_{3}$ as an internal standard.

(17) (a) Dierck, R.; Armstrong, J. C.; Boese, R.; Vollhardt, K. P. C. Angew. Chem. 1986, 98, 270271; Angew. Chem. Int. Ed. Engl. 1986, 25, 268-269. (b) Neenan, T. X.; Whitesides, G. M. J. Org. Chem. 1988, 53, 2489-2496. (c) Sonoda, M.; Inaba, A.; Itahashi, K.; Tobe, Y. Org. Lett. 2001, 3, 2419-2421.

(18) Several hexaethynylbenzene derivatives were prepared by substitution with 12: (a) Ito, S.; Inabe, H.; Morita, N.; Ohta, K.: Kitamura, T.; Imafuku, K. J. Am. Chem. Soc. 2003, 125, 1669-1680. (b) Nierle, J.; Barth, D.; Kuck, D. Eur. J. Org. Chem. 2004, 867-872. (c) Hasegawa, M.; Enozawa, H.; Kawabata, Y.; Iyoda, M. J. Am. Chem. Soc. 2007, 129, 3072-3073. (d) Schmittel, M.; Mal, P. Chem. Commun. 2008, 960-962.

(19) (a) Zhao, Y.; Schultz, N. E.; Truhlar, D. G. J. Chem. Phys. 2005, 123, 161103. (b) Zhao, Y.; Schultz, N. E.; Truhlar, D. G. J. Chem. Theory Comput. 2006, 2, 364-382. (c) Zhao, Y.; Truhar, D. G. J. Chem. Theory Comput. 2006, 2, 1009-1018. (d) Toyota, S.; Miyahara, H.; Goichi, M.; Yamasaki, S.; Iwanaga, T. Bull. Chem. Soc. Jpn. 2009, 82, 931-945.

(20) For a [14]DBA ring, 168-172 ${ }^{\circ}$ for 'spoke' bond angles were reported: (a) Baldwin, K. P.; Matzger, A. J.; Scheiman, D. A.; Tessier, C. A.; Vollhardt, K. P. C.; Youngs, W. J. Synlett 1995, 1215-1218. (b) Hinrichs, H.; Fischer, A. K.; Jones, P. G.; Hopf, H.; Haley, M. M. Org. Lett. 2005, 7, 3793-3795. (c) Blanchette, H. S.; Brand, S. C.; Naruse, H.; Weakley, T. J. R.; Haley, M. M. -50 - 
Tetrahedron 2000, 56, 9581-9588. (d) O'Coonor, M. J.; Yelle, R. B.; Zakharov, L. N.; Haley, M. M.J. Org. Chem. 2008, 73, 4424-4432.

(21) (a) Wan, W. B.; Haley, M. M. J. Org. Chem. 2001, 66, 3893-3901. (b) West, K.; Wang, C.; Batsanov, A. S.; Bryce, M. R. J. Org. Chem. 2006, 71, 8541-8544.

(22) (a) Zhou, Q.; Carroll, P. J.; Swager, T. M. J. Org. Chem. 1994, 59, 1294-1301. (b) Hisaki, I.; Eda, T.; Sonoda, M.; Niino, H.; Sato, T.; Wakabayashi, T.; Tobe, Y. J. Org. Chem. 2005, 70, 18531864.

(23) Another dihedral angle between mean planes of nearly planar butadiyne-bridged two naphthalene rings in ring $\mathrm{E}$ (i.e. $\mathrm{C}(34)-\mathrm{C}(43)$ vs. $\mathrm{C}(48)-\mathrm{C}(57)$ ) was $1.8^{\circ}$.

(24) For the chemical shift calculations, the author employed the HF method because this method had been shown to be most reliable to evaluate the chemical shifts (i.e. magnetic properties) of annulenes: for example, Williams, R. V.; Armantrout, J. R.; Twamley, B.; Mitchell, R. H.; Ward, T. R.; Bandyopadhyay, S. J. Am. Chem. Soc. 2002, 124, 13495-13505.

(25) (a) Jain, R.; Bally, T.; Rablen, P. R. J. Org. Chem. 2009, 74, 4017-4023. (b) Bally, T.; Rablen, P. R. J. Org. Chem. 2011, 76, 4818-4830. (c) Cossi, M.; Scalmani, G.; Rega, N.; Barone, V. J. Chem. Phys. 2002, 117, 43-54.

(26) Pople, J. A.; Schneider, W. G.; Bernstein, H. J. High-resolution Nuclear Magnetic Resonance, McGraw-Hill Book Company, Inc., New York, 1959, pp. 422-432.

(27) Williams, R. V.; Armantrout, J. R.; Twamley, B.; R. Mitchell, H.; Ward, T. R.; Bandyopadhyay, S. J. Am. Chem. Soc. 2002, 124, 13495-13505.

(28) (a) Jain, R.; Bally, T.; Rablen, P. R. J. Org. Chem. 2009, 74, 4017-4023. (b) Bally, T.; Rablen, P. R. J. Org. Chem. 2011, 76, 4818-4830. (c) Cossi, M.; Scalmani, G.; Rega, N.; Barone, V. J. Chem. Phys. 2002, 117, 43-54.

(29) Baldwin, K. P.; Matzger, A. J.; Scheiman, D. A.; Tessier, C. A.; Vollhardt, K. P. C.; Youngs, W. J. Synlett 1995, 1216-1218

(30) (a) Okamoto, Y.; Ikai, T. Chem. Soc. Rev. 2008, 37, 2593-2608. (b) Ikai, T.; Okamoto, Y. Chem. Rev. 2009, 109, 6077-6101.

(31) The following chiral chromatography columns used for the attempted optical resolution of 4 and 5: DAICEL CHIRALPAK AD (4.6 mm × $250 \mathrm{~mm})$, DAICEL CHIRALCEL OD-H (4.6 mm $\times$ - 51 - 
$250 \mathrm{~mm})$, DAICEL CHIRALCEL OA $(4.6 \mathrm{~mm} \times 250 \mathrm{~mm})$, DAICEL CHIRALPAK IA (4.6 mm $\times$ $250 \mathrm{~mm}$ ), DAICEL CHIRALPAK IB (4.6 mm × $250 \mathrm{~mm})$, DAICEL CHIRALPAK IC (4.6 mm × $250 \mathrm{~mm})$, SHISEIDO Chiral RU-2 (4.6 mm $\times 150 \mathrm{~mm})$, SHISEIDO Chiral CD-Ph $(4.6 \mathrm{~mm} \times 150$ $\mathrm{mm})$, SUMICHIRAL OA-8000 (4.6 mm × $250 \mathrm{~mm}$ ), SUMICHIRAL CW cyclohexyl OMe (4.6 $\mathrm{mm} \times 250 \mathrm{~mm}$ ), Chiralcel OB-H (used for only 4), Chiralcel OJ-H (used for only 4), Chiralpak AS-H (used for only 4), Chiralpak OT(+) (used for only 4)

(32) The latter behavior can be attributed to the change of ratio of the conformational population. As shown in Table S3, for both 4 and $\mathbf{5}$, the calculated chemical shifts of the $D_{3}$ structure are down field shifted compared to those of the $C_{2}$ structure. Hence, the observed down field shifts upon decreasing the temperature is likely due to the population of the more stable $D_{3}$ conformers.

(33) (a) Lippert, A. R.; Naganawa, A.; Keleshian, V. L.; Bode, J. W. J. Am. Chem. Soc. 2010, 132, 15790-15799. (b) He, M.; Bode, J. W. Proc. Natl. Acad. Sci. 2011, 108, 14752-14756.

(34) Bedard, T. C.; Moore, J. S. J. Am. Chem. Soc. 1995, 117, 10662-19671.

(35) Huynh, C.; Linstrumelle, G. Tetrahedron 1988, 44, 6337-6344.

(36) Because of the instability of the material, the melting point was not determined.

(37) Hellberg, J.; Allared, F.; Pelcman, M. Synth. Commun. 2003, 33, 2751-2756.

(38) Sonoda, M.; Inaba, A.; Itahashi, K.; Tobe, Y. Org. Lett. 2001, 3, 2419-2421.

(39) Still, I. W. J.; Natividad-Preyra, R.; Toste, F. D. Can. J. Chem. 1999, 77, 113-121.

(40) Zhang, Y.; Shibatomi, K.; Yamamoto, H. Synlett 2005, 18, 2837-2842.

(41) Compound 6 was hardly soluble to any solvents and only slightly soluble to aromatic solvents such as toluene and $p$-dichlorobenzene at elevated temperature. The ${ }^{13} \mathrm{C}$ NMR spectrum of 6 is not reported because the signal intensities were low and most of the signals overlapped with the signals of the aromatic solvent and, therefore, were concealed by them. 
Chopter 3

Oxidative Cyclodimerization that Folllows Tandem Cyclization of Dehydrobenzo[14]annulenes Induced by Alkyllithium 


\subsection{Introduction}

Highly ethynylated compounds have rich potential to transform into polycyclic aromatic hydrocarbons by intramolecular cyclizations between the sp carbons because of high reactivity of carbon-carbon triple bonds. ${ }^{1}$ Particularly those with cyclic structures are useful for the construction of new carbon frameworks which are otherwise difficult to obtain. Moreover, cyclic precursors would limit the number of the possible pathways due to steric constraints. Indeed, a few examples of efficient transformations of dehydrobenzannulenes into polycyclic carbon frameworks were reported as exemplified for octadehydrodibenzo[12] annulene, ${ }^{2}$ hexadehydrotribenzo[12]annulene, ${ }^{3}$ and tetradehydrodibenzo[8]annulene. ${ }^{4}$ The reactions are typically induced by attack of a nucleophile, ${ }^{4 a}$ an electrophile, ${ }^{2,4 b, 5}$ or a radical ${ }^{3 \mathrm{~d}, 6}$ or initiated by reduction to generate a radical anion. ${ }^{3 \mathrm{a}-\mathrm{c}, 7}$

The author envisaged that octadehydrotribenzo[14]annulene ([14]DBA) $\mathbf{1 a}^{8}$ and its congeners 2-4 would serve as intriguing substrates for multiple trasnannular bond formation to yield new polycyclic frameworks because of the presence of four closely located triple bonds. Additionally, the distorted butadiye unit is expected to trigger reactions induced by an electrophile ${ }^{2 a}$ or a nucleophile, ${ }^{4 a}$ which would not occur for unactivated acetylenic bonds. ${ }^{4 a, 9}$ The author report here the results of the reactions of [14]DBA 1 and its congeners 2-4 with butyllithium ( $n$-BuLi): the author discovered an unprecedented oxidative cyclodimerization to form eight-membered ring products, in which two indeno[2,1-a]fluorene components were connected by a single and a double bonds, following three-fold transannular $\mathrm{C}-\mathrm{C}$ bond formations.

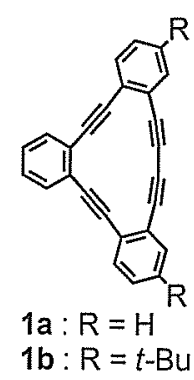

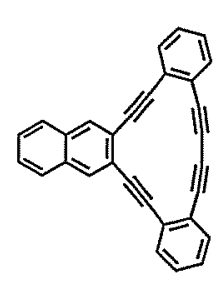

2

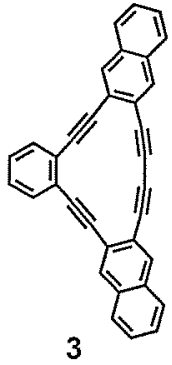

3

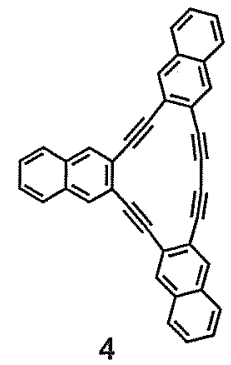

4

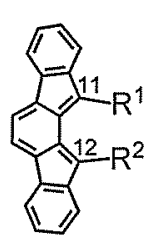

5a: $R^{1}=R^{2}=P h$

5b: $R^{1}=R^{2}=$ Mes

5c: $R^{1}=H, R^{2}=L i$

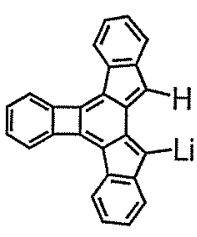

22

First the author envisioned the possible pathways for the tandem transannular cyclizations of 1 a as shown in Scheme 1. In the initial step, the author assume the formation of a 5-membered ring, 
following addition of a nucleophiles to the diyne moiety of $1 \mathbf{a}$, takes place to give intermediate 7 on the basis of the previous reports. ${ }^{2 a, 3,4 a}$ For the second step, there are two options of transannular bond formation in the remaining 11-membered ring; formation of a four-membered ring to give 9 or a five-membered ring to form a 5-8-5 ring system 8. In the former case, the resulting 9-membered ring can be further divided into 5-6 or 4-7 ring systems to afford tetracyclic intermediates 11 bearing an indeno[2,1-a]fluorene substructure or $\mathbf{1 0}$ possessing two benzocyclobutene units. As to the indeno[2,1-a]fluorene framework, while Le Berre et al. reported the synthesis of unstable 11,12-diphenylderivatives $5 \mathbf{a}^{10}{ }^{10}$ the robust dimesityl substituted derivative $\mathbf{5 b}$ was recently synthesized and its physical properties including singlet diradical character was clarified. ${ }^{11}$ These results suggests that the expected product $\mathbf{1 2}$ formed by interception of $\mathbf{1 1}$ with an electrophile must be substantially reactive.
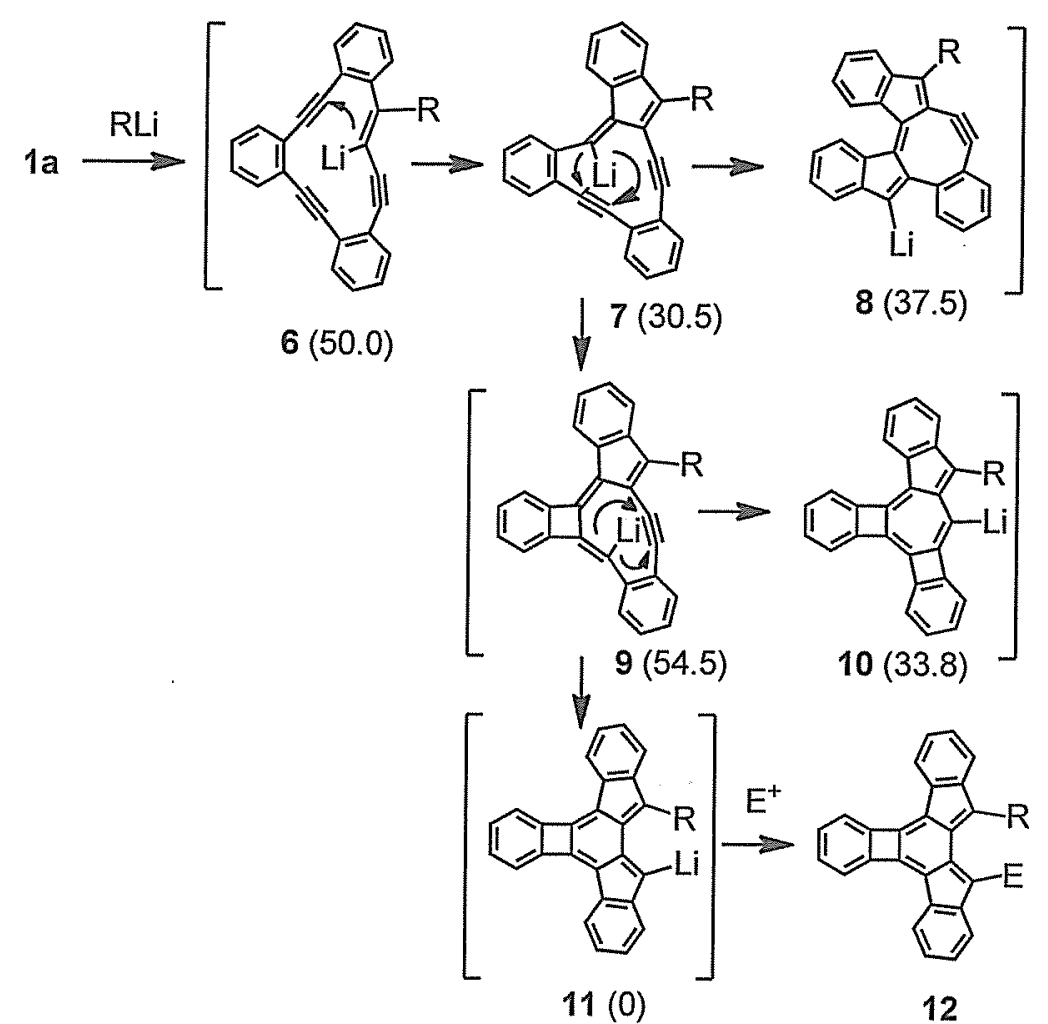

Scheme 1. A working hypothesis for tandem transannular cyclizations of [14]DBA 1a with calculated energies $(\mathrm{kcal} / \mathrm{mol})$ relative to 11 by DFT ((R)B3LYP/6-31G*) method in parentheses. 


\subsection{Reaction of [14]DBA with $\boldsymbol{n}$-Butyllithium and Structural Elucidations}

\subsubsection{Reaction of [14]DBA derivatives}

When di-tert-butyl[14]DBA $1 \mathrm{~b}$ was treated with $n$-BuLi at $-78^{\circ} \mathrm{C}$ in THF followed by quenching with water or 1-iodobutane at the same temperature, single products $\mathbf{1 3} \mathbf{a}$ and $\mathbf{1 3} \mathbf{b}$ were obtained in $61 \%$ and $67 \%$ yields, respectively. The ${ }^{13} \mathrm{C}$ NMR spectra (Figure 1) of these products exhibited four sp carbon signals, implying that an addition of $n$-BuLi took place to the diyne moiety which is followed by a transannular cyclization forming a five-membered ring (Scheme 2). In the ${ }^{1} \mathrm{H}$ NMR spectrum of 13a, the vinyl proton signal appears at a high field ( $\delta 8.75 \mathrm{ppm})$, consistent with the $E$ configuration of the double bond in view of the similar anisotropic effects due to proximate triple bonds reported for the related dehydroannulenes. ${ }^{12}$

(a)

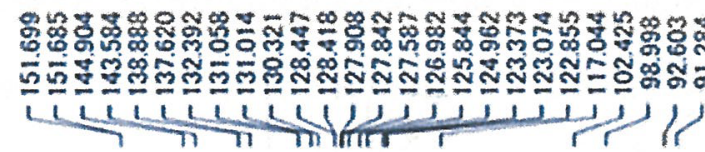

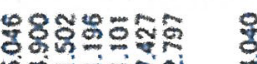

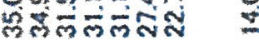

परी 1

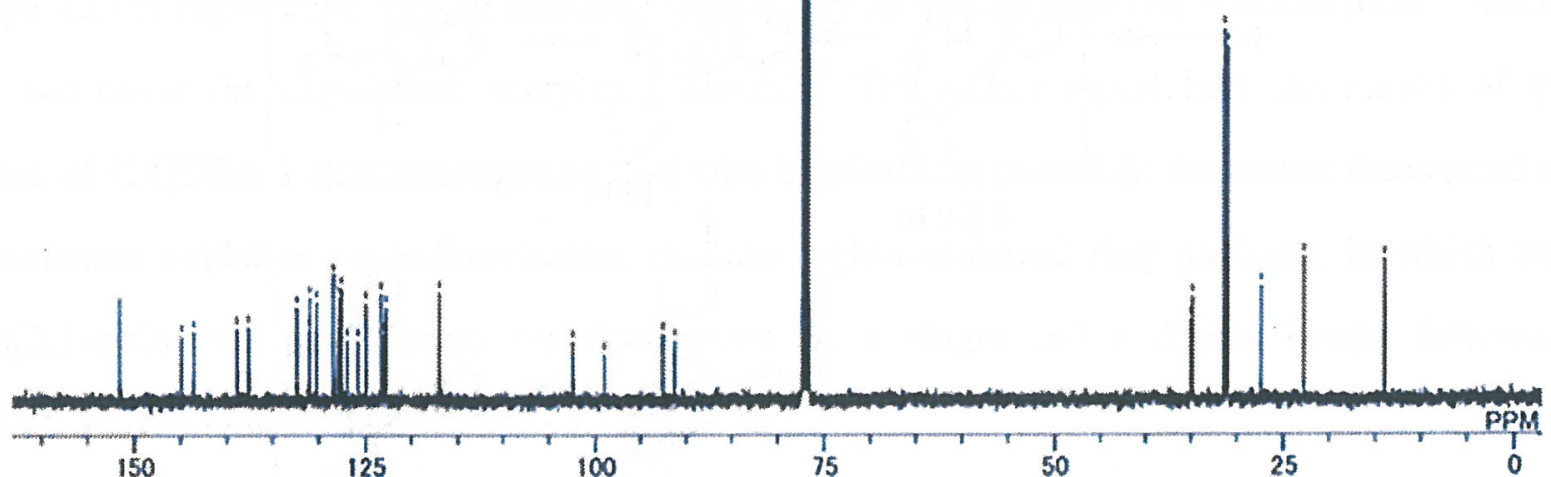

(b)

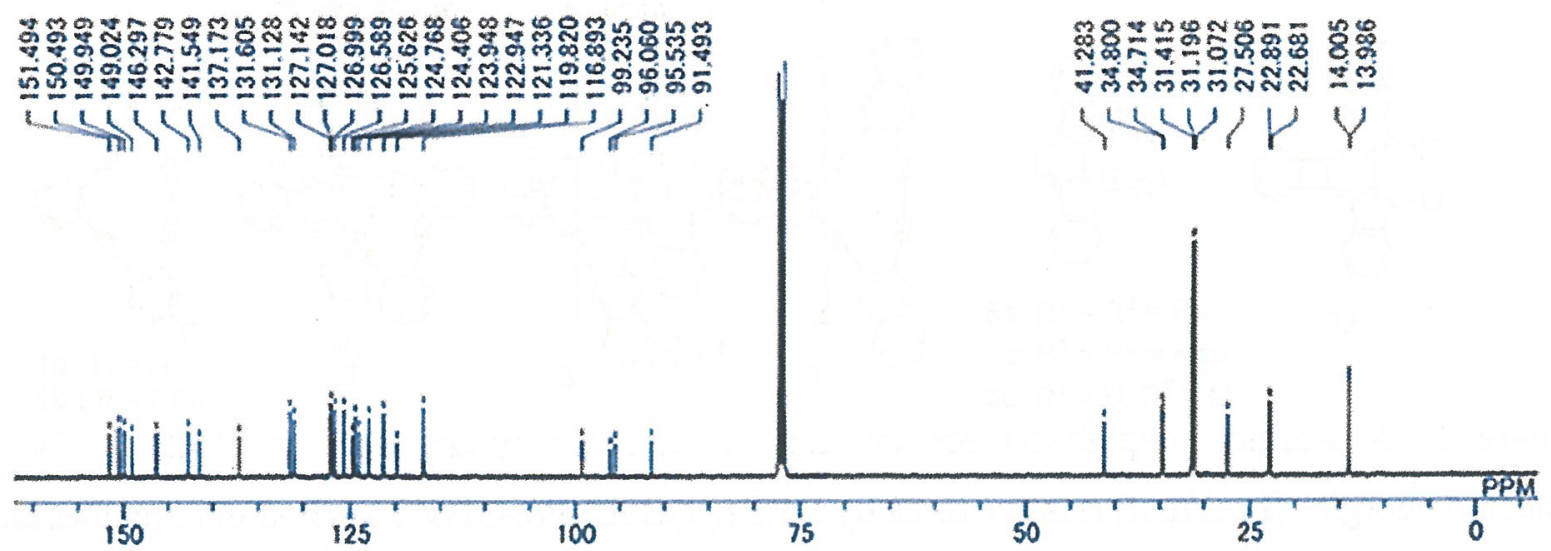

Figure 1. ${ }^{13} \mathrm{C}$ NMR spectra of (a) $13 \mathbf{a}$ and (b) $\mathbf{1 3 b}$. 


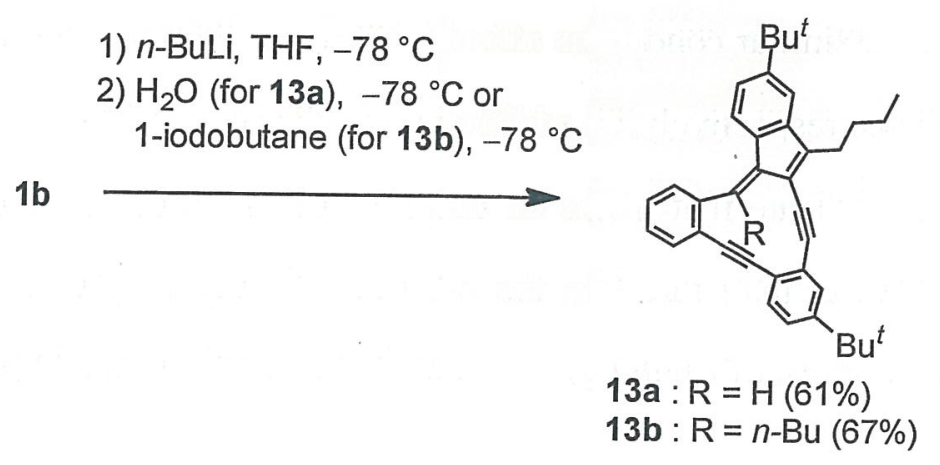

Scheme 2. Transannular cyclization of $\mathbf{1 b}$ at low temperature.

On the contrary, when $\mathbf{1 b}$ was treated with $n$-BuLi ( 3 equivalents) ${ }^{13}$ at $-78{ }^{\circ} \mathrm{C}$ and the mixture was warmed up to room temperature before quenching with water, three products $14 \mathbf{b}, \mathbf{1 5 b}$, and $\mathbf{1 6} \mathbf{b}$ were isolated in 18,20, and 16\% yields, respectively. Most surprisingly, the mass spectrum of $14 \mathrm{~b}$ indicates that the molecular formula $\left(\mathrm{C}_{76} \mathrm{H}_{74}\right)$ corresponds a dimer of $\mathbf{1 b}$ which is two-electron oxidized. ${ }^{1} \mathrm{H}$ and ${ }^{13} \mathrm{C}$ NMR spectra (Figure 2) of $\mathbf{1 4 b}$ imply that $\mathbf{1 4 b}$ has a symmetric structure, in which tribenzo-fused tetracyclic frameworks are connected with a single and a double bonds. The final structural determination of $\mathbf{1 4 b}$ was done by X-ray crystallographic analysis of the corresponding product 3a derived from 1a (vide infra), because the correlation spectroscopies such as HMBC and HMQC were not applicable owing to the presence of contiguous quaternary carbon atoms.

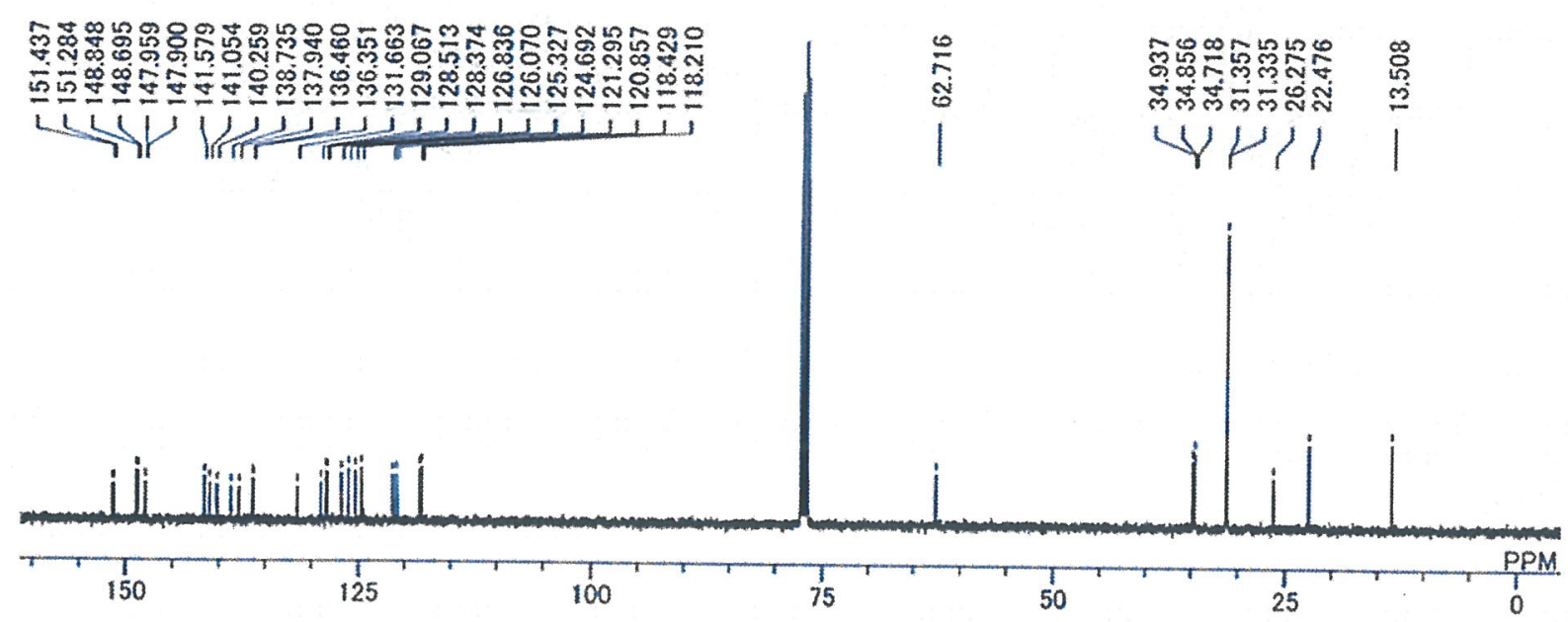

Figure 2. ${ }^{13} \mathrm{C}$ NMR spectrum of $\mathbf{1 4 b}$. 
The reaction of 1a under similar conditions afforded the corresponding products 14a, 15a, and 16a in $13,1.3$, and $1.0 \%$ yields, respectively. In addition, oxidative dimer 17 was isolated in $7.3 \%$ yield. The NMR spectra of 17 indicate that it has an unsymmetric structure contrary to 14a. The much lower yields of the products than those in the case of $\mathbf{1 b}$ may be due to facile intermolecular reactions because of the absence of $t$-butyl groups that would suppress such processes.

\subsubsection{Crystal structures of dimeric products}

The structures of the dimers $14 a$ and 17 were determined by X-ray crystallographic analysis for the crystals obtained by recrystallization from a mixture of $\mathrm{CHCl}_{3} / \mathrm{MeCN}$ and $\mathrm{CH}_{2} \mathrm{Cl}_{2} / \mathrm{MeCN}$, respectively. ${ }^{14}$ The structure of $\mathbf{1 4 a}$ shows that it possesses two indeno[2,1-a]fluorene frameworks which are connected with a single and a double bonds at the respective five-membered rings to form an eight-membered ring in the center (Figure 3). The indenofluorene units are facing but twisted to each other due to steric repulsion between the closely located benzene rings. The two $n$-butyl groups stretch up and down from the molecular backbone. It should also be pointed out that it contains two biphenylene units at the long axis ends and a 9,9'-bifluorenylidene substructure in the center.
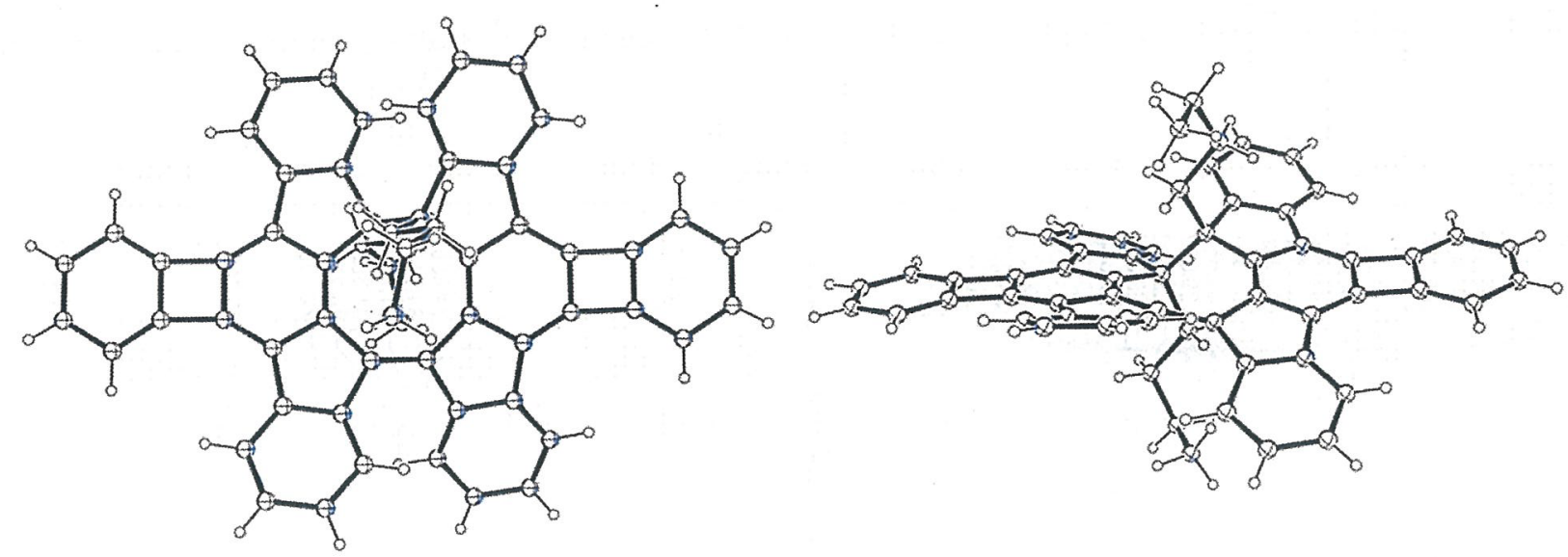

Figure 3. Top and side views of ORTEP drawings of 14a. Displacement ellipsoids are drawn at 30\% probability level.

The crystal structure of $\mathbf{1 7}$ reveals that it also consists of two indeno[2,1-a]fluorene frameworks which are connected with a single and a double bonds (Figure 4). However, here the single bond is 
formed between a five-membered ring of one of the indenofluorene unit and a benzene ring of the counterpart, though the double bond is formed between two five-membered rings similar to 14a. The two indenofluorene units orient in an opposite direction and are offset to each other to form a seven-membered ring in the center. The two $n$-butyl groups are located in the same face of the molecular backbone which is bent in an "L" shape.
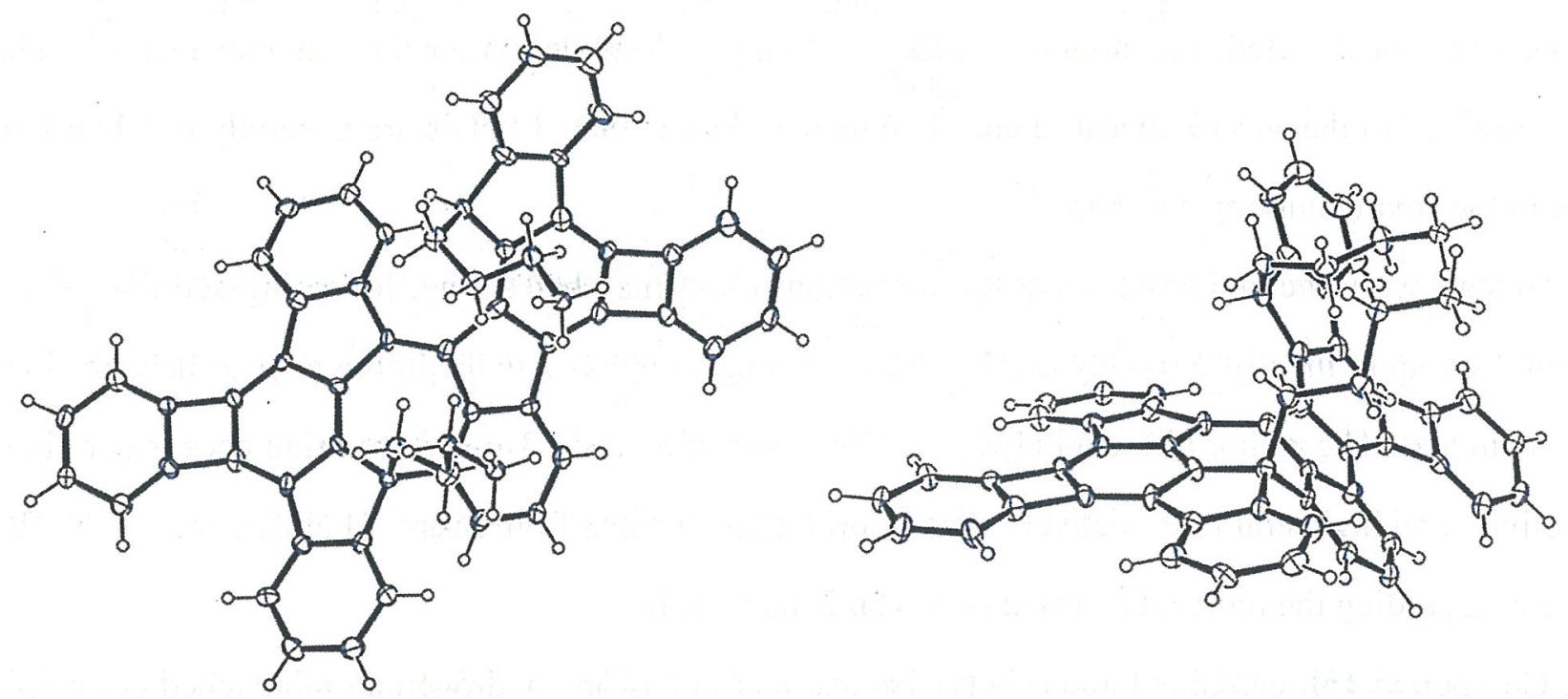

Figure 4. Top and side views of ORTEP drawings of 17. Displacement ellipsoids are drawn at the $30 \%$ probability level. Solvent molecules are omitted for clarity.

\subsubsection{Structure Elucidation of $\mathbf{1 5 b}$ by ${ }^{1} \mathrm{H} \mathrm{NMR},{ }^{13} \mathrm{C} \mathrm{NMR}, \mathrm{HMQC}$, and $\mathrm{HMBC}$ spectra}

For the structures of $\mathbf{1 5 a}, \mathbf{b}$ and $\mathbf{1 6} \mathbf{a}, \mathbf{b}$, the mass, ${ }^{1} \mathrm{H}$ NMR, and ${ }^{13} \mathrm{C}$ NMR spectra indicate that 15a,b contain three $n$-butyl groups and one hydrogen atom and therefore is two-electron oxidized from 1a,b, whereas 16a,b possess two $n$-butyl groups and four hydrogen atoms and are two-electron reduced. However, because crystals suitable for X-ray analysis were not obtained despite intensive attempts including derivatization to crystalline materials, the structure of $\mathbf{1 5 b}$ and $\mathbf{1 6} \mathbf{b}$ were elucidated on the basis of correlation NMR spectra such as HMQC and HMBC using the $t$-butyl group as one of the clue of correlations. ${ }^{14}$

For the elucidation of the structure, as a first step, all possible structures were listed based on the information obtained from mass, ${ }^{1} \mathrm{H}$ NMR, and ${ }^{13} \mathrm{C}$ NMR spectra. Next, I extracted some criteria regarding the molecular structure from the correlation spectra to eliminate the structures which did 
not agree with the criteria. As a result, the author assigned the structure of $\mathbf{1 5 b}$ to the candidate that agreed with all criteria.

As to the correlation spectra, HMBC spectrum detects correlations between hydrogen and carbon atoms over long ranges of 2 and 3 bonds, whereas HMQC spectrum detects correlations between hydrogen and carbon atoms which are separated by one bond. In HMBC spectrum, though correlations over 2 bonds are generally observed, correlations over long range of 3 bonds are sometimes not detected. The author consider that only the correlations within the range of 3 bonds are observed in the spectra, because correlations over longer than 3 bonds are generally not detected due to the small coupling constants. ${ }^{15}$

To start with, the author assumed the formation of a 5-membered ring, following addition of an $n$-butyl group to the diyne moiety of $\mathbf{1 b}$, took place to give anion $\mathbf{7}$ in the initial step, as described in the main text. The author also excluded a 1,2-diene structure and a 3-membered ring because of high reactivity and high strain, respectively. The information obtained from mass, ${ }^{1} \mathrm{H} N \mathrm{NR}$, and ${ }^{13} \mathrm{C}$ NMR spectra regarding the molecular structure of $\mathbf{1 5 b}$ is listed below:

1. Compound $\mathbf{1 5 b}$ contains three $n$-butyl groups. It also has one hydrogen atom attached to an $\mathrm{sp}^{3}$ carbon.

2. The ${ }^{13} \mathrm{C}$ NMR spectrum indicate that the molecular backbone of $\mathbf{1 5 b}$, excluding the $n$-butyl and $t$-butyl groups, consists of 11 tertiary $\mathrm{sp}^{2}, 13$ quaternary $\mathrm{sp}^{2}$, and 2 quaternary $\mathrm{sp}^{3}$ carbon atoms, implying that the backbone adopts tribenzo-fused tetracyclic structure generated by the formation of three $\mathrm{C}-\mathrm{C}$ bonds across the 14-membered ring.

3. The ${ }^{1} \mathrm{H}$ NMR spectrum shows a vinyl proton signal at $\delta 6.81 \mathrm{ppm}$.

4. On the basis of the number of $n$-butyl groups (i.e. three) and quaternary $\mathrm{sp}^{3}$ carbon atoms (i.e. two), it is assumed that one $n$-butyl group is attached to a quaternary $\mathrm{sp}^{3}$ carbon atom, whereas both of the remaining two $n$-butyl groups are attached to the other quaternary $\mathrm{sp}^{3}$ carbon atom.

On the basis of the assumptions and information, 14 possible structures are listed $\mathbf{A 1 - A 1 4}$ shown in Scheme 3: 

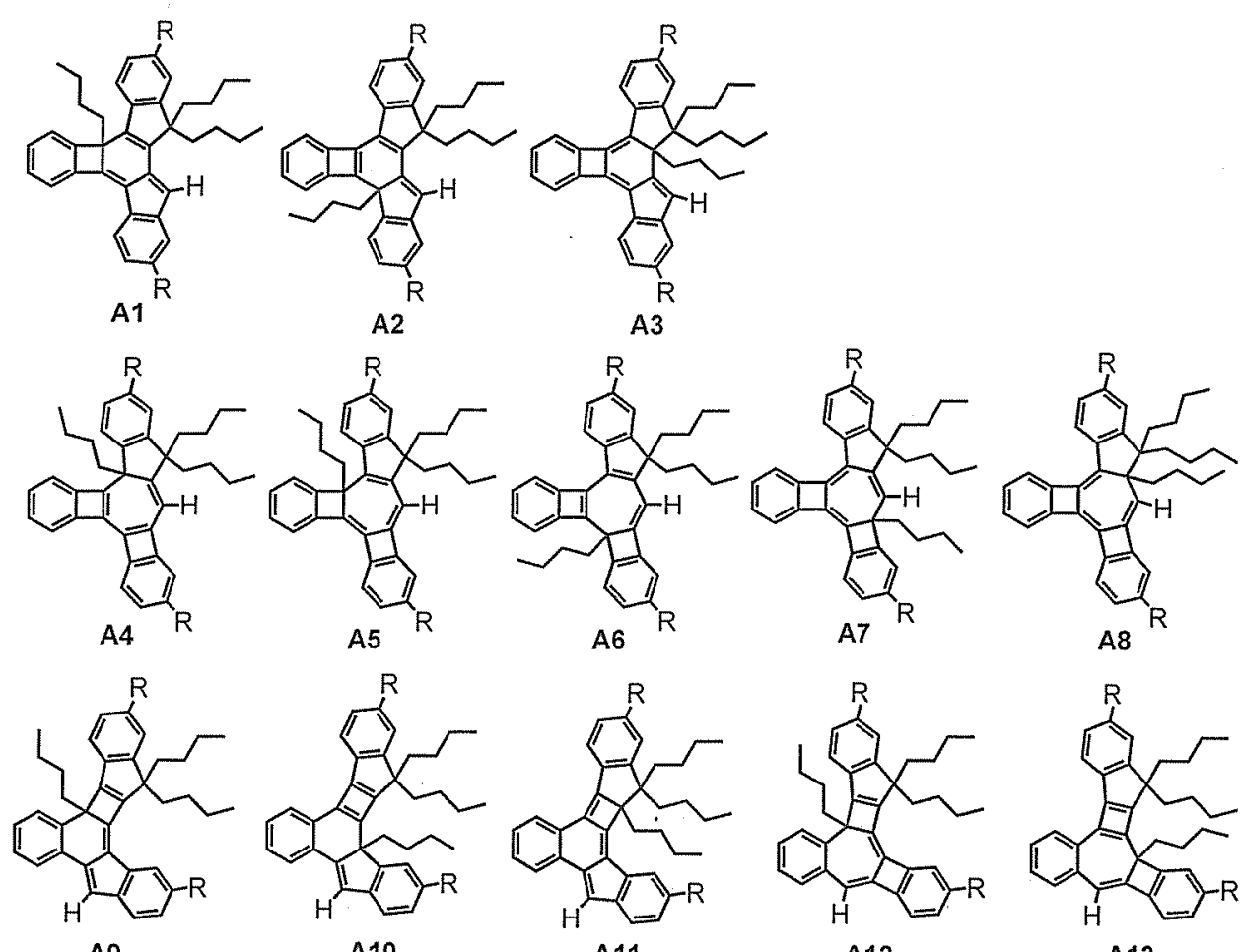

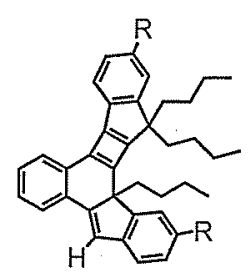

A10

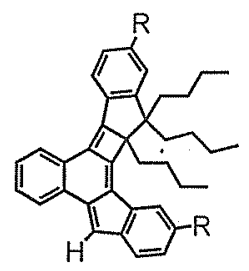

A11

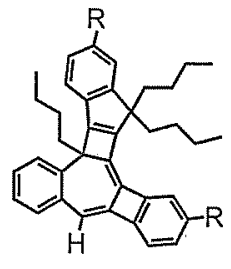

A12

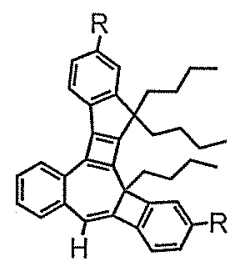

A13

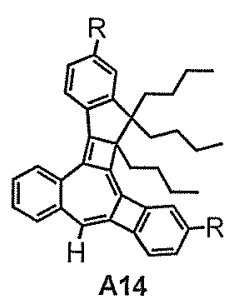

Scheme 3. Possible structures for $15 \mathrm{~b}$. $(\mathrm{R}=t$-butyl)

The three signals denoted as $\mathrm{C} 1-\mathrm{C} 3$ at around $\delta 40 \mathrm{ppm}$ in the ${ }^{13} \mathrm{C}$ NMR spectrum can be assigned to the methylene carbon atoms, which are adjacent to quaternary $\mathrm{sp}^{3}$ carbon atoms, of the three $n$-butyl groups. From the HMQC spectrum, the two neighboring signals $\mathrm{C} 1$ and $\mathrm{C} 2$ at $39 \mathrm{ppm}$ shows correlation with a pair of multiplets $\left(\mathrm{H}_{\mathrm{b}}\right)$ that appear at $\delta 1.6-2.0 \mathrm{ppm}$, i.e. those at the highest field and the second lowest field, and the signal C3 at $43 \mathrm{ppm}$ shows correlation with a pair of multiplets at the lowest and the second highest fields of the same multiplet signals for $\mathrm{H}_{\mathrm{b}}$ (Figure 5 , red-dotted line).

Additionally, two quaternary $\mathrm{sp}^{3}$ carbons denoted as $\mathrm{C} 4$ and $\mathrm{C} 5$ at around 57 and $59 \mathrm{ppm}$, respectively, shows correlations with the multiplet signals $\mathrm{H}_{\mathrm{b}}$ (Figure 6, red-dotted line), indicating that two $n$-butyl groups are attached to one quaternary carbon $\mathrm{C} 4$ and the other $n$-butyl group is attached to the other quaternary carbon $\mathrm{C} 5$. By combining the above information, it is reasonable to assume that the two methylene carbons $\mathrm{C} 1$ and $\mathrm{C} 2$ are located adjacent to the quaternary $\mathrm{sp}^{3}$ carbon $\mathrm{C} 4$, and the other methylene carbon $\mathrm{C} 3$ is located adjacent to the quaternary $\mathrm{sp}^{3}$ carbon $\mathrm{C} 5$.

The criterion 1 is the correlation between vinyl hydrogen $H_{a}$ and methylene carbon $C 3$, and 
quaternary $\mathrm{sp}^{3}$ carbon $\mathrm{C} 5$ : In the HMBC spectrum, the vinyl hydrogen denoted as $\mathrm{H}_{\mathrm{a}}$ which resonates at $\delta 6.81 \mathrm{ppm}$ shows correlations with the methylene carbon $\mathrm{C} 3$ of the $n$-butyl group and the quaternary $\mathrm{sp}^{3}$ carbon $\mathrm{C} 5$ (Figure 6, blue-dotted lines), indicating that the corresponding vinyl carbon is located adjacent to $\mathrm{C} 5$. For instance, whereas $\mathbf{A} 7$ is consistent with this criterion because the vinyl hydrogen of $\mathbf{A} 7$ is located within 2-bond range from $\mathrm{C} 5, \mathbf{A} \mathbf{1}$ in not because the vinyl hydrogen of A1 is located apart from C5 out of a 4-bond distance (Scheme 4). Judging from whether the structure is consistent with this criterion or not, the author assigned " $\mathrm{Y}$ " or " $\mathrm{N}$ ", respectively, as shown in Table 1, leaving only $\mathbf{A} 7$ and $\mathbf{A} \mathbf{8}$ for the candidates for $\mathbf{1 5 b}$.
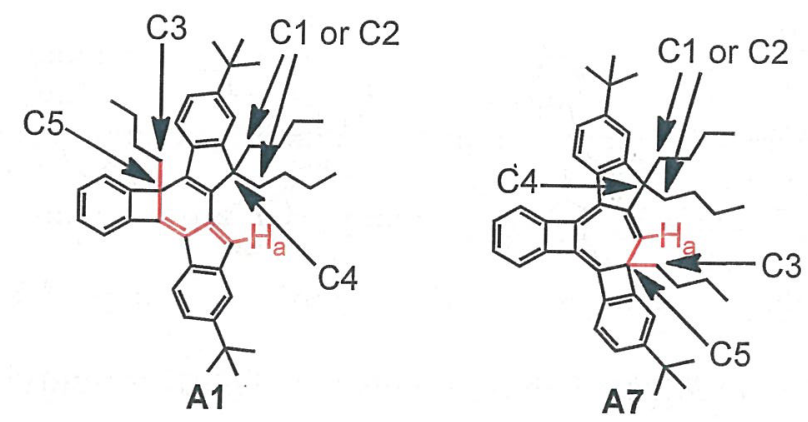

Scheme 4.

Table 1.

\begin{tabular}{ccccccccccccccc}
\hline Criterion & A1 & A2 & A3 & A4 & A5 & A6 & A7 & A8 & A9 & A10 & A11 & A12 & A13 & A14 \\
\hline 1 & N & N & N & N & N & N & Y & Y & N & N & N & N & N & N \\
2 & & & & & & & Y & N & & & & & & \\
\hline
\end{tabular}

The Criterion 2 is the correlation between quaternary $\mathrm{sp}^{3}$ carbon atoms $\mathrm{C} 4, \mathrm{C} 5$ and aromatic hydrogens: Both the two quaternary $\mathrm{sp}^{3}$ carbons $\mathrm{C} 4$ and $\mathrm{C} 5$ showed correlations with aromatic hydrogens (Figure 6, green-dotted lines), though the assignments for these hydrogens are not possible. A7 is consistent with this criterion, because the quaternary carbons C4 and C5 are both located within a 3-bond range from the corresponding aromatic hydrogen indicated in red in Scheme 5. On the other hand, A8 is not consistent, because the tertiary carbon C5 is not located within a 3-bond distance from any of the aromatic hydrogens (Scheme 5).

Consequently, I concluded that the molecular structure of $15 \mathrm{~b}$ was A7. 

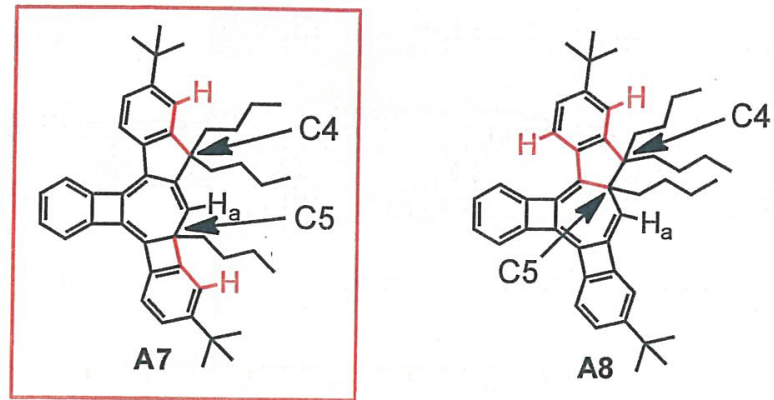

Scheme 5.

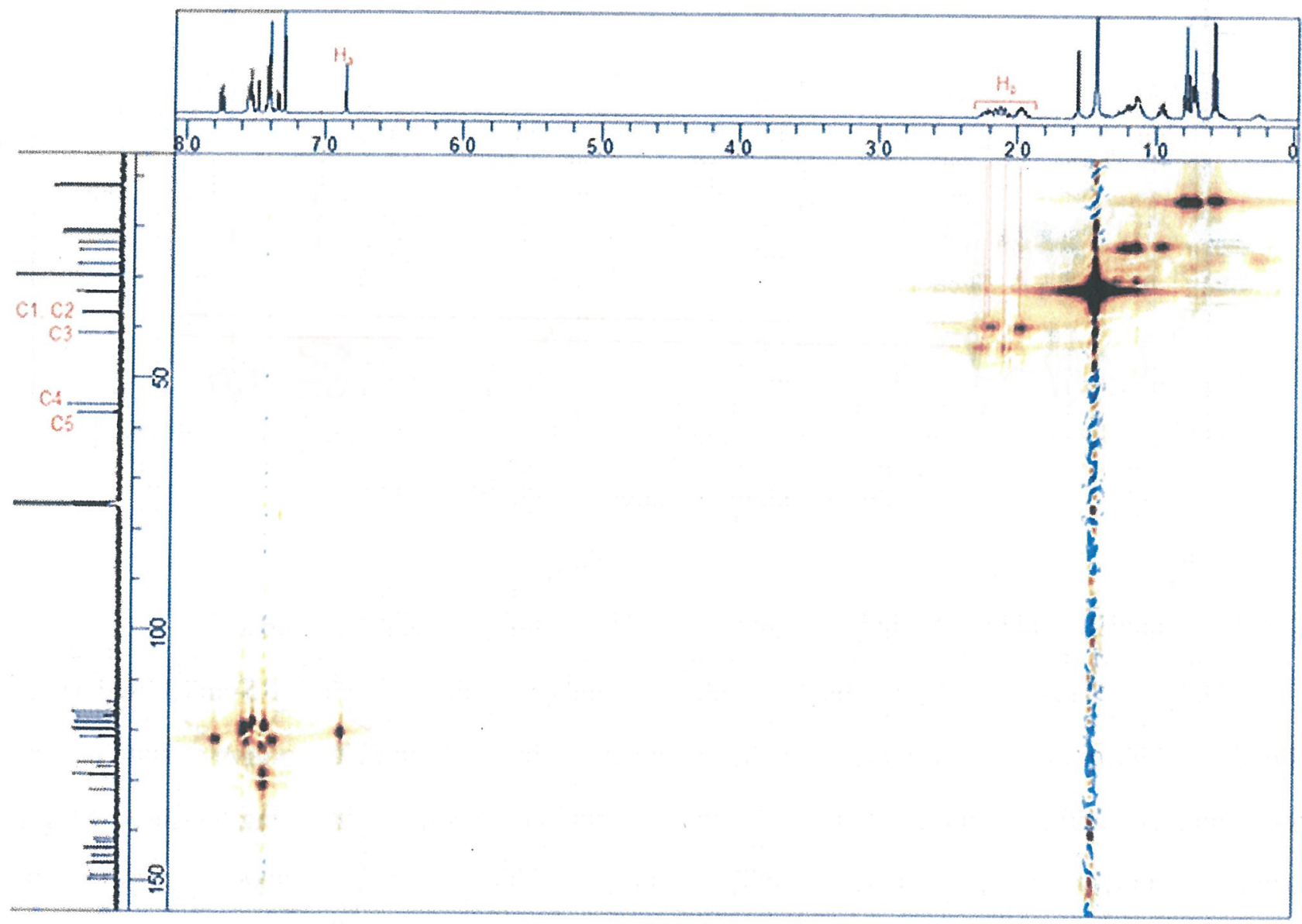

Figure 5. HMQC spectrum of $\mathbf{1 5 b}$. 


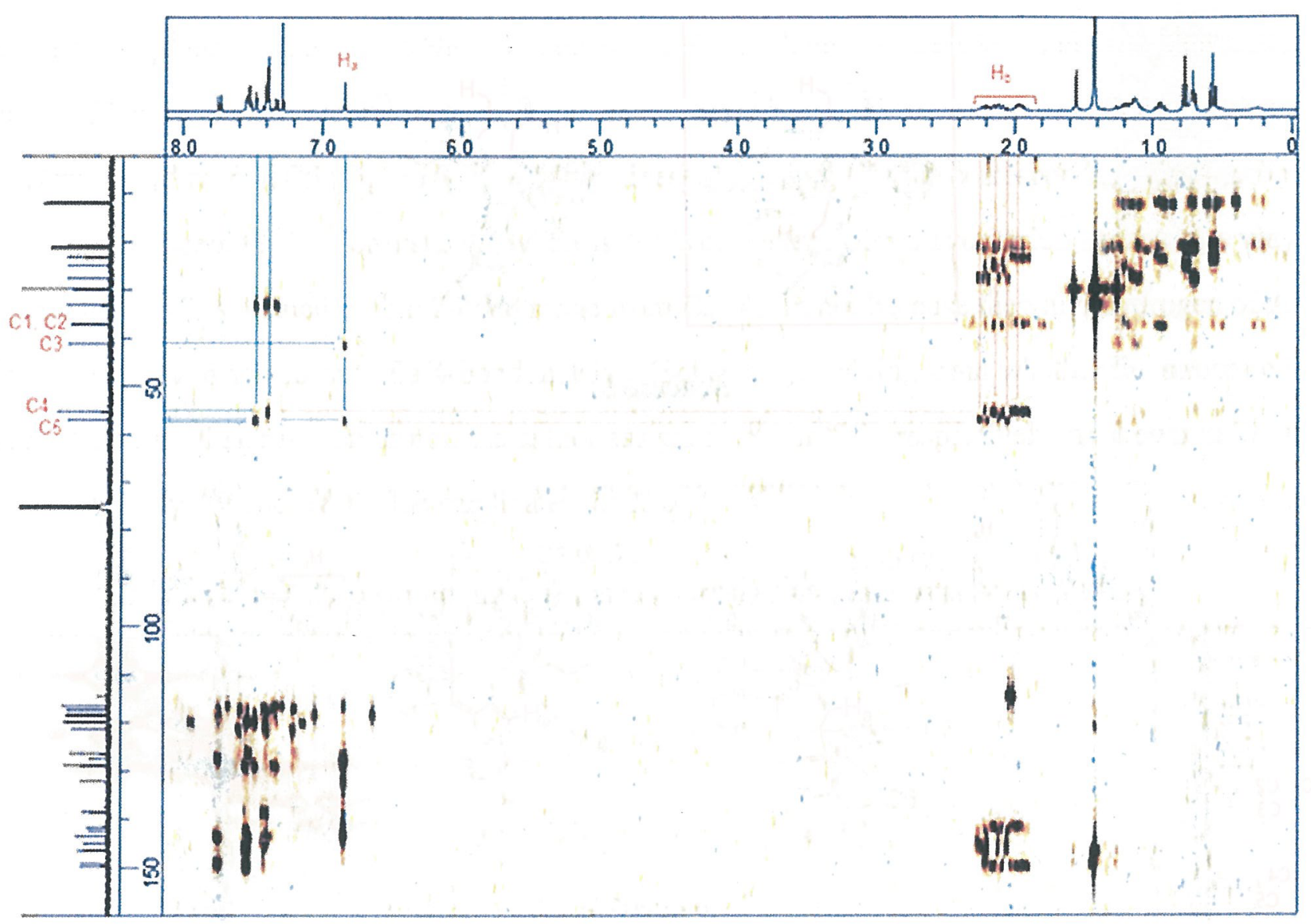

Figure 6. HMBC spectrum of $\mathbf{1 5 b}$.

\subsubsection{Structure Elucidation of $\mathbf{1 6 b}$ by ${ }^{1} \mathrm{H} N M R,{ }^{13} \mathrm{C}$ NMR, HMQC, and HMBC spectra}

Similar to the assignment of $\mathbf{1 5 b}$, the author assumed the formation of a 5 -membered ring, following addition of an $n$-butyl group to the diyne moiety of $\mathbf{1 b}$, took place to give anion $\mathbf{7}$ in the initial step. The author also excluded a 1,2-diene structure and a 3-membered ring because of high reactivity and high strain, respectively. The information obtained from mass, ${ }^{1} \mathrm{H} N M R$, and ${ }^{13} \mathrm{C} N M R$ spectra regarding the molecular structure of $\mathbf{1 6} \mathbf{b}$ is listed below:

1. Compound $\mathbf{1 6 b}$ contains two $n$-butyl groups and four hydrogen atoms.

2. The ${ }^{13} \mathrm{C}$ NMR spectrum shows that the molecular backbone of $\mathbf{1 6} \mathbf{b}$, excluding the $n$-butyl and $t$-butyl groups, consists of 11 tertiary $\mathrm{sp}^{2}, 13$ quaternary $\mathrm{sp}^{2}, 1$ tertiary $\mathrm{sp}^{3}$ and 2 secondary $\mathrm{sp}^{3}$ carbon atoms, indicating that the backbone adopts a tribenzo-fused tricyclic structure generated by the formation of two C-C bonds across the 14-membered ring.

3. The ${ }^{1} \mathrm{H}$ NMR spectrum shows a vinyl proton signal for $\mathrm{H}_{\mathrm{a}}$ at $\delta 6.44 \mathrm{ppm}$, two doublet signals for 
$\mathrm{H}_{\mathrm{b}}$ and $\mathrm{H}_{\mathrm{d}}$ at $\delta 3.99$ and $3.77 \mathrm{ppm}$, respectivrly, and a triplet signal for $\mathrm{H}_{\mathrm{c}}$ at $\delta 3.74 \mathrm{ppm}$. The two doublet signals for $\mathrm{H}_{\mathrm{b}}$ and $\mathrm{H}_{\mathrm{d}}$ show a geminal coupling with each other, indicating that these are methylene hydrogens bound to a ring carbon. The triplet signal for $\mathrm{H}_{\mathrm{c}}$ shows a relatively small coupling constant $(J=5.2 \mathrm{~Hz})$, indicating that this methine hydrogen couples with methylene hydrogens in an $n$-butyl group located adjacent to a ring carbon.

On the basis of the assumptions and information, 41 possible structures are listed B1-B41 shown in Scheme 6.
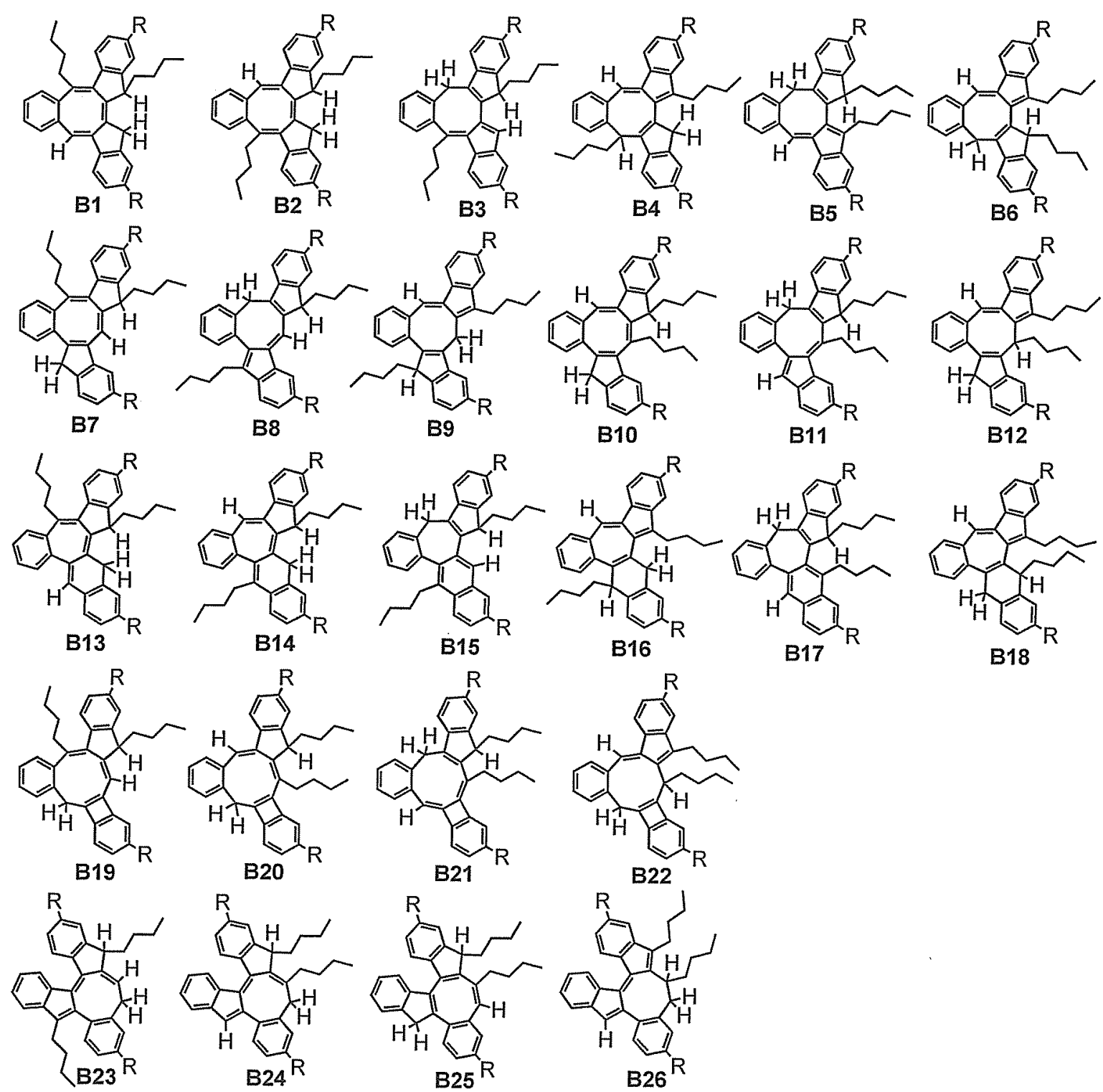

B17
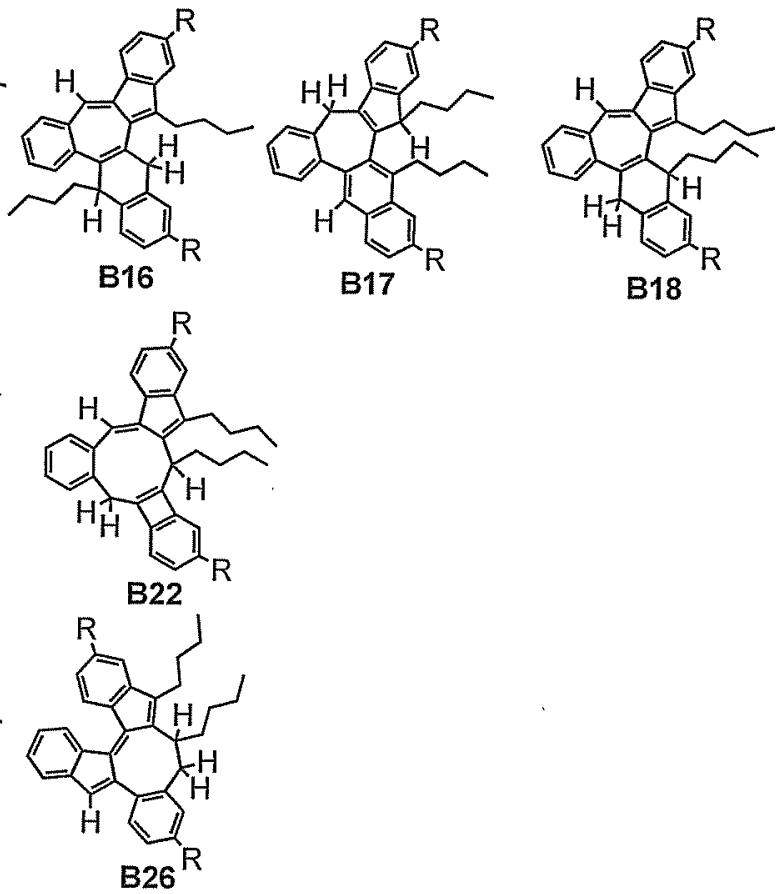

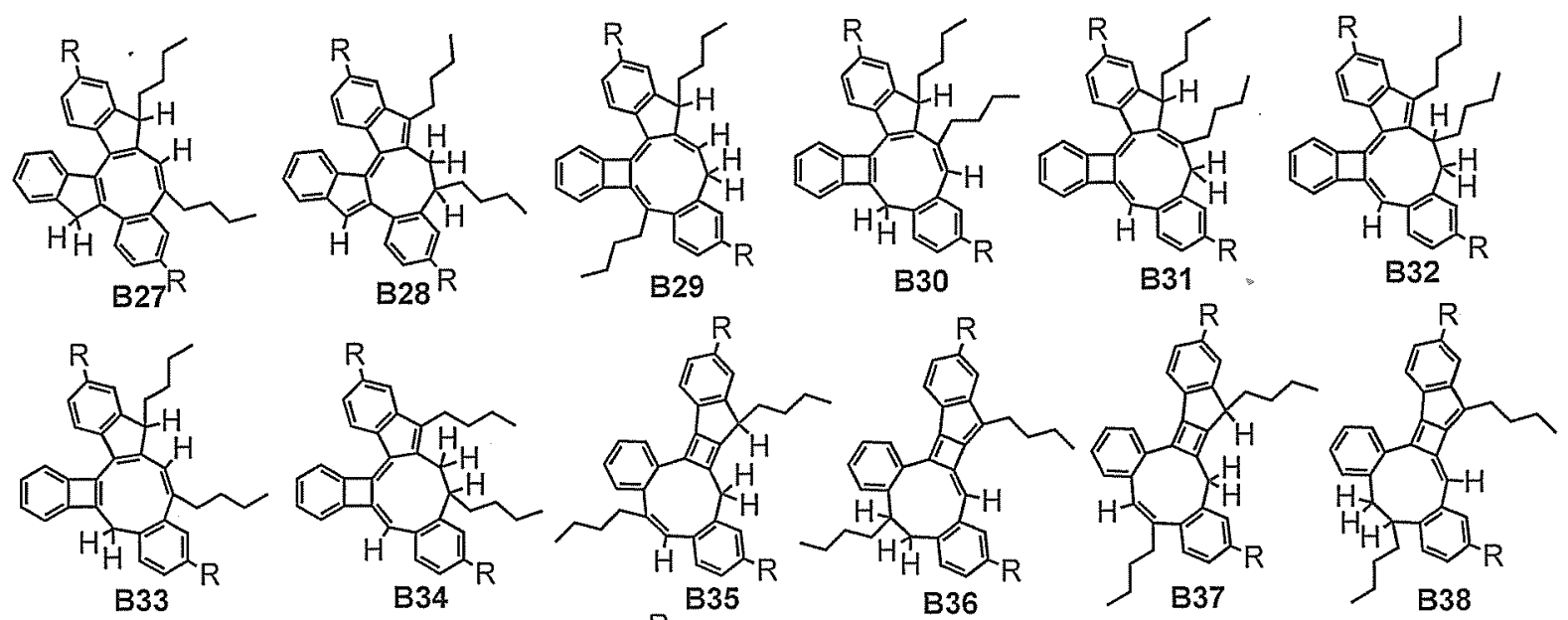

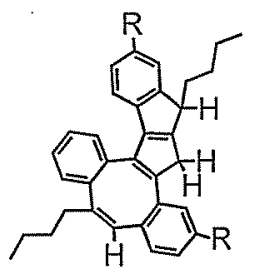

B39
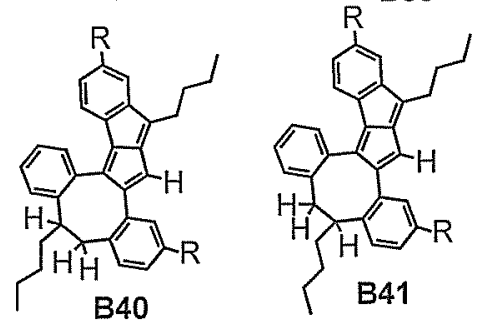

B37

$\mathrm{B} 38$

Scheme 6. Possible structures for $16 \mathrm{~b}(\mathrm{R}=t$-butyl $)$

First, the author assigned the methylene carbon atoms denoted as $\mathrm{C} 1-\mathrm{C} 3$ and the tertiary $\mathrm{sp}^{3}$ carbon atom denoted as C4. From the HMQC spectrum, since the two carbons $\mathrm{C} 1$ and $\mathrm{C} 2$ show correlations with the methylene hydrogens $\mathrm{H}_{\mathrm{f}}$ and $\mathrm{H}_{\mathrm{e}}$ (Figure 7, red-dotted lines), respectively, both carbons $\mathrm{C} 1$ and $\mathrm{C} 2$ are assigned to methylene carbons in the $n$-butyl group located adjacent to (a) ring carbon(s). The $\mathrm{sp}^{3}$ carbon $\mathrm{C} 3$ shows a correlation with the two hydrogens $\mathrm{H}_{\mathrm{b}}$ and $\mathrm{H}_{\mathrm{d}}$ which resonate at $\delta 3.8-4.0 \mathrm{ppm}$ (Figure 7, blue-dotted lines) with a geminal coupling, indicating that $\mathrm{C} 3$ is a secondary $\mathrm{sp}^{3}$ ring carbon atom. Similarly, the $\mathrm{sp}^{3}$ carbon $\mathrm{C} 4$ shows a correlation with the triplet proton signal for $\mathrm{H}_{\mathrm{c}}$ at $\delta 3.74 \mathrm{ppm}$ (Figure 7, green-dotted lines), indicating that $\mathrm{C} 4$ is a tertiary ring carbon atom.

In the HMBC spectrum, the triplet signal for $\mathrm{H}_{\mathrm{c}}$ at $3.74 \mathrm{ppm}$ shows a correlation with the methylene the carbon $\mathrm{C} 1$, indicating that $\mathrm{C} 1$ in an $n$-butyl group is attached to the tertiary $\mathrm{sp}^{3}$ carbon C4. As indicated from the possible structures in Scheme 6 , an $n$-butyl group is attached to an $\mathrm{sp}^{3}$ carbon atom and another $n$-butyl group is attached to an $\mathrm{sp}^{2}$ carbon atom. Therefore, the methylene carbon $\mathrm{C} 2$ should be attached to an $\mathrm{sp}^{2}$ ring carbon atom.

The criterion 1 is the correlation between vinyl hydrogen $\mathrm{Ha}$ and methylene carbon atom $\mathrm{C} 2$ : In 
the HMBC spectrum, the vinyl hydrogen $\mathrm{H}_{\mathrm{a}}$ shows a correlation with the methylene carbon $\mathrm{C} 2$ (Figure 8; blue-dotted lines). For instance, whereas B25 is consistent with this criterion because $\mathrm{H}_{\mathrm{a}}$ of B25 is located within a 3-bond range from C2, B1 is not consistent because the vinyl hydrogen of $\mathbf{B 1}$ is not located within a 3-bond distance from C2 (Scheme 7). All of B1-B22 are not consistent with this criterion. Judging from whether the structure is consistent with this criterion or not, the author assigned "Y" or "N", respectively, as shown in Table 2, leaving B25, B26, B30, B33, B35, $\mathbf{B 3 7}$, and $\mathbf{B 3 9}$ for the candidates for $\mathbf{1 6 b}$.
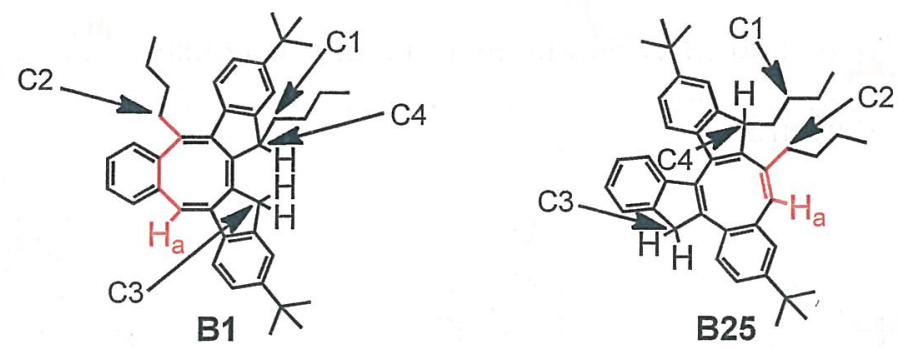

Scheme 7.

Table 2.

\begin{tabular}{ccccccccccc}
\hline Criterion & B23 & B24 & B25 & B26 & B27 & B28 & B29 & B30 & B31 & B32 \\
\hline 1 & $\mathrm{~N}$ & $\mathrm{~N}$ & $\mathrm{Y}$ & $\mathrm{N}$ & $\mathrm{Y}$ & $\mathrm{N}$ & $\mathrm{N}$ & $\mathrm{Y}$ & $\mathrm{N}$ & $\mathrm{N}$ \\
2 & & & $\mathrm{Y}$ & & $\mathrm{Y}$ & & & $\mathrm{N}$ & & \\
3 & & & $\mathrm{Y}$ & & $\mathrm{N}$ & & & & & \\
\hline
\end{tabular}

\begin{tabular}{cccccccccc}
\hline Criterion & B33 & B34 & B35 & B36 & B37 & B38 & B39 & B40 & B41 \\
\hline 1 & $\mathrm{Y}$ & $\mathrm{N}$ & $\mathrm{Y}$ & $\mathrm{N}$ & $\mathrm{Y}$ & $\mathrm{N}$ & $\mathrm{Y}$ & $\mathrm{N}$ & $\mathrm{N}$ \\
2 & $\mathrm{~N}$ & & $\mathrm{~N}$ & & $\mathrm{~N}$ & & $\mathrm{~N}$ & & \\
3 & & & & & & & & & \\
\hline
\end{tabular}

The criterion 2 is the correlation between secondary $\mathrm{sp}^{3}$ carbon atom $\mathrm{C} 3$ and aromatic hydrogens: In the HMBC spectrum, the secondary $\mathrm{sp}^{3}$ carbon $\mathrm{C} 3$ shows a correlation with the aromatic hydrogen $\mathrm{H}_{\mathrm{g}}$ (Figure 8, green-dotted lines). In addition, the aromatic hydrogen $\mathrm{H}_{\mathrm{g}}$ is not located adjacent to $t$-butyl groups, because the two tertiary $\mathrm{sp}^{3}$ carbons $\mathrm{C} 5$ and C6 show correlations with other four aromatic hydrogens (Figure 8, black-dotted lines) which are attached to the neighboring carbons of 
the $t$-butyl groups (indicated as $\mathrm{H}^{\prime}$ in Scheme 8). Furthermore, the signal of $\mathrm{H}_{\mathrm{g}}$ in the ${ }^{1} \mathrm{H} \mathrm{NMR}$ spectrum shows a doublet of doublet coupling pattern $(J=8.0,2.0 \mathrm{~Hz})$ due to $o$ - and $m$-couplings.

For instance, the aromatic hydrogen of $\mathbf{B 3 5}$ highlighted by red circle in Scheme 8, which is within a 3-bond distance from the secondary $\mathrm{sp}^{3}$ carbon $\mathrm{C} 3$, coincides $\mathrm{H}^{\prime}$ which is attached to the adjacent of the $t$-butyl groups, excluding this possibility. B25 and B30 are consistent with this criterion, because the aromatic hydrogens highlighted by red circle, which are within a 3-bond distance from $\mathrm{C} 3$, are different from H'. However, B30 is excluded because the aromatic hydrogen highlighted by red circle would not show the $o$ - and $m$-coupling pattern. These considerations leave only candidates B25 and B29 (Table 2, Criterion 2).

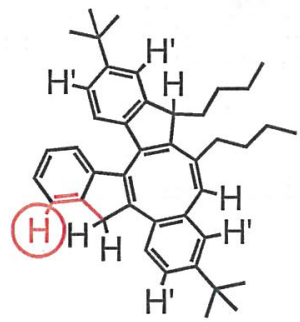

B25

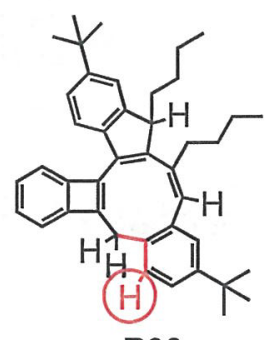

B30

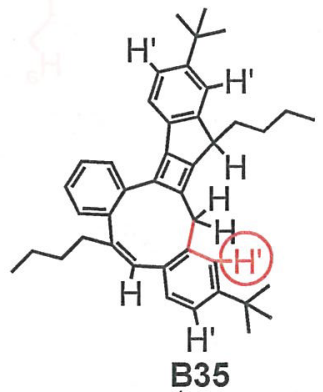

B35

\section{Scheme 8.}

The criterion 3 is the correlation between methylene hydrogens $H_{e}, H_{f}$ and quaternary $\mathrm{sp}^{2}$ carbon atoms: The two multiplet signals for $\mathrm{H}_{\mathrm{e}}$ at $\delta 1.6-1.9 \mathrm{ppm}$ and $\mathrm{H}_{\mathrm{f}}$ at $\delta 2.2-2.5 \mathrm{ppm}$, which correspond to the methylene hydrogens in the $n$-butyl groups located adjacent to the ring carbons, show correlations (Figure 8, purple-dotted lines) with the quaternary $\mathrm{sp}^{2}$ carbon atom resonating at $\delta 151$ ppm (highlighted by green circle, Figure 8). B27 is not consistent with this criterion, because there is no $\mathrm{sp}^{2}$ carbon which would show correlations with the methylene hydrogens of the both $n$-butyl groups. On the other hand, B25 is consistent with this criterion, because the $\mathrm{sp}^{2}$ carbon atom (highlighted by green color) should show correlations with the methylene hydrogens of the both n-butyl groups.

As a result, the author concluded that the molecular structure of $\mathbf{1 6 b}$ was $\mathbf{B 2 5}$. 

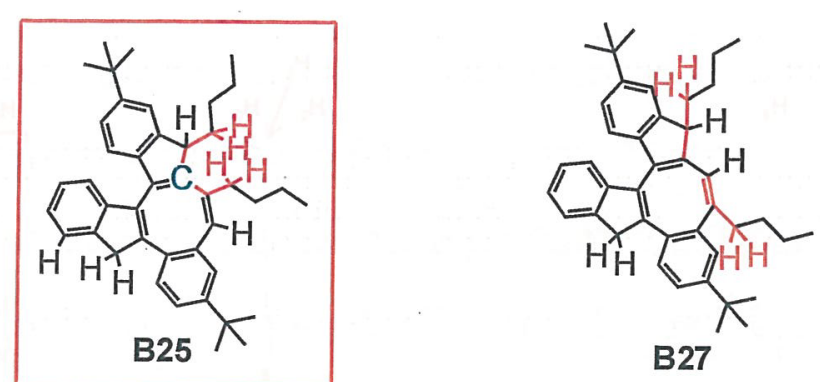

Scheme 9.

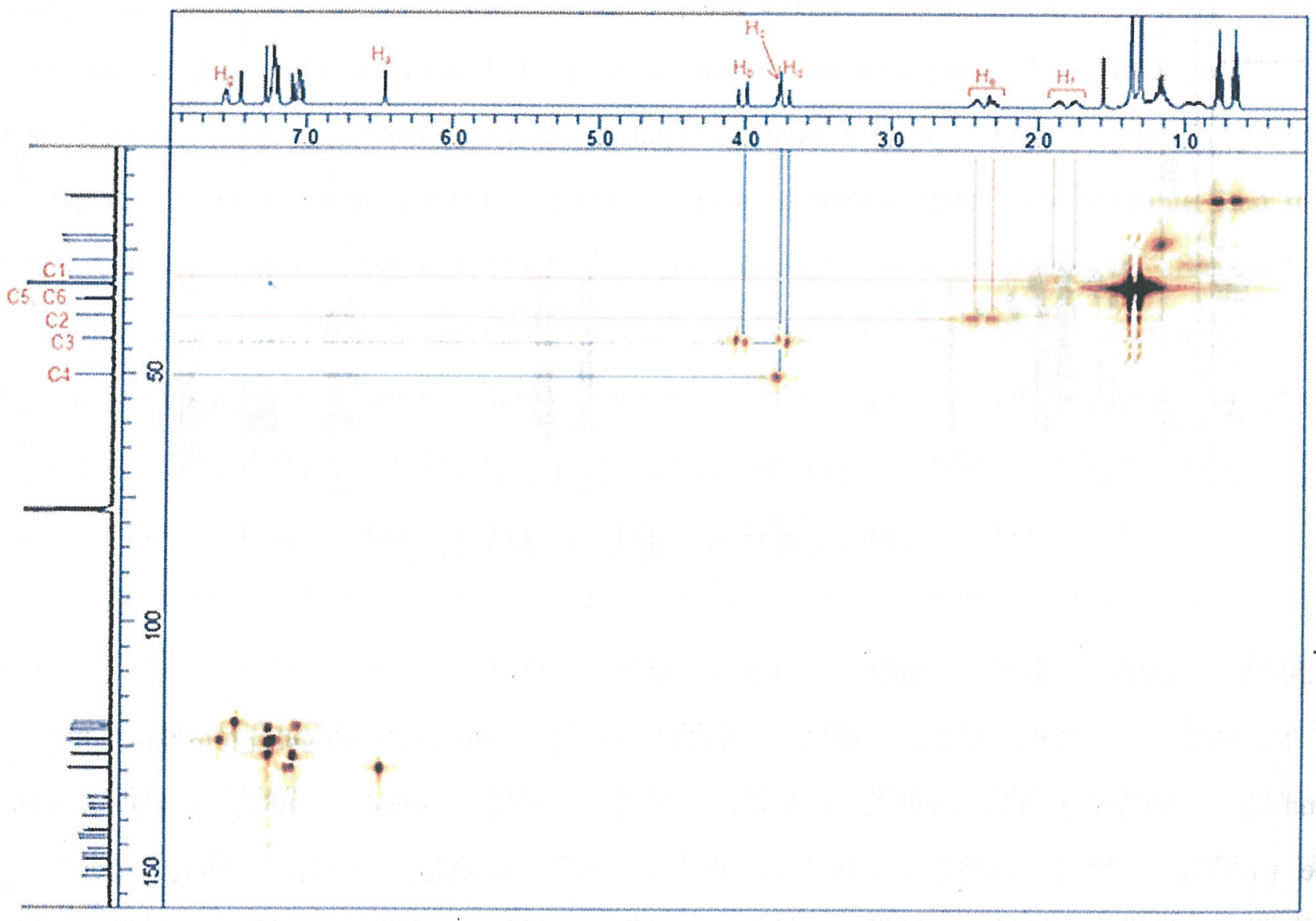

Figure 7. HMQC spectrum of $\mathbf{1 6 b}$.

-69 - 


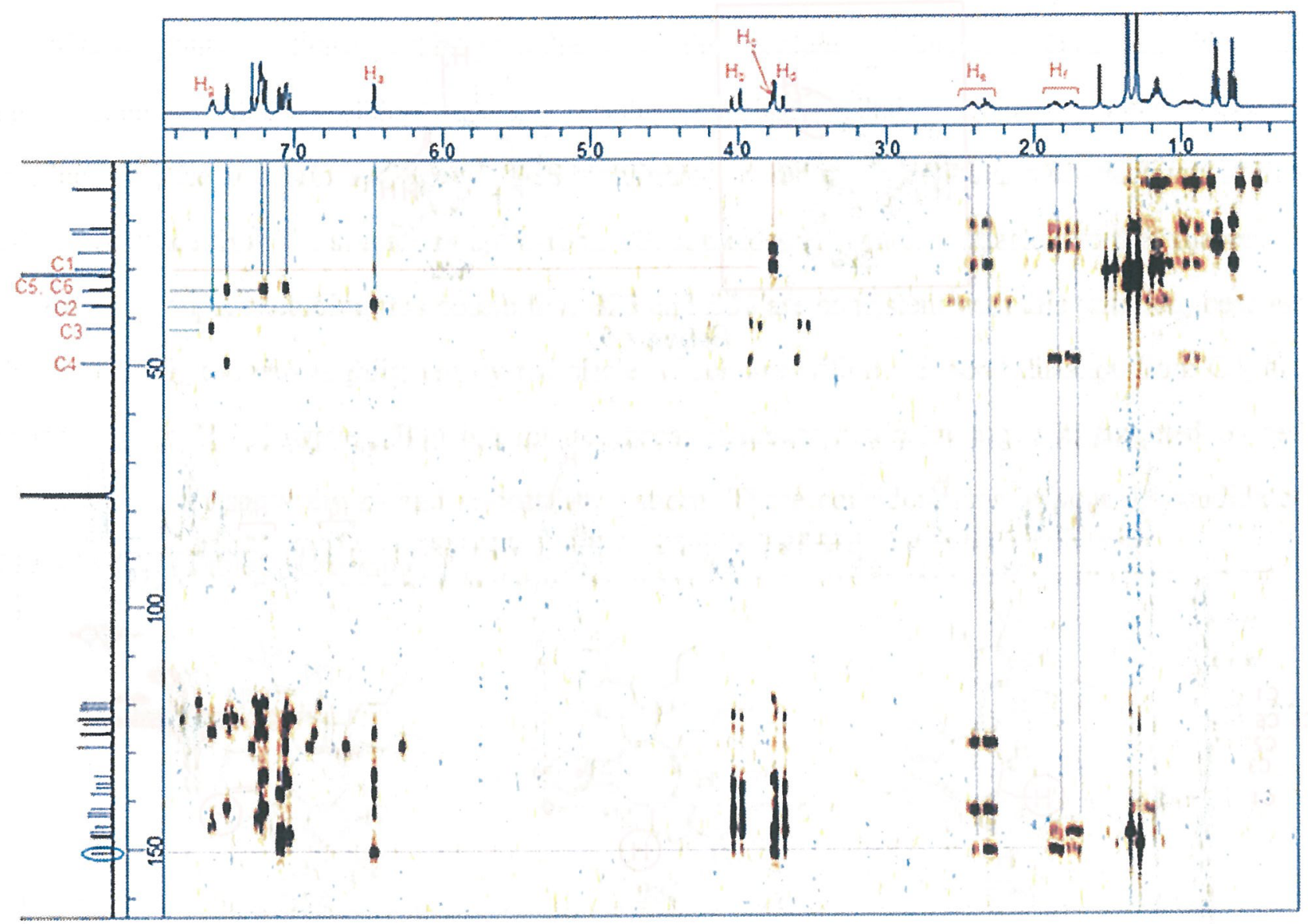

Figure 8. HMBC spectrum of $16 \mathrm{~b}$.

\subsection{Theoretical Investigation of Dimer Formations}

The structures of $\mathbf{1 5 a}$ and $\mathbf{1 6 a}$ were determined by the similarities of their spectra to those of $\mathbf{1 5 b}$ and $\mathbf{1 6 b}$, respectively. As a result, the author was able to propose the structures of $\mathbf{1 5 a}, \mathbf{b}$ and $\mathbf{1 6 a}, \mathbf{b}$ to be tribenzo-fused tetracyclic 4-4-5-7 and tricyclic 5-5-8 systems formed by three and two transannular bond formations, respectively (Scheme 10).

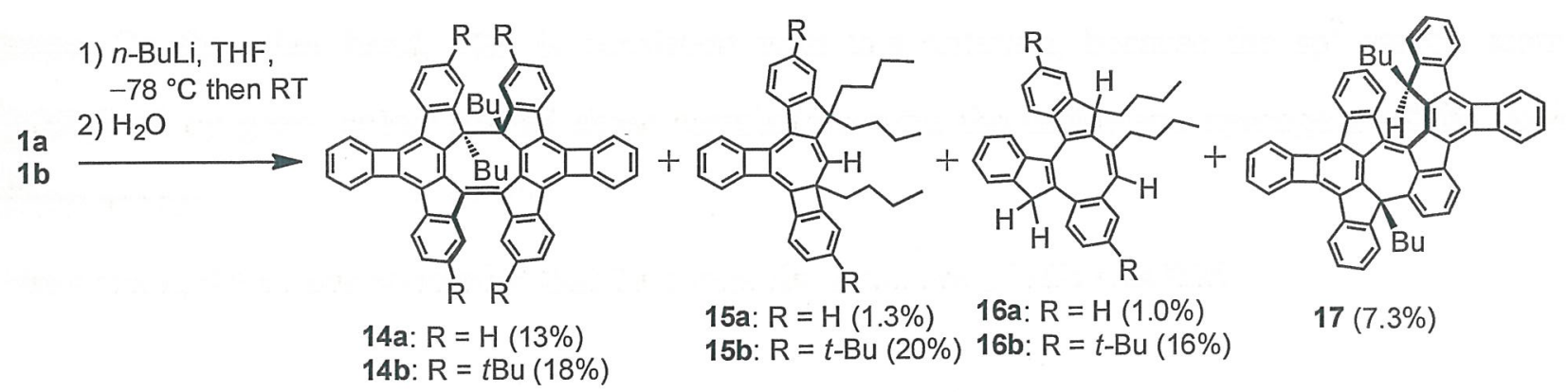

Scheme 10. Tandem transannular cyclization of [14]DBAs $\mathbf{1 a}$ and $\mathbf{1 b}$ induced by n-BuLi. 
The formation of the three types products 14-16 are interpreted in terms of the pathways shown in Scheme 1. The relative energies of the organolithium intermediates estimated by DFT calculations at the B3LYP/6-31G* level of theory are also shown in paretheses. The calculated energies suggest that the cyclization pathway leading to 7 is energetically favored though both of the second steps (7-8 and 7-9) are endergonic. This is consistent with that fact that 7 was intercepted as $\mathbf{1 3 a}, \mathbf{b}$ when the reaction was conducted at low temperature. Although the formation of 5-8 rings to give $\mathbf{8}$ is energetically more favored than that of 4-9 rings to give 9, considerable amount of products via the latter intermediate were obtained. ${ }^{16}$ Addition of another $n$-butyl group to 8 accompanied by two-electron reduction gives $\mathbf{1 6} \mathbf{a}, \mathbf{b}$ after quenching with water. In the third bond formation step from 9, though the formation of 4-7 rings to give $\mathbf{1 0}$ is energetically much less favorable than the cyclization to $\mathbf{1 1}$, substantial amount of $\mathbf{1 5 a}, \mathbf{b}$ were obtained via intermediate $\mathbf{1 0}$, after further addition of two $n$-butyl groups accompanied by two-electron oxidation. ${ }^{16}$ On the other hand, when 5-6 rings are formed to generate 11 , it undergoes dimerization to give 14 and 17 through a pathway discussed below. Multiple addition of nucleophiles as well as dimerization which proceed through redox processes are reported in a number of reactions of [60]fullerene with nucleophiles. ${ }^{17}$

A tentative mechanism for the oxidative cyclodimerization step is shown in Scheme 11. It consists of initial $\mathrm{C}-\mathrm{C}$ bond formation between intermediate 11 to give 18, rotation of the single bond to 19 , and the second bond formation to give 20 . Subsequent oxidation, either in-situ by the species present in the reaction mixture or by oxygen during workup, ${ }^{18}$ furnishes the observed major dimeric product $14 a, b$. On the other hand, $\mathrm{C}-\mathrm{C}$ bond formation in 18 at the proximate carbons followed by hydrogen transfer and oxidation give the minor dimer 17 via 19. To gain support from theoretical calculations, the activation energies for the above processes were estimated by using as-indacene as a model compound. $^{19}$

First, the author assumed that dilithio dianionic intermediate 21 is formed as an immediate precursor of main product $\mathbf{1 4 a}$ which is oxidized by air during workup or in-situ by other species present in the reaction mixture (Scheme 11). In addition to the stepwise bond formations to produce 21 also described in the main text, the author considered a concerted bond formation pathway shown in Scheme 11. To reduce the computational cost, as-indacenyllithium S1 was used as a model of 
benzocyclobtenoindeno[2,1-a]fluorenyllithium 11. Geometric optimizations and their vibration analyses were performed for all of the transition states and related molecules at the B3LYP/6-31G(d) level of theory using the Gaussian09 program. All transition states obtained were confirmed to have only one imaginary frequency. IRC calculations were performed to examine that TSs obtained connect reactants and products shown in Scheme 9, black bars and lines.

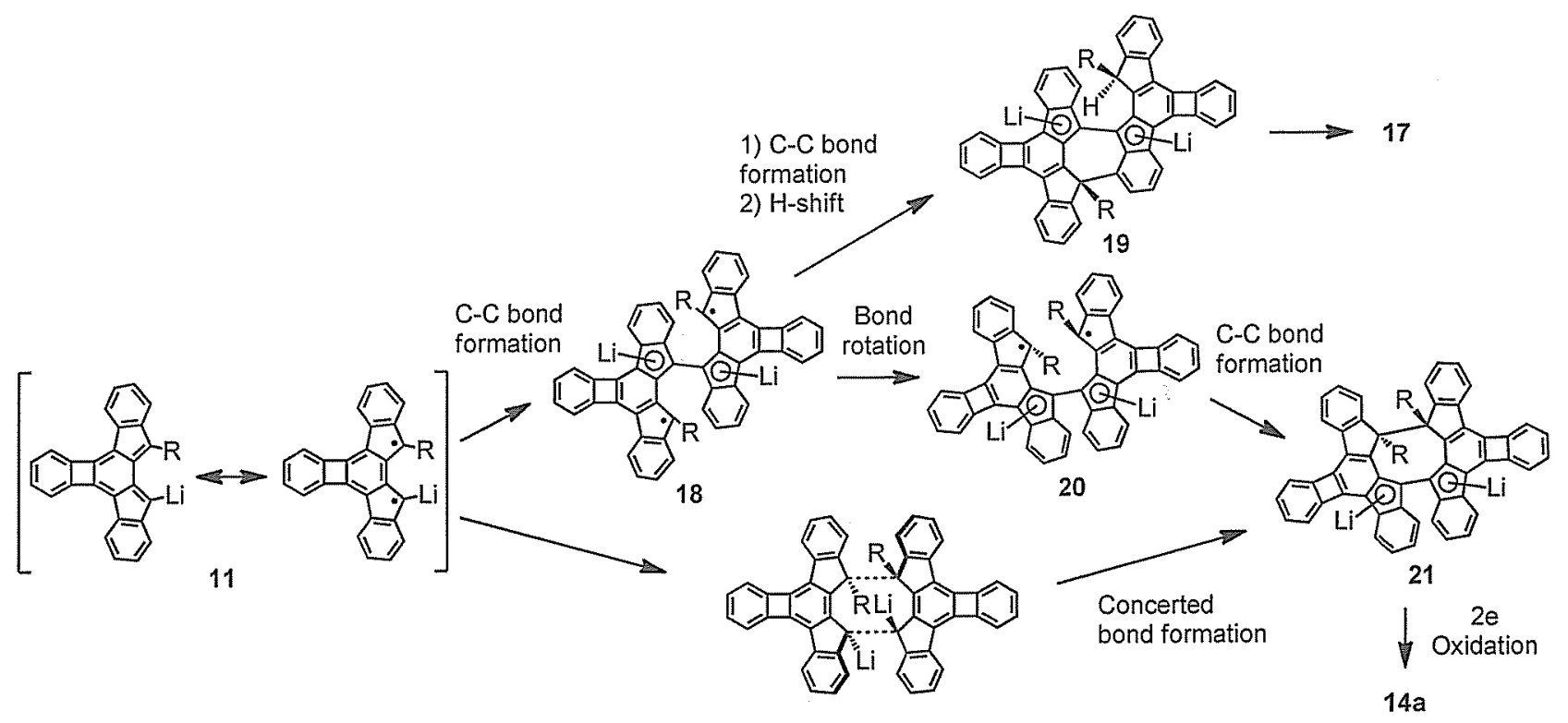

Scheme 11. A tentative reaction mechanism for the oxidative dimer formation.

Because the transition state search for dimerization of $\mathbf{S 1}$ via a concerted cycloaddition route was not successful, stepwise modes of $\mathrm{C}-\mathrm{C}$ bond formation were investigated. Although the initial bis(lithium cyclopentadienide) intermediate $\mathbf{S} 2$ was found to be substantially more stable than $\mathbf{S 1}$, the barrier for the bond formation $(49.2 \mathrm{kcal} / \mathrm{mol})$ was extremely high for a reaction to occur at room temperature. Subsequent rotation of the connecting single bond from anti-conformer $\mathbf{S} 2$ to syn-conformer $\$ 3$ takes place with a small barrier of ca. $7 \mathrm{kcal} / \mathrm{mol}$. The transition state for the final bond formation leading from $\mathbf{S 3}$ to $\mathbf{S 4}(18.9 \mathrm{kcal} / \mathrm{mol})$ is within a reasonable range for a reaction to take place near room temperature.

Inclusion of solvent (THF) by the SCRF method ${ }^{20}$ substantially reduced the energies of the transition states and intermediates (Figure 9, red bars and lines). For example, by single point calculation by using the CPCM model ${ }^{21}$ with the UAKS radius, ${ }^{22}$ the transition state energy from $\mathrm{S} 1$ 
to $\mathbf{S} 2$ was reduced by $10 \mathrm{kcal} / \mathrm{mol}$. However, the transition state energy is still too large for a room temperature reaction.

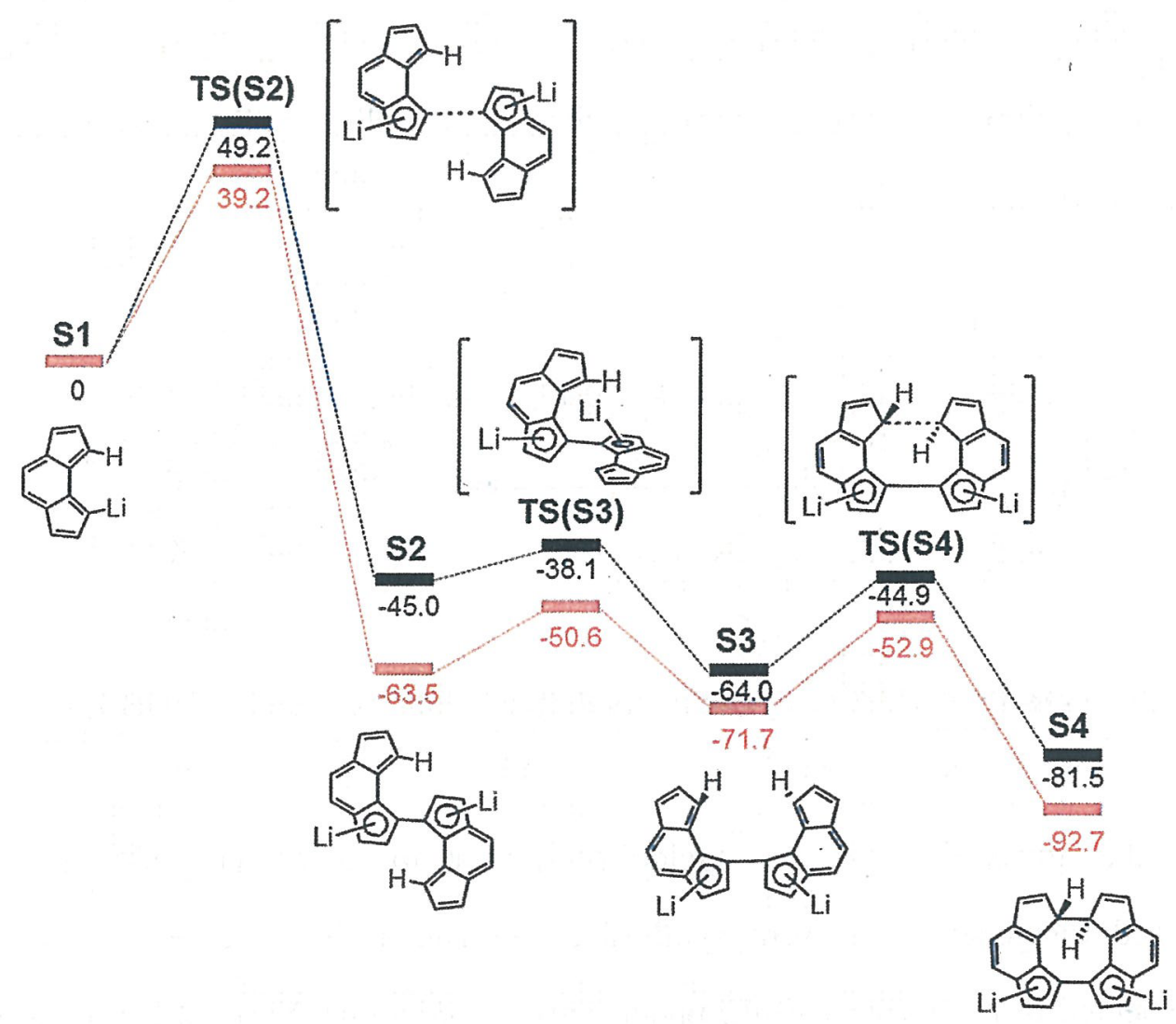

Figure 9. Relative energies $(\mathrm{kcal} / \mathrm{mol})$ of intermediates and transition states calculated by DFT method at the (R)B3LYP/6-31G* level of theory.

These results suggest that the electronic properties of $\mathbf{S 1}$ and the transition state to $\mathbf{S} \mathbf{2}$ may not be reasonably accounted for by the DFT calculations assuming closed-shell electronic configurations in view of the diradicaloid properties of as-indacene and indeno[2,1-a]fluorine. In this respect, the author estimated the singlet biradical character of an intermediate organolithium model 22 together with those of its substructure 5c and as-indacenyllithium. Although the biradical character of 22 $(17 \%)$ is relatively smaller than those of $5 \mathbf{c}(31 \%)$ and as-indacene model (34\%), probably because the Kékule structure of $\mathbf{2 2}$ is emphasized due to the fusion of the benzocyclobutene unit (i.e. Mills-Nixon effect), ${ }^{23}$ it nevertheless exhibits is a weak radical character. It is therefore reasonable to assume that this anomalous dimerization reaction takes place because of the biradical character of intermediate $\mathbf{1 1}$ having an indenofluorene structure. 


\subsection{Investigation of the Generality of Dimer Formation}

To know the scope of the oxidation cyclodimerization with regard to nucleophiles, several reagents, including $\mathrm{MeLi}, t$-BuLi, were investigated. ${ }^{24}$ However, only when ethyllithium/sec-butyllithium complex ${ }^{25}$ was used, the corresponding cyclic dimeric product $14 \mathrm{c}$ was isolated in $23 \%$ yield (Scheme 12).

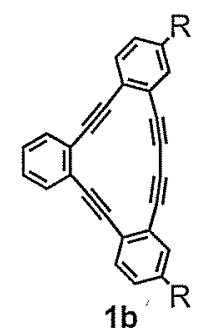

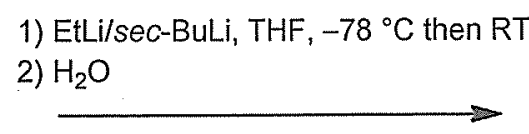

$\mathrm{R}=t-\mathrm{Bu}$

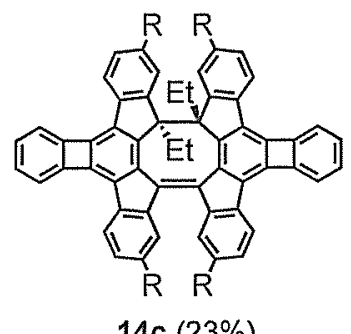

$14 \mathrm{c}(23 \%)$

Scheme 12. Oxidative cyclodimers derived from extended [14]DBAs.

To extend the generality of the cyclodimerization to other [14]DBA substrates, the naphthalene-fused congeners 2-4 were synthesized as shown in Scheme 13, and then these compounds subjected to react with $n$-BuLi under similar conditions. When 2 having a naphthalene unit at the short axis end of the [14]DBA core was used, the corresponding dimeric product 14d was isolated in $13 \%$ yield. $^{26}$ On the other hand, when 3 having naphthalene units at both ends of the long axis was used, the blue color developed after quenching the reaction with water, suggesting the formation of $14 \mathrm{e}$, gradually changed to orange during purification by silica gel chromatography to give $37 \mathbf{a}$ as a product which was isolated in $23 \%$ yield. ${ }^{26}$ The ${ }^{1} \mathrm{H}$ NMR spectrum of $37 \mathbf{a}$ exhibited only 15 signals for the aromatic protons, suggesting that dehydrogenation of $14 \mathrm{e}$ took place. The structure was finally established by X-ray crystallographic analysis as shown in Figure 10. The formation of $37 \mathrm{a}$ is explained by dehydrogenative $\mathrm{C}-\mathrm{C}$ bond formation between the proximate naphthalene units of $14 \mathrm{e}$. Similarly, 4 having naphthalene rings at both long and short axis ends gave dehydrogenated dimeric product $\mathbf{3 7 b}$ in $31 \%$ yield. ${ }^{26}$ These results clearly show that the anomalous oxidative cyclodimerization is a general reaction pathway for BuLi-induced cyclization reaction of [14]DBAs, leading to a new hydrocarbon framework consisting of indenofluorene substructures. 


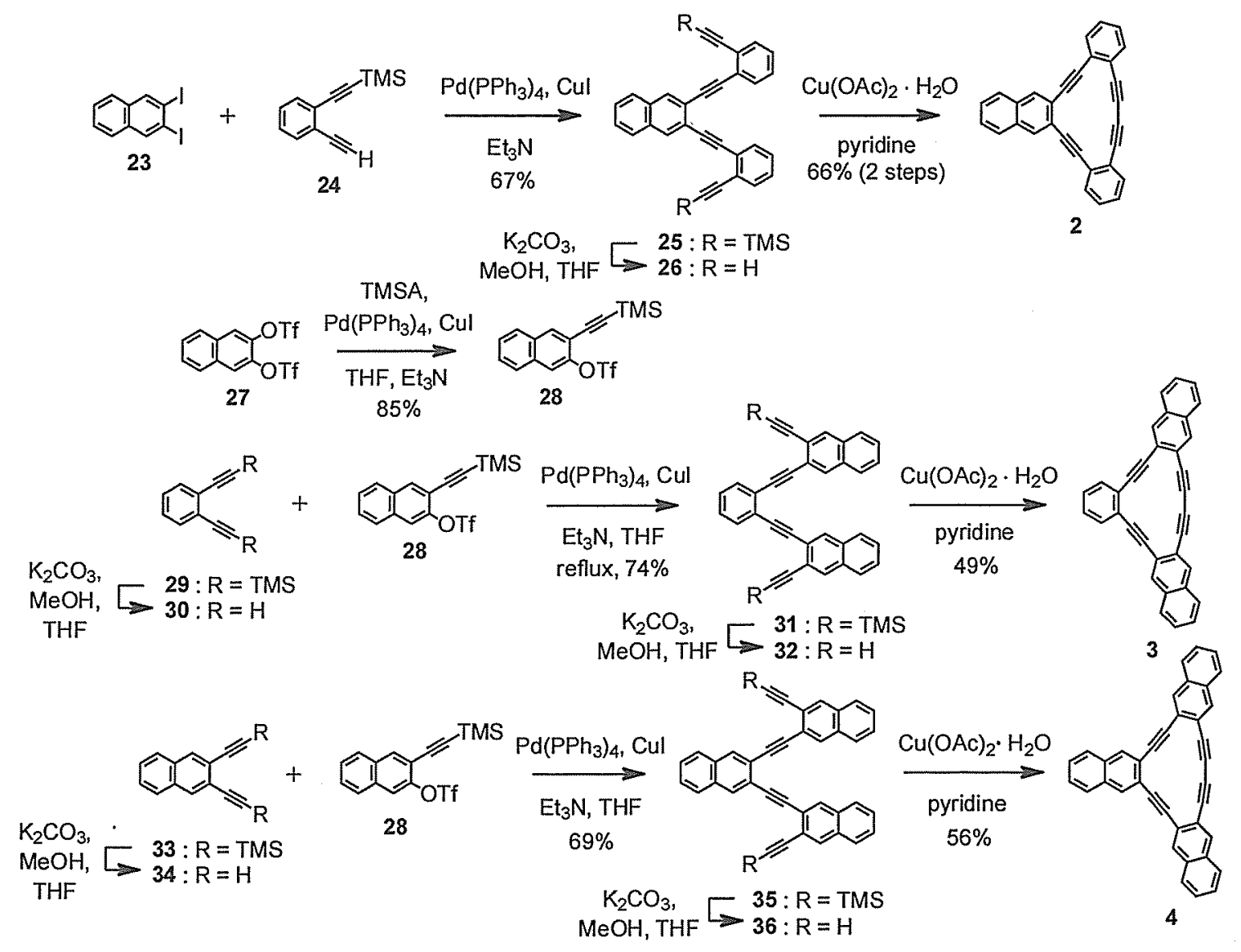

Scheme 13. Synthesis of [14]DBA congeners 2-4.

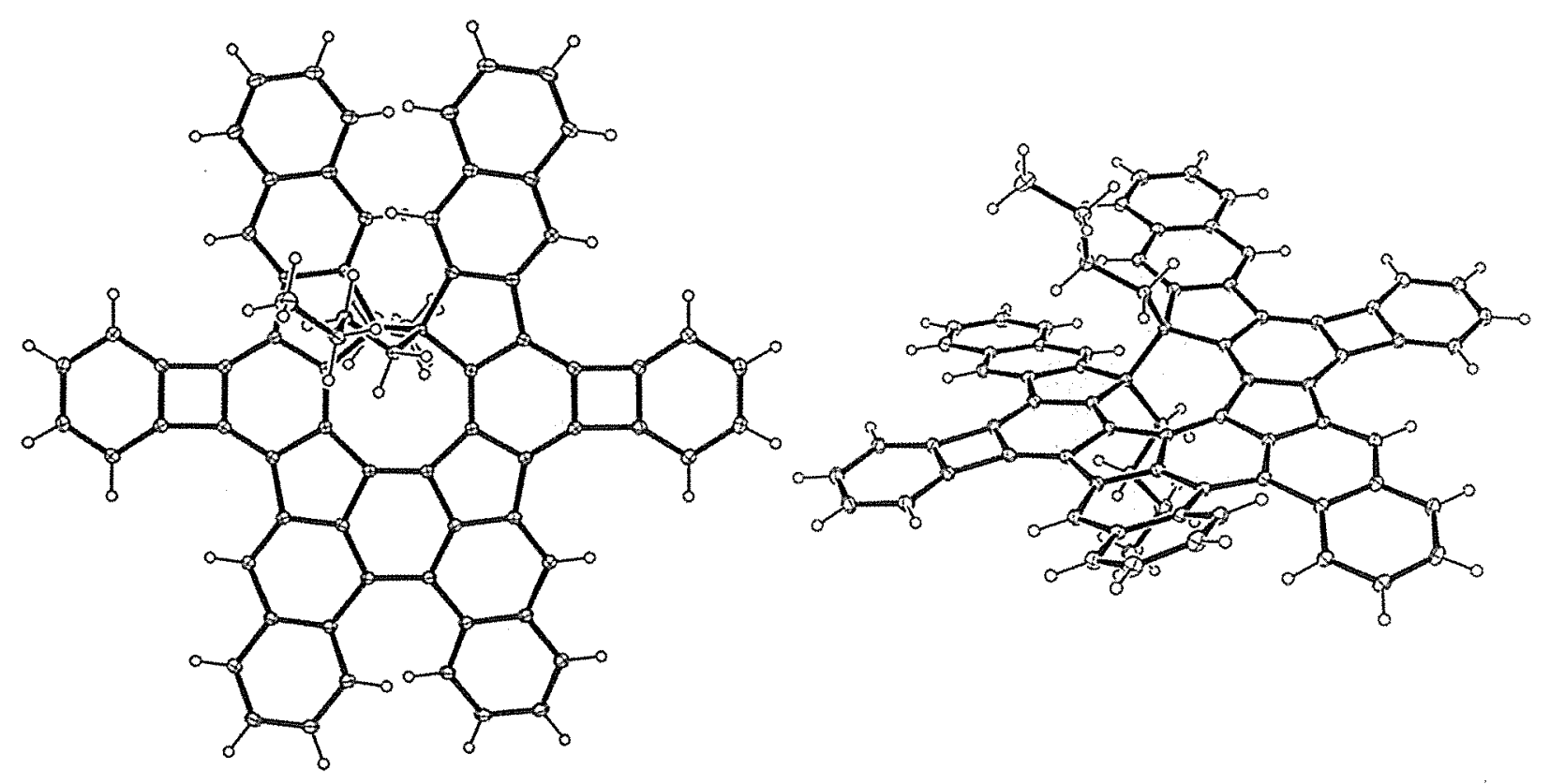

Figure 10. Top and side views of ORTEP drawings of 37a. Displacement ellipsoids are drawn at the $30 \%$ probability level. Solvent molecules are omitted for clarity. 


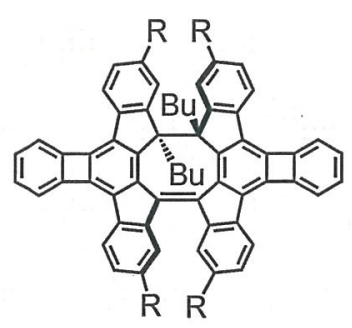

14a: $R=H$

14b: $\mathrm{R}=t-\mathrm{Bu}$

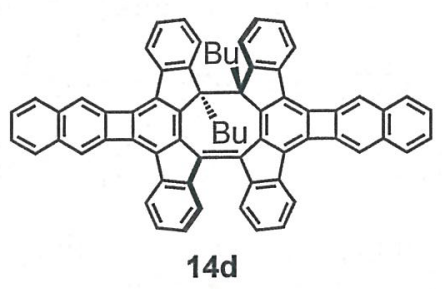

$14 d$

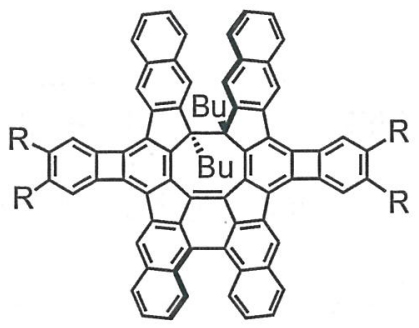

37a: $\mathrm{R}=\mathrm{H}$

$37 b_{R}^{R}=$

Scheme 14. Oxidative cyclodimers derived from extended [14]DBAs

\subsection{Optical and Electrochemical Properties of Dimeric Products}

The absorption spectra of $\mathbf{1 4 a}, \mathbf{b}, \mathbf{d}$ and $\mathbf{3 7 a}, \mathbf{b}$ are shown in Figure 11. The optical and electrochemical data obtained from experiments and the relevant energy levels from calculations are summarized in Table 3. Both compounds 14a,b exhibit absorption maxima at $605 \mathrm{~nm}$, whereas 14d showed a slight hypsochromic shift with an absorption maximum at $600 \mathrm{~nm}$. Moreover, both dehydrogenated dimers 37a,b show absorption maxima at $513 \mathrm{~nm}$, substantially hypsochromic shifted from those of $\mathbf{1 4 a , b}$. These shifts are consistent with the larger HOMO-LUMO gaps of 37a,b estimated by the DFT calculations (2.83 and $2.82 \mathrm{eV}$, respectively) than that of 14a (2.32 eV). The TD-DFT calculations (Table 3) also support the hypsochromic shfts of 37a,b (the lowest-energy transition at $503 \mathrm{~nm}$ ) compared with 14a,d (600 and $602 \mathrm{~nm}$, respectively).

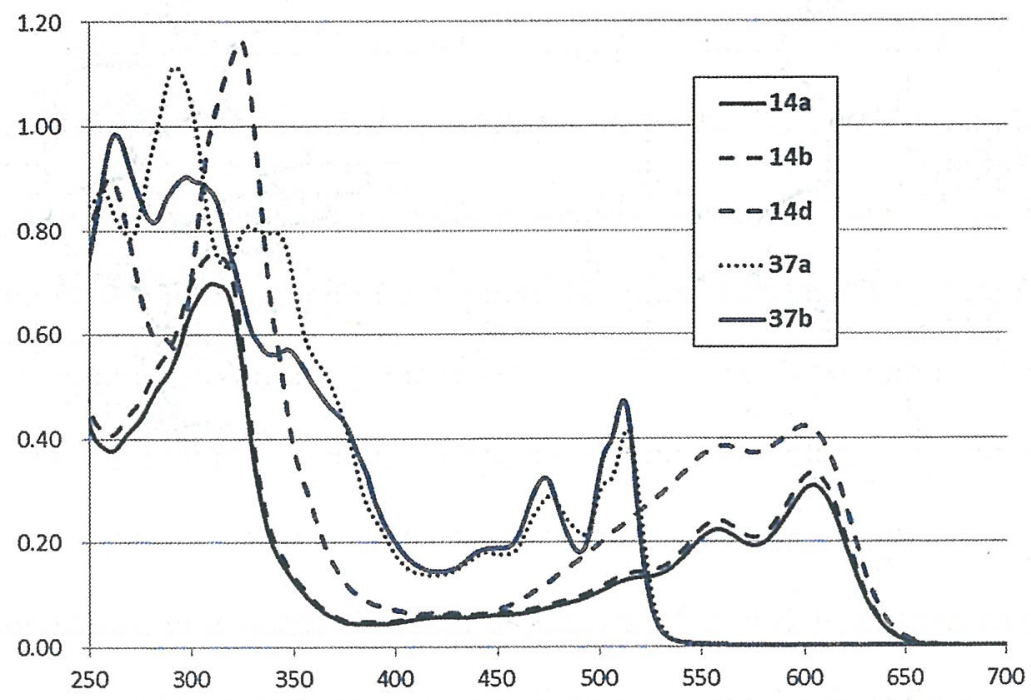

Figure 11. Absorption spectra of 14a,b,d and 37a,b. 
Table 3. Optical and electrochemical data and calculated HOMO-LUMO levels of $\mathbf{1 4 a , b , d}$, and $37 \mathrm{a}, \mathrm{b}$

\begin{tabular}{c|cccc|ccc}
\hline & \multicolumn{4}{|c|}{ Experimental } & \multicolumn{3}{c}{ Calculated $^{\mathrm{d}}$} \\
\cline { 2 - 8 } & $\lambda_{\max }$ & HOMO & LUMO & $E_{\mathrm{g}, \mathrm{CV}}$ & HOMO & LUMO & $E_{\mathrm{g}}$ \\
\hline $\mathbf{1 4 a}$ & 605 & -4.80 & -2.71 & 2.09 & -4.88 & -2.56 & 2.32 \\
$\mathbf{1 4 b}$ & 605 & -4.89 & -2.73 & 2.16 & N.D. & N.D. & N.D. \\
$\mathbf{1 4 d}$ & 600 & -4.97 & -2.89 & 2.08 & -5.02 & -2.69 & 2.33 \\
$\mathbf{3 7 a}$ & 513 & -5.05 & $-e$ & & -5.08 & -2.25 & 2.83 \\
$\mathbf{3 7 b}$ & 513 & -5.03 & $-e$ & & -5.19 & -2.37 & 2.82 \\
\hline
\end{tabular}

${ }^{a}$ Maximum wavelength of the longest wavelength absorption band.

${ }^{b}$ Determined from cyclic voltammograms, using ferrocene as a standard.

${ }^{c}$ Determined from the difference between the HOMO and LUMO levels by cyclic voltammograms.

${ }^{d}$ HOMO and LUMO levels were calculated by DFT method at the (R)B3LYP/6-31G* level of theory. To reduce the computational costs, methyl groups were used instead of the $n$-butyl groups.

${ }^{e}$ Reversible reduction wave was not observed in cyclic voltammograms.

It should also be pointed out that the 9,9'-bifluorenylidene chromophore found in $14 \mathbf{a}, \mathbf{b}, \mathbf{d}$ is reported by Heeger and Wudl to be a promising non-fullerene electron acceptor component for bulk

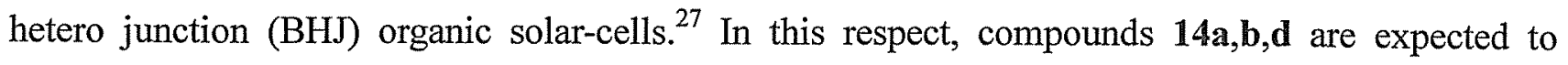
function as acceptor components of BHJ solar cells in view of not only the presence of a 9,9'-bifluorenylidene substructure but also their small HOMO-LUMO gaps (2.08-2.16 eV) and the relatively high LUMO levels $(-2.71--2.89 \mathrm{eV})$, the latter being known to generate larger open-circuit voltage. ${ }^{28}$

\subsection{Conclusion}

In conclusion, tandem transannular cyclization of [14]DBAs 1a,b and 2-4 induced by an addition of $n$-BuLi led to the discovery of an unprecedented cyclodimerization to form eight-membered ring products $\mathbf{1 4 a}, \mathbf{b}, \mathbf{d}$ in which two indeno[2,1-a]fluorene components are connected by a single and a double bonds, following three-fold transannular bond formations. In the case of naphthalene congeners 3 and 4 , the corresponding dimers $\mathbf{3 7 a}, \mathbf{b}$ in which dehydrogenative $\mathrm{C}-\mathrm{C}$ bond formation took place from the initial dimers 14 e, f were obtained, respectively, demonstrating the generality of 
the reaction for [14]DBA derivatives. Though the mechanism of the reaction is not understood, and the selectivity of the reaction is not very good (up to $30 \%$ ), the reaction provides a new approach to otherwise unaccessible hydrocarbon framework which may be of optoelectronic interest. 


\subsection{Experimental Section}

General Experimental Methods. ${ }^{1} \mathrm{H}$ and ${ }^{13} \mathrm{C}$ NMR spectra were recorded in $\mathrm{CDCl}_{3}$ at $30{ }^{\circ} \mathrm{C}$ unless otherwise stated. When $\mathrm{CDCl}_{3}$ or $\mathrm{CD}_{2} \mathrm{Cl}_{2}$ was used as a solvent, the chemical shifts were referenced to the residual solvent protons in the ${ }^{1} \mathrm{H}$ NMR (7.26 and $5.32 \mathrm{ppm}$, respectively) and to solvent carbons in the ${ }^{13} \mathrm{C}$ NMR (77.0 and $53.1 \mathrm{ppm}$, respectively). Mass spectral analyses were performed with $\mathrm{EI}, \mathrm{FAB}$, or laser desorption ionization (LDI) mode. IR spectra were recorded as a $\mathrm{KBr}$ disk or a neat film. Melting points were measured with a hot-stage apparatus equipped with a thermometer. Column chromatography and TLC were performed with silica gel (70-230 mesh) and precoated silica gel plates, respectively. Preparative recycling GPC separation was undertaken using two $600 \mathrm{~mm} \times$ $20 \mathrm{~mm}$ GPC columns with $\mathrm{CHCl}_{3}$ as the eluent. Purification by HPLC was undertaken using preparative ODS column $(250 \mathrm{~mm} \times 20 \mathrm{~mm})$ with a mixture of $\left.\mathrm{CH}_{2} \mathrm{Cl}_{2} / \mathrm{CH}_{3} \mathrm{CN}\right)$ as the eluent.

All reagents were obtained from commercial suppliers and used as received. Solvents were dried (drying agent in parentheses) and distilled prior to use: $i-\mathrm{Pr}_{2} \mathrm{NH}(\mathrm{KOH}), \mathrm{Et}_{3} \mathrm{~N}(\mathrm{KOH})$, pyridine $(\mathrm{KOH})$. THF was dried by a Glass Contour solvent purification system.

Reaction of $\mathbf{1 b}$ with $\boldsymbol{n}$-butyllithium at low temperature. A solution of $n$-butyllithium (1.55 $\mathrm{M}$ in hexane, $450 \mu \mathrm{L}, 0.698 \mathrm{mmol})$ was added dropwise via a syringe to a solution of $\mathbf{1 b}(101 \mathrm{mg}, 0.231$ $\mathrm{mmol})$ in THF $(20 \mathrm{~mL})$ at $-78^{\circ} \mathrm{C}$. After stirring at $-78{ }^{\circ} \mathrm{C}$ for $20 \mathrm{~min}$, water $(5 \mathrm{~mL})$ was added and the mixture was stirred for $30 \mathrm{~min}$ before warming up to room temperature. An aqueous solution of $\mathrm{NH}_{4} \mathrm{Cl}$ was added, and the reaction mixture was extracted with $\mathrm{CH}_{2} \mathrm{Cl}_{2}$. The extract was washed with brine and dried over anhydrous $\mathrm{MgSO}_{4}$. After removal of the solvent, the residue was purified by chromatography (silica gel, $\mathrm{CH}_{3} \mathrm{Cl} /$ hexanes $\left.=1 / 9\right)$ to afford $13 \mathrm{a}(72.1 \mathrm{mg}, 63 \%$ ) as a yellow solid. 13a: m.p. 93.0-94.0 ${ }^{\circ} \mathrm{C} .{ }^{1} \mathrm{H} \mathrm{NMR}\left(400 \mathrm{MHz}, \mathrm{CDCl}_{3}\right) \delta 8.75(\mathrm{~s}, 1 \mathrm{H}), 8.34(\mathrm{~d}, J=7.6,1 \mathrm{H}), 8.15(\mathrm{~d}, J$ $=8.0 \mathrm{~Hz}, 1 \mathrm{H}), 7.69(\mathrm{~d}, J=7.6 \mathrm{~Hz}, 1 \mathrm{H}), 7.63(\mathrm{~d}, J=2.0 \mathrm{~Hz}, 1 \mathrm{H}), 7.57(\mathrm{~d}, J=8.0 \mathrm{~Hz}, 1 \mathrm{H}), 7.54(\mathrm{dd}, J$ $=7.6,7.6 \mathrm{~Hz}, 1 \mathrm{H}), 7.48(\mathrm{~d}, J=1.6 \mathrm{~Hz}, 1 \mathrm{H}), 7.42-7.38(\mathrm{~m}, 3 \mathrm{H}), 2.93(\mathrm{t}, J=7.2 \mathrm{~Hz}, 2 \mathrm{H}), 1.87-1.80$ $(\mathrm{m}, 2 \mathrm{H}), 1.57-1.50(\mathrm{~m}, 2 \mathrm{H}), 1.42(\mathrm{~s}, 9 \mathrm{H}), 1.38(\mathrm{~s}, 9 \mathrm{H}), 1.03(\mathrm{t}, J=7.6 \mathrm{~Hz}, 3 \mathrm{H}) .{ }^{13} \mathrm{C} \mathrm{NMR}(100 \mathrm{MHz}$, $\left.\mathrm{CDCl}_{3}\right) \delta 151.70,151.69,144.9,143.6,138.9,137.6,132.4,131.1,131.0,130.3,128.45,128.42$, $127.9,127.8,127.6,127.0,125.8,125.0,123.4,123.1,122.9,117.0,102.4,99.0,92.6,91.3,35.0$, 
$34.9,31.5,31.2,31.1,27.4,22.8,14.0$. IR (KBr) 3054, 2958, 2897, 2160, 1577, 1487, 1421, 1314, 1249, 1176, 1130, 907, 841, 744, 699, $636 \mathrm{~cm}^{-1}$. MS (EI) $\mathrm{m} / z 493.4\left(\mathrm{M}^{+}\right)$. HRMS (EI) Calcd for $\mathrm{C}_{38} \mathrm{H}_{38}$ : 494.2974. Found: 494.2976.

A solution of $n$-butyllithium $(1.55 \mathrm{M}$ in hexane, $450 \mu \mathrm{L}, 0.698 \mathrm{mmol})$ was added dropwise via a syringe to a solution of $1 \mathbf{b}(100 \mathrm{mg}, 0.229 \mathrm{mmol})$ in THF $(20 \mathrm{~mL})$ at $-78^{\circ} \mathrm{C}$. After stirring at $-78{ }^{\circ} \mathrm{C}$ for $20 \mathrm{~min}$, a solution of 1-iodobutane $(140 \mathrm{mg}, 0.761 \mathrm{mmol})$ in THF $(5 \mathrm{~mL})$ was added dropwise. After stirring at $-78{ }^{\circ} \mathrm{C}$ for $30 \mathrm{~min}$, an aqueous solution of $\mathrm{NH}_{4} \mathrm{Cl}$ was added, and the reaction mixture was extracted with $\mathrm{CH}_{2} \mathrm{Cl}_{2}$. The extract was washed with brine and dried over anhydrous $\mathrm{MgSO}_{4}$. After removal of the solvent, the residue was purified by chromatography (silica gel, $\mathrm{CH}_{3} \mathrm{Cl} / \mathrm{h}$ exanes $\left.=1 / 9\right)$ to afford $13 \mathrm{~b}(84.0 \mathrm{mg}, 67 \%)$ as a yellow solid. $13 \mathrm{~b}:$ m.p. $84.0-85.0^{\circ} \mathrm{C} .{ }^{1} \mathrm{H}$ $\operatorname{NMR}\left(400 \mathrm{MHz}, \mathrm{CDCl}_{3}\right) \delta 7.57(\mathrm{dd}, J=7.6,7.2 \mathrm{~Hz}, 2 \mathrm{H}), 7.45-7.39(\mathrm{~m}, 3 \mathrm{H}), 7.34(\mathrm{dd}, J=7.6,7.2$ $\mathrm{Hz}, 1 \mathrm{H}), 7.29(\mathrm{~d}, J=1.2 \mathrm{~Hz}, 1 \mathrm{H}), 7.25(\mathrm{~d}, J=7.6 \mathrm{~Hz}, 2 \mathrm{H}), 7.03(\mathrm{dd}, J=8.0,1.6 \mathrm{~Hz}, 1 \mathrm{H}), 3.78-3.71$ (m, 1H), 2.96-2.73 (m, 3H), 1.81-1.72 (m, 2H), 1.57-1.50 (m, 2H), 1.42-1.18 (m, 4H), $1.34(\mathrm{~s}, 9 \mathrm{H})$, $1.31(\mathrm{~s}, 9 \mathrm{H}), 1.02(\mathrm{t}, J=7.2 \mathrm{~Hz}, 3 \mathrm{H}), 0.82(\mathrm{t}, J=7.2 \mathrm{~Hz}, 3 \mathrm{H}) .{ }^{13} \mathrm{C} \mathrm{NMR}\left(100 \mathrm{MHz}, \mathrm{CDCl}_{3}\right) \delta 151.5$, $150.5,150.0,149.0,146.3,142.8,141.5,137.2,131.6,131.1,127.1,127.02,127.00,126.6,125.6$, $124.8,124.4,123.9,122.9,121.3,119.8,116.9,99.2,96.1,95.5,91.5,41.3,34.8,34.7,31.4,31.2$, $31.1,27.5,22.9,22.7,14.01,13.99$. IR (KBr) 2959, 2146, 1250, 946, 847, 749, $634 \mathrm{~cm}^{-1}$. MS (EI) $m / z 550.1\left(\mathrm{M}^{+}\right)$. HRMS (EI) Calcd for $\mathrm{C}_{42} \mathrm{H}_{46}: 550.3600$. Found: 550.3609 .

Reaction of $1 \mathrm{~b}$ with $n$-butyllithium at room temperature A solution of $n$-butyllithium $(1.60 \mathrm{M}$ in hexane, $1.25 \mathrm{~mL}, 2.06 \mathrm{mmol}$ ) was added dropwise via a syringe to a solution of $1 \mathbf{b}(300 \mathrm{mg}, 0.687$ $\mathrm{mmol})$ in THF $(30 \mathrm{~mL})$ at $-78{ }^{\circ} \mathrm{C}$. After stirring at $-78^{\circ} \mathrm{C}$ for $15 \mathrm{~min}$ under an argon atmosphere, the cooling bath was removed and the reaction mixture was gradually warmed up to room temperature. After stirring at $30 \mathrm{~min}$, water $(20 \mathrm{~mL})$ was added via a syringe and the reaction mixture was stirred for $5 \mathrm{~min}$. An aqueous solution of $\mathrm{NH}_{4} \mathrm{Cl}$ was added, and the reaction mixture was extracted with $\mathrm{CH}_{2} \mathrm{Cl}_{2}$. The extract was washed with brine and dried over anhydrous $\mathrm{MgSO}_{4}$. After removal of the solvent, the residue was separated by chromatography (silica gel, hexanes $/ \mathrm{CHCl}_{3}=9 / 1$ ) into three fractions containing compound $\mathbf{1 4 b}, \mathbf{1 5 b}$ and $\mathbf{1 6 b}$, respectively. Compound $\mathbf{1 4 b}(60.9 \mathrm{mg}, 18 \%)$ was 
isolated as a blue solid by additional chromatography (silica gel, hexanes/ $\mathrm{CHCl}_{3}=9 / 1$ ) followed by recrystallization from a mixture of $\mathrm{CH}_{2} \mathrm{Cl}_{2} / \mathrm{CH}_{3} \mathrm{CN}$. Compounds $\mathbf{1 5 b}(81.9 \mathrm{mg}, 20 \%)$ and $\mathbf{1 6 b}(61.8$ $\mathrm{mg}, 16 \%$ ) were isolated both as red solids by recycling GPC followed by chromatography (silica gel, hexanes $\left./ \mathrm{CHCl}_{3}=19 / 1\right)$. 14b: m.p. $235-240{ }^{\circ} \mathrm{C} .{ }^{1} \mathrm{H} \mathrm{NMR}\left(400 \mathrm{MHz}, \mathrm{CDCl}_{3}\right) \delta 8.25$ (d, $J=1.6 \mathrm{~Hz}$, $2 \mathrm{H}), 7.57(\mathrm{dd}, J=8.0,2.0 \mathrm{~Hz}, 4 \mathrm{H}), 7.39-7.36(\mathrm{~m}, 4 \mathrm{H}), 7.02-6.95(\mathrm{~m}, 4 \mathrm{H}), 7.02-6.95(\mathrm{~m}, 8 \mathrm{H}), 6.31$ $(\mathrm{s}, 2 \mathrm{H}), 1.92-1.85(\mathrm{~m}, 2 \mathrm{H}), 1.24(\mathrm{~s}, 18 \mathrm{H}), 1.13(\mathrm{~s}, 18 \mathrm{H}), 1.13-1.07(\mathrm{~m}, 2 \mathrm{H}), 0.69-0.59(\mathrm{~m}, 4 \mathrm{H})$, $0.32-0.22(\mathrm{~m}, 2 \mathrm{H}), 0.28(\mathrm{t}, J=7.6 \mathrm{~Hz}, 6 \mathrm{H})-0.04-0.13(\mathrm{~m}, 2 \mathrm{H}) .{ }^{13} \mathrm{C} \mathrm{NMR}\left(100 \mathrm{MHz}, \mathrm{CDCl}_{3}\right) \delta$ $151.4,151.3,148.8,148.7,148.0,147.9,141.6,141.1,140.3,138.8,137.9,136.46,136.35,131.7$, $129.1,128.5,128.4,126.8,126.1,125.3,124.7,121.3,120.9,118.4,118.2,62.7,34.94,34.86,34.7$, 31.4, 31.3, 26.3, 22.5, 13.5. IR (KBr) 3057, 2978, 2871, 1682, 1604, 1478, 1463, 1408, 1364, 1263, 1157, 981, 823, $737 \mathrm{~cm}^{-1}$. MS (EI) $m / z 987.6\left(\mathrm{M}^{+}\right)$. Anal. Calcd for $\mathrm{C}_{76} \mathrm{H}_{74}: \mathrm{C}, 92.45 ; \mathrm{H}, 7.55$. Found: C, 92.55; H, 7.60. 15b: m.p. $101.0-102.0{ }^{\circ} \mathrm{C}$ (decomp.). ${ }^{1} \mathrm{H}$ NMR $\left(400 \mathrm{MHz}, \mathrm{CDCl}_{3}\right) \delta 7.71$ $(\mathrm{d}, J=7.6 \mathrm{~Hz}, 1 \mathrm{H}), 7.52-7.49(\mathrm{~m}, 3 \mathrm{H}), 7.45(\mathrm{~d}, J=1.2 \mathrm{~Hz}, 1 \mathrm{H}), 7.39-7.34(\mathrm{~m}, 4 \mathrm{H}), 7.30(\mathrm{dd}, J=8.0$, $1.6 \mathrm{~Hz}, 1 \mathrm{H}), 6.81(\mathrm{~s}, 1 \mathrm{H}), 2.24-1.89(\mathrm{~m}, 6 \mathrm{H}), 1.397(\mathrm{~s}, 9 \mathrm{H}), 1.392(\mathrm{~s}, 9 \mathrm{H}), 1.28-1.03(\mathrm{~m}, 7 \mathrm{H}), 0.97-$ $0.88(\mathrm{~m}, 2 \mathrm{H}), 0.74(\mathrm{t}, J=7.2 \mathrm{~Hz}, 3 \mathrm{H}), 0.68(\mathrm{t}, J=7.2 \mathrm{~Hz}, 3 \mathrm{H}), 0.54(\mathrm{t}, J=7.2 \mathrm{~Hz}, 3 \mathrm{H}), 0.74-0.65(\mathrm{~m}$, $1 \mathrm{H}), 0.55-0.47(\mathrm{~m}, 1 \mathrm{H}), 0.26-0.19(\mathrm{~m}, 1 \mathrm{H}) .{ }^{13} \mathrm{C} \mathrm{NMR}\left(100 \mathrm{MHz}, \mathrm{CDCl}_{3}\right) \delta 151.6,151.0,148.5$, $148.1,146.9,145.4,145.3,144.1,143.5,140.4,133.9,130.9,130.7,129.2,128.3,123.2,121.9$, $121.76,121.65,120.5,120.1,119.4,118.9,118.3,58.8,57.2,43.1,39.1,38.8,35.0,34.9,31.7,31.6$, 29.3, 26.7, 25.1, 23.2, 22.9, 22.7, 13.89, 13.86, 13.5. IR (KBr) 2931, 26867, 1667, 1611, 1457, 1453, $1411,1355,1251,1149,911,823 \mathrm{~cm}^{-1}$. MS (EI) $\mathrm{m} / z 608.7\left(\mathrm{M}^{+}\right)$. HRMS (EI) Calcd for $\mathrm{C}_{46} \mathrm{H}_{56}$ : 608.4382. Found: 608.4379. 16b: m.p. $110.0-111.0{ }^{\circ} \mathrm{C}$ (decomp.). ${ }^{1} \mathrm{H}$ NMR (400 $\left.\mathrm{MHz} \mathrm{CDCl}_{3}\right) \delta$ $7.53(\mathrm{dd}, J=8.0,2.0 \mathrm{~Hz}, 1 \mathrm{H}), 7.43(\mathrm{~s}, 1 \mathrm{H}), 7.23-7.17(\mathrm{~m}, 5 \mathrm{H}), 7.07(\mathrm{~d}, J=8.0 \mathrm{~Hz}, 1 \mathrm{H}), 7.04-7.01$ $(\mathrm{m}, 2 \mathrm{H}), 6.44(\mathrm{~s}, 1 \mathrm{H}), 3.99(\mathrm{~d}, J=23.2 \mathrm{~Hz}, 1 \mathrm{H}), 3.74(\mathrm{t}, J=5.2 \mathrm{~Hz}, 1 \mathrm{H}), 3.70(\mathrm{~d}, J=22.8 \mathrm{~Hz}, 1 \mathrm{H})$, 2.43-2.37 (m, 1H), 2.33-2.25 (m, 1H), 1.88-1.79 (m, 1H), 1.76-1.67 (m, 1H), $1.34(\mathrm{~s}, 9 \mathrm{H}), 1.28(\mathrm{~s}$, 9H), $1.27-1.05(\mathrm{~m}, 6 \mathrm{H}), 0.98-0.83(\mathrm{~m}, 2 \mathrm{H}), 0.74(\mathrm{t}, 7.2 \mathrm{~Hz}, 3 \mathrm{H}), 0.62(\mathrm{t}, J=7.2 \mathrm{~Hz}, 3 \mathrm{H}) .{ }^{13} \mathrm{C} \mathrm{NMR}$ $\left(100 \mathrm{MHz} \mathrm{CDCl}_{3}\right) \delta 150.9,149.7,147.6,147.3,146.5,145.3,143.3,142.6,141.6,138.7,137.3$, $136.4,135.0,129.04,129,00,126.4,126.1,124.3,123.41,123.38,123.1,121.2,120.5,119.8,49.8$, $42.6,37.8,34.7,34.3,31.7,31.2,30.33,30.27,26.7,22.9,21.9,13.9,13.7 . \mathrm{IR}$ (KBr) 2909, 2831, 
$1589,1432,1411,1399,1345,1253,1134,911,878,720 \mathrm{~cm}^{-1}$. MS (EI) $m / z 554.3\left(\mathrm{M}^{+}\right)$. HRMS (EI) Calcd for $\mathrm{C}_{42} \mathrm{H}_{50}: 554.3913$. Found: 554.3923.

Reaction of 1 a with $n$-butyllithium at room temperature A solution of $n$-butyllithium (1.65 M in hexane, $850 \mu \mathrm{L}, 1.40 \mathrm{mmol})$ was added dropwise via a syringe to a solution of $1 \mathrm{a}(150 \mathrm{mg}, 0.462$ $\mathrm{mmol})$ in THF $(20 \mathrm{~mL})$ at $-78^{\circ} \mathrm{C}$. After stirring at $-78^{\circ} \mathrm{C}$ for $15 \mathrm{~min}$ under an argon atmosphere, the cooling bath was removed and the reaction mixture was gradually warmed up to room temperature. After stirring for $30 \mathrm{~min}$, water $(10 \mathrm{~mL})$ was added via a syringe and the reaction mixture was stirred for 5 min. An aqueous solution of $\mathrm{NH}_{4} \mathrm{Cl}$ was added, and the reaction mixture was extracted with $\mathrm{CH}_{2} \mathrm{Cl}_{2}$. After removal of the solvent, the residue was separated into four fractions by chromatography (silica gel, hexanes $\left./ \mathrm{CHCl}_{3}=4 / 1\right)$. Compound $14 \mathrm{a}(22.8 \mathrm{mg}, 13 \%)$ was isolated as a blue solid by further chromatography (silica gel, hexanes $/ \mathrm{CHCl}_{3}=9 / 1$ ) followed by recrystallization from a mixture of $\mathrm{CH}_{2} \mathrm{Cl}_{2} / \mathrm{CH}_{3} \mathrm{CN}$. Compounds $15 \mathrm{a}(3.0 \mathrm{mg}, 1.3 \%)$ and $16 \mathrm{a}(2.1 \mathrm{mg}, 1.0 \%)$ were isolated both as red solids by HPLC (an ODS column, $\left.\mathrm{CH}_{2} \mathrm{Cl}_{2}: \mathrm{CH}_{3} \mathrm{CN}=1 / 4\right) .17(12.8 \mathrm{mg}, 7.3 \%$ ) was isolated as an orange solid by further chromatography (silica gel, hexanes/ $\mathrm{CHCl}_{3}=4 / 1$ ) followed by recycling GPC. 14a: m.p. $>300^{\circ} \mathrm{C} .{ }^{1} \mathrm{H}$ NMR $\left(400 \mathrm{MHz}, \mathrm{CDCl}_{3}\right) \delta 8.37$ (d, $J=8.0 \mathrm{~Hz}$, 2H), 7.67-7.64 (m, 4H), $7.38(\mathrm{dd}, J=7.6,7.6 \mathrm{~Hz}, 2 \mathrm{H}), 7.32(\mathrm{dd}, J=7.6,7.6 \mathrm{~Hz}, 2 \mathrm{H}), 7.10-7.06(\mathrm{~m}$, $8 \mathrm{H}), 7.04-7.01(\mathrm{~m}, 4 \mathrm{H}), 6.25(\mathrm{~d}, J=8.0 \mathrm{~Hz}, 2 \mathrm{H}), 1.91-1.82(\mathrm{~m}, 2 \mathrm{H}), 1.12-1.05(\mathrm{~m}, 2 \mathrm{H}), 0.71-0.61$ $(\mathrm{m}, 4 \mathrm{H}), 0.36-0.26(\mathrm{~m}, 2 \mathrm{H}), 0.32(\mathrm{t}, J=7.6 \mathrm{~Hz}, 6 \mathrm{H}), 0.13-0.05(\mathrm{~m}, 2 \mathrm{H}) .{ }^{13} \mathrm{C}$ NMR $(100 \mathrm{MHz}$, $\left.\mathrm{CDCl}_{3}\right) \delta 151.2,151.0,147.6,147.5,141.8,141.2,140.8,138.7,138.6,138.4,137.2,131.9,130.0$, $129.4,128.8,128.7,128.63,128.62,127.3,125.7,125.4,121.5,120.8,118.7,118.5,63.1,34.7,26.4$, 22.7, 13.6. IR (KBr) 3063, 2964, 2855, 1622, 1457, 1411, 1334, 1213, 1117, 1001, 829, $735 \mathrm{~cm}^{-1}$. MS (EI) $m / z 762.3\left(\mathrm{M}^{+}\right)$. Anal. Calcd for $\mathrm{C}_{60} \mathrm{H}_{42}$ : C, 94.45, H, 5.55. Found: C, 94.73; H, 5.86. 15a: m.p. 113.0-114.0 ${ }^{\circ} \mathrm{C}$ (decomp.). ${ }^{1} \mathrm{H}$ NMR (400 $\left.\mathrm{MHz}, \mathrm{CD}_{2} \mathrm{Cl}_{2}\right) \delta 7.80-7.78(\mathrm{~m} .1 \mathrm{H}), 7.63$ (d, $J=7.6$ $\mathrm{Hz}, 1 \mathrm{H}), 7.59-7.56(\mathrm{~m}, 2 \mathrm{H}), 7.46-7.35(\mathrm{~m}, 5 \mathrm{H}), 7.30-7.24(\mathrm{~m}, 3 \mathrm{H}), 6.88(\mathrm{~s}, 1 \mathrm{H}), 2.24-2.06(\mathrm{~m}, 4 \mathrm{H})$, 2.01-1.96 (m, 2H), 1.28-1.06 (m, 8H), 0.99-0.90 (m, 2H), 0.81-0.70 (m, 2H), $0.76(\mathrm{t}, J=7.6 \mathrm{~Hz}$, $3 \mathrm{H}), 0.70(\mathrm{t}, J=7.6 \mathrm{~Hz}, 3 \mathrm{H}), 0.52(\mathrm{t}, J=7.6 \mathrm{~Hz}, 3 \mathrm{H}), 0.48-0.39(\mathrm{~m}, 1 \mathrm{H}), 0.29-0.17(\mathrm{~m}, 1 \mathrm{H}) .{ }^{13} \mathrm{C}$ NMR $\left(100 \mathrm{MHz}, \mathrm{CDCl}_{3}\right) \delta 151.8,149.0,146.9,145.2,145.1,144.4,143.9,142.9,133.43,133.39$, 
$131.0,129.3,128.4,127.5,126.5,125.2,124.6,122.1,122.0,121.7,121.3,120.9,120.4,120.3,58.9$, $57.3,43.3,39.2,38.9,29.3,26.7,25.1,23.3,22.9,22.8,13.9,13.8,13.5$. IR (KBr) 2988, 2865, 1698, $1656,1456,1478,1411,1379,1245,1178,967,825,744 \mathrm{~cm}^{-1}$. MS (FAB) $m / z 496.3\left(\mathrm{M}^{+}\right)$. HRMS (EI) Calcd for $\mathrm{C}_{38} \mathrm{H}_{40}$ : 496.3130. Found: 496.3121. 16a: m.p. 120.0-121.0 ${ }^{\circ} \mathrm{C}$ (decomp.). ${ }^{1} \mathrm{H}$ NMR $\left(400 \mathrm{MHz} \mathrm{CDCl}_{3}\right) \delta 7.55-7.53(\mathrm{~m}, 1 \mathrm{H}), 7.40-7.38(\mathrm{~m}, 1 \mathrm{H}), 7.23-7.21(\mathrm{~m}, 2 \mathrm{H}), 7.19-7.13(\mathrm{~m}, 6 \mathrm{H})$, $7.10-7.08(\mathrm{~m}, 1 \mathrm{H}), 7.03-7.01(\mathrm{~m}, 1 \mathrm{H}), 6.41(\mathrm{~s}, 1 \mathrm{H}), 4.01(\mathrm{~d}, J=22.8 \mathrm{~Hz}, 1 \mathrm{H}), 3.77(\mathrm{t}, J=4.8 \mathrm{~Hz}$, $1 \mathrm{H}), 3.76(\mathrm{~d}, J=22.4 \mathrm{~Hz}, 1 \mathrm{H}), 2.43-2.37(\mathrm{~m}, 1 \mathrm{H}), 2.32-2.25(\mathrm{~m}, 1 \mathrm{H}), 1.92-1.83(\mathrm{~m}, 1 \mathrm{H}), 1.73-1.64$ $(\mathrm{m}, 1 \mathrm{H}), 1.25-1.06(\mathrm{~m}, 6 \mathrm{H}), 0.81-0.71(\mathrm{~m}, 2 \mathrm{H}), 0.65(\mathrm{t}, J=7.2 \mathrm{~Hz}, 3 \mathrm{H}), 0.62(\mathrm{t}, J=7.2 \mathrm{~Hz}, 3 \mathrm{H}) .{ }^{13} \mathrm{C}$ NMR $\left(100 \mathrm{MHz}, \mathrm{CDCl}_{3}\right) \delta 151.3,147.4,146.6,145.1,144.1,143.3,142.8,139.2,137.9,137.5$, $136.7,129.7,129.3,128.7,126.9,126.17,126.15,126.1,124.47,124.46,123.5,122.8,121.2,121.1$, $49.7,42.6,37.8,30.31,30.26,26.4,23.1,21.9,13.9,13.7 . \mathrm{IR}(\mathrm{KBr}) 3008,2956,2856,1686,1611$, $1467,1443,1411,1356,1245,1156,978,834,725 \mathrm{~cm}^{-1}$. MS (EI) $m / z 442.1\left(\mathrm{M}^{+}\right)$. HRMS (EI) Calcd for $\mathrm{C}_{34} \mathrm{H}_{34}: 442.2661$. Found: 442.2657. 17: m.p. $>300{ }^{\circ} \mathrm{C} .{ }^{1} \mathrm{H}$ NMR $\left(400 \mathrm{MHz}, \mathrm{CDCl}_{3}\right) \delta 7.81-7.79$ $(\mathrm{m}, 1 \mathrm{H}), 7.77-7.73(\mathrm{~m}, 2 \mathrm{H}), 7.71(\mathrm{~d}, J=8.0 \mathrm{~Hz}, 1 \mathrm{H}), 7.67(\mathrm{~d}, J=7.2 \mathrm{~Hz}, 1 \mathrm{H}), 7.56-7.54(\mathrm{~m}, 3 \mathrm{H})$, $7.48(\mathrm{~d}, J=8.0 \mathrm{~Hz}, 2 \mathrm{H}), 7.44(\mathrm{~d}, J=7.6 \mathrm{~Hz}, 1 \mathrm{H}), 7.39-7.36(\mathrm{~m}, 2 \mathrm{H}), 7.33(\mathrm{dd}, J=7.6,7.6 \mathrm{~Hz}, 1 \mathrm{H})$, $7.15(\mathrm{dd}, J=7.6,7.6 \mathrm{~Hz}, 1 \mathrm{H}), 7.06-7.04(\mathrm{~m}, 1 \mathrm{H}), 7.01-6.91(\mathrm{~m}, 7 \mathrm{H}), 4.67(\mathrm{~m}, 1 \mathrm{H}), 2.20-2.13(\mathrm{~m}$, $1 \mathrm{H}), 2.03-1.89(\mathrm{~m}, 2 \mathrm{H}), 1.85-1.77(\mathrm{~m}, 1 \mathrm{H}), 0.98-0.77(\mathrm{~m}, 7 \mathrm{H}), 0.59(\mathrm{t}, J=7.6 \mathrm{~Hz}, 3 \mathrm{H}), 0.58(\mathrm{t}, J=$ 7.6 Hz, 3H), 0.50-0.40 (m, 1H). ${ }^{13} \mathrm{C}$ NMR (100 MHz, $\left.\mathrm{CDCl}_{3}\right) \delta 151.3,151.2,150.9,150.7,147.6$, $147.5,147.0,143.9,143.2,142.7,141.70,141.65,141.4,141.1,139.6,139.3,138.6,138.2,136.9$, $136.8,135.7,133.4,131.3,130.7,130.4,129.6,129.5,128.7,128.61,128.58,128.56,128.4,127.8$, $127.6,127.5,127.4,127.3,127.2,126.9,126.3,124.7,124.4,122.8,122.4,122.1,120.2,118.43$, $118.40,118.37,118.3,57.5,50.5,38.6,33.3,27.3,26.2,22.8,22.6,13.9,13.8$. IR (KBr) 3021, 2977, $2821,1625,1431,1400,1331,123,1117,1001,821,735 \mathrm{~cm}^{-1}$. MS (EI) $m / z 762.8\left(\mathrm{M}^{+}\right)$. HRMS (EI) Calcd for $\mathrm{C}_{60} \mathrm{H}_{42}$ : 762.3287. Found: 762.3294 .

Reaction of $1 \mathrm{~b}$ with ethyllithium/sec-butyllithium complex at room temperature. Ethyllithium/sec-butyllithium complex was prepared according to the reported procedure. ${ }^{25}$ A solution of ethyllithium/sec-butyllithium $(1.28 \mathrm{M}$ in cyclohexane, $550 \mu \mathrm{L}, 0.704 \mathrm{mmol})$ was 
added dropwise via a syringe to a solution of $\mathbf{1 b}(100 \mathrm{mg}, 0.229 \mathrm{mmol})$ in THF $(20 \mathrm{~mL})$ at $-78{ }^{\circ} \mathrm{C}$. After stirring at $-78^{\circ} \mathrm{C}$ for $15 \mathrm{~min}$ under an argon atmosphere, the cooling bath was removed and the reaction mixture was gradually warmed up to room temperature. After stirring at 25 min, water (5 $\mathrm{mL}$ ) was added via a syringe and the reaction mixture was stirred for $10 \mathrm{~min}$. An aqueous solution of $\mathrm{NH}_{4} \mathrm{Cl}$ was added, and the reaction mixture was extracted with $\mathrm{CH}_{2} \mathrm{Cl}_{2}$. The extract was washed with brine and dried over anhydrous $\mathrm{MgSO}_{4}$. After removal of the solvent, the residue was separated by twice of chromatography (silica gel, hexanes $/ \mathrm{CHCl}_{3}=9 / 1$ ) followed by recrystallization from a mixture of $\mathrm{CH}_{2} \mathrm{Cl}_{2} / \mathrm{CH}_{3} \mathrm{CN}$ to give $14 \mathrm{c}(24.4 \mathrm{mg}, 23 \%)$ as a blue solid. 14c: m.p. $>300{ }^{\circ} \mathrm{C}$. ${ }^{1} \mathrm{H} \mathrm{NMR}$ $\left(400 \mathrm{MHz} \mathrm{CDCl}_{3}\right) \delta 8.25(\mathrm{~s}, 2 \mathrm{H}), 7.57(\mathrm{dd}, J=8.0,2.0 \mathrm{~Hz}, 4 \mathrm{H}), 7.39-7.35(\mathrm{~m}, 4 \mathrm{H}), 7.02-6.95(\mathrm{~m}$, $8 \mathrm{H}), 6.31(\mathrm{~s}, 2 \mathrm{H}), 1.91-1.84(\mathrm{~s}, 2 \mathrm{H}), 1.24(\mathrm{~s}, 18 \mathrm{H}) 1.13(\mathrm{~s}, 18 \mathrm{H}), 1.18-1.13(\mathrm{~m}, 2 \mathrm{H}), 0.73(\mathrm{t}, J=7.6$ $\mathrm{Hz}, 6 \mathrm{H}) .{ }^{13} \mathrm{C} \mathrm{NMR}\left(100 \mathrm{MHz}, \mathrm{CDCl}_{3}\right) \delta 151.2,151.0,148.6,148.4,147.7,147.6,141.3,140.8$, $140.0,138.5,137.7,136.2,136.1,131.4,128.8,128.2,128.1,126.6,125.8,125.1,124.4,121.0$, $120.6,118.2,117.9,62.5,34.7,34.6,34.5,31.09,31.07,26.0$. IR (KBr) 3091, 2944, 2831, 1632, $1477,1401,1414,1143,1125,998,845,731 \mathrm{~cm}^{-1}$. MS (FAB) $m / z 930.1\left(\mathrm{M}^{+}\right)$. HRMS (EI) Calcd for $\mathrm{C}_{72} \mathrm{H}_{66}: 930.5165$. Found: 930.5168 .

\section{2,3-(\{[2-(trimethylsilyl)ethynyl]phenyl\}ethynyl)naphthalene (25). $\mathrm{Pd}\left(\mathrm{PPh}_{3}\right)_{4}(62.1 \mathrm{mg}, 0.0537$} $\mathrm{mmol}$ ) and CuI (19.8 $\mathrm{mg}, 0.104 \mathrm{mmol})$ were added to a solution of $23^{29}$ (950 $\left.\mathrm{mg}, 2.50 \mathrm{mmol}\right)$ and $24^{29}(1.26 \mathrm{~g}, 6.35 \mathrm{mmol})$ in degassed $\mathrm{Et}_{3} \mathrm{~N}(5 \mathrm{~m})$ and THF $(5 \mathrm{~mL})$. After stirring at $60^{\circ} \mathrm{C}$ under an argon atmosphere, an aqueous solution of $\mathrm{NH}_{4} \mathrm{Cl}$ was added. The reaction mixture was extracted with $\mathrm{CHCl}_{3}$, and the extract was washed with brine and dried over anhydrous $\mathrm{MgSO}_{4}$. After removal of the solvent, the residue was purified by chromatography (silica gel, hexanes/ $\mathrm{CHCl}_{3}=4 / 1$ ) to afford 25 (876 mg, 67\%) as a pale yellow solid. 25: m.p. $162.0-163.0{ }^{\circ} \mathrm{C}$. ${ }^{1} \mathrm{H} \mathrm{NMR} \mathrm{(400} \mathrm{MHz,}$ $\left.\mathrm{CDCl}_{3}\right) \delta 8.12(\mathrm{~s}, 2 \mathrm{H}), 7.79-7.77(\mathrm{~m}, 2 \mathrm{H}), 7.60-7.58(\mathrm{~m}, 2 \mathrm{H}), 7.54-7.50(\mathrm{~m}, 4 \mathrm{H}), 7.29-7.25(\mathrm{~m}, 4 \mathrm{H})$, $0.27(\mathrm{~s}, 18 \mathrm{H}) .{ }^{13} \mathrm{C} \mathrm{NMR}\left(100 \mathrm{MHz}, \mathrm{CDCl}_{3}\right) \delta 132.5,132.22,132.17,132.1,128.2,128.0,127.6$, $127.3,126.3,125.7,122.5,103.5,98.8,92.4,91.8,0.02$. IR (KBr) 3060, 2957, 2898, 2205, 2159, $1483,1444,1408,1250,864,843,757,699,644 \mathrm{~cm}^{-1}$. MS (EI) $m / z 520.7\left(\mathrm{M}^{+}\right)$. HRMS (EI) Calcd for $\mathrm{C}_{36} \mathrm{H}_{32} \mathrm{Si}_{2}: 520.2043$. Found: 520.2040 . 
[14]DBA derivative 2. To a suspension of $\mathrm{K}_{2} \mathrm{CO}_{3}(425 \mathrm{mg}, 3.08 \mathrm{mmol})$ in $\mathrm{MeOH}(15 \mathrm{~mL})$ was added a solution of 25 (400 $\mathrm{mg}, 0.768 \mathrm{mmol})$ in THF $(10 \mathrm{~m}$ ) via a syringe. After stirring for $25 \mathrm{~min}$ at room temperature under an $\mathrm{Ar}$ atmosphere, an aqueous solution of $\mathrm{NH}_{4} \mathrm{Cl}$ was added. The reaction mixture was extracted with ether, and the extract was washed with brine and dried over anhydrous $\mathrm{MgSO}_{4}$. After removal of the solvent, the residue was dissolved in $40 \mathrm{~mL}$ of ether. The solution containing 26 was added dropwise to a solution of $\mathrm{Cu}(\mathrm{OAc})_{2} \cdot \mathrm{H}_{2} \mathrm{O}(616 \mathrm{mg}, 3.09 \mathrm{mmol})$ in pyridine $(100 \mathrm{~mL}$ ) over a period of $10 \mathrm{~h}$, and the mixture was stirred for another $3 \mathrm{~h}$. The reaction mixture was passed through a short silica gel column $\left(\mathrm{CHCl}_{3}\right)$ to remove copper salts. The elute was washed with conc. $\mathrm{HCl}$ while cooling with ice bath to remove pyridine followed by brine and dried over anhydrous $\mathrm{MgSO}_{4}$. After removal of the solvent, the residue was washed with hexanes and AcOEt to afford 2 (191 mg, 66\%) as a pale yellow solid. 2: m.p. 260.0-265.0 ${ }^{\circ} \mathrm{C}$ (decomp.). ${ }^{1} \mathrm{H}$ NMR (400 $\left.\mathrm{MHz} \mathrm{CDCl}_{3}\right) \delta 8.41(\mathrm{~s}, 2 \mathrm{H}), 7.91-7.89(\mathrm{~m}, 4 \mathrm{H}), 7.58-7.54(\mathrm{~m}, 4 \mathrm{H}), 7.47$ (ddd $J=7.6,7.4,1.2 \mathrm{~Hz}$, 2H), 7.39 (ddd, $J=7.6,7.6,1.2 \mathrm{~Hz}, 2 \mathrm{H}) .{ }^{13} \mathrm{C} \mathrm{NMR}\left(100 \mathrm{MHz}, \mathrm{CDCl}_{3}\right) \delta 136.5,133.2,132.3,129.8$, $129.3,128.7,128.0,127.5,127.4,122.9,120.3$, 94.1, 92.0, 85.9, 80.2. IR (KBr) 3058, 2924, 2851, $2214,2168,1507,1470,1448,1385,754,667,580 \mathrm{~cm}^{-1}$. MS (EI) $m / z 374.5\left(\mathrm{M}^{+}\right)$. Anal. Calcd for $\mathrm{C}_{34} \mathrm{H}_{14}: \mathrm{C}, 96.23, \mathrm{H}, 3.77$. Found: $\mathrm{C}, 96.53 ; \mathrm{H}, 4.02$.

Reaction of 2 with $n$-butyllithium at room temperature A solution of $n$-butyllithium (1.65 $\mathrm{M}$ in hexane, $490 \mu \mathrm{L}, 0.809 \mathrm{mmol})$ was added dropwise via a syringe to a solution of $2(99.6 \mathrm{mg}, 0.266$ $\mathrm{mmol})$ in THF $(20 \mathrm{~mL})$ at $-78^{\circ} \mathrm{C}$. After stirring at $-78^{\circ} \mathrm{C}$ for $15 \mathrm{~min}$ under an argon atmosphere, the cooling bath was removed and the reaction mixture was gradually warmed up to room temperature. After stirring at room temperature at $30 \mathrm{~min}$, water $(10 \mathrm{~mL})$ was added via a syringe and the reaction mixture was stirred for $5 \mathrm{~min}$. An aqueous solution of $\mathrm{NH}_{4} \mathrm{Cl}$ was added, and the reaction mixture was extracted with $\mathrm{CH}_{2} \mathrm{Cl}_{2}$. The extract was washed with brine and dried over anhydrous $\mathrm{MgSO}_{4}$. After removal of the solvent, the residue was purified by chromatography (silica gel, hexanes $/ \mathrm{CHCl}_{3}$ $=4 / 1$ ) followed by recrystallization from a mixture of $\mathrm{CH}_{2} \mathrm{Cl}_{2} / \mathrm{CH}_{3} \mathrm{CN}$ to afford $14 \mathrm{~d}(14.8 \mathrm{mg}, 13 \%)$ as blue solid. The presence of the tributylated product corresponding to $15 \mathbf{b}$ was indicated by the ${ }^{1} \mathrm{H}$ NMR (e.g. a diagnostic vinyl proton signal at $\delta 7.79 \mathrm{ppm}$ ), though it was not isolated, whereas the 
dibutylated product corresponding to $\mathbf{1 6 b}$ was not detected in the ${ }^{1} \mathrm{H}$ NMR spectra of the chromatography fractions. 14d: m.p. $>300{ }^{\circ} \mathrm{C} .{ }^{1} \mathrm{H} \mathrm{NMR}\left(400 \mathrm{MHz}, \mathrm{CDCl}_{3}\right) \delta 8.43(\mathrm{~d}, J=8.0 \mathrm{~Hz}$, 2H), 7.83-7.78 (m, 4H), 7.71-7.69 (m, 4H), 7.47 (dd, $J=7.2,7.2 \mathrm{~Hz}, 2 \mathrm{H}), 7.42-7.37(\mathrm{~m}, 10 \mathrm{H}), 7.14$ $(\mathrm{d}, J=7.6 \mathrm{~Hz}, 2 \mathrm{H}), 7.10(\mathrm{~d}, J=7.6 \mathrm{~Hz}, 2 \mathrm{H}), 6.31(\mathrm{~d}, J=7.6 \mathrm{~Hz}, 2 \mathrm{H}), 1.98-1.91(\mathrm{~m}, 2 \mathrm{H}), 1.19-1.11$ $(\mathrm{m}, 2 \mathrm{H}), 0.70-0.61(\mathrm{~m}, 4 \mathrm{H}), 0.34-0.28(\mathrm{~m}, 2 \mathrm{H}), 0.31(\mathrm{t}, J=7.2 \mathrm{~Hz}, 6 \mathrm{H}), 0.17-0.05(\mathrm{~m}, 2 \mathrm{H}) .{ }^{13} \mathrm{C}$ NMR $\left(100 \mathrm{MHz}, \mathrm{CDCl}_{3}\right) \delta 148.5,147.7,147.0,146.9,141.5,140.9,140.4,139.7,139.1,139.0$, $138.1,135.30,135.26,133.4,131.2,130.1,129.4,129.1,128.83,128.77,127.5,126.7,126.6,126.0$, 125.6, 121.8, 121.1, 116.8, 116.5, 62.8, 34.6, 26.3, 22.6, 13.5. IR (KBr) 3063, 2964, 2855, 1622, $1457,1411,1334,1213,1117,1001,829,735 \mathrm{~cm}^{-1}$. MS (EI) $m / z 862.5\left(\mathrm{M}^{+}\right)$. HRMS (EI) Calcd for $\mathrm{C}_{68} \mathrm{H}_{46}: 862.3600$. Found: 862.3602 .

3-[(trimethylsilyl)ethynyl]-2-naphthyl trifluoromethanesulfonate (28). $\mathrm{Pd}\left(\mathrm{PPh}_{3}\right)_{4}(40.5 \mathrm{mg}, 35.0$ $\mu \mathrm{mol})$ and $\mathrm{CuI}(12.3 \mathrm{mg}, 65.0 \mu \mathrm{mol})$ were added to a solution of $27^{30}(1.27 \mathrm{~g}, 3.00 \mathrm{mmol})$ and (trimethylsilyl)acetylene (TMSA) $(0.650 \mathrm{~mL}, 4.60 \mathrm{mmol})$ in THF $(5 \mathrm{~mL})$ and $\mathrm{Et}_{3} \mathrm{~N}(5 \mathrm{~mL})$ under an argon atmosphere. After stirring for $7 \mathrm{~h}$ at room temperature, the reaction mixture was passed through a short silica gel column $\left(\mathrm{CHCl}_{3}\right)$. The product was purified by chromatography (silica gel, hexanes/AcOEt $=97 / 3)$ to afford $28(0.959 \mathrm{~g}, 86 \%)$ as a pale yellow oil. $28:{ }^{1} \mathrm{H}$ NMR (300 MHz, $\left.\mathrm{CDCl}_{3}\right) \delta 8.09(\mathrm{~s}, 1 \mathrm{H}), 7.84-7.81(\mathrm{~m}, 2 \mathrm{H}), 7.72(\mathrm{~s}, 1 \mathrm{H}), 7.60-7.55(\mathrm{~m}, 2 \mathrm{H}), 0.31(\mathrm{~s}, 9 \mathrm{H}) .{ }^{13} \mathrm{C}$ NMR $\left(75 \mathrm{MHz} \mathrm{CDCl}_{3}\right) \delta 146.7,134.7,132.7,131.8,128.2,127.9,127.70,127.66,119.5,118.8,115.9$, $102.2,97.9,-0.41$. IR (neat) $3062,2963,2901,2163,1601,1499,1462,1428,1251,1221,1138$, $921,889,852,749,674,614 \mathrm{~cm}^{-1}$. MS (EI) $m / z 372.4\left(\mathrm{M}^{+}\right)$.

1,2-Bis(2-\{3-[(trimethylsilyl)ethynyl]naphthyl\}ethynyl)benzene (31). To a suspension of $\mathrm{K}_{2} \mathrm{CO}_{3}$ $(2.30 \mathrm{~g}, 16.6 \mathrm{mmol})$ in $\mathrm{MeOH}(15 \mathrm{~mL})$ was added a solution of $29^{31}(1.51 \mathrm{~g}, 5.58 \mathrm{mmol})$ in THF (10 $\mathrm{mL}$ ) under an argon atmosphere. After stirring at room temperature for $15 \mathrm{~min}$, an aqueous solution of $\mathrm{NH}_{4} \mathrm{Cl}$ was added. The reaction mixture was extracted with ether. The extract was washed with brine and dried over anhydrous $\mathrm{MgSO}_{4}$. After removal of the solvent, the residue was purified by chromatography (silica gel, hexanes/ $\left.\mathrm{CHCl}_{3}=9 / 1\right)$ to afford $30(536 \mathrm{mg}, 76 \%)$ as a pale yellow oil. $\mathrm{Pd}\left(\mathrm{PPh}_{3}\right)_{4}(412 \mathrm{mg}, 0.357 \mathrm{mmol})$ and $\mathrm{CuI}(136 \mathrm{mg}, 0.714 \mathrm{mmol})$ were added to a solution of 30 (450 
$\mathrm{mg}, 3.57 \mathrm{mmol})$ and $28(3.97 \mathrm{~g}, 10.7 \mathrm{mmol})$ in degassed THF $(20 \mathrm{~mL})$ and $\mathrm{Et}_{3} \mathrm{~N}(5 \mathrm{~mL})$ under an argon atmosphere. After heating for $12 \mathrm{~h}$ under reflux, an aqueous solution of $\mathrm{NH}_{4} \mathrm{Cl}$ was added. The reaction mixture was extracted with $\mathrm{CHCl}_{3}$. The extract was washed with brine and dried over anhydrous $\mathrm{MgSO}_{4}$. After removal of the solvent, the residue was purified by chromatography (silica gel, hexanes $\left./ \mathrm{CHCl}_{3}=7 / 3\right)$ to afford $31(1.50 \mathrm{~g}, 74 \%)$ as pale yellow solid. 31: m.p. $124.0-125.0^{\circ} \mathrm{C}$. ${ }^{1} \mathrm{H}$ NMR $\left(400 \mathrm{MHz}, \mathrm{CDCl}_{3}\right) \delta 8.18(\mathrm{~s}, 2 \mathrm{H}), 8.08(\mathrm{~s}, 2 \mathrm{H}), 7.78(\mathrm{~d}, J=8.0 \mathrm{~Hz}, 2 \mathrm{H}), 7.70-7.68(\mathrm{~m}, 2 \mathrm{H})$, $7.59(\mathrm{~d}, J=8.4 \mathrm{~Hz}, 2 \mathrm{H}), 7.48(\mathrm{ddd}, J=8.0,6.8,1.2 \mathrm{~Hz}, 2 \mathrm{H}), 7.44-7.37(\mathrm{~m}, 4 \mathrm{H}), 0.30(\mathrm{~s}, 18 \mathrm{H}) .{ }^{13} \mathrm{C}$ NMR $\left(100 \mathrm{MHz}, \mathrm{CDCl}_{3}\right) \delta 132.44,132.41,132.36,132.3,131.8,128.0,127.6,127.2,126.2,122.6$, 122.1, 103.6, 98.3, 92.8, 91.9, -0.01. IR (KBr) 3054, 2956, 2896, 2204, 2153, 1947, 1586, 1487, $1465,1407,1249,1159,952,893,855,745,701,646 \mathrm{~cm}^{-1}$. MS (EI) $\mathrm{m} / \mathrm{z} 570.8\left(\mathrm{M}^{+}\right)$. Anal. Calcd for $\mathrm{C}_{40} \mathrm{H}_{34} \mathrm{Si}_{2}$ : C, 84.16, H, 6.00. Found: C, 84.53; H, 6.36.

[14]DBA derivative 3. To a suspension of $\mathrm{K}_{2} \mathrm{CO}_{3}(954 \mathrm{mg}, 6.90 \mathrm{mmol})$ in $\mathrm{MeOH}(20 \mathrm{~mL})$ was added a solution of $\mathbf{3 1}$ (985 mg, $1.73 \mathrm{mmol})$ in THF (15 mL) under an argon atmosphere. After stirring for $20 \mathrm{~min}$ at room temperature, an aqueous solution of $\mathrm{NH}_{4} \mathrm{Cl}$ was added. The reaction mixture was extracted with ether. The extract was washed brine and dried over anhydrous $\mathrm{MgSO}_{4}$. After removal of the solvent, the residue was dissolved in $40 \mathrm{~mL}$ of ether. The solution containing 32 was added dropwise at room temperature to a solution of $\mathrm{Cu}(\mathrm{OAc})_{2} \cdot \mathrm{H}_{2} \mathrm{O}(1.38 \mathrm{~g}, 6.91 \mathrm{mmol})$ in pyridine $(100 \mathrm{~mL})$ over a period of $10 \mathrm{~h}$, and then the mixture was stirred for another $5 \mathrm{~h}$. The reaction mixture was passed through a short silica gel column $\left(\mathrm{CHCl}_{3}\right)$ to remove copper salts. The elute was washed with conc. $\mathrm{HCl}$ while cooling with ice bath to remove pyridine followed by brine and dried over anhydrous $\mathrm{MgSO}_{4}$. After removal of the solvent, the residual solid was washed with hexanes and AcOEt to afford 3 (359 mg, 49\%) as a pale yellow solid, which gradually decomposed at room temperature. 3: decomposed before melting. ${ }^{1} \mathrm{H} \mathrm{NMR}\left(400 \mathrm{MHz}, \mathrm{CDCl}_{3}\right) \delta 8.30(\mathrm{~s}, 2 \mathrm{H})$, $8.04(\mathrm{~s}, 2 \mathrm{H}), 7.88-7.84(\mathrm{~m}, 6 \mathrm{H}), 7.58-7.55(\mathrm{~m}, 4 \mathrm{H}), 7.43-7.41(\mathrm{~m}, 2 \mathrm{H}) .{ }^{13} \mathrm{C} \mathrm{NMR}(100 \mathrm{MHz}$, $\left.\mathrm{CDCl}_{3}\right) \delta 136.1,133.4,132.7,132.0,129.5,128.1,128.0,127.75,127.73,127.6,125.1,123.8,119.7$, 93.2, 93.1, 85.7, 80.0. IR (KBr) 3058, 2924, 2851, 2214, 2168, 1507, 1470, 1448, 1385, 754, 667, $580 \mathrm{~cm}^{-1}$. MS (LDI) $\mathrm{m} / \mathrm{z} 424.7\left(\mathrm{M}^{+}\right)$. HRMS (EI) Calcd for $\mathrm{C}_{34} \mathrm{H}_{16}: 424.1252$. Found: 424.1248. 
Reaction of 3 with $n$-butyllithium at room temperature. A solution of $n$-butyllithium (1.65 $\mathrm{M}$ in hexane, $650 \mu \mathrm{L}, 1.07 \mathrm{mmol}$ ) was added dropwise via a syringe to a solution of $3(150 \mathrm{mg}, 0.353$ $\mathrm{mmol})$ in THF $(20 \mathrm{~mL})$ at $-78{ }^{\circ} \mathrm{C}$. After stirring at $-78^{\circ} \mathrm{C}$ for $15 \mathrm{~min}$ under an argon atmosphere, the cooling bath was removed and the reaction mixture was gradually warmed up to room temperature. After stirring at $30 \mathrm{~min}$, water $(10 \mathrm{~mL})$ was added via a syringe and the reaction mixture was stirred for $5 \mathrm{~min}$. An aqueous solution of $\mathrm{NH}_{4} \mathrm{Cl}$ was added, and the reaction mixture was extracted with $\mathrm{CH}_{2} \mathrm{Cl}_{2}$. The extract was washed with brine and dried over anhydrous $\mathrm{MgSO}_{4}$. After removal of the solvent, the residue was purified by chromatography (silica gel, hexanes $/ \mathrm{CHCl}_{3}=4 / 1$ ). The initial blue color of the fraction containing $14 \mathrm{e}$ started to change to orange during chromatography, and it completely changed when a solution of the fraction was left under ambient conditions. The resulting solid was purified by recycling GPC to afford $37 \mathbf{a}(39.1 \mathrm{mg}, 23 \%)$ as an orange solid. The presence of both tributylated and dibutylated products corresponding to $\mathbf{1 5 b}$ and $\mathbf{1 6 b}$, respectively, was indicated by the ${ }^{1} \mathrm{H}$ NMR spectra (e.g. diagnostic vinyl proton signals at $\delta 6.85$ and $6.40 \mathrm{ppm}$, respectively) of the chromatography fractions, though they were not isolated. 37a: m.p. $>300{ }^{\circ} \mathrm{C} .{ }^{1} \mathrm{H}$ NMR (400 MHz, $\left.\mathrm{CDCl}_{3}\right) \delta 9.09(\mathrm{~d}, J=8.4 \mathrm{~Hz}, 2 \mathrm{H}), 8.37(\mathrm{~s}, 2 \mathrm{H}), 8.23(\mathrm{~d}, J=7.6 \mathrm{~Hz}, 2 \mathrm{H}), 8.22(\mathrm{~s}$, $2 \mathrm{H}), 8.06(\mathrm{~d}, J=8.4 \mathrm{~Hz}, 2 \mathrm{H}), 7.68(\mathrm{dd}, J=7.6,7.6 \mathrm{~Hz}, 2 \mathrm{H}), 7.55(\mathrm{dd}, J=8.0,7.6 \mathrm{~Hz}, 4 \mathrm{H}), 7.35-$ $7.32(\mathrm{~m}, 6 \mathrm{H}), 7.15-7.13(\mathrm{~m}, 6 \mathrm{H}), 6.52(\mathrm{~s}, 2 \mathrm{H}), 2.03-1.96(\mathrm{~m}, 2 \mathrm{H}), 1.46-1.38(\mathrm{~m}, 2 \mathrm{H}), 0.62-0.53(\mathrm{~m}$, $4 \mathrm{H}), 0.44-0.33(\mathrm{~m}, 2 \mathrm{H}), 0.24-0.14(\mathrm{~m}, 2 \mathrm{H}), 0.20(\mathrm{t}, J=7.2 \mathrm{~Hz}, 6 \mathrm{H}) .{ }^{13} \mathrm{C} \mathrm{NMR}\left(100 \mathrm{MHz}, \mathrm{CDCl}_{3}\right) \delta$ $151.6,151.1,147.5,144.9,143.1,142.8,138.1,138.0,135.9,134.9,133.4,133.0,132.4,131.9$, $130.9,130.6,129.7,129.43,129.39,129.3,129.0,128.8,128.7,127.7,126.6,126.0,125.4,125.1$, $124.9,122.7,119.5,118.9,118.8,64.3,38.6,26.6,22.6,13.6$. IR (KBr) 3063, 2964, 2855, 1622, $1457,1411,1334,1213,1117,1001,829,735 \mathrm{~cm}^{-1}$. MS (EI) $m / z 961.6\left(M^{+}\right)$. Anal. Calcd for $\mathrm{C}_{76} \mathrm{H}_{48}$ : C, 94.97; H, 5.03. Found: C, 94.59; H, 4.88 .

2,3-Bis(2-\{3-[(trimethylsilyl)ethynyl]naphthyl\}ethynyl)naphthalene (35). To a suspension of $\mathrm{K}_{2} \mathrm{CO}_{3}(5.16 \mathrm{~g}, 37.3 \mathrm{mmol})$ in $\mathrm{MeOH}(30 \mathrm{~mL})$ was added a solution of $33^{32}$ (3.00 g, $\left.9.36 \mathrm{mmol}\right)$ in THF (20 mL) under an argon atmosphere. After stirring for $15 \mathrm{~min}$ at room temperature, an aqueous solution of $\mathrm{NH}_{4} \mathrm{Cl}$ was added. The reaction mixture was extracted with ether. The extract was washed with brine and dried over anhydrous $\mathrm{MgSO}_{4}$. After removal of the solvent, the residue was purified 
by chromatography (silica gel, hexanes $\left./ \mathrm{CHCl}_{3}=4 / 1\right)$ to afford $34(1.25 \mathrm{~g}, 76 \%)$ as a white solid. $\mathrm{Pd}\left(\mathrm{PPh}_{3}\right)_{4}(555 \mathrm{mg}, 0.480 \mathrm{mmol})$ and $\mathrm{CuI}(181 \mathrm{mg}, 0.950 \mathrm{mmol})$ were added to a solution of 28 $(5.45 \mathrm{~g}, 14.6 \mathrm{mmol})$ in degassed THF $(20 \mathrm{~mL})$ and $\mathrm{Et}_{3} \mathrm{~N}(5 \mathrm{~mL})$. After heating under reflux for $12 \mathrm{~h}$, an aqueous solution of $\mathrm{NH}_{4} \mathrm{Cl}$ was added. The reaction mixture was extracted with $\mathrm{CHCl}_{3}$. The extract was washed with brine and dried over anhydrous $\mathrm{MgSO}_{4}$. After removal of the solvent, the residue was purified by chromatography (silica gel, hexanes $\left./ \mathrm{CHCl}_{3}=4 / 1\right)$ to afford $35(2.08 \mathrm{~g}, 69 \%)$ as a white solid. 35: m.p. $194.0-196.0^{\circ} \mathrm{C} .{ }^{1} \mathrm{H}$ NMR ( $\left.400 \mathrm{MHz}, \mathrm{CDCl}_{3}\right) \delta 8.19$ (s, 2H), 8.17 (s, 2H), 8.08 (s, 2H), 7.83-7.80 (m, 2H), 7.78 (d, $J=8.4 \mathrm{~Hz}, 2 \mathrm{H}), 7.58$ (d, $J=8.0 \mathrm{~Hz}, 2 \mathrm{H}), 7.54-7.52$ (m, 2H), 7.48 (ddd, $J=7.6,7.6,1.2 \mathrm{~Hz}, 2 \mathrm{H}), 7.42$ (ddd, $J=7.6,7.6,1.2 \mathrm{~Hz}, 2 \mathrm{H}), 0.30(\mathrm{~s}, 18 \mathrm{H}) ;{ }^{13} \mathrm{C}$ NMR $\left(100 \mathrm{MHz}, \mathrm{CDCl}_{3}\right) \delta 132.52,132.47,132.38,132.36,131.8,127.7,127.6,127.27,127.25$, 127.2, 122.8, 122.7, 122.2, 103.7, 98.3, 92.3, 92.1, 0.06. IR (KBr) 2956, 2196, 2148, 1248, 842, 818, $750 \mathrm{~cm}^{-1}$. MS (EI) $m / z 620.9\left(\mathrm{M}^{+}\right)$. HRMS (EI) Calcd for $\mathrm{C}_{44} \mathrm{H}_{36} \mathrm{Si}_{2}: 620.2356$. Found: 620.2355 .

[14]DBA derivative 4. To a suspension of $\mathrm{K}_{2} \mathrm{CO}_{3}(450 \mathrm{mg}, 3.26 \mathrm{mmol})$ in $\mathrm{MeOH}(20 \mathrm{~mL})$ was added a solution of $35(501 \mathrm{mg}, 0.807 \mathrm{mmol})$ in THF $(20 \mathrm{~mL})$ under an argon atmosphere. After stirring at room temperature for $15 \mathrm{~min}$, an aqueous solution of $\mathrm{NH}_{4} \mathrm{Cl}$ was added. The reaction mixture was extracted with ether. The extract was washed with brine and dried over anhydrous $\mathrm{MgSO}_{4}$. After removal of the solvent, the residue was dissolved in $100 \mathrm{~mL}$ of ether. The solution containing 36 was added dropwise at room temperature to a solution of $\mathrm{Cu}(\mathrm{OAc})_{2} \cdot \mathrm{H}_{2} \mathrm{O}(645 \mathrm{mg}$, $3.23 \mathrm{mmol})$ in pyridine $(100 \mathrm{~mL}$ ) over a period of $12 \mathrm{~h}$, and the mixture was stirred for another $5 \mathrm{~h}$. The reaction mixture was passed through a short silica gel column $\left(\mathrm{CHCl}_{3}\right)$ to remove copper salts. The elute was washed with conc. $\mathrm{HCl}$ while cooling with ice bath to remove pyridine followed by brine and dried over anhydrous $\mathrm{MgSO}_{4}$. After removal of the solvent, the residue was washed with AcOEt to afford 4 (214 mg, 56\%) as a pale yellow solid. 4: m.p. $>300{ }^{\circ} \mathrm{C} .{ }^{1} \mathrm{H}$ NMR (400 MHz, $\left.\mathrm{CDCl}_{3}\right) \delta 8.40(\mathrm{~s}, 2 \mathrm{H}), 8.35(\mathrm{~s}, 2 \mathrm{H}), 8.02(\mathrm{~s}, 2 \mathrm{H}), 7.90-7.88(\mathrm{~m}, 4 \mathrm{H}), 7.85-7.83(\mathrm{~m}, 2 \mathrm{H}), 7.59-7.54$ $(\mathrm{m}, 6 \mathrm{H}) .{ }^{13} \mathrm{C} \mathrm{NMR}\left(100 \mathrm{MHz}, \mathrm{CDCl}_{3}\right) \delta 136.6,133.5,132.8,132.4,132.1,129.5,128.0,127.8$, 127.7, 127.6, 127.5, 127.4, 125.3, 120.7, 119.8, 93.3, 92.3, 85.8, 80.0. IR (KBr) 3058, 2924, 2851, 2214, 2168, 1507, 1470, 1448, 1385, 754, 667, $580 \mathrm{~cm}^{-1}$. MS (EI) $\mathrm{m} / \mathrm{z} 474.7\left(\mathrm{M}^{+}\right)$. Anal. Calcd for 
$\mathrm{C}_{38} \mathrm{H}_{18}: \mathrm{C}, 96.18 ; \mathrm{H}, 3.82$. Found: C, 96.46; H, 4.06.

Reaction of 4 with $n$-butyllithium at room temperature. A solution of $n$-butyllithium (1.65 $\mathrm{M}$ in hexane, $670 \mu \mathrm{L}, 1.11 \mathrm{mmol})$ was added dropwise via a syringe to a solution of $4(173 \mathrm{mg}, 0.365$ $\mathrm{mmol})$ in THF $(20 \mathrm{~mL})$ at $-78^{\circ} \mathrm{C}$. After stirring at $-78^{\circ} \mathrm{C}$ for $15 \mathrm{~min}$ under an argon atmosphere, the cooling bath was removed and the reaction mixture was gradually warmed up to room temperature. After stirring at $30 \mathrm{~min}$, water $(10 \mathrm{~mL})$ was added via a syringe and the reaction mixture was stirred for $5 \mathrm{~min}$. An aqueous solution of $\mathrm{NH}_{4} \mathrm{Cl}$ was added, and the reaction mixture was extracted with $\mathrm{CH}_{2} \mathrm{Cl}_{2}$. The extract was washed with brine and dried over anhydrous $\mathrm{MgSO}_{4}$. After removal of the solvent, the residue was purified by chromatography (silica gel, hexanes $/ \mathrm{CHCl}_{3}=4 / 1$ ). The initial blue color of the fraction containing $14 \mathrm{e}$ started to change to orange during chromatography, and it completely changed when a solution of the fraction was left under ambient conditions. The residual solid was purified by recycling GPC followed by recrystallization from a mixture of $\mathrm{CH}_{2} \mathrm{Cl}_{2} / \mathrm{CH}_{3} \mathrm{CN}$ to afford $37 \mathbf{b}(60.5 \mathrm{mg}, 31 \%)$ as an orange solid. The presence of neither tributylated nor dibutylated products corresponding $15 \mathrm{~b}$ and $16 \mathrm{~b}$, respectively, was indicated in the ${ }^{1} \mathrm{H}$ NMR spectra of the chromatography fractions. 37b: m.p. $>300{ }^{\circ} \mathrm{C} .{ }^{1} \mathrm{H}$ NMR $\left(400 \mathrm{MHz}, \mathrm{CDCl}_{3}\right) \delta 9.13(\mathrm{~d}, \mathrm{~J}=8.4 \mathrm{~Hz}$, $2 \mathrm{H}), 8.53(\mathrm{~s}, 2 \mathrm{H}), 8.37(\mathrm{~s}, 2 \mathrm{H}), 8.33(\mathrm{~d}, J=7.6 \mathrm{~Hz}, 2 \mathrm{H}), 8.17(\mathrm{~d}, J=8.0 \mathrm{~Hz}, 2 \mathrm{H}), 7.84-7.81(\mathrm{~m}, 4 \mathrm{H})$, $7.72(\mathrm{dd}, J=7.6,7.2 \mathrm{~Hz}, 2 \mathrm{H}), 7.61-7.54(\mathrm{~m}, 8 \mathrm{H}), 7.50-7.47(\mathrm{~m}, 4 \mathrm{H}), 7.37(\mathrm{dd}, J=7.6,7.2 \mathrm{~Hz}, 2 \mathrm{H})$, $7.18(\mathrm{~d}, J=8.0 \mathrm{~Hz}, 2 \mathrm{H}), 6.58(\mathrm{~s}, 2 \mathrm{H}), 2.13-2.07(\mathrm{~m}, 2 \mathrm{H}), 1.53-1.45(\mathrm{~m}, 2 \mathrm{H}), 0.60-0.53(\mathrm{~m}, 4 \mathrm{H})$, 0.39-0.32 (m, 2H), 0.25-0.15 (m, 2H), $0.19(\mathrm{t}, J=7.2 \mathrm{~Hz}, 6 \mathrm{H}) .{ }^{13} \mathrm{C}$ NMR $\left(100 \mathrm{MHz}, \mathrm{CDCl}_{3}\right) \delta$ $148.4,147.3,146.9,144.9,142.4,142.2,138.1,137.8,136.9,135.4,135.3,135.0,134.0,133.5$, $133.0,132.4,132.0,131.3,131.0,130.7,129.8,129.6,129.5,129.0,128.9,128.8,127.8,127.6$, $127.3,126.7,126.1,125.6,125.1,123.3,119.8,116.8,116.7,64.1,36.6,26.6,22.7,13.5 . \mathrm{IR}(\mathrm{KBr})$ $3063,2964,2855,1622,1457,1411,1334,1213,1117,1001,829,735 \mathrm{~cm}^{-1}$. MS (FAB) $m / z 1061.6$ $\left(\mathrm{M}^{+}\right)$. HRMS (EI) Calcd for $\mathrm{C}_{84} \mathrm{H}_{52}: 1060.4069$. Found: 1060.4071. 


\subsection{References and Notes}

(1) For recent general discussions about alkyne cyclizations, see: (a) Wang, K. K. Chem. Rev. 1996, 96, 207-222. (b) Gilmore, K.; Alabugin, I. V. Chem. Rev. 2011, 111, 6513-6556. (c) Alabugin, I. V.; Gilmore, K.; Monoharan, M. J. Am. Chem. Soc. 2011, 133, 12608-12623.

(2) (a) Zhou, Q.; Carroll, P. J.; Swager, T. M. J. Org. Chem. 1994, 59, 1294-1301. (b) T. Takeda, T.; Inukai, K.; Tahara, K.; Tobe, Y. J. Org. Chem. 2011, 76, 9116-9121. (c) Chase, D. T.; Rose, B. D.; McClintock, S. P.; Zakharov, L. N.; Haley, M. M. Angew. Chem. 2011, 123, 1159-1162; Angew. Chem. Int. Ed. 2011, 50, 1127-1130.

(3) (a) Youngs, W. J.; Djebli, A.; Tessier, C. A. Organometallics 1991, 10, 2089-2090. (b) Malaba, D.; Djebli, A.; Chen, L.; Zarate, E. A.; Tessier, C. A.; Youngs, W. J. Organometallics 1993, 12, 1266-1276. (c) Alabugin, I. V.; Gilmore, K.; Patil, S.; Monoharan, M.; Kovalenko, S. V.; Clark, R. J.; Ghiviriga, I. J. Am. Chem. Soc. 2008, 130, 11535-11545.

(4) (a) Babu, G.; Orita, A.; Otera, J. Chem. Lett. 2008, 37, 1296-1297. (b) Xu, F.; Peng, L.; Orita, A.; Otera, J. Org. Lett. 2012, 14, 3970-3973.

(5) (a) Schreiner, P. R.; Prall, M.; Lutz, V. Angew. Chem. 2003, 115, 5935-5938; Angew. Chem. Int. Ed. 2003, 42, 5757-5760. (b) Chen, X.; Lu, P.; Wang, Y. Chem. Eur. J. 2011, 17, 8105-8114. (c) Huang, X.; Zeng, L.; Zeng, Z.; Wu, J. Chem. Eur. J. 2011, 17, 14907-14915.

(6) (a) Alabugin, I. V.; Monoharan, M. J. Am. Chem. Soc. 2005, 127, 12583-12594; b) I. V. Alabugin, I. V.; Timokhin, V. I.; Abrams, J. N.; Monoharan, M.; Abrams, R.; Ghiviriga, I. J. Am. Chem. Soc. 2008, 130, 10984-10995. (c) Byers, P. M.; Alabugin, I. V. J. Am. Chem. Soc. 2012, 134, 9609-9614.

(7) Bradshaw, J. D.; Solooki, D.; Tessier, C. A.; Youngs, W. J. J. Am. Chem. Soc. 1994, 116, 3177-3179.

(8) (a) Baldwin, K. P.; Matzger, A. J.; Scheiman, D. A.; Tessier, C. A.; Vollhardt, K. P. C.; Youngs, W. J. Synlett 1995, 1215-1218. (b) Marden, J. A.; Miller, J. J.; Haley, M. M. Angew. Chem. 2004, 116, 1726-1729; Angew. Chem. Int. Ed. 2004, 43, 1694-1697.

(9) (a) Normant, J. F.; Alexakis, A. Synthesis 1981, 841-870. (b) Zhang, D.; Ready, J. M. J. Am. Chem. Soc. 2006, 128, 15050-15051.

(10) (a) Étienne, A.; Le Berre, A. C. R. Hebd. Seances Acad. Sci. 1956, 242, 1493-1496. (b) Étienne, 
A.; Le Berre, A. C. R. Hebd. Seances Acad. Sci. 1956, 242, 1899-1901. (c) Le Berre, A. C. R. Hebd. Seances Acad. Sci. 1956, 242, 2365-2367. (d) Le Berre, A. Ann. Chim. 1957, 13, 371-379.

(11) Shimizu, A.; Tobe, Y. Angew. Chem. 2011, 123, 7038-7042; Angew. Chem. Int. Ed. 2011, 50, 6906-6910.

(12) Pople, J. A.; Untch, K. G. J. Am. Chem. Soc. 1966, 88, 4811-4815.

(13) Compound $\mathbf{1 4 b}$ was best obtained when 3 equivalents of $n$-BuLi and THF as solvent were used. When 1 equivalent of $n$-BuLi was used, about one half of the starting material $\mathbf{1 b}$ was recovered giving a mixture products which did not contain $\mathbf{1 4 b .}$

(14) For the examples of structure elucidation by using HMBC NMR experiments, see: (a) M. A. J. Akkerman, M. A. J.; Neijman, E. W. J. F.; Wijmenga, S. S.; Hilbers, C. W.; Bermel, W. J. Am. Chem. Soc. 1990, 112, 7462-7474. (b) Köck, M.; Reif, B.; Fenical, W.; Griesinger, C. Tetrahedron Lett. $1996,37,363-366$.

(15) (a) Claridge, T. D. W. High-Resolution NMR Techniques in Organic Chemistry, Vol. 19, Elsevier Science, 1999, pp. 250-257. (b) Hansen, P. E. Prog. Nucl. Magn. Reson. Spectrosc. 1981, 14, 179-296. (c) Vasavi, Y.; Parthiban, N.; Kumar, D. S.; Banji, D.; Srisutherson, N.; Ghosh, S.; Chakravarthy, M. V. K. Int. J. Pharm. Tech. Res. 2011, 3, 1410-1422.

(16) Though the reasons for these discrepancies are not understood, one possible interpretation is the relatively low activation energies for the four-membered ring formation (to give $\mathbf{9}$ from $\mathbf{7}$ or $\mathbf{1 0}$ from 9) compared to those for the five-membered ring formation (to give $\mathbf{8}$ from 7 or $\mathbf{1 1}$ from 9) because of the proximity effect. Namely, the calculated distance between the $\mathrm{C}-\mathrm{C}$ bond formation carbons in 7 is shorter for the four-membered ring formation (2.92 $\AA$ ) than for the five-membered ring formation $(3.69 \AA)$. In the case of 9, the corresponding distances are 2.82 and $3.24 \AA$, respectively. Though this explanation contradicts the Baldwin's rule (i.e. 4-exo-dig vs. 5-endo-dig modes), the steric constraint due to the medium-sized rings of 7 and 9 would play a major role for the inversed selectivity. Baldwin, J. E. J. Chem. Soc., Chem. Commun. 1976, 734-736.

(17) (a) Murata, Y.; Komatsu, K.; Wan, T. S. M. Tetrahedron Lett. 1996, 37, 7061-7064. (b) Schick, G.; Kampe, K. D.; Hirsch, A. J. Chem. Soc., Chem. Commun. 1995, 2023-2024. (c) Zhang, Y.; Matsuo, Y.; Li, C. Z.; Tanaka, H.; Nakamura, E. J. Am. Chem. Soc. 2011, 133, 8086-8089. 
(18) An air oxidation of a dicyclopentadienyl dianion to a fulvalene structure has been known: (a) Escher, A.; Rutsch, W.; Neuenschwander, M. Helv. Chem. Acta. 1986, 69, 1644-1654. (b) Peabody, S. W.; Breiner, B.; Kovalenko, S. V.; Patil, S.; Alabugin, I. V. Org. Biomol. Chem. 2005, 3, $218-221$. (19) The transition state search was undertaken at TS-Technology Inc.

(20) (a) Dillet, V.; Rinaldi, D.; Rivail, J. L. J. Phys. Chem. 1994, 98, 5034-5039. (b) Dillet, V.; Rinaldi, D.; Bertrán, J.; Rivail, J. L. J. Chem. Phys. 1996, 104, 9437-9444.

(21) Barone, V.; Cossi, M. J. Phys. Chem. A 1998, 102, 1995-2001.

(22) Takano, Y.; Houk, K. N. J. Chem. Theory Comput. 2005, 1, 70-77.

(23) Frank, N. L.; Siegel J. S. in Advances in Theoretically Interesting Molecules, Vol. 3 (Eds.: R. P. Thummel), JAI Press, 1995, pp. 209-260.

(24) The reaction of $\mathbf{1 b}$ with $\mathrm{MeLi}, t-\mathrm{BuLi}$, and $\mathrm{PhLi}$ only gave complex mixtures of products which did not contain products corresponding to $\mathbf{1 4 - 1 6}$. The reason for this different reactivity is not clarified.

(25) (a) Weiner, M. A.; West, R. J. Am. Chem. Soc. 1963, 85, 485-486. (b) R. C. Morrison, Patent WO/1983/003251, PCT/US1983/000314

(26) For the reaction of 2-4, tributylated (2e-oxidized) and dibutylated (2e-reduced) products corresponding to $\mathbf{1 5 b}$ and $\mathbf{1 6 b}$ were occasionally detected in the chromatography fractions by ${ }^{1} \mathrm{H}$ NMR spectra, though they were not isolated. For the detail, see Experimental Section in Supporting Information.

(27) (a) Brunetti, F. G.; Gong, X.; Tang, M.; Heeger, A. J.; Wudl, F. Angew. Chem. 2010, 122, 542-546; Angew. Chem. Int. Ed. 2010, 49, 532-536. (b) Gong, X.; Tong, M.; Brunetti, F. G.; Seo, J.; Sun, Y.; Moses, D.; Wudl, F.; Heeger, A. J. Adv. Mater. 2011, 23, 2272-2277. (c) Sun, G. Y.; Li, H. B.; Geng, Y.; Su, Z. M. Theor. Chem. Acc. 2012, 131, 1099-1107.

(28) (a) Koster, L. J. A.; Mihailetchi, V. D.; Blom, P. W. M. Appl. Phys. Lett. 2006, 88, 093511-093513. (b) Scharber, M. C.; Mühlbacher, D.; Koppe, M.; Denk, P.; Waldauf, C.; Heeger, A. J.; Brabec, C. J. Adv. Mater. 2006, 18, 789-794. (c) Dennler, G.; Schaber, M. C.; Ameri, T.; Denk, P.; Forberich, K.; Waldauf, C.; Brabec, C. J. Adv. Mater. 2008, 20, 579-583. (d) Ross, R. B.; Cardona, C. M.; Guldi, D. M.; Sankaranarayanan, S. G.; Reese, M. O.; Kopidakis, N.; Peet, J.; Walker, B.; Bazan, 
G. C.; Keuren, E. V.; Holloway, B. C.; Drees, M. Nat. Mater. 2009, 8, 208-212.

(29) Nobusue, S.; Mukai, Y.; Fukumoto, Y.; Umeda, R.; Tahara, K.; Sonoda, M.; Tobe, Y. Chem. Eur. J. 2012, 18, 12814-12824.

(30) Frigoli, M.; Moustrou, C.; Samat, A.; Guglielmetti, R. Eur. J. Org. Chem. 2003, 2799-2812.

(31) Yasuike, S.; Kiharada, T.; Tsuchiya, T.; Kurita, J. J. Chem. Pharm. Bull. 2003, 51, 1283-1288.

(32) Bowles, D. M.; Anthony, J. E. Org. Lett. 2000, 2, 85-87. 
Chapter 4

Synthesis and Properties of Indeno[2,1-a]fluorene Dimer Having Twisted Cyclooctatetraene Core 


\subsection{Introduction}

Cyclooctatetraene (COT) adopts a nonplanar tub-shaped conformation of $D_{2 d}$ symmetry with alternating single and double bonds in the ground state. ${ }^{1}$ Though the dihedral angle between vicinal double bonds is $56^{\circ}$ in the crystal structure so that the conjugation interaction between $\pi$ bonds is small, this geometry satisfies the bond angle constraint. ${ }^{2}$ It is well known that the variable-temperature NMR spectra of substituted COT derivatives exhibited the dynamic processes due to ring inversion and $\pi$-bond shifts (Scheme 1). ${ }^{3}$ The planar $D_{4 h}$ and $D_{8 h}$ structures, in which the double bonds are localized or delocalized, are only the presumable transition states of double bond shifts and ring inversions, respectively. This assumption is also supported by theoretical calculations. ${ }^{4}$ Since the planar $D_{4 h}$ and $D_{8 h}$ structures represent nonaromatic and anti-aromatic $8 \pi$ systems, respectively, the destabilization energy due to $8 \pi$ anti-aromaticity was estimated to be ca. $2.4 \mathrm{kcal} / \mathrm{mol}$ on the basis of the experimentally determined difference between these transition state energies, i.e., the barriers for ring inversion and bond shifting. ${ }^{3 \mathrm{~b}}$

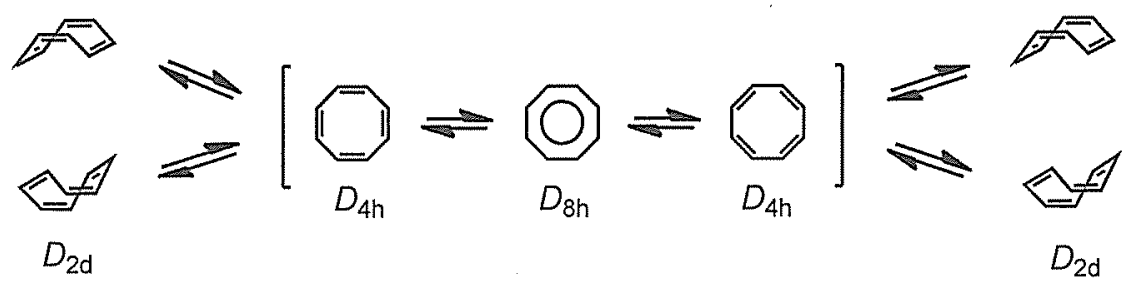

Scheme 1. Schematic drawings of ring inversion and double bond shifts of COT.

Because it is difficult to experimentally investigate the unsubstituted planar COT, planarized geometries of COTs have been achieved by annelation of small rings to make the inner bond angles of the eight-membered ring larger or embedding the COT system into a part of a large rigid $\pi$-system (Figure 1). ${ }^{5}$ For instance, planar COTs $1^{6}$ and $2^{7}$ quarter-annelated with tetrafluorocyclobutene and bicyclo[2.1.1]hexene units, respectively, have been synthesized and proved to adopt approximately planar conformations with apparent bond length alternation by X-ray crystallographic analyses. Cyclic quaterthiophene 3 planarized by the sulfur bridges have also been synthesized. ${ }^{8}$ On the other hand, fused tetrameric porphyrin sheet 4 and its analogues bearing a COT unit at the center of the molecular backbone, which are estimated to adopt planar geometries by theoretical calculation, have 
been synthesized. ${ }^{9}$ As shown in Figure 1, the $\operatorname{NICS}^{10}$ values of the hypothetical planar COT and the congeners enforced to adopt planar geometries are large positive values, indicative of strong anti-aromaticity of planar COT. Therefore, the previous researches for the COT ring systems are limited to those bearing natural tub-shape and those enforced to adopt planar conformations.

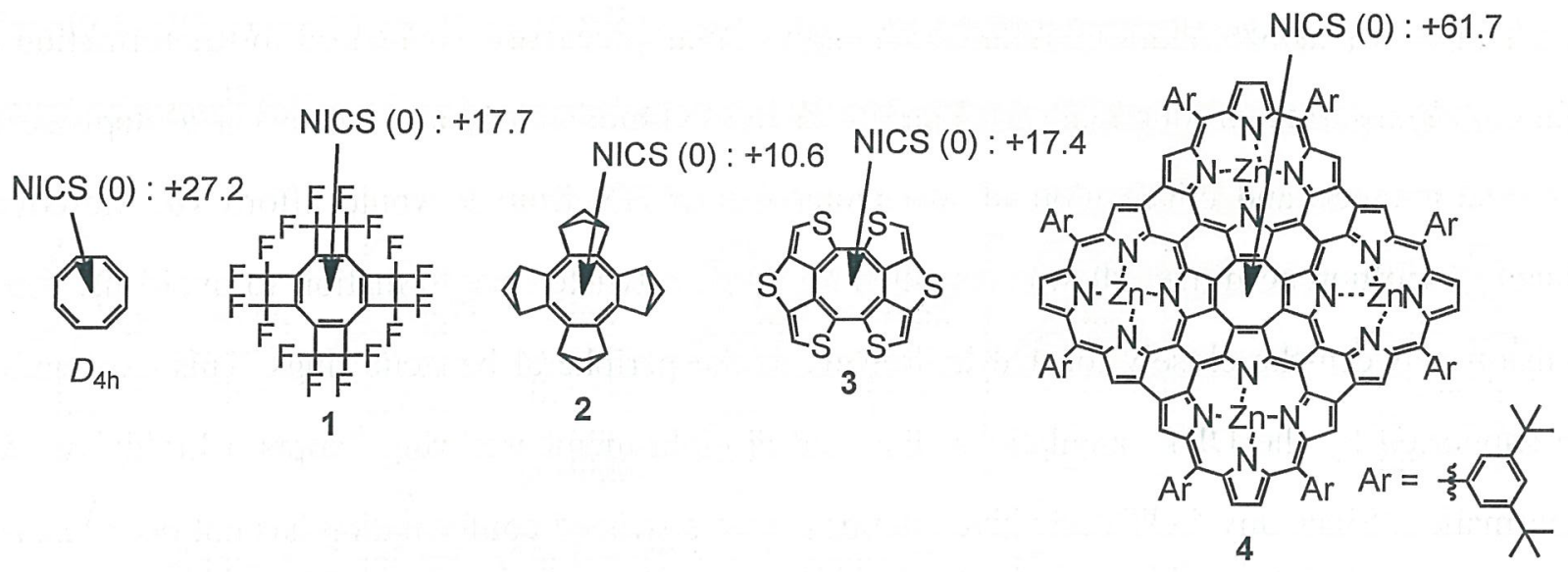

Figure 1. Hypothetical planar COT $\left(D_{4 h}\right)$ and planarized COT derivatves and their NICS $(0)$ values.

As described in Chapter 3, the author discovered that the reaction of dehydrobenzo[14]annulene ([14]DBA) 5 induced by an addition of $n$-butyllithium led to an unprecedented cyclodimerization to form eight-membered ring product 7 in which two indeno[2,1-a]fluorene components are connected by a single and a double bonds, following three-fold transannular bond formations across the 14-membered ring of 5 (Scheme 2). Though the reaction mechanism to form the eight-membered ring was not fully understood, the author conjectured that this anomalous, formal [4+4] cyclodimerization reaction took place because of the biradical character of a plausible intermediate 6 having an indeno[2,1-a]fluorene structure.
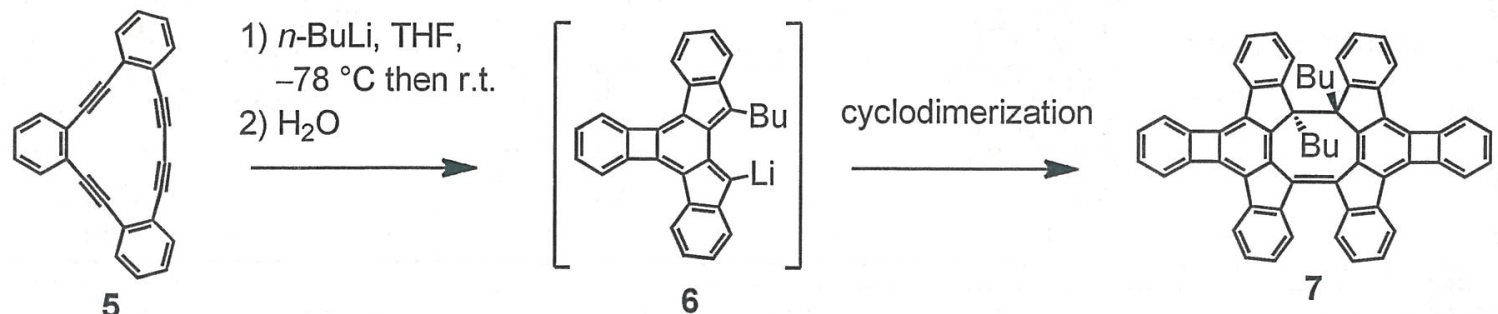

Scheme 2. Unprecedented dimerization of $\mathbf{5}$ induced by an addition of $n$-butyllithium. 
Inspired by this unusual ring formation, i.e., potential [4+4] cyclodimerization of an indeno[2,1-a]fluorene derivative, the author designed a synthetic route to a new polycyclic ring system 10,11,11':12,12'-biindeno[2,1-a]fluorenediylidene, consisting of two indeno[2,1-a]fluorene units connected by two double bonds via cyclodimerization of indeno[2,1-a]fluorene derivative 8 having a leaving group as shown in Scheme 3. Namely, the author conjectured that in-situ generation of indeno[2,1-a]fluorene derivative 8 from an appropriate precursor would lead to the formation of eight-membered ring product 9 by formal [4+4] cyclodimerization, no matter via a stepwise or concerted manner, and elimination of two molecules of HX from 9 would afford 10. Moreover, indeno[2,1-a]fluorene dimer $\mathbf{1 0}$ was expected to adopt a twisted conformation to avoid the steric repulsion between the closely located hydrogens of the peripheral benzene rings. This expectation was supported by the DFT calculations; the central eight-membered ring adopts a highly twisted conformation. Since any COT derivative adopting such a twisted conformation has not been known, it is of great interest to study the physical properties of this ring system. In addition, since the molecular framework of $\mathbf{1 0}$ is $C_{2}$ symmetric structure and therefore is chiral, if the barrier for the ring flip is large enough for isolation of enantiomer (typically $>22 \mathrm{kcal} / \mathrm{mol}$ ), 10 may provide a new basis for chiral ligands of $C_{2}$ symmetry which are potentially useful for chiral catalysts. On the other hand, C-C bond formation by oxidative dehydrogenation at the closely located carbon atoms of $\mathbf{1 0}$ would give a new planar hydrocarbon framework 11 having a planar COT unit in the center. Although the carbon framework fused by five- and six-membered rings around the central eight-membered ring (i.e., the one corresponding to devoid of the peripheral benzene rings of 10 ) was already prepared. ${ }^{11}$ its physical properties are still unexplored because the previous works focused mainly on the anti-aromaticity of the COT ring.

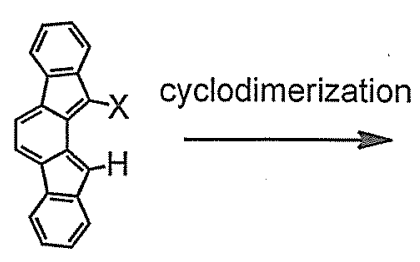

8

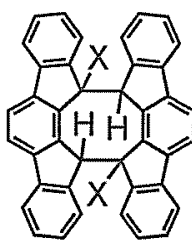

9

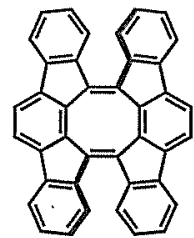

10

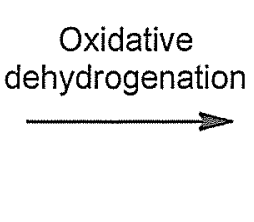

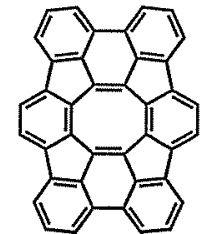

11

Scheme 3. A proposed reaction pathway for the formation of indeno[2,1-a]fluorene dimer $\mathbf{1 0}$. 


\subsection{Synthesis, Crystal Structure, and Properties of Indeno[2,1-a]fluorene Dimer}

To generate indenofluorene derivative $\mathbf{8}$, the author planned to use 11,12-dibromo-11,12-dihydroindeno[2,1-a]fluorene (14) as its precursor. Namely, the author conjectured that the desired intermediate $8(\mathrm{X}=\mathrm{Br})$ would be generated from 14 via a 1,4-elimination of $\mathrm{HBr}$ by treatment with a base. Compound 14 was prepared from the known indeno $[2,1-a]$ fluorene-11,12-dione $(12)^{12}$ by reduction with $\mathrm{NaBH}_{4}$ in $\mathrm{THF}$ in the presence of a small amount of water ${ }^{13}$ followed by bromination of diol 13 with $\mathrm{PBr}_{3}$ in $72 \%$ yield for 2 steps (Scheme 4).

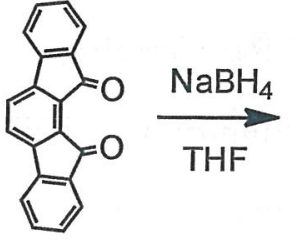

12

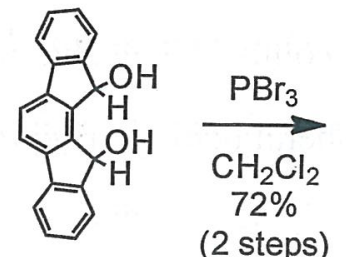

13

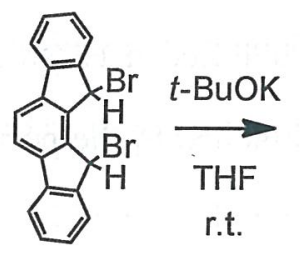

14

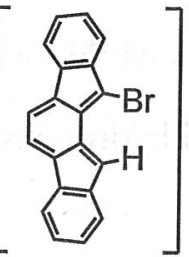

$8(X=B r)$

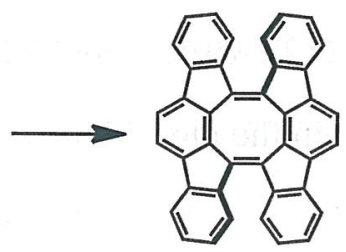

$10(34 \%)$

Scheme 4. Synthesis of indeno[2,1-a]fluorene dimer $\mathbf{1 0}$ and preparation of $\mathbf{1 4}$.

When 14 was treated with potassium tert-butoxide in THF at room temperature, a single product 10, which exhibited green color in solid state and in concentrated solution, was obtained in $34 \%$
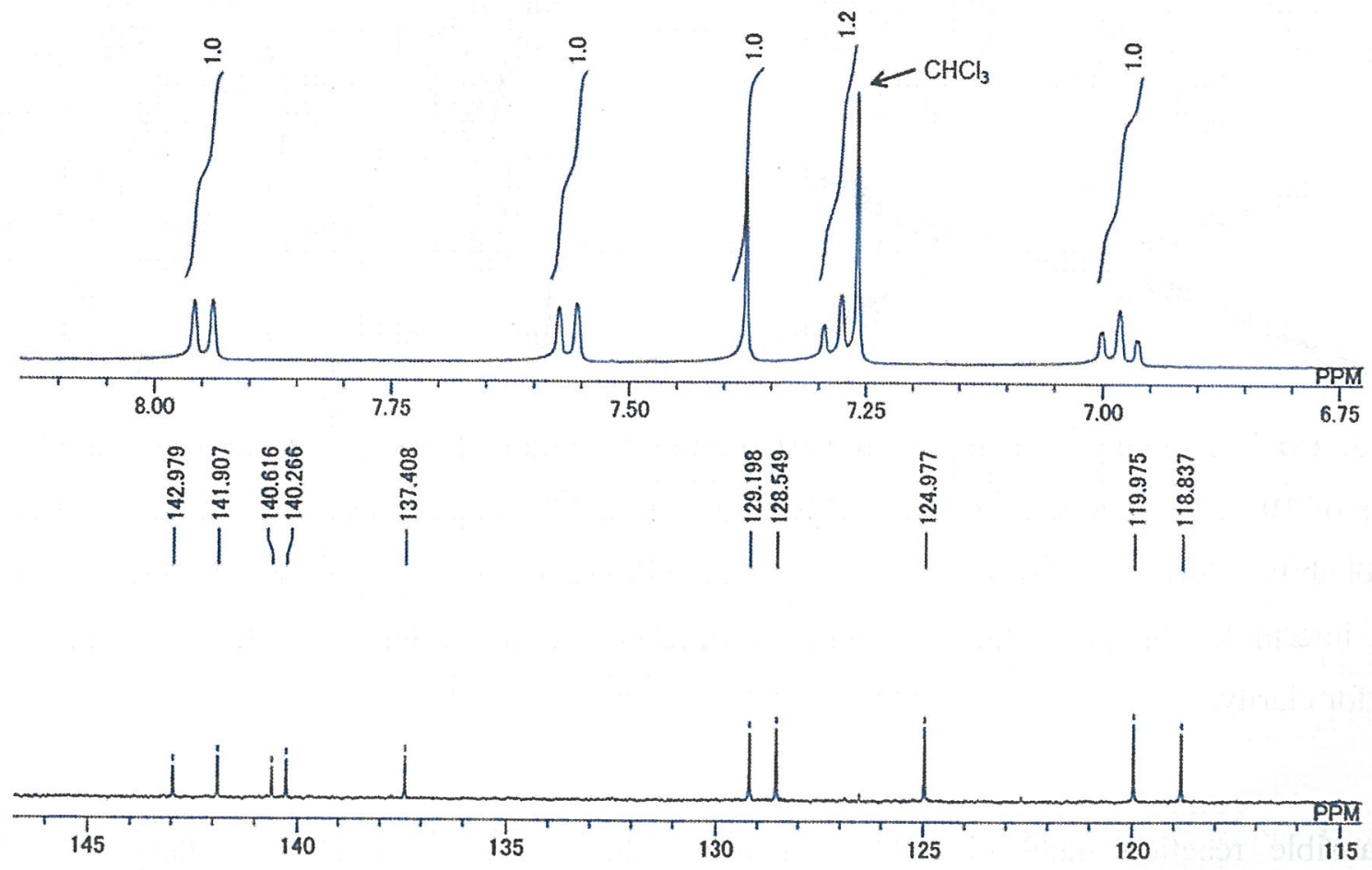

Figure 2. Partial ${ }^{1} \mathrm{H}$ and ${ }^{13} \mathrm{C}$ NMR spectra of $\mathbf{1 0}$. 
yield. The mass spectrum of $\mathbf{1 0}$ indicated that the molecular formula $\left(\mathrm{C}_{40} \mathrm{H}_{20}\right)$ corresponded a dimer of $8\left(\mathrm{X}=\mathrm{Br}\right.$ ) minus two molecules of $\mathrm{HBr}$. Additionally, ${ }^{1} \mathrm{H}$ and ${ }^{13} \mathrm{C}$ NMR spectra of $\mathbf{1 0}$ (Figure 2) implied that $\mathbf{1 0}$ had a highly symmetric structure consisting of only $\mathrm{sp}^{2}$ carbon atoms as indicated by the presence of $20 \mathrm{sp}^{2}$ carbon signals in the ${ }^{13} \mathrm{C}$ NMR spectrum. These spectral data agreed with the desired dimeric product $\mathbf{1 0}$. Recrystallization of $\mathbf{1 0}$ from a mixture of benzene/methanol solution gave a green crystal suitable for X-ray crystallography, and the final structural determination of $\mathbf{1 0}$ was done by X-ray crystallographic analysis as shown in Figure 3.

The X-ray crystallographic analysis of $\mathbf{1 0}$ revealed that it indeed had a cyclic dimer structure of indeno[2,1-a]fluorene frameworks and adopted a twisted conformation due to the steric repulsion between the closely located hydrogens attached to the peripheral benzene rings (Figure 3).

(a)

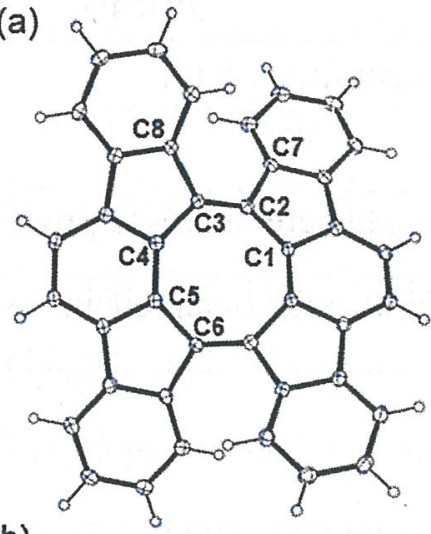

(b)

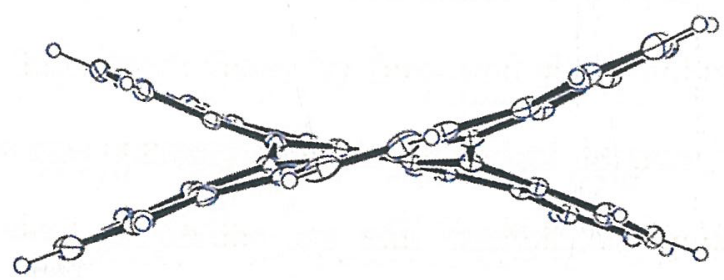

(c)
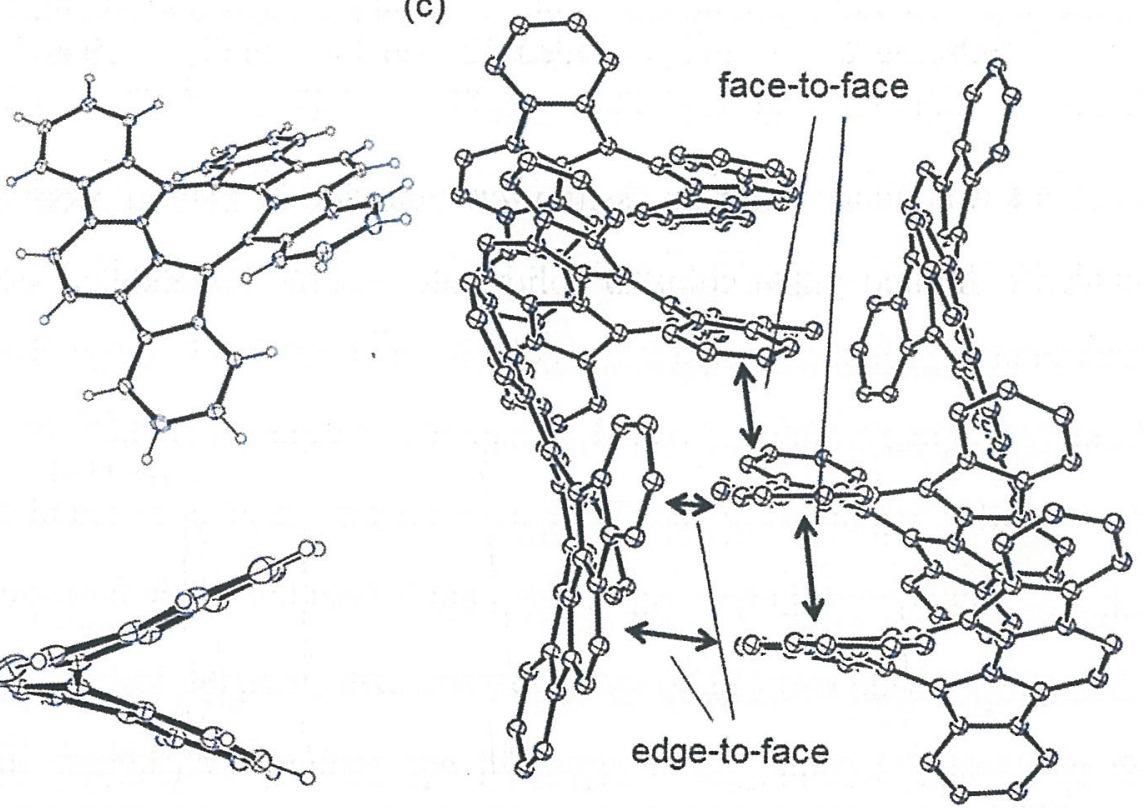

Figure 3. (a) Top views, one with numbering and the other showing the twisting, of ORTEP drawings of 10. (b) A side view of an ORTEP drawing of 10. Displacement ellipsoids are drawn at $30 \%$ probability level. (c) Two sets of three crystallographically independent molecules of $\mathbf{1 0}$, showing intermolecular interactions between the neighboring molecules whose hydrogen atoms are omitted for clarity.

A plausible reaction mechanism for the formation of $\mathbf{1 0}$ is shown in Scheme 5. [4+4] Cycloaddition of indeno[2,1-a]fluorene derivative $8(\mathrm{X}=\mathrm{Br})$, generated by 1,4-elimination of $\mathrm{HBr}$ 
from 14, takes place to afford 16. Subsequent elimination of two molecules of $\mathrm{HBr}$ from 16 gives $\mathbf{1 0 .}$ Although a concerted [4+4] cycloaddition is a symmetry forbidden thermal process, ${ }^{14}$ I conjectured that the biradical character of $\mathbf{8}(\mathrm{X}=\mathrm{Br})$ may play a principle role for the processes, i.e., reducing the kinetic barrier for a stepwise radical process. To gain support from theoretical calculations, the singlet biradical characters of $8(X=B r)$ and the parent compound $8(X=H)$ were calculated ${ }^{15}$ by the natural orbital occupation number (NOON) of the LUMO in a spin-unrestricted calculation. ${ }^{16}$ The broken-symmetry UHF/6-31G* calculations of $8(X=\mathrm{Br})$ and $8(X=H$; Figure 4$)$ gave LUMO occupation numbers of 0.61 in both cases. Using the Yamaguchi scheme, ${ }^{17}$ the singlet biradical character of both $8(\mathrm{X}=\mathrm{Br})$ and $8(\mathrm{X}=\mathrm{H})$ were estimated to be 0.32 . Although the biradical character of $8(\mathrm{X}=\mathrm{Br}$ ) is not large compared to those of highly reactive molecules (e.g. indeno[2,1-b]fluorene (16) and indeno[1,2-a]fluorene (17) whose biradical characters are 0.68 and 0.59, respectively; Figure 4), it nevertheless is substantial (Scheme 6). Therefore it may be reasonable to assume that the dimerization reaction takes place most likely via a stepwise radical pathway due to the biradical character of intermediate $15{ }^{18}$

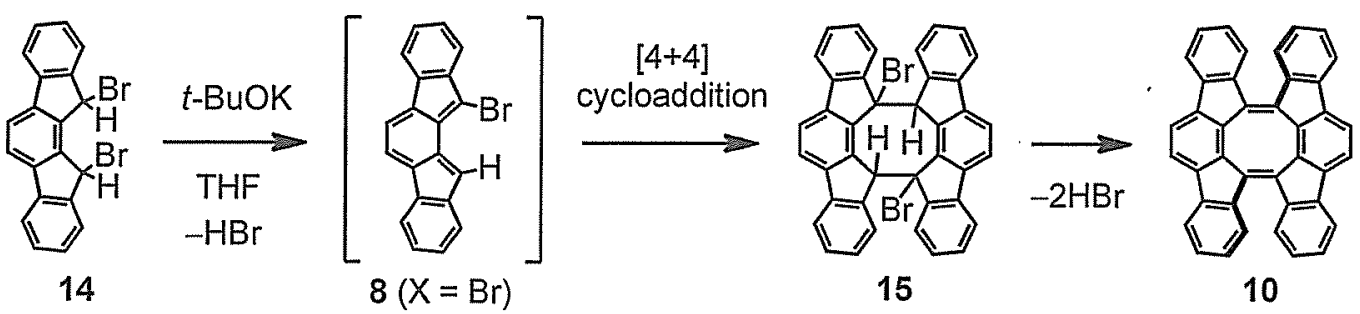

Scheme 5. A plausible reaction mechanism for the formation of $\mathbf{1 0 .}$

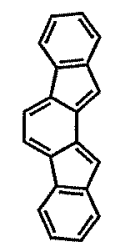

$8(X=H)$

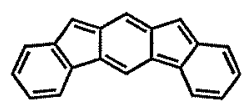

16

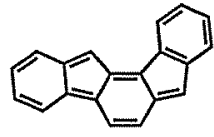

17

Figure 4. Indenofluorene isomers

The theoretical and experimental (X-ray) structures of $\mathbf{1 0}$ are compared in Table 1. For the theoretical calculation, B3LYP functionals were used. For the observed data, since there are three 
crystallographically independent molecules in a unit cell, the mean values for the bond lengths and angles are presented in addition to those showing the largest-smallest values. Most of the structural parameters agree well to each other. The only slight difference was found in the magnitude of twising. The experimental torsion angles around the double bonds connecting the indenofluorene units (i.e. $\mathrm{C}(2)-\mathrm{C}(3)$, numbers shown in Figure 3(a)) are slightly smaller than those of calculated structures. Figure 3(c) shows two sets of three crystallographically independent molecules of $\mathbf{1 0}$ showing intermolecular interactions between the neighboring molecules. The two crystallographically independent molecules of the same sense of chirality stack to each other in a face-to-face geometry, whose short contact distances are ca. 3.4-3.8 $\AA$. The third antipodal molecule locates nearly perpendicular to the above molecular pair in an edge-to-face geometry with the short carbon-carbon contact distances are ca. 3.6-3.8 $\AA$.

Table 1. Comparison of the experimental and calculated geometries of $\mathbf{1 0 .}$

\begin{tabular}{c|cc|c}
\hline \multirow{2}{*}{$\begin{array}{c}|c| \\
\text { exo-bond length }[\AA]^{a}\end{array}$} & Range & Mean value & B3LYP/6-31G* \\
\hline & $1.367-1.374$ & 1.369 & 1.374 \\
endo-bond length of 5-membered ring $[\AA]^{b}$ & $1.485-1.495$ & 1.490 & 1.492 \\
endo-bond length of 6-membered ring $[\AA]^{c}$ & $1.401-1.406$ & 1.404 & 1.405 \\
torsion angle of outer twisting $\left[{ }^{\circ}\right]^{d}$ & $17.8-20.3$ & 19.0 & 22.3 \\
torsion angle of inner twisting $\left[{ }^{\circ}\right]^{e}$ & $36.3-41.1$ & 38.7 & 41.4 \\
torsion angle of COT ring $\left[{ }^{\circ}\right]^{f}$ & $20.3-26.4$ & 23.4 & 26.2 \\
\hline
\end{tabular}

${ }^{a}$ Bond length of the central COT ring that is exocyclic to the indenofluorene frameworks (i.e. $\mathrm{C}(2)-\mathrm{C}(3)$ ).

${ }^{b, c}$ Bond length of the central COT ring that is endocyclic to the 5 -membered ring (i.e. $\mathrm{C}(3)-\mathrm{C}(4)$ ) and the 6-membered ring (i.e. $\mathrm{C}(4)-\mathrm{C}(5))$ of the indenofluorene frameworks, respectively.

${ }^{d, e}$ Dihedral angles of the outer (i.e. $C(7)-C(2)-C(3)-C(8)$ ) and inner (i.e. $C(1)-C(2)-C(3)-C(4)$ ) twisting around the double bonds, respectively.

${ }^{f}$ Dihedral angle of the central COT ring (i.e. C(3)-C(4)-C(5)-C(6)).

As to the COT core of $\mathbf{1 0}$, clear bond length alternation was identified. Similar magnitude of 
alternations is reproduced by the theoretical calculations. To evaluate anti-aromaticity of the eight-membered ring of $\mathbf{1 0}$, nucleus independent chemical shifts (NICS) developed by Schleyer et al. was calculated on the basis of the HF/6-31G*//B3LYP/6-31G* level ${ }^{19}$ of theory. ${ }^{15}$ The NICS(0) at the center of the twisted eight-membered ring of $\mathbf{1 0}$ was +11.9 , indicating considerable anti-aromatic character of the ring. The smaller NICS value for the twisted COT unit than those of the parent planar $D_{4 \mathrm{~h}}$ COT (+27.2) and annelated derivatives shown in Figure 1 clearly indicates the decreased anti-aronaticity in $\mathbf{1 0}$ owing to the geometrical twisting.

\subsection{Skeletal Rearrangement of Indeno[2,1-a]fluorene Dimer}

With an intention to convert indenofluorene dimer $\mathbf{1 0}$ to the planar hydrocarbon $\mathbf{1 1}$, I examined oxidative cyclodehydrogenation between the peripheral benzene benzene carbons of $\mathbf{1 0}$. For this purpose, an oxidizing reagent $\mathrm{FeCl}_{3}$ dissolved in nitromethane was used. ${ }^{20}$ As a results, a single product which exhibited purple color in solid state was obtained in 64\% yield (Scheme 6). However, the mass spectrum of the product exhibited that its molecular formula remained unchanged from that of 10. Additionally, the ${ }^{1} \mathrm{H}$ and ${ }^{13} \mathrm{C}$ NMR spectra showed 10 and 21 signals (Figure 5), respectively, whereas the desired product 11 should show 4 and 10 signals, respectively. These spectral data indicated that a skeletal rearrangement of $\mathbf{1 0}$ took place to produce a less-symmetric product. However, the structural determination of the product from the spectral data was difficult because of the presence of many quaternary carbon atoms.

A crystal of the product suitable for X-ray crystallographic analysis was obtained from a mixture of $o$-dichlorobenzene/methanol solvent and X-ray crystallographic analysis was done as shown in Figure 6. The X-ray analysis revealed that it was benzo[p]fluoreno[1,2-g]indeno[1,2-c]chrysene-15,16-diylidene (18) with a seven-membered ring inthe center. In this case too there are three crystallographically independent molecules in crystal unit cell, and two of them are disordered (Figure 6(b)). Compound 18 also adopts a twisted conformation because of the steric repulsion of the closely located hydrogens. Similar to the crystal of $\mathbf{1 0}$, two crystallographically independent molecules of the same sense of chirality stack to each other in a face-to-face geometry whose short contact distances are 3.5-3.9 $\AA$, whereas the third antipodal 


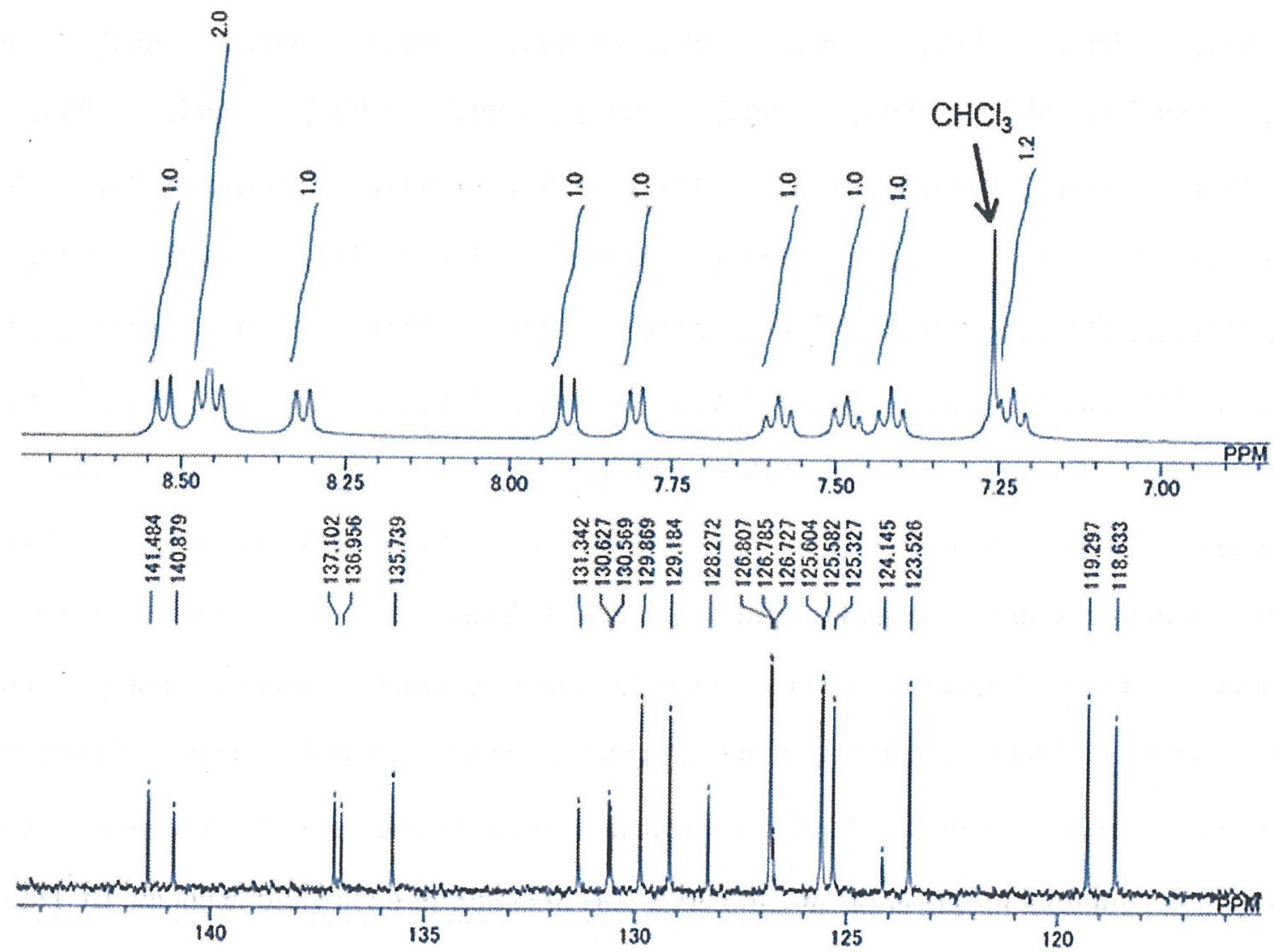

Figure 5. Partial ${ }^{1} \mathrm{H}$ and ${ }^{13} \mathrm{C}$ NMR spectra of $\mathbf{1 8}$.

molecule locates nearly perpendicular to the above molecular pair in an edge-to-face geometry with the short carbon-carbon contact distances are ca. 3.6-3.9 $\AA$. Contrary to the crystal of 10, however, there is no short contact between the crystallographically independent unit consisting of three molecules.

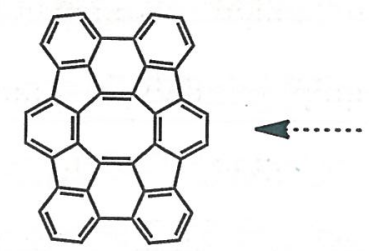

11

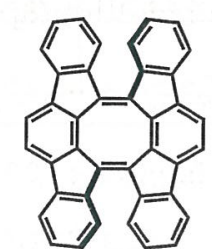

10

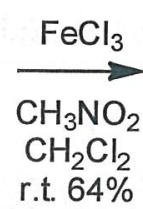

r.t. $64 \%$

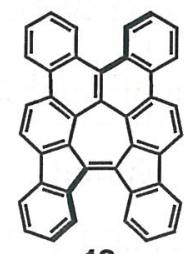

18

Scheme 6. Rearrangement of $\mathbf{1 0}$ in the presence of $\mathrm{FeCl}_{3}$ in nitromethane.

The rearrangement of $\mathbf{1 0}$ into $\mathbf{1 8}$ can be interpreted as that of 9,9'-bifluoronylidene into dibenzo $[g, p]$ chrysene, which was actually observed previously under thermal conditions. ${ }^{21}$ The similar arrangements were also observed in fullerene ${ }^{22}$ and other polycyclic hydrocarbons. ${ }^{23}$ The 
(a)

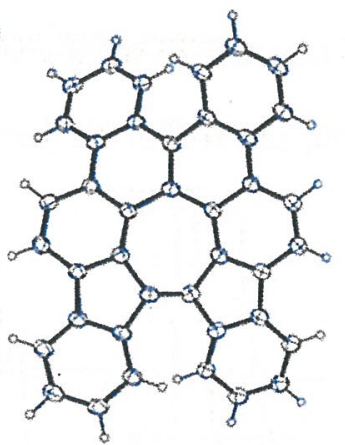

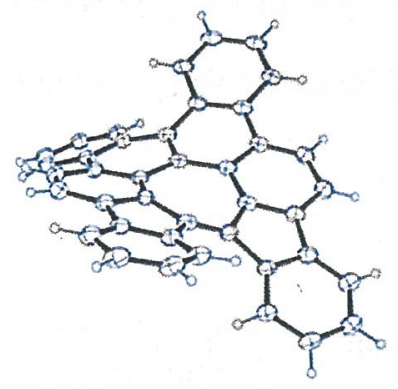

(b)

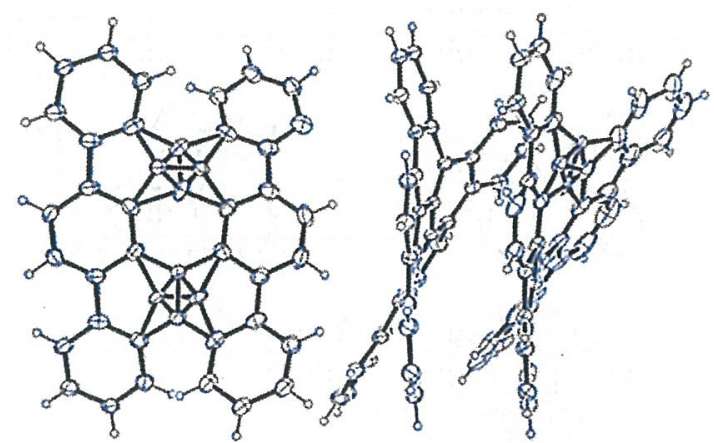

(c)

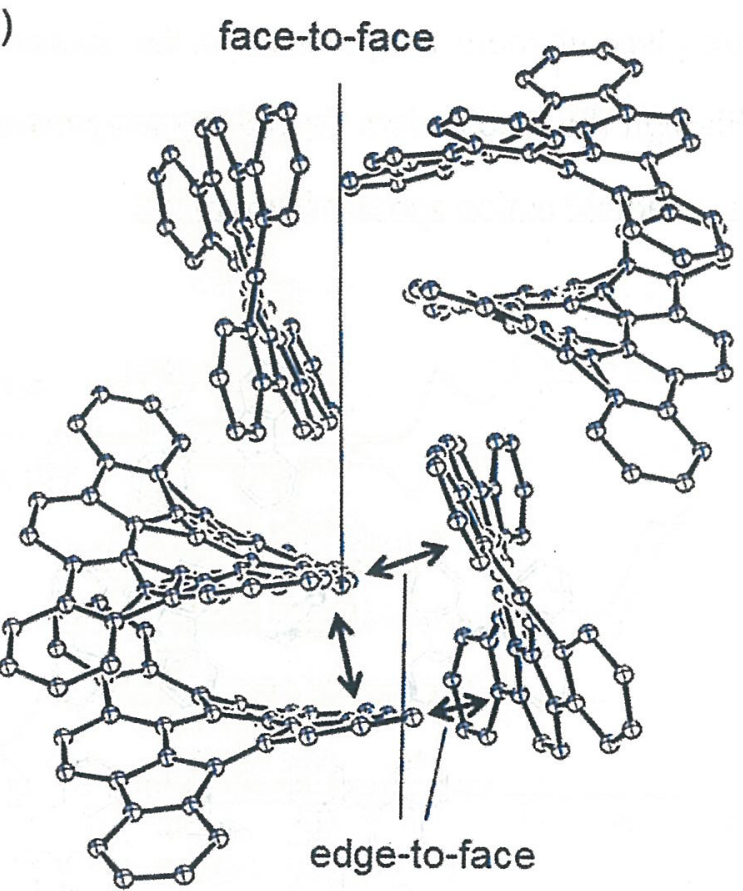

Figure 6. (a) Top views, one of three crystallographically independent molecules, of ORTEP drawings of 18. (b) Disordered structures of three crystallographically independent molecules. Displacement ellipsoids are drawn at $30 \%$ probability level. (c) Two sets of three crystallographically independent molecules of $\mathbf{1 8}$ showing intermolecular interactions between the neighboring molecules whose hydrogen atoms omitted for clarity.

rearrangement of fullerene was interpreted by a mechanism known as Stone-Wales rearrangement in which it formally requires the two sigma bonds shown to be broken, and the new bonds to be formed as indicated by the double headed arrows (Scheme 7), ${ }^{22}$ On the other hand, the rearrangement of 9,9'-bifluorenylidene was explained in terms of initial addition of a radical species as shown in Scheme 8. ${ }^{21 \mathrm{~d}}$ The notable difference between rearrangements of $\mathbf{1 0}$ and 9,9'-bifluorenylidene is the reaction conditions: whereas heating up to ca. $400{ }^{\circ} \mathrm{C}$ was necessary in the latter case, the reaction

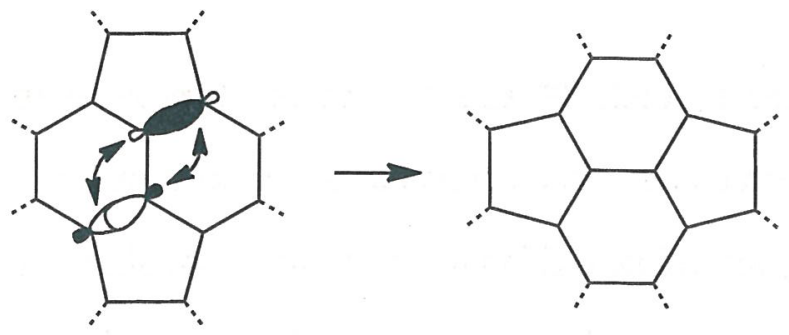

Scheme 7. Structural rearrangement of $\mathrm{C}_{60}$ known as the Stone-Wales rearrangement. 
took place at room temperature in the former case yet in the presence of oxidizing reagent $\mathrm{FeCl}_{3}$. Although the mechanism for the rearrangement of $\mathbf{1 0}$ is not fully understood, the author conjectured that a radical cation species is involved.
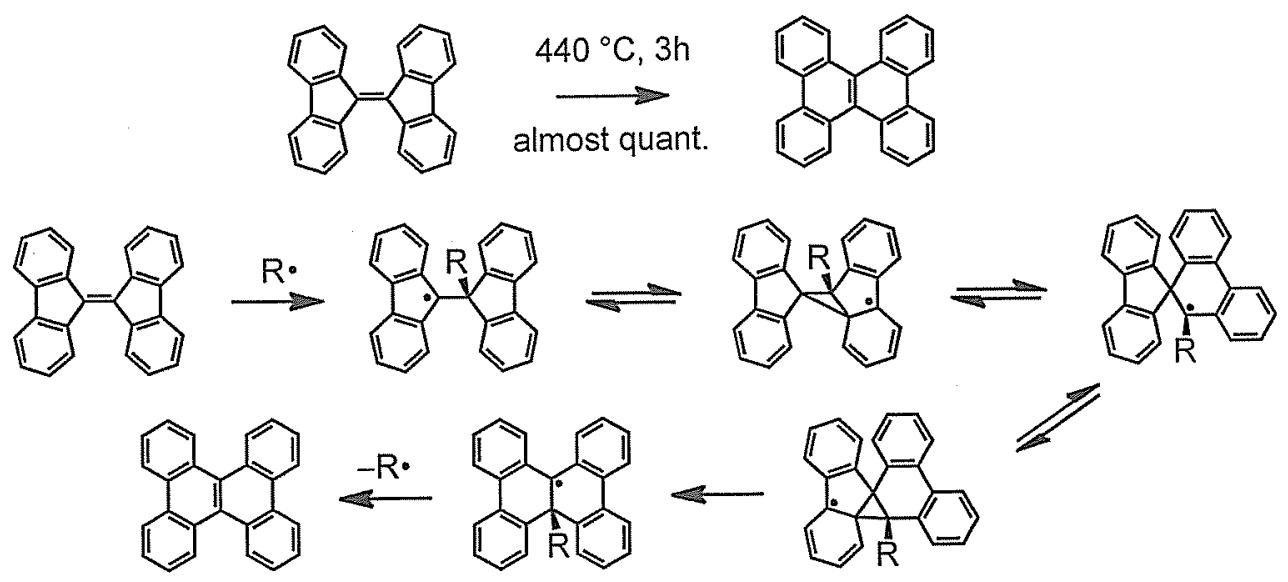

Scheme 8. Rearrangement of 9,9'-bifluorenylidene and a proposed mechanism of rearrangement induced by addition of a radical species.

\subsection{Optical and Electrochemical Properties}

The absorption spectra and cyclic voltammograms of $\mathbf{1 0}$ and $\mathbf{1 8}$ are shown in Figure 7. Both absorption spectra of $\mathbf{1 0}$ and $\mathbf{1 8}$ show weak absorption band at long wavelength region. Particularly, the spectrum of $\mathbf{1 0}$ has a broad absorption extending up to about $850 \mathrm{~nm}$, indicating that the HOMO-LUMO gap of $\mathbf{1 0}$, is relatively small. DFT calculations also exhibited that the HOMO-LUMO gap of $\mathbf{1 0}(2.21 \mathrm{eV})$ is smaller than that of $18(2.60 \mathrm{eV})$. The longer wavelength absorption of $\mathbf{1 0}$ accounted for by the anti-aromaticity of the COT ring of 10. Additionally, the HOMO and LUMO of $\mathbf{1 0}$ is mainly localized in the central eight-membered ring and the shape of HOMO and LUMO resemble with that of parent $D_{4 h}$-COT (Figure 8), indicating the anti-aromaticity of the COT ring of $\mathbf{1 0 .}$

The cyclic voltammograms of both 10 and 18 showed two reversible reduction waves. The presence of two reduction waves of $\mathbf{1 0}$ corresponds to the generation of $10 \pi$ aromatic dianion at the central ring. On the contrary, reversible oxidative waves were not observed for the both compounds; the absence of the reversible wave of $\mathbf{1 0}$ may correspond to the skeletal rearrangement induced by 
the oxidizing reagent.
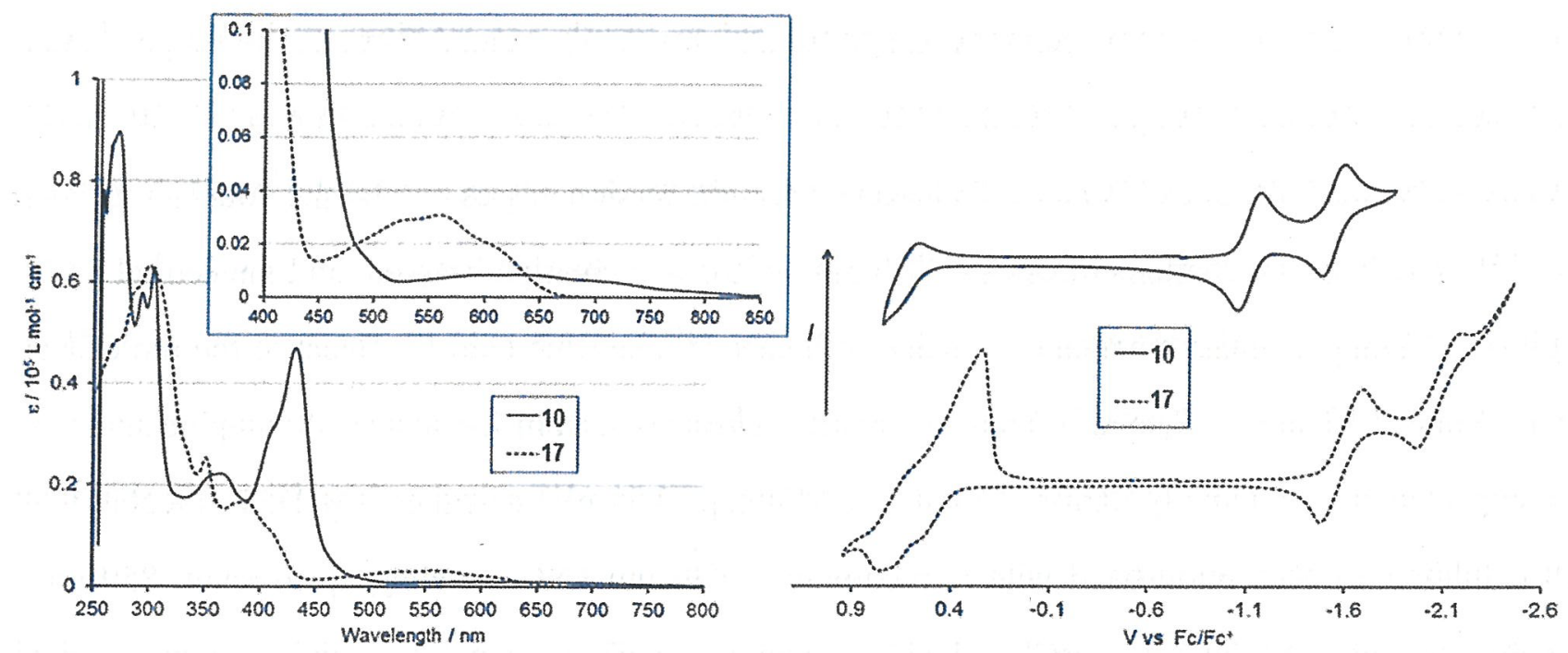

Figure 7. (left) UV/vis absorption apectra of 10 and 18 in $\mathrm{CH}_{2} \mathrm{Cl}_{2}$. (right) Cyclic voltammograms of 10 and 17. Conditions: in $\mathrm{CH}_{2} \mathrm{Cl}_{2}$ at room temperature, $0.1 \mathrm{M} \mathrm{Bu}_{4} \mathrm{NClO}_{4}$, working electrode: glassy carbon, counter electrode: $\mathrm{Pt}$, reference electrode: $\mathrm{Ag} / \mathrm{AgNO}_{3}$, scan rate: $0.1 \mathrm{~V} / \mathrm{s}$.
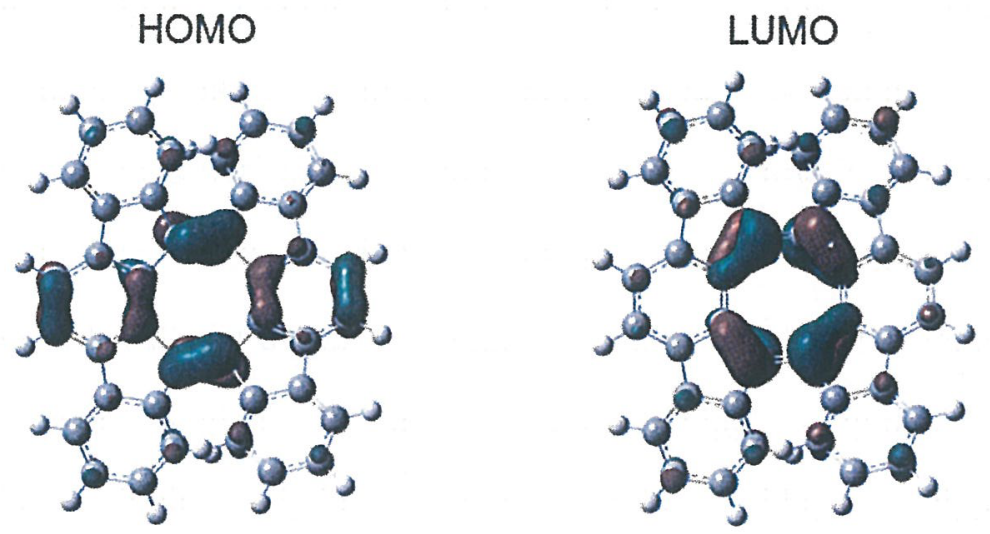

Figure 8. HOMO and LUMO of $\mathbf{1 0 .}$ 


\subsection{Conclusion}

11,11':12,12'-Biindeno[2,1-a]fluorenediylidene (10), which consists of two indeno[2,1-a]fluorene units connected by two double bonds, was synthesized by [4+4] cycloaddition of in-situ generated indeno[2,1-a]fluorene derivative $\mathbf{8}(\mathrm{X}=\mathrm{Br})$. It adopts a twisted conformation to avoid steric repulsion between the closely located hydrogens, with the torsion angles around the double bonds of ca. $23^{\circ}$. The bond alternations of central COT ring of $\mathbf{1 0}$ was clearly observed, and the central COT unit of $\mathbf{1 0}$ exhibits anti-aromaticity as indicated by the NICS value $(+11.9)$. Because the molecular framework of $\mathbf{1 0}$ adopts $C_{2}$ symmetric structure, it is chiral as seen in X-ray crystallographic analysis. As expected from relatively narrow HOMO-LUMO gap $(2.21 \mathrm{eV})$ calculated by DFT calculations, 10 exhibited an absorption band with a maximum at $634 \mathrm{~nm}$ and extending up to about $850 \mathrm{~nm}$. Treatment of $\mathbf{1 0}$ with $\mathrm{FeCl}_{3}$ in nitromethane triggered the rearrangement into benzo[ $p]$ fluoreno[1,2-g]indeno[1,2-c]chrysene-15,16-diylidene (18). The unexpected rearrangement

of 10 resembles to the Stone-Wales rearrangement observed in the 9,9'-bifluorenylidene ${ }^{21}$ and fullerene derivatives. ${ }^{22}$ 


\subsection{Experimental Section}

General Experimental Methods. ${ }^{1} \mathrm{H}$ and ${ }^{13} \mathrm{C}$ NMR spectra were recorded in $\mathrm{CDCl}_{3}$ at $30^{\circ} \mathrm{C}$. When $\mathrm{CDCl}_{3}$ was used as a solvent, the chemical shifts were referenced to the residual solvent protons in the ${ }^{1} \mathrm{H}$ NMR (7.26 ppm) and to solvent carbons in the ${ }^{13} \mathrm{C}$ NMR (77.0 ppm). Mass spectral analyses were performed with FAB mode. IR spectra were recorded as a $\mathrm{KBr}$ disk. Melting points were measured with a hot-stage apparatus equipped with a thermometer. Column chromatography and TLC were performed with silica gel (70-230 mesh) and precoated silica gel plates, respectively.

All reagents were obtained from commercial suppliers and used as received. THF and $\mathrm{CH}_{2} \mathrm{Cl}_{2}$ were dried by a Glass Contour solvent purification system.

11,12-Dibromo-11,12-dihydroindeno[2,1-a]fluorene (14). $\mathrm{NaBH}_{4}(1.08 \mathrm{~g}, 28.5 \mathrm{mmol})$ was added to a solution of $12^{12}(2.00 \mathrm{~g}, 7.08 \mathrm{mmol})$ in THF $(25 \mathrm{~mL})$ and water $(0.8 \mathrm{~mL})$ at room temperature. After stirring at $60{ }^{\circ} \mathrm{C}$ for $3 \mathrm{~h}$ under an argon atmosphere, the reaction mixture was diluted with water, and organic layer was separated and dried over anhydrous $\mathrm{MgSO}_{4}$. The solvent was removed under reduced pressure, and the residual solid was dissolved in $\mathrm{CH}_{2} \mathrm{Cl}_{2}(30 \mathrm{~mL})$. To the solution containing 13 was added dropwise a solution of $\mathrm{PBr}_{3}(4.88 \mathrm{~g}, 18.0 \mathrm{mmol})$ in $\mathrm{CH}_{2} \mathrm{Cl}_{2}(5 \mathrm{~mL})$ via a dropping funnel at $0{ }^{\circ} \mathrm{C}$ over a period of $20 \mathrm{~min}$. After stirring at $0{ }^{\circ} \mathrm{C}$ for $30 \mathrm{~min}$ under an argon atmosphere, water was added at $0{ }^{\circ} \mathrm{C}$. The reaction mixture was extracted with $\mathrm{CHCl}_{3}$, and the extract was washed with brine and dried over anhydrous $\mathrm{MgSO}_{4}$. After removal of the solvent, the residue was washed with EtOH and AcOEt to afford $14(2.10 \mathrm{~g}, 72 \%)$ as a pale yellow solid. 14: $\mathrm{mp}$ 202.0-204.0 ${ }^{\circ} \mathrm{C}$; ${ }^{1} \mathrm{H} \mathrm{NMR}\left(400 \mathrm{MHz}, \mathrm{CDCl}_{3}, 30{ }^{\circ} \mathrm{C}\right) \delta 7.77$ (s, $\left.2 \mathrm{H}\right), 7.72(\mathrm{~d}, J=7.6 \mathrm{~Hz}, 4 \mathrm{H}), 7.43$ (dd, $J=7.6,7.2 \mathrm{~Hz}, 2 \mathrm{H}), 7.38$ (dd, $J=7.6,7.6 \mathrm{~Hz}, 2 \mathrm{H}), 6.40(\mathrm{~s}, 2 \mathrm{H}) ;{ }^{13} \mathrm{C} \mathrm{NMR}\left(100 \mathrm{MHz}, \mathrm{CDCl}_{3}\right.$, $\left.30^{\circ} \mathrm{C}\right) \delta 145.2,144.3,141.1,140.6,128.9,126.5,125.1,124.1,120.2,51.1$; IR (KBr) 3058, 2974, 1497, 1646, 1441, 1416, 1366, 1326, 1190, 1057, 761, $702 \mathrm{~cm}^{-1}$; MS (FAB) m/z 409.1 (M+); HRMS (FAB) calcd. for $\mathrm{C}_{20} \mathrm{H}_{12} \mathrm{Br}_{2}$ 409.9306, found 409.9301 .

Compound 14 should have two stereoisomers. Although it was difficult to determine whether the produst adopts cis or trans isomer, a single isomer was obtained, indicating from ${ }^{1} \mathrm{H}$ NMR spectrum. 
11,11':12,12'-Biindeno[2,1-a]fluorenediylidene (10). To a solution of $8(\mathrm{X}=\mathrm{Br})(50.5 \mathrm{mg}, 0.123$ $\mathrm{mmol})$ in THF $(20 \mathrm{~mL})$ was added a solution of potassium tert-butoxide $(69.2 \mathrm{mg}, 0.616 \mathrm{mmol})$ in THF (5 mL) dropwise over a period of $20 \mathrm{~min}$. After stirring at room temperature for $20 \mathrm{~min}$ under an argon atmosphere, water $(3 \mathrm{~mL})$ was added, and the reaction mixture was stirred for $15 \mathrm{~min}$. Then the reaction mixture was diluted with water and extracted with $\mathrm{CHCl}_{3}$. The extract was washed with brine and dried over anhydrous $\mathrm{MgSO}_{4}$. After removal of the solvent, the residue was purified by chromatography (silica gel, hexanes: $\left.\mathrm{CHCl}_{3}=9: 1\right)$ to afford $\mathbf{1 0}(10.3 \mathrm{mg}, 34 \%$ ) as a green sold. $\mathbf{1 0}$ : mp 223.0-224.0 ${ }^{\circ} \mathrm{C} ;{ }^{1} \mathrm{H}$ NMR $\left(400 \mathrm{MHz}, \mathrm{CDCl}_{3}, 30^{\circ} \mathrm{C}\right) \delta 7.95(\mathrm{~d}, J=8.0 \mathrm{~Hz}, 4 \mathrm{H}), 7.56(\mathrm{~d}, J=7.6$ $\mathrm{Hz}, 4 \mathrm{H}), 7.38(\mathrm{~s}, 4 \mathrm{H}), 7.28(\mathrm{dd}, \mathrm{J}=7.6,7.6 \mathrm{~Hz}, 4 \mathrm{H}), 6.98(\mathrm{dd}, \mathrm{J}=7.6,7.6 \mathrm{~Hz}, 4 \mathrm{H}) ;{ }^{13} \mathrm{C} \mathrm{NMR}(100$ $\left.\mathrm{MHz}_{3} \mathrm{CDCl}_{3}, 30^{\circ} \mathrm{C}\right) \delta 143.0,141.9,140.6,140.3,137.4,129.2,128.5,125.0,120.0,118.8 ; \mathrm{IR}(\mathrm{KBr})$ $3055,3021,2989,1477,1444,1384,1245,965,825,763,721 \mathrm{~cm}^{-1}$; UV-vis $\left(\mathrm{CH}_{2} \mathrm{Cl}_{2}\right) \lambda_{\max }(\varepsilon) 634$ (840) nm; MS (FAB) m/z 500.5 (M+); HRMS (FAB) calcd. for $\mathrm{C}_{40} \mathrm{H}_{20} 500.1565$, found 500.1562.

benzo[p]fluoreno[1,2-g]indeno[1,2-c]chrysene-15,16-diylidene (18). To a solution of 10 (25.8 mg, $0.0515 \mathrm{mmol})$ in $\mathrm{CH}_{2} \mathrm{Cl}_{2}(20 \mathrm{~mL})$ was added a solution of $\mathrm{FeCl}_{3}(85.2 \mathrm{mg}, 0.525 \mathrm{mmol})$ in nitromethane $(3 \mathrm{~mL})$ at room temperature. After stirring at $50{ }^{\circ} \mathrm{C}$ under an argon atmosphere, $\mathrm{MeOH}$ $(10 \mathrm{~mL})$ was added via a syringe, and then the reaction mixture was stirred for $10 \mathrm{~min}$ at room temperature. The reaction mixture was diluted with water and extracted with $\mathrm{CHCl}_{3}$. The extract was washed with brine and dried over anhydrous $\mathrm{MgSO}_{4}$. After removal of the solvent, the residue was purified by chromatography (silica gel, hexanes: $\mathrm{CHCl}_{3}=9: 1$ ) followed by to afford 18 (16.4 mg, $64 \%)$ as a purple solid. 18: $\mathrm{mp} 211.0-212.0{ }^{\circ} \mathrm{C} ;{ }^{1} \mathrm{H} \mathrm{NMR}\left(400 \mathrm{MHz}, \mathrm{CDCl}_{3}, 30^{\circ} \mathrm{C}\right) \delta 8.53(\mathrm{~d}, J=$ $8.0 \mathrm{~Hz}, 2 \mathrm{H}), 8.47(\mathrm{~d}, J=7.2 \mathrm{~Hz}, 2 \mathrm{H}), 8.45(\mathrm{~d}, J=7.2 \mathrm{~Hz}, 2 \mathrm{H}), 8.32(\mathrm{~d}, J=8.0 \mathrm{~Hz}, 2 \mathrm{H}), 7.91(\mathrm{~d}, J=$ $8.0 \mathrm{~Hz}, 2 \mathrm{H}), 7.81(\mathrm{~d}, J=7.6 \mathrm{~Hz}, 2 \mathrm{H}), 7.59(\mathrm{dd}, J=7.6,7.2 \mathrm{~Hz}, 2 \mathrm{H}), 7.48(\mathrm{dd}, J=8.0,7.2 \mathrm{~Hz}, 2 \mathrm{H})$, $7.42(\mathrm{dd}, J=7.2,6.8 \mathrm{~Hz}, 2 \mathrm{H}), 7.23(\mathrm{dd}, J=7.6,7.6 \mathrm{~Hz}, 2 \mathrm{H}) ;{ }^{13} \mathrm{C} \mathrm{NMR}\left(100 \mathrm{MHz}, \mathrm{CDCl}_{3}, 30{ }^{\circ} \mathrm{C}\right) \delta$ $141.5,140.9,137.1,137.0,135.7,131.3,130.63,130.57,129.9,129.2,128.3,126.81,126.79,126.7$, 125.60, 125.58, 125.3, 124.1, 123.5, 119.3, 118.6; IR (KBr) 3068, 3011, 2978, 1499, 1470, 1387, 899, 823, $765 \mathrm{~cm}^{-1}$; UV-vis $\left(\mathrm{CH}_{2} \mathrm{Cl}_{2}\right) \lambda_{\max }$ (E) 560 (3070) nm; MS (FAB) $\mathrm{m} / z 500.9\left(\mathrm{M}^{+}\right)$; HRMS (FAB) calcd. for $\mathrm{C}_{40} \mathrm{H}_{20} 500.1565$, found 500.1553 . 


\subsection{References and Notes}

(1) (a) Karle, I. L. J. Chem. Phys. 1952, 20, 65-70. (b) Bastiansen, O.; Hedberg, L.; Hedberg, K. J. Chem. Phys. 1957, 27, 1311-1317. (c) Traetterberg, M. Acta Chem. Scand. 1966, 20, 1724-1726.

(2) Bordner, J.; Parker, R. G.; Stanford, R. H. Acta Crystallogr. Sect. B 1972, 28, 1069-1075.

(3) (a) Anet, F. A. L. J. Am. Chem. Soc. 1962, 84, 671-672. (b) Anet, F. A. L.; Bourn, A. J. R.; Lin, Y. S. J. Am. Chem. Soc. 1964, 86, 3576-3577. (c) Oth, J. F. M. Pure Appl. Chem. 1971, 25, 573-622. (d) Luz, Z.; Meiboom, S. J. Chem. Phys. 1973, 59, 1077-1091. (e) Naor, R.; Luz, Z. J. Chem. Phys. 1982, 76, 5662-5664.

(4) Hrovat, D. A.; Borden, W. T. J. Am. Chem. Soc. 1992, 114, 5879-5881.

(5) For recent reviews about planarized COTs, see: (a) Klärner, F. G. Angew. Chem. Int. Ed. 2001, 40, 3977-3981. (b) Nishinaga, T.; Ohmae, T.; Iyoda, M. Symmetry 2010, 2, 76-97.

(6) Soulen, R. L.; Choi, S. K.; Park, J. D. J. Fluorine Chem. 1973/74, 3, 141-150.

(7) Matsuura, A.; Komatsu, K. J. Am. Chem. Soc. 2001, 123, 1768-1769.

(8) (a) Nakamura, Y.; Aratani, N.; Shinokubo, H.; Takagi, A.; Kawai, T.; Matsumoto, T.; Yoon, Z. S.; Kim, D. Y.; Ahn, T. K.; Kim, D.; Muranaka, A.; Kobayashi, N.; Osuka, A. J. Am. Chem. Soc. 2006, 128, 4119-4127. (b) Nakamura, Y.; Aratani, N.; Furukawa, K.; Osuka, A. Tetrahedron 2008, 64, 11433-11439. (c) Nakamura, Y.; Aratani, N.; Osuka, A. Chem. Asian. J. 2007, 2, 860-866.

(9) Ohmae, T.; Nishinaga, T.; Wu, M.; Iyoda, M. J. Am. Chem. Soc. 2010, 132, 1066-1074.

(10) (a) Schleyer, P. v. R.; Maerker, C.; Dransfeld, A.; Jiao, H.; Hommes, N. J. R. V. E. J. Am. Chem. Soc. 1996, 118, 6317-6318. (b) Chen, Z.; Wannere, C. S.; Corminboeuf, C.; Puchta, R.; Schleyer, P. v. R. Chem. Rev. 2005, 105, 3842-3888.

(11) (a) Hellwinkel, D.; Reiff, G. Angew. Chem. Int. Ed. 1970, 9, 527-528. (b) Hellwinkel, D.; Reiff, G.; Nykodym, V. Liebigs Ann. Chem. 1977, 1013-1025.

(12) (a) Rainbolt, J. E.; Miller, G. P. J. Org. Chem. 2007, 72, 3020-3030. (b) Thirion, D.; Poriel, C.; Rault-Berthelot, J.; Barrière, F.; Jeannin, O. Chem. Eur. J. 2010, 16, 13646-13658.

(13) Zeynizadeh, B.; Bahyar, T. Bull. Chem. Soc. Jpn. 2005, 78, 307-315.

(14) Woodward, R. B.; Hoffmann, R. J. Am. Chem. Soc. 1965, 87, 395-397.

(15) DFT and HF calculations were performed with the Gaussian 09 program. All geometry 
optimizations were carried out at the (R)B3LYP level of density functional theory with the 6-31G(d) basis set. The nature of the stationary points was assessed by means of vibrational frequency analysis. Gaussian 09, Revision C.01, M. J. Frisch, G. W. Trucks, H. B. Schlegel, G. E. Scuseria, M. A. Robb, J. R. Cheeseman, G. Scalmani, V. Barone, B. Mennucci, G. A. Petersson, H. Nakatsuji, M. Caricato, X. Li, H. P. Hratchian, A. F. Izmaylov, J. Bloino, G. Zheng, J. L. Sonnenberg, M. Hada, M. Ehara, K. Toyota, R. Fukuda, J. Hasegawa, M. Ishida, T. Nakajima, Y. Honda, O. Kitao, H. Nakai, T. Vreven, J. A. Montgomery, Jr., J. E. Peralta, F. Ogliaro, M. Bearpark, J. J. Heyd, E. Brothers, K. N. Kudin, V. N. Staroverov, R. Kobayashi, J. Normand, K. Raghavachari, A. Rendell, J. C. Burant, S. S. Iyengar, J. Tomasi, M. Cossi, N. Rega, J. M. Millam, M. Klene, J. E. Knox, J. B. Cross, V. Bakken, C. Adamo, J. Jaramillo, R. Gomperts, R. E. Stratmann, O. Yazyev, A. J. Austin, R. Cammi, C. Pomelli, J. W. Ochterski, R. L. Martin, K. Morokuma, V. G. Zakrzewski, G. A. Voth, P. Salvador, J. J. Dannenberg, S. Dapprich, A. D. Daniels, Ö. Farkas, J. B. Foresman, J. V. Ortiz, J. Cioslowski, and D. J. Fox, Gaussian, Inc., Wallingford CT, 2009.

(16) (a) Döhnert, D.; Koutecký, J. J. Am. Chem. Soc. 1980, 102, 1789-1796. (b) Jung, Y.; Head-Gordon, M. ChemPhysChem 2003, 4, 522-525.

(17) Yamaguchi, K. Chem. Phys. Lett. 1975, 33, 330-335.

(18) Formal [4+4] cycloaddition concerning an $o$-quinodimethane moiety was reported: Tanaka, T.; Nakamura, Y.; Osuka, A. Chem. Eur. J. 2008, 14, 204-211

(19) For the NICS calculation, the HF method was used because this had been shown to be reliable means for evaluating the NICS values. For example, see: Gogonea, V.; Schleyer, P. v. R.; Schreiner, P. R. Angew. Chem. Int. Ed. 1998, 37, 1945-1948.

(20) This is one of the general methods of oxidative dehydrogenation. For example, see: Ito, S.; Wehmeier, M.; Brand, J. D.; Kübel, C.; Epsch, R.; Rabe, J. P.; Müllen, K. Chem. Eur. J. 2000, 6, 4327-4342.

(21) (a) Alder, R. W.; Whittaker, G. J. Chem. Soc., Perkin Trans. 2 1975, 712-715. (b) Hagen, S.; Nuechter, U.; Nuechter, M.; Zimmermann, G. Tetrahedron Lett. 1994, 35, 7013-7014. (c) Hagen, S.; Christoph, H.; Zimmermann, G. Tetrahedron 1995, 51, 6961-6970. (d) Alder, R. W.; Harvey, J. 
N. J. Am. Chem. Soc. 2004, 126, 2490-2494.

(22) (a) Stone, A. J.; Wales, D. J. Chem. Phys. Lett. 1986, 128, 501-503. (b) Zheng, H.; Li, J.; Zhao, X. Dalton Trans. 2012, 41, 14281-14287.

(23) (a) Fowler, P. W.; Baker, J. J. Chem. Soc., Perkin Trans. 2 1992, 1665-1666. (b) Dosa, P. I.; Gu, Z.; Hager, D.; Karney, W. L.; Vollhardt, K. P. C. Chem. Commun. 2009, 1967-1969. (c) Yamazaki, K.; Niitsu, N.; Nakamura, K.; Kanno, M.; Kono, H. J. Phys. Chem. A 2012, 116, 11441-11450. 
- 114 - 
Chapter 5

Tetracyclopentatetraphenylene: Synthesis and Properties of Conjugated Macrocyclic System Consisting of as-Indacene Substructure 


\subsection{Introduction}

The indenofluorene frameworks, 6-5-6-5-6 fused ring systems, are intriguing structural moieties in view of their unique optoelectronic and biradical characters. In particular, due to the presence of $o$ and $p$-quinodimethane moieties, these compounds have been studied because of their low-energy bandgaps and excellent electrochemical properties, which make them potential candidates for optoelectronic materials. $^{1-3}$

There are five indenofluorene isomers 1-5 depending on the substitution pattern of five- and six-membered rings. Recently, Haley et al. reported the synthesis and properties of bis[(triisopropyl)ethynyl] substituted indeno[1,2-b]fluorene $\mathbf{1 b}$ and its derivatives having a $p$-quinodimethane moiety, which was regarded as a fully conjugated $20 \pi$-electron hydrocarbon with fused $s$-trans diene linkages. ${ }^{1}$ As to the indeno[2,1-a]fluorene (2a) and indeno[2,1-b]fluorene (3a) frameworks having an $o$ - and a $p$-quinodimethane moieties, respectively, dimesityl substituted derivatives $\mathbf{2} \mathbf{b}^{2}$ and $\mathbf{3} \mathbf{b}^{3}$ were synthesized and their biradical and optpelectronic properties were theoretically and experimentally investigated. On the other hand, indeno[2,1-c]fluorene (4) and indeno[1,2-a]fluorene (5) are thus far not known.

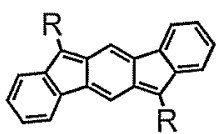

$1 \mathrm{a}: \mathrm{R}=\mathrm{H}$

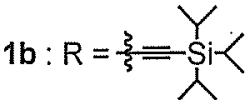

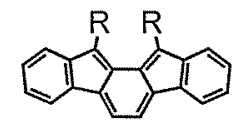

$2 a: R=H$

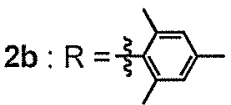

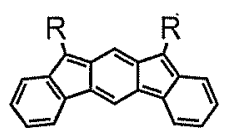

$3 a: \mathrm{R}=\mathrm{H}$

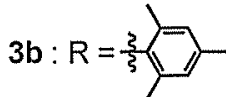

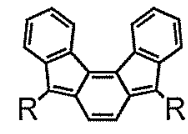

4

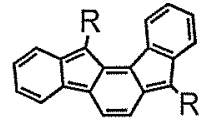

5

Figure 1. Indenofluorene isomers.

To compare the effect of the annulation mode on the electronic configuration of indenofluorenes, singlet biradical character of isomers 1-5 were calculated by the natural orbital occupation number (NOON) of the LUMO in a spin-unrestricted calculation. ${ }^{4}$ The broken-symmetry UHF/6-31G* calculations of 1-5 gave occupation numbers, from which the indices of biradical character were estimated by using the Yamaguchi scheme as shown in Table 1. ${ }^{5}$ The HOMO and LUMO levels of 1-5 were also elucidated on the basis of the DFT calculations at the (R)B3LYP/6-31G* levels of theory. The results are listed in Table 1 . Whereas compounds 1a, 2a, and 4 exhibit relatively large 
HOMO-LUMO gaps and small biradical characters, $\mathbf{3 a}$ and $\mathbf{5}$ have substantially small HOMO-LUMO gaps and large biradical characters, suggesting that compounds $\mathbf{3 a}$ and $\mathbf{5}$ are attractive synthetic targets. Indeed, it was shown that $\mathbf{3 b}$ exhibited anomalous optical property which led to a novel design principle for low-energy-absorbing molecules. ${ }^{3}$ On the other hand, it would be quite difficult to prepare and isolate $\mathbf{5}$ and its derivatives, because the ground state of $\mathbf{5}$ is triplet and the energy difference between singlet and triplet states is significantly large.

Table 1. Singlet-triplet energy gap, HOMO-LUMO gap, and biradical character of $\mathbf{1 - 5}$.

\begin{tabular}{rrrrrr}
\hline & S-T gap $(\mathrm{kJ} / \mathrm{mol})^{a}$ & ${\text { HOMO }(\mathrm{eV})^{b}}^{b}$ & ${\text { LUMO }(\mathrm{eV})^{b}}^{b}$ & H-L gap (eV) & ${\text { Biradical character }(\%)^{c}}^{c}$ \\
\hline $\mathbf{1 a}$ & 78.5 & -5.22 & -2.61 & 2.61 & 30.2 \\
$\mathbf{2 a}$ & 53.9 & -5.11 & -2.85 & 2.26 & 32.5 \\
$\mathbf{3 a}$ & 6.7 & -4.56 & -3.22 & 1.34 & 68.3 \\
$\mathbf{4}$ & 61.7 & -5.07 & -2.64 & 2.43 & 29.3 \\
$\mathbf{5}$ & -40.0 & -4.55 & -3.18 & 1.37 & 58.9 \\
$\mathbf{6 a}$ & 23.0 & -4.43 & -2.91 & 1.52 & 57.9 \\
\hline
\end{tabular}

${ }^{a}$ Triplet energy minus singlet energy calculated on the basis of the UB3LYP/6-31G* level of theory.

${ }^{b}$ HOMO and LUMO energy level calculated on the basis of the RB3LYP/6-31G* level of theory.

$c$ Biradical character calculated using the UHF/6-31G*//RB3LYP/6-31G* (for 1 and 3-5) or UHF/6-31G*//UB3LYP/6-31G* (for 2) level of theory and based on Yamaguchi scheme. 5

On the basis of the above calculations and the results described in Chapter 4, the author designed tetracyclopenta[ $\left[e f_{2}, k l, p q r, v w x\right]$ tetraphenylene (6a) consisting of alternating five- and six-membered rings around the central cyclooctatetraene (COT) core, and thus having indeno[2,1-c]fluorene substructures. The resonance structures and prospective bond shifting are shown in Scheme 2 . Because the spin density of $6 \mathbf{a}$ is expected to delocalize over the molecule as shown in Scheme 2, it would be thermodynamically stabilized and exhibit high-spin states, i.e. biradical character (58\%, Table 1) as well as quaterradical character. Moreover, this compound is expected to exhibit anti-aromatic character because it has an inner $8 \pi$ (cyclooctatetraene) and an outer $20 \pi$ conjugated cyclic systems. Compound $\mathbf{6 a}$ is also expected to have a relatively small HOMO-LUMO gap (1.52 eV) based on the DFT calculations (Table 1). Therefore, I planned to synthesize 
tetramesityl-substituted derivative $\mathbf{6} \mathbf{b}$ with a prospect of steric protection, determine its crystal and electronic structures, and elucidate optical and electrochemical properties.

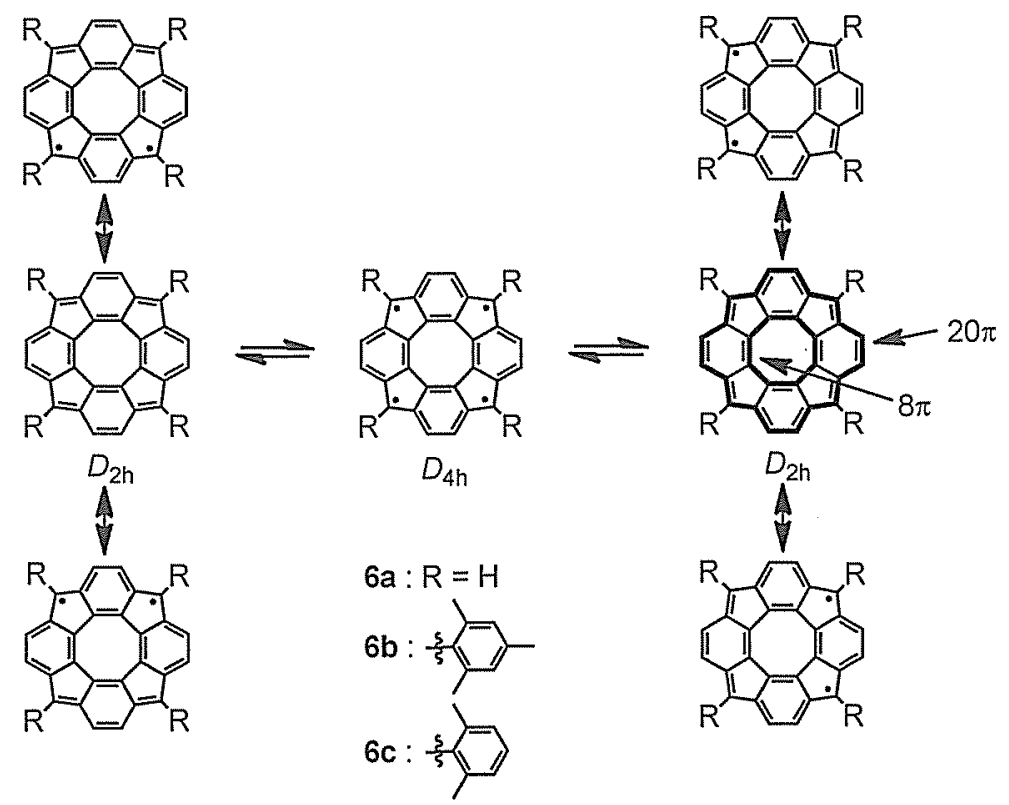

Scheme 1. Resonance structures and bond shifting of $\mathbf{6}$.

\subsection{Synthesis}

The synthesis of $\mathbf{6 b}$ is shown in Scheme 3. 2,2'-Diiodo-3,6-dimethylbiphenyl (9) was prepared according to the reported procedure. ${ }^{6,7}$ For the preparation of 1,4,9,12-tetramethyltetraphenylene (10), it was reported that dilithiation of 9 by $n$-butyllithium followed by treatment with $\mathrm{CuCl}_{2}$ gave 10 in only $3 \%$ yield. ${ }^{7 a}$ However, the author found that, when sec-butyllithium was used for dilithiation, 10 was obtained in $21 \%$ yield. Compound 10 was oxidized using potassium permanganate in pyridine and water to yield the corresponding tetracid 11. Acid 11 was treated with thionyl chloride to give the corresponding tetracid chloride which was reacted with mesitylene in the presence of $\mathrm{AlCl}_{3}$ to give 1,4,9,12-tetrakis(2,4,6-trimethylbenzoyl)tetraphenylene (12) in 28\% yield for 2 steps. For the preparation of precursor 14 , tetrahydro derivative of $6 \mathrm{a}$, reduction of 12 with $\mathrm{LiAlH}_{4}$ and acid-promoted Friedel-Crafts cyclization of $\mathbf{1 3}$ was examined. However, when trifluoromethanesulfonic acid was used for the Friedel-Crafts reaction, ${ }^{8}$ 1,4-dihydro-1,4,7,10-tetramesityltetracyclopenta[def,jkl,pqr,vwx]tetraphenylene (15) was obtained, which was partially dehydrogenated from the expected product 14. Because such oxidation of 14 
unlikely to occur under the reaction conditions, compound $\mathbf{1 5}$ may be formed from diketodiol $\mathbf{1 6}$ which is formed by partial reduction of $\mathbf{1 2}$. Finally, oxidative dehydrogenation of $\mathbf{1 5}$ with DDQ gave final product $\mathbf{6} \mathbf{b}$ as a dark-red solid. Because ${ }^{1} \mathrm{H}$ NMR spectrum of $\mathbf{6} \mathbf{b}$ using a sample obtained by column chromatography exhibited extensive broadening of all signals probably because of the presence of oxidized species, the purification by recrystallization following column chromatography was indispensable to obtain pure $\mathbf{6} \mathbf{b}$. Thus the target compound $\mathbf{6} \mathbf{b}$ was synthesized in less than $0.3 \%$ isolated yield for 8 steps.

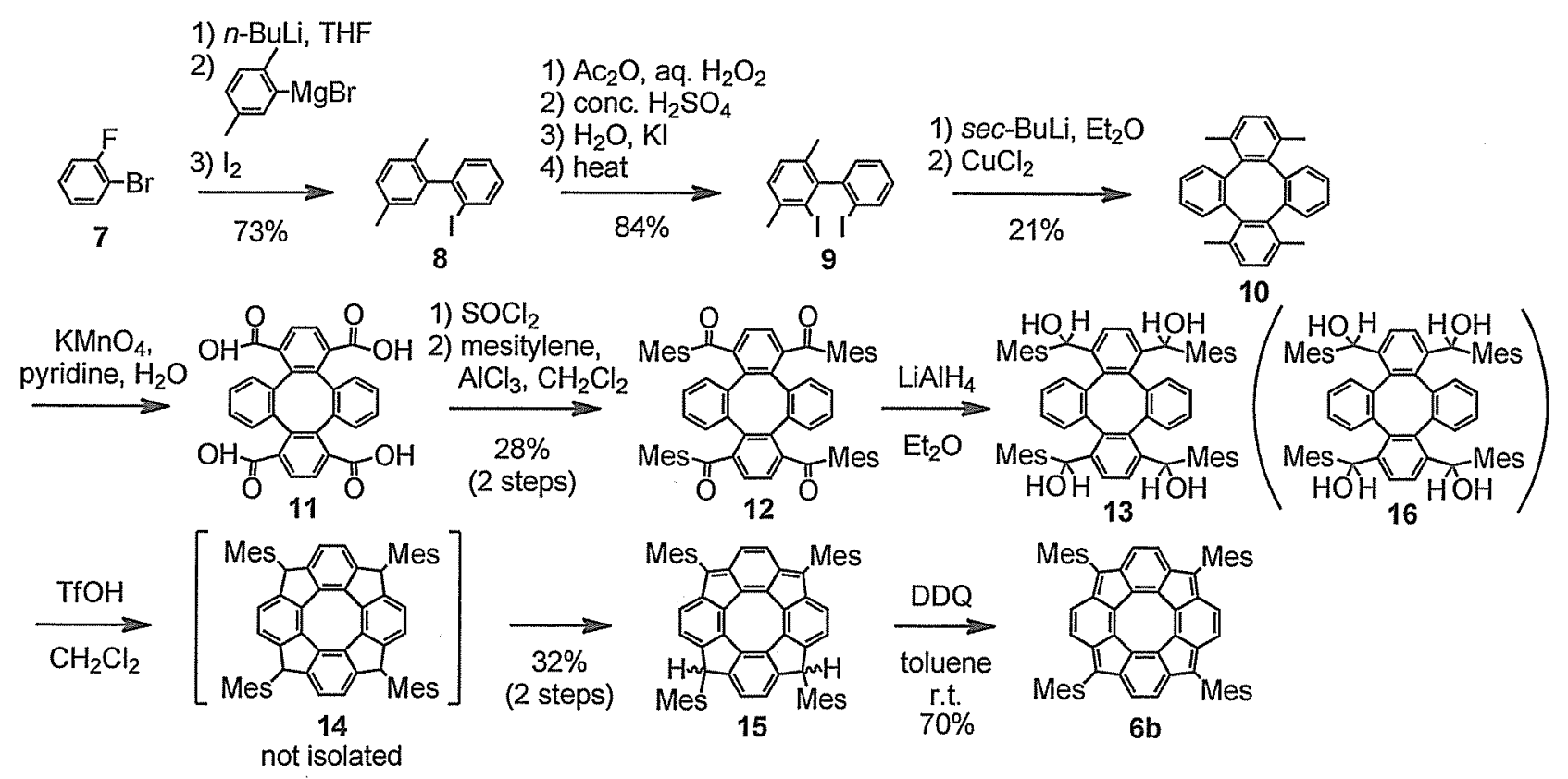

Scheme 2. Synthesis of $6 \mathrm{~b}$.

\subsection{Theoretical Calculation}

The spin contamination and the energy difference between singlet and triplet states of $6 \mathrm{a}$ were calculated on the basis of the RB3LYP/6-31G* and UB3LYP/6-31G* levels of theory (Table 2). The resulting open-shell singlet structure with spin-contamination of $\left\langle S^{2}\right\rangle=1.202$ was more stable than the closed shell singlet and triplet biradical states, suggesting that the ground state of 6 a is open-shell singlet. The optimized geometries of the open-shell singlet and triplet states calculated by UB3LYP methods adopt $D_{4 h}$ symmetry, whereas the closed-shell singlet state calculated by RB3LYP method 
Table 2. The spin contamination and energy differences $(\mathrm{kJ} / \mathrm{mol})$ between closed-shell singlet $\left(D_{2 h}\right)$ and open-shell singlet $\left(D_{4 h}\right)$, and triplet $\left(D_{4 h}\right)$ states.

\begin{tabular}{cccc}
\hline$\Delta E(\mathrm{~T}-\mathrm{OS})^{a}$ & $<\mathrm{S}^{2}>^{b}$ & $\Delta E(\mathrm{OS}-\mathrm{CS})^{b}$ & $\Delta E(\mathrm{~T}-\mathrm{CS})^{d}$ \\
\hline 23.0 & 1.202 & -3.4 & 19.5 \\
\hline
\end{tabular}

${ }^{a}$ Triplet energy minus open-shell singlet energy

${ }^{b}$ Spin contamination for the open-shell singlet

${ }^{c}$ Open-shell singlet energy minus closed-shell (RB3LYP) singlet energy

${ }^{d}$ Triplet energy minus RB3LYP singlet energy

adopts $D_{2 h}$ symmetry (Figure 1 ). As mentioned above, the optimized $D_{4 h}$-symmetric structure of $6 \mathrm{a}$ indicated that the spin distribution of $\mathbf{6 a}$ was delocalized over the molecule. This indication was supported by the spin density distribution calculated at the UBHandHLYP/6-31G*//UB3LYP/6-31G* level of theory (Figure 2). The spin densities are mainly delocalized to the outer 20-membered carbons, especially to the peripheral five-membered ring carbons.
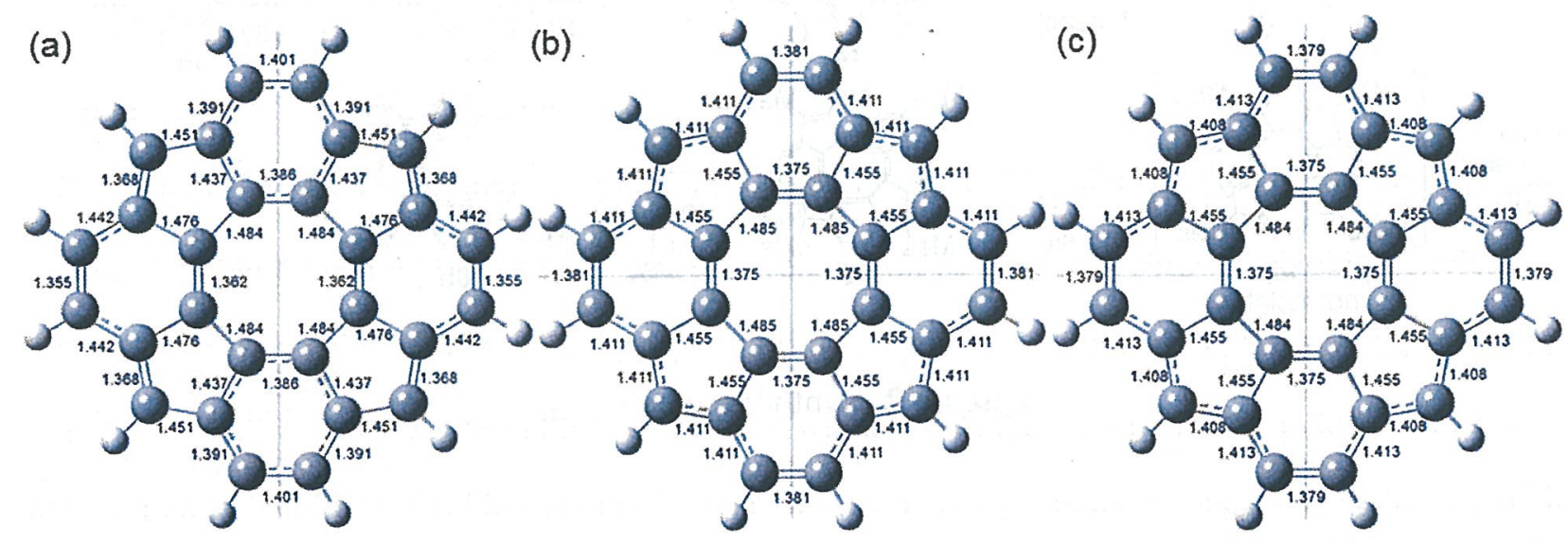

Figure 2. Optimized geometries of 6a for (a) closed-shell singlet (RB3LYP/6-31G*), (b) open-shell singlet (UB3LYP/6-31G*), and (c) triplet (UB3LYP/6-31G*) states, with bond lengths. Dotted lines indicate the axes of symmetry.

To evaluate the anti-aromaticity owing to the eight- and twenty-membered rings, NICS values ${ }^{9}$ were calculated for both $D_{2 h}$ and $D_{4 h}$ structures using GIAO-RHF/6-31G* and UHF/6-31G* levels of theory, respectively, as shown in Scheme 4. ${ }^{10}$ The NICS values in the central right-membered ring of 6a $(+26.0)$ is almost identical with that of the hypothetical $D_{4 h}$-symmetric COT $(+27.2)$. The larger 


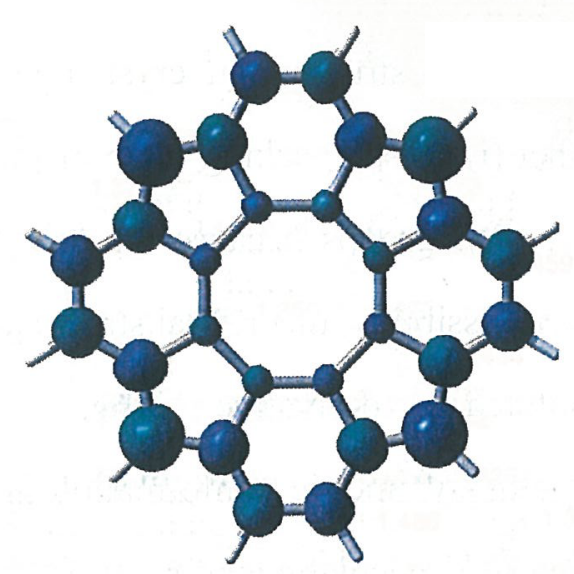

Figure 3. Spin density distribution of 6a calculated at UBHandHLYP/6-31G* level.

NICS value was detected in the peripheral five-membered ring. On the other hand, the anti-aromaticity of $\mathbf{6 a}$ is much larger than that of methylene-bridged tetraphenylene $(+8.8)$ having a planar COT core, suggesting that both the twenty-membered ring and eight-membered ring contribute to the strong anti-aromatic character of $\mathbf{6 a}$.

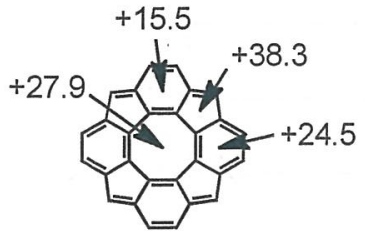

$D_{2 h}$

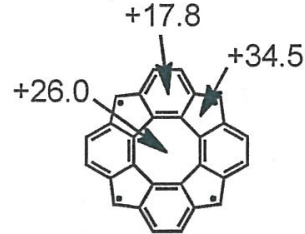

$D_{4 h}$

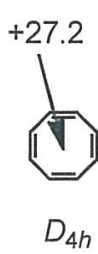

$D_{4 h}$

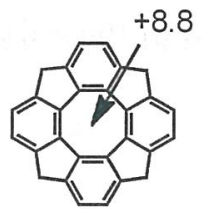

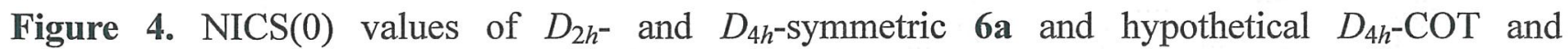
methylene-bridged tetraphenylene.

\subsection{Crystal Structure and Optical Properties}

Because a crystal of $\mathbf{6 b}$ suitable for X-ray analysis was obtained from a solution of $\mathrm{CHCl}_{3}$, the structure was determined by X-ray crystallograohic analysis as shown in Figure 3. The tetracyclopenta[def,jkl,pqr,vwx]tetraphenylene core adopts a completely planar structure, and the mesityl groups adopts almost perpendicular with a large dihedral angles of $72-88^{\circ}$ with the backbone. As to the bond length alternation of the planar aromatic core, $\mathbf{6 b}$ was expected to adopt highly-symmetric structure of $D_{4 h}$ symmetry in the ground state on the basis of the theoretical calculations. However, contrary to my expectation, the X-ray crystallographic analysis of $\mathbf{1 b}$ 
exhibited that it adopts a $C_{2}$-symmetric structure in crystalline state (Figure 4). The observed discrepancy can be ascribed to either (i) crystal packing force favoring the $C_{2}$ symmetric structure or (ii) the substituent effect of the mesityl groups because the calculations were done on the parent hydrocarbon 6a. To clarify the latter possibility, theoretical structure optimization was undertaken for tetrakis(2,6-dimethylphenyl)-substituted derivative $\mathbf{6 c}$, because optimization of tetramesityl-substituted $\mathbf{6 b}$ to a highly-symmetric conformation is difficult due to the presence of $C_{3}$-symmetric $p$-methyl groups. The DFT calculations of $6 \mathbf{c}$ on the basis of UB3LYP/6-31G* level of theory exhibited that the $D_{2 h}$ structure of $6 \mathbf{c}$ is more stable than the $D_{4 h}$ structure, contrary to the parent compound $\mathbf{6 a}$. These results suggest that the substituents may play a role for the localization of spin density in the central backbone of $\mathbf{6 b}$. It should be pointed out, however, that the bond as well as spin localization may dependent on the conformation of the aryl substituents, i.e. the dihedral angles of the aryl groups with respect to the central backbone. In the optimized structure of $6 \mathrm{c}$ of $D_{2 h}$ symmetry mentioned above, the dihedral angles are $+81.7^{\circ},-81.9^{\circ},+81.6^{\circ}$, and $-81.5^{\circ}$, which may favor the low symmetric structure. Further investigation is necessary to clarify the effect of the conformation of the substituents.
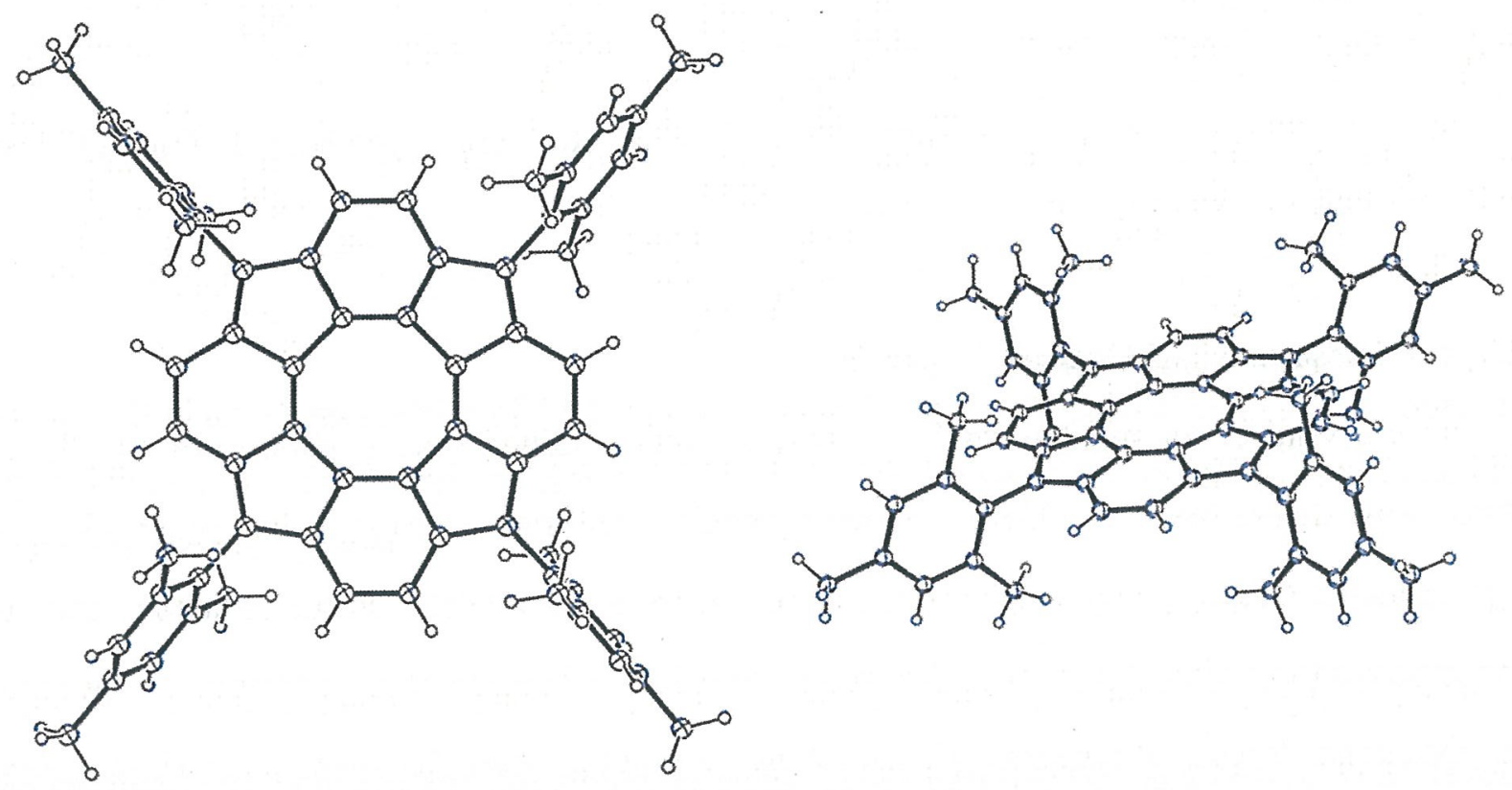

Figure 5. Top views of ORTEP drawings of 1b. Displacement ellipsoids are drawn at 30\% probability level. Disordered solvent molecules are omitted for clarity. 


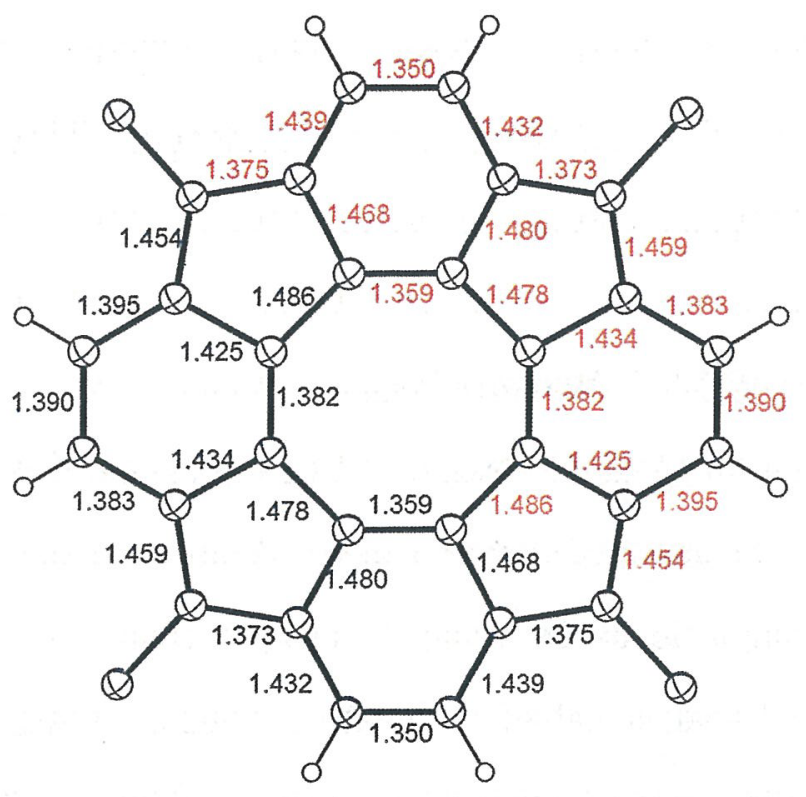

Figure 6. Bond lengths of cyclopenta[def,jkl,pqr,vwx]tetraphenylene framework observed by X-ray analysis. Displacement ellipsoids are drawn at 30\% probability level. Disordered solvent molecules and mesityl groups are omitted for clarity.

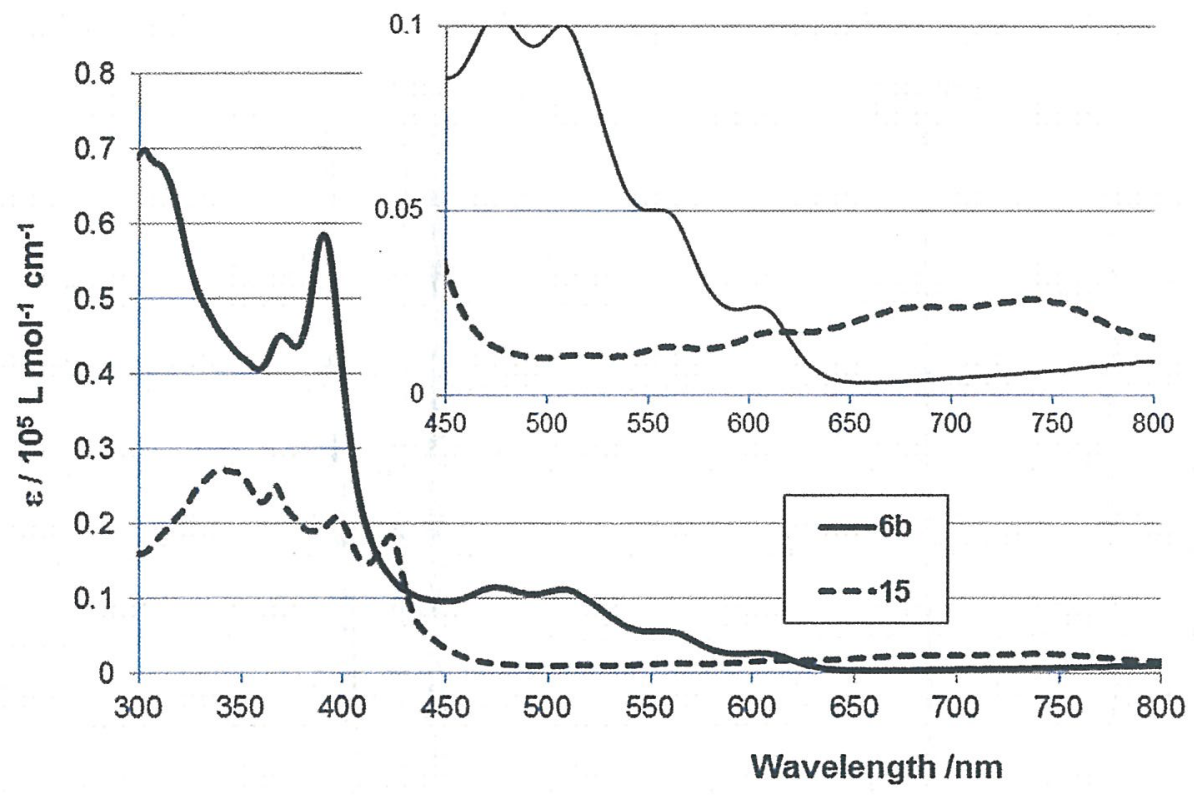

Figure 7. UV-vis absorption spectra of $\mathbf{6 b}$ and $\mathbf{1 5 .}$

The absorption spectra of $\mathbf{6 b}$ and its precursor $\mathbf{1 5}$ are shown in Figure 5. Compound $\mathbf{6 b}$ exhibits a broad and longer wavelength absorption band with an absorption maximum in near infrared region at longer than $800 \mathrm{~nm}$. The TD-DFT calculations of $6 \mathrm{a}$ on the basis of the TD-UB3LYP/6-31G* level 
of theory predict that 6 a shows the lowest-energy transition at $1034 \mathrm{~nm}$. It should be pointed out that compound 15 also exhibited a relatively long wavelength absorption band due to the indeno[2.1-c]fluorene chromophore present in it.

\subsection{Variable-Temperature ${ }^{1} \mathrm{H}$ NMR Measurements}

The ${ }^{1} \mathrm{H}$ NMR spectrum of $\mathbf{6 b}$ at $40{ }^{\circ} \mathrm{C}$ is shown at the top of Figure 6 . While the singlet signals due to the mesityl groups are observed, a broad signal denoted as $\mathrm{H}_{\mathrm{a}}$ was observed at around $\delta$ 2.6-2.8 ppm, which is assignable to the aromatic protons of the tetracyclopentatetraphenylene framework. Moreover, the broad signal of $\mathrm{H}_{\mathrm{a}}$ gradually becomes sharpened on decreasing the temperature, indicating the presence of a thermally excited triplet state. This is consistent with the low S-T gap (23 kJ/mol) estimated by theoretical calculations for 6a. The observation of one aromatic signal for the core protons indicates two possibilities regarding the structure of $\mathbf{6 b}$ in solution: (i) it adopts $D_{4 h}$-symmetric structure, or (ii) it adopts the $D_{2 h}$-symmetric structures whose

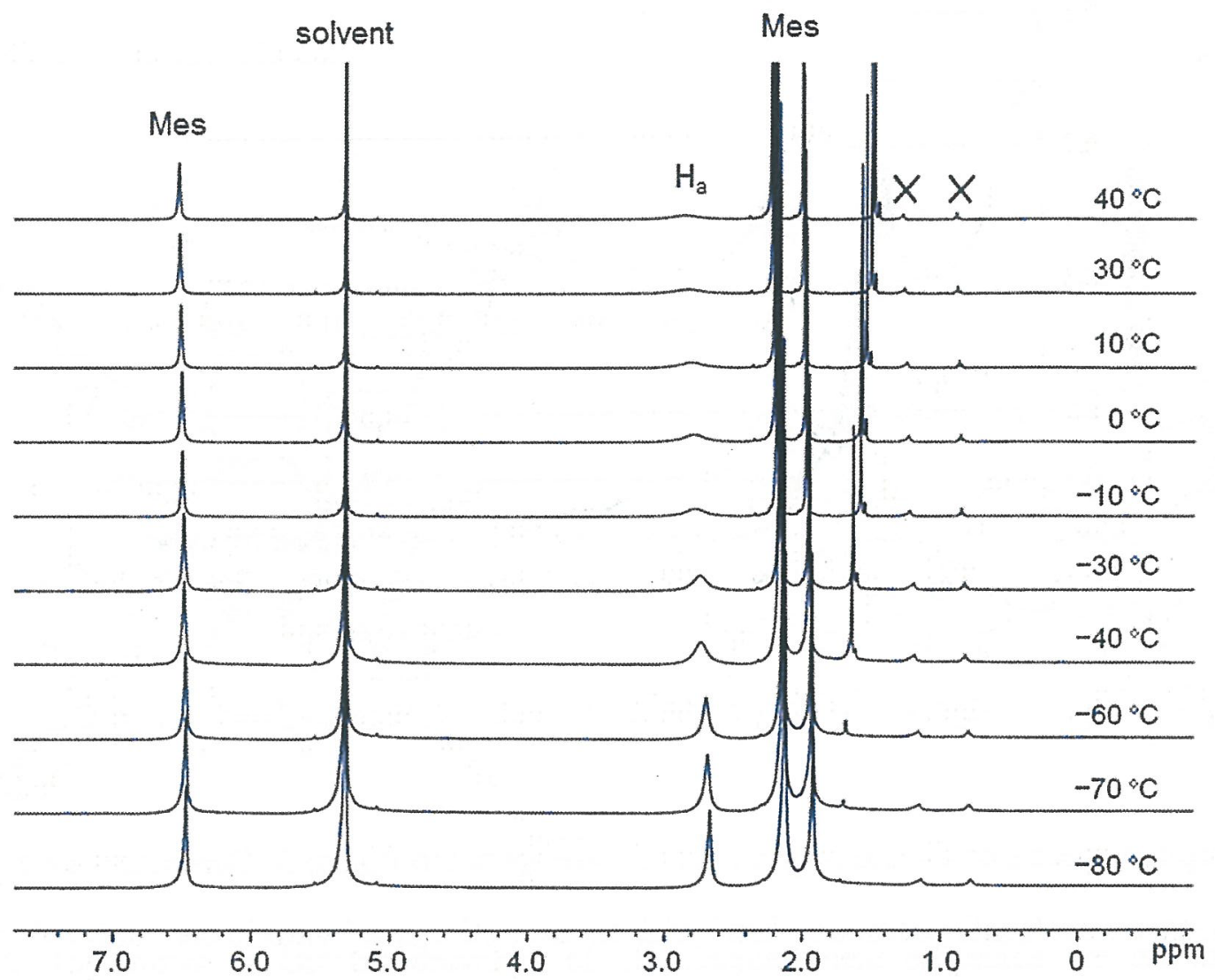

Figure 6. Variable-Temperature ${ }^{1} \mathrm{H}$ NMR spectra of $\mathbf{6 b}\left(400 \mathrm{MHz}, \mathrm{CD}_{2} \mathrm{Cl}_{2}, 40\right.$ to $\left.-80^{\circ} \mathrm{C}\right)$. 
interconversion rate is faster than the NMR timescale (Scheme 2). However, it is not possible to determine which is the case at this moment.

It is worth mentioning that the core aromatic proton $\mathrm{H}_{\mathrm{a}}$ appears considerably high-field at $\delta 2.7 \mathrm{ppm}$ at $-60^{\circ} \mathrm{C}$, indicating a strong anti-aromatic character of $6 \mathrm{~b}$. To verify the upfield shifts of the signals, NMR chemical shifts for the core aromatic protons $6 \mathrm{a}$ and $\mathbf{6 c}$ in the ground states were calculated on the basis of the UHF/6-31G* level of theory. The calculated chemical shifts for the $D_{2 h}$-symmetric $6 \mathrm{c}$ are 3.1 and $3.5 \mathrm{ppm}$ which are close to the observed chemical shift, whereas that for the $D_{4 h}$-symmetric $6 \mathrm{a}$ is $-2.5 \mathrm{ppm}$, indicating that the presence of substituents causes a considerable down-field shift of the core aromatic protons. It is not clear, however, whether this is due to the anisotropic effect of the substituent itself or due to the bond localization effect of the substituent discussed in the previous section.

\subsection{Conclusion}

Tetramesityl-subsituted tetracyclopenta[ $\left[d e f_{2} j k l, p q r, v w x\right]$ tetraphenylene (6b) consisting of alternating five- and six-membered rings around the central cyclooctatetraene (COT) core was synthesized. The quantum chemical calculations indicated that the ground electronic configuration of the parent hydrocarbon $\mathbf{6 a}$ is an open-shell singlet, and the spin density distribution is completely delocalized over the molecule. X-ray crystallographic analysis of $\mathbf{6} \mathbf{b}$ shows that it adopts a $D_{2 h}$-symmetric structure. The discrepancy was discussed on the basis of the theoretical calculations for the model compound $\mathbf{6 c}$ which turned out to favor a $D_{2 h}$-symmetric structure. On the basis of the ${ }^{1} \mathrm{H}$ NMR spectra, compound $\mathbf{6 b}$ was shown to exhibit anti-aromatic character due to the inner $8 \pi$ (COT) and outer $20 \pi$ conjugated cyclic systems. It was not impossible, however, to determine the two possibilities regarding the structure of $\mathbf{6 b}$ in solution, either the $D_{4 h}$ structure or the rapidly equilibrating $D_{2 h}$-symmetric structures. To clarify the structure and electronic configuration of $6 \mathbf{b}$, more studies should be done on EPR, SQUID as well as more sophisticated theoretical calculations. 


\subsection{Experimental Section}

General Experimental Methods. ${ }^{1} \mathrm{H}$ and ${ }^{13} \mathrm{C}$ NMR spectra were recorded in $\mathrm{CDCl}_{3}$ at $30{ }^{\circ} \mathrm{C}$ unless otherwise stated. When $\mathrm{CDCl}_{3}$ or $\mathrm{CD}_{2} \mathrm{Cl}_{2}$ was used as a solvent, the chemical shifts were referenced to the residual solvent protons in the ${ }^{1} \mathrm{H}$ NMR $(7.26,5.32 \mathrm{ppm}$, respectively) and to solvent carbons in the ${ }^{13} \mathrm{C}$ NMR $(77.0,53.1 \mathrm{ppm}$, respectively). Mass spectral analyses were performed with EI, FAB, or laser desorption ionization (LDI) mode. IR spectra were recorded as a $\mathrm{KBr}$ disk or a neat film. Melting points were measured with a hot-stage apparatus equipped with a thermometer. Column chromatography and TLC were performed with silica gel (70-230 mesh) and precoated silica gel plates, respectively. Preparative recycling GPC separation was undertaken using two $600 \mathrm{~mm} \times 20$ mm GPC columns with $\mathrm{CHCl}_{3}$ as the eluent.

All reagents were obtained from commercial suppliers and used as received. Solvents were dried (drying agent in parentheses) and distilled prior to use: pyridine (KOH). THF, $\mathrm{Et}_{2} \mathrm{O}$, and $\mathrm{CH}_{2} \mathrm{Cl}_{2}$ were dried by a Glass Contour solvent purification system.

1,4,9,12-Tetramethyltetraphenylene (10). A solution of $s e c$-butyllithium $(1.0 \mathrm{M}$ in cyclohexanes, $33.0 \mathrm{~mL}, 33.0 \mathrm{mmol})$ was added dropwise to a solution of $9^{7}(6.51 \mathrm{~g}, 15.0 \mathrm{mmol})$ in $\mathrm{Et}_{2} \mathrm{O}(75 \mathrm{~mL})$ at $-78{ }^{\circ} \mathrm{C}$. After stirring at $-78{ }^{\circ} \mathrm{C}$ under an argon atmosphere for $2 \mathrm{~h}, \mathrm{CuCl}_{2}(6.05 \mathrm{~g}, 45.0 \mathrm{mmol})$ was added, and then cooling bath was removed and the reaction mixture was gradually warmed up to room temperature. After stirring at room temperature for $10 \mathrm{~h}$, the reaction mixture was diluted with water and $1 \mathrm{M}$ aq. $\mathrm{HCl}$ was added. The reaction mixture was extracted with $\mathrm{Et}_{2} \mathrm{O}$, and the extract was washed with brine and dried over anhydrous $\mathrm{MgSO}_{4}$. After removal of the solvent, the residue was purified by chromatography (silica gel, $\mathrm{CHCl}_{3}:$ hexanes $\left.=1: 9\right)$ to afford $\mathbf{1 0}(569 \mathrm{mg}, 21 \%)$ as a white solid. 10: ${ }^{1} \mathrm{H}$ NMR (400 MHz, $\left.\mathrm{CDCl}_{3}, 30^{\circ} \mathrm{C}\right) \delta$ 7.15-7.12 (m, 4H), 7.07-7.05 (m, 4H), $6.98(\mathrm{~s}, 4 \mathrm{H})$, $2.05(\mathrm{~s}, 12 \mathrm{H}) ; \mathrm{MS}(\mathrm{EI}) \mathrm{m} / \mathrm{z} 360.1(\mathrm{M})^{+}$. The spectral data agreed with those reported in the literature. $^{7 \mathrm{a}}$

1,4,9,12-Tetrakis(2,4,6-trimethylbenzoyl)tetraphenylene (12). $\mathrm{KMnO}_{4}$ (4.60 g, $29.1 \mathrm{mmol}$ ) was added to a solution of $\mathbf{1 0}(1.30 \mathrm{~g}, 3.61 \mathrm{mmol})$ in pyridine $(30 \mathrm{~mL})$ and water $(10 \mathrm{~mL})$ at $90^{\circ} \mathrm{C}$. After 
stirring at $90{ }^{\circ} \mathrm{C}$ for $30 \mathrm{~min}$, an additional $\mathrm{KMnO}_{4}(4.52 \mathrm{~g}, 28.6 \mathrm{mmol})$ and water $(5 \mathrm{~mL})$ was added, and the reaction mixture was stirred at $90^{\circ} \mathrm{C}$ for $11 \mathrm{~h}$. The precipitated solid was removed by filtration through celite. Most of the solvent was removed, and conc. $\mathrm{HCl}$ was added. The precipitated white solid was filtered and dried under reduced pressure. The white solid was dissolved in $\mathrm{SOCl}_{2}(25 \mathrm{~mL})$ and the reaction mixture was stirred in $70^{\circ} \mathrm{C}$ for $1 \mathrm{~h}$, and then excess $\mathrm{SOCl}_{2}$ was removed. The residue was dissolved in $\mathrm{CH}_{2} \mathrm{Cl}_{2}(15 \mathrm{~mL})$, and mesitylene $(8.67 \mathrm{~g}, 72.1 \mathrm{mmol})$ and $\mathrm{AlCl}_{3}(3.83 \mathrm{~g}, 28.7 \mathrm{mmol})$ was added. The reaction mixture was stirred at room temperature for $5 \mathrm{~h}$ under an argon atmosphere. An excess $\mathrm{AlCl}_{3}$ was decomposed with water, and $1 \mathrm{M}$ aq. $\mathrm{HCl}$ was added. The reaction mixture was extracted with $\mathrm{CH}_{2} \mathrm{Cl}_{2}$, and the extract was washed with brine and dried over anhydrous $\mathrm{MgSO}_{4}$. After removal of the solvent, the residue was purified by chromatography (silica gel, $\mathrm{CHCl}_{3} /$ hexanes $\left.=4 / 1\right)$ and recycling $\mathrm{GPC}$ to afford $12(898 \mathrm{mg}, 1.01$ mmol, $28 \%$ ) as a pale yellow solid. 12: $\mathrm{mp} 189.0-190.0^{\circ} \mathrm{C} ;{ }^{1} \mathrm{H} \mathrm{NMR}\left(400 \mathrm{MHz}, \mathrm{CDCl}_{3}, 30{ }^{\circ} \mathrm{C}\right) \delta$ $7.27(\mathrm{~s}, 4 \mathrm{H}), 7.07-7.05(\mathrm{~m}, 4 \mathrm{H}), 6.99(\mathrm{~m}, 4 \mathrm{H}), 6.76(\mathrm{~s}, 8 \mathrm{H}), 2.26(\mathrm{~s}, 12 \mathrm{H}), 2.00(\mathrm{~s}, 24 \mathrm{H}) ;{ }^{13} \mathrm{C} \mathrm{NMR}$ $\left(100 \mathrm{MHz}_{2} \mathrm{CDCl}_{3}, 30^{\circ} \mathrm{C}\right) \delta 197.5,143.3,138.9,138.8,138.5,137.3,135.3,130.5,128.6,126.0$, $21.0,20.3 ; \mathrm{MS}(\mathrm{EI}) \mathrm{m} / \mathrm{z} 889.1(\mathrm{M})^{+}$.

\section{1,4-Dihydro-1,4,7,10-tetramesityltetracyclopenta[def,jkl,pqr,vwx]tetraphenylene (15). $\mathrm{LiAlH}_{4}$} $(45.6 \mathrm{mg}, 1.20 \mathrm{mmol})$ was added to a solution of $12(89.1 \mathrm{mg}, 0.100 \mathrm{mmol})$ in $\mathrm{Et}_{2} \mathrm{O}(20 \mathrm{~mL})$. After stirring at room temperature for $1 \mathrm{~h}$, water was added, and the reaction mixture was extracted with $\mathrm{CH}_{2} \mathrm{Cl}_{2}$. The extract was washed with brine and dried over anhydrous $\mathrm{MgSO}_{4}$. After removal of the solvent, the residue was dissolved in $\mathrm{CH}_{2} \mathrm{Cl}_{2}(10 \mathrm{~mL})$. To the solution containing 13 was added trifluoromethanesulfonic acid $(0.50 \mathrm{~mL})$ was added, and the reaction mixture was stirred at room temperature for $30 \mathrm{~min}$. An aqueous solution of $\mathrm{NaHCO}_{3}$ was added, and the reaction mixture was extracted with $\mathrm{CH}_{2} \mathrm{Cl}_{2}$. The extract was washed with brine and dried over anhydrous $\mathrm{MgSO}_{4}$. After removal of the solvent, the residue was purified by chromatography (silica gel, $\mathrm{CHCl}_{3}$ :hexanes $=$ 1:4) followed by recycling GPC to afford $15(26.4 \mathrm{mg}, 32 \%)$ as a green solid. 15: $1 \mathrm{H} \mathrm{(400} \mathrm{MHz,}$ $\left.\mathrm{CDCl} 3,30^{\circ} \mathrm{C}\right) \delta 6.92-6.91(\mathrm{~m}, 6 \mathrm{H}), 6.70(\mathrm{~s}, 2 \mathrm{H}), 6.59(\mathrm{~s}, 2 \mathrm{H}), 6.37(\mathrm{~J}=7.6 \mathrm{~Hz}, 2 \mathrm{H}), 5.99(\mathrm{~d}, \mathrm{~J}=7.6$ $\mathrm{Hz}, 2 \mathrm{H}), 5.82(\mathrm{~s}, 2 \mathrm{H}), 5.14(\mathrm{~s}, 2 \mathrm{H}), 2.52(\mathrm{~s}, 6 \mathrm{H}), 2.31(\mathrm{~s}, 6 \mathrm{H}), 2.25(\mathrm{~s}, 6 \mathrm{H}), 2.17(\mathrm{~s}, 6 \mathrm{H}), 2.15(\mathrm{~s}, 6 \mathrm{H})$, 
$1.65(\mathrm{~s}, 6 \mathrm{H}) ;{ }^{13} \mathrm{C} \mathrm{NMR}\left(100 \mathrm{MHz}, \mathrm{CDCl}_{3}, 30^{\circ} \mathrm{C}\right) \delta 148.9,146.9,146.7,144.3,139.8,139.5,137.7$, 137.3, 137.2, 137.0, 136.9, 136.8, 136.2, 134.8, 134.6, 132.8, 130.7, 129.9, 128.7, 128.09, 128.07, $125.6,125.2,120.6,120.2,48.8,21.6,21.1,20.8,20.00,19.98,19.2$; MS (EI) $m / z 822.6(\mathrm{M})^{+}$.

1,4,7,10-Tetramesityltetracyclopenta[def,jkl,pqr,vwx] tetraphenylene $(6 \mathrm{~b})$. To a solution of 15 (18.6 mg, $22.6 \mu \mathrm{mol})$ in toluene $(10 \mathrm{~mL})$ was added 2,3-dichloro-5,6-dicyano-p-benzoquinone (DDQ) was added. After stirring at room temperature under an argon atmosphere for $15 \mathrm{~min}$, the reaction mixture was purified by chromatography (silica gel, $\mathrm{CHCl}_{3}$ :hexanes $=1 / 5$ ) to give dark-red solid (13.0 mg, 70\%) which exhibits considerably broad signal in ${ }^{1} \mathrm{H}$ NMR spectrum. The residual solid was recrystallized in $\mathrm{CHCl}_{3}$ to afford $6 \mathbf{b}\left(4.40 \mathrm{mg}, 24 \%\right.$ ) as a dark-red solid. $6 \mathbf{b}:{ }^{1} \mathrm{H}$ NMR (400 $\left.\mathrm{MHz}, \mathrm{CD}_{2} \mathrm{Cl}_{2},-80^{\circ} \mathrm{C}\right) \delta 6.47(\mathrm{~s}, 8 \mathrm{H}), 2.67(\mathrm{~s}, 8 \mathrm{H}), 2.13(\mathrm{~s}, 24 \mathrm{H}), 1.92(\mathrm{~s}, 12 \mathrm{H}) ; \mathrm{MS}(\mathrm{FAB}) \mathrm{m} / \mathrm{z}$ $820.8(\mathrm{M})^{+}$; HRMS (FAB) calcd. for $\mathrm{C}_{64} \mathrm{H}_{52} 820.4069$, found 820.4062 . 


\subsection{References and Notes}

(1) (a) Chase, D. T.; Rose, B. D.; McClintock, S. P.; Zakharov, L. N.; Haley, M. M. Angew. Chem. Int. Ed. 2011, 50, 1127-1130. (b) Chase, D. T.; Fix, A. G.; Rose, B. D.; Weber, C. D.; Nobusue, S.; Stockwell, C. E.; Zakharov, L. N.; Lonergan, M. C.; Haley, M. M. Angew. Chem. Int. Ed. 2011, 50, 11103-11106. (c) Chase, D. T.; Fix, A. G.; Kang, S. J.; Rose, B. D.; Weber, C. D.; Zhong, Y.; Zakharov, L. N.; Lonergan, M. C.; Nuckolls, C.; Haley, M. M. J. Am. Chem. Soc. 2012, 134, $10349-10352$.

(2) Shimizu, A.; Tobe, Y. Angew. Chem. Int. Ed. 2011, 50, 6906-6910.

(3) Shimizu, A.; Kishi, R.; Shiomi, D.; Sato, K.; Takui, T.; Hisaki, I.; Miyata, M.; Nakano, M.; Tobe, Y. et al. submitted.

(4) (a) Döhnert, D.; Koutecký, J. J. Am. Chem. Soc. 1980, 102, 1789-1796. (b) Jung, Y.; Head-Gordon, M. ChemPhysChem 2003, 4, 522-525.

(5) Yamaguchi, K. Chem. Phys. Lett. 1975, 33, 330-335.

(6) Laughlin, B. J.; Smith, R. C. Macromolecules 2010, 43, 3744-3749.

(7) (a) Hellwinkel, D.; Reiff, G.; Nykodym, V. Liebigs Ann. Chem. 1977, 1013-1025. (b) Sato, T.; Shimizu, K.; Moriya, H. J. Chem. Soc., Perkin Trans. 1 1974, 1537-1539.

(8) Li, G.; Wang, E.; Chen, H.; Li, H.; Liu, Y.; Wang, P. G. Tetrahedron 2008, 64, 9033-9043.

(9) (a) Schleyer, P. v. R.; Maerker, C.; Dransfeld, A.; Jiao, H.; Hommes, N. J. R. V. E. J. Am. Chem. Soc. 1996, 118, 6317-6318. (b) Chen, Z.; Wannere, C. S.; Corminboeuf, C.; Puchta, R.; Schleyer, P. v. R. Chem. Rev. 2005, 105, 3842-3888.

(10) For the NICS calculation, the HF method was used because this had been shown to be reliable means for evaluating the NICS values. For example, see: Gogonea, V.; Schleyer, P. v. R.; Schreiner, P. R. Angew. Chem. Int. Ed. 1998, 37, 1945-1948. 


\section{Generall Conclusion}

The author investigated the dynamic behaviors of propeller-shaped molecules consisting of DBAs as shape-persistent components and the transformation of DBAs into structurally novel polycyclic aromatic hydrocarbons taking advantage of the high reactivity of the acetylene units. Additionally, the author investigated the synthesis and properties of novel polycyclic aromatic hydrocarbons inspired by the results obtained from the skeletal transformation of DBAs.

In chapter 2 , the synthesis and dynamic behavior of propeller-shaped tris[14]DBA and its extended homolog, which consist of core benzene ring that is fused by three [14]DBA blades, are described. Although the overlap between the adjacent blades seemed extremely large, it was shown that the ring inversion took place readily, indicating the acetylene units bent with low activation energies. Through this work, it was revealed that the acetylene linkages can be deformed much more than that are generally recognized in the transition state of the ring flip. These results are useful for the molecular design of shape-persistent molecules that are based on related DBA units, in particular when molecular flexibility and dynamic properties are concerned.

Chapter 3 describes the generation of novel polycyclic hydrocarbons by cyclodimerization following tandem transannular bond formations between sp carbon atoms of [14]DBA. Namely, reaction of [14]DBA with $n-\mathrm{BuLi}$ led to an unprecedented cyclodimerization to form eight-membered ring product in which two indeno[2,1-a]fluorene components are connected by a single and a double bonds, following three-fold transannular bond formations. Though the cyclodimerization mechanism is not fully understood, it is assumed that the biradical character of a plausible intermediate having indeno[2,1-a]fluorene framework may play a major role. These results demonstrate that novel carbon frameworks which are otherwise difficult to obtain can be prepared by intramolecular bond formations of dehydrobenzoannulenes.

In Chapter 4, inspired by the formal [4+4] cyclodimerization of an indenofluorene intermediate proposed in Chapter 3,11,11':12,12'-biindeno[2,1-a]fluorenediylidene, which consists of two indeno[2,1-a]fluorene units connected by two double bonds, was synthesized by $[4+4]$ cycloaddition of in-situ generated indeno[2,1-a]fluorene derivative. It adopts a twisted conformation to avoid steric 
repulsion, therefore contains twisted cyclooctatetraene (COT) ring in the center. The structure and physical properties, in connection with anti-aromatic character, were investigated by X-ray analysis, cyclic voltammetry, UV-vis and NMR spectroscopies, and quantum chemical simulations, exhibiting that the molecule is the first COT derivative having a twisted conformation.

Chapter 5 described the synthesis and properties of tetramesityl-substituted tetracyclopenta[def,jkl,pqr,vwx] tetraphenylene derivative consisting of alternating five- and six-membered rings around the central COT core. The anti-aromatic character due to the inner $8 \pi$ (COT) and outer $20 \pi$ conjugated cyclic systems was identified. Although the quantum chemical calculations indicated that the spin density distributions of parent tetracyclopenta[def,jkl,pqr,vwx]tetraphenylene is delocalized over the molecule favoring the $D_{4 h}$ structure, X-ray analysis of tetramesityl-substituted derivative as well as calculations for the model compound tetrakis(2,6-dimethylphenyl)-substituted derivative favored the less symmetric $D_{2 h}$ structure. Although more studies should be done on EPR, SQUID as well as more sophisticated theoretical calculations for the elucidation of structure and electronic configurations, this work will provide an insight particularly regarding the quaterradical character. 


\section{List of Publications}

(1) "Molecular Propellers that Consist of Dehydrobenzo[14]annulene Blades"

Nobusue, S.; Mukai, Y.; Fukumoto, Y.; Umeda, R.; Tahara, K.; Sonoda, M.; Tobe, Y.

Chem. Eur. J. 2012, 18, 12814-12824.

(2) "Oxidative Cyclodimerization that Follows Tandem Cyclization of Dehydrobenzo[14]annulenes Induced by Alkyllithium"

Nobusue, S.; Shimizu, A.; Hori, K.; Hisaki, I.; Miyata, M.; Tobe, Y.

Angew. Chem. Int. Ed.

in press

The following publication is not included in this thesis:

(1) "Electron-Accepting 6,12-Diethynylindeno[1,2-b]fluorenes: Synthesis, Crystal Structures, and Photophysical Properties"

Chase, D. T.; Fix, A. G.; Rose, B. D.; Weber, C. D.; Nobusue, S.; Stockwell, C. E.; Zakharov, L. N.; Lonergan, M. C.; Haley, M. M.

Angew. Chem. Int. Ed. 2011, 50, 11103-11106. 


\section{Acknowledgement}

The present studies have been carried out at the Division of Frontier Materials Science, Graduate School of Engineering Science, Osaka University during 2007-2013 under the direction of Professor Yoshito Tobe.

The author would like to express his sincere gratitude to Professor Yoshito Tobe for his instructive guidance, invaluable discussion, and encouragement throughout the course of these studies. The author is deeply grateful to Associate Professor Keiji Hirose for helpful suggestions and discussion. He is also grateful to Dr. Kazukuni Tahara for helpful advices and attractive discussion. He is also deeply grateful to Dr. Akihiro Shimizu for valuable advices and suggestions. The author thanks and feels very fortunate to all members of Professor Yoshito Tobe's research group.

The author would like to express his gratitude to Professor Shinji Toyota in Faculty of Science, Okayama University of Science and Professor Gaku Yamamoto in School of Science, Kitasato University for their valuable suggestions regarding dynamic NMR spectroscopy. He also would like to express his gratitude to Dr. Ichiro Hisaki in Graduate School of Engineering, Osaka University for the measurement of X-ray crystallographic analysis. He also would like to express his gratitude to Professor Kenji Hori in Graduate School of Science and Engineering, Yamaguchi University for the theoretical calculations.

The author thanks Mr. Kazuo Fukuda in Faculty of Engineering Science, Osaka University for the measurement of mass spectra.

The author would like to Global COE Program "Global Education and Research Center for Bio-Environmental Chemistry" of Osaka University for fellowship during 2010-2011, and Sigma Research Assistant in Graduate School of Engineering Science during 2011-2013.

Finally, the author sincerely thanks his family, Mr. Michinori Nobusue, Ms. Naomi Nobusue, and Mr. Keita Nobusue for their constant assistance and encouragement.

March, 2013

Shunpei Nobusue 